\title{
BWR Steel Containment Corrosion
}

Manuscript Completed: April 1996

Date Published: April 1996

C. P. Tan, G. Bagchi

Division of Engineering

Office of Nuclear Reactor Regulation

U.S. Nuclear Regulatory Commission

Washington, DC 20555-0001
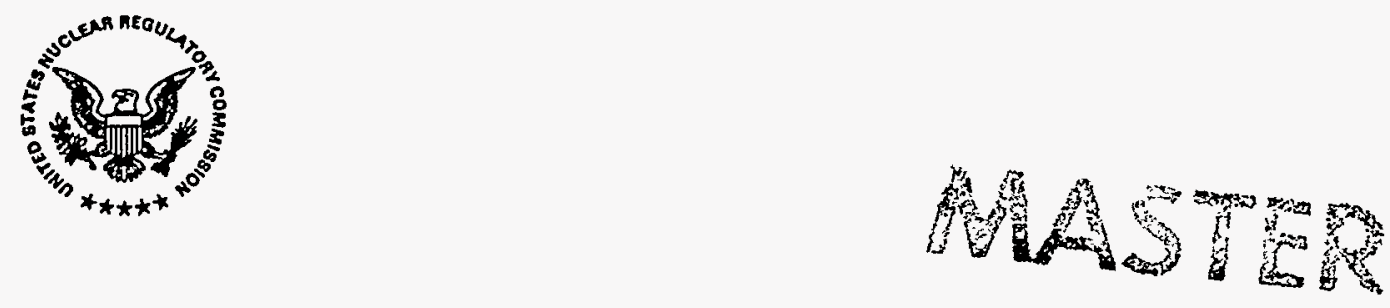


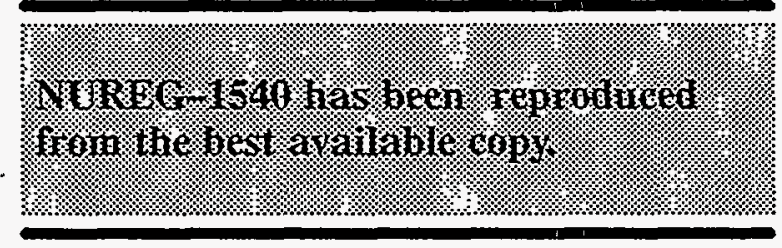




\begin{abstract}
The report describes regulatory actions taken after corrosion was discovered in the drywell at the Oyster Creek Plant and in the torus at the Nine Mile Point 1 Plant. The report describes the causes of corrosion, requirements for monitoring corrosion, and measures to mitigate the corrosive environment for the two plants. The report describes the issuances of generic letters and information notices either to collect information

alert the licensees of similar plants about the existence of such a problem. Implementation of measures to enhance the containment performance under severe accident conditions is discussed. A study by Brookhaven National Laboratory (BNL) of the performance of a degraded containment under severe accident conditions is summarized. The details of the BNL study are in the appendix to the report.
\end{abstract} to determine whether the problem is generic or to 


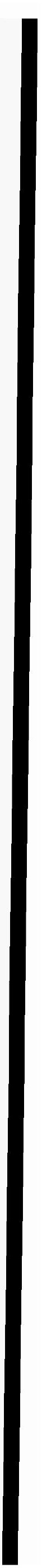




\section{CONTENTS}

\section{Page}

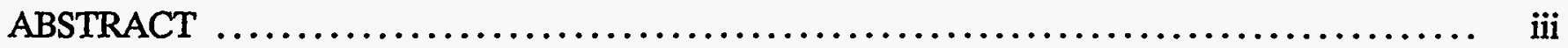

EXECUTIVE SUMMARY $\ldots \ldots \ldots \ldots \ldots \ldots \ldots \ldots \ldots \ldots \ldots \ldots \ldots \ldots \ldots \ldots \ldots \ldots \ldots \ldots \ldots \ldots \ldots$

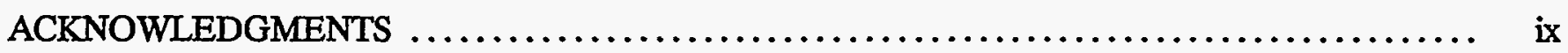

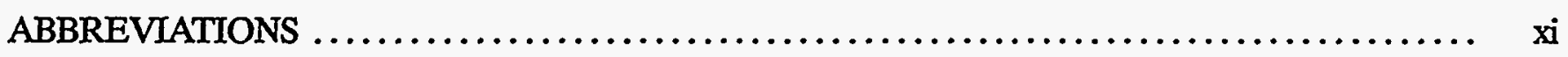

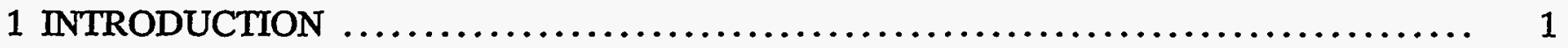

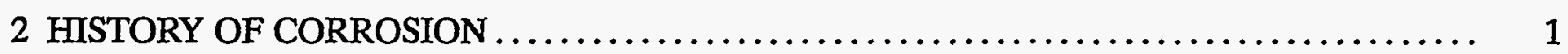

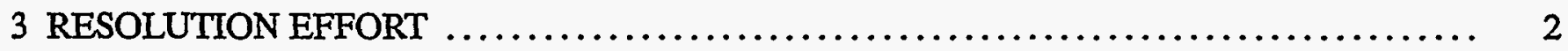

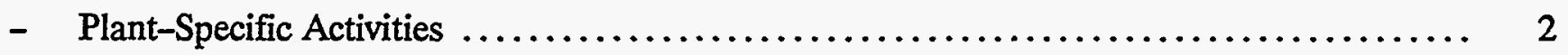

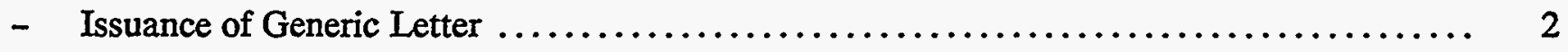

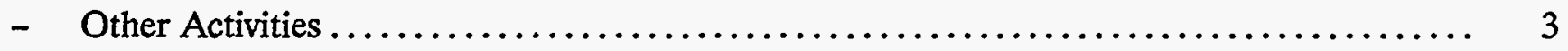

- Containment Inservice Degradation Assessment $\ldots \ldots \ldots \ldots \ldots \ldots \ldots \ldots \ldots \ldots \ldots \ldots . \ldots$

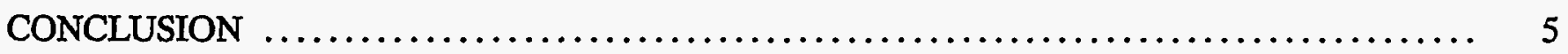

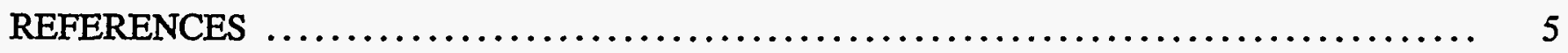

Appendix A: BNL Technical Report, "Containment Inservice Degradation Assessment” 


\section{EXECUTIVE SUMMARY}

The containment is the most important structure. It is the last barrier against radioactive release to the environment and is essential to protecting the health and safety of the general public. Every care is exercised in its design and construction. To ensure its performance, after construction the containment is subjected to a pressure testing at 1.15 times the design pressure and to an integrated leak rate test (ILRT). To assure its continued integrity, the containment is given periodic inspections and IIRTs.

Although steel containments were designed and constructed according to stringent requirements and with great care, they have been found to be degraded, although, not enough to put the public health and safety at risk. The discovery of corrosion in the sand cushion area of the steel drywell of the Mark I containment at Oyster Creek in 1986 and the detection of corrosion on the inside face of the uncoated steel torus shell of Nine Mile Point 1 wetwell in 1988 were of great concern to the staff because there are 22 Mark I plants with similarly designed steel drywells and tori. For the two plants with the corrosion uncovered, the concern was whether they could continue their operation safely. For the other Mark I plants it was uncertain if they have the same corrosion problem.

To resolve the concerns of the two plants, the licensing staff worked closely with the licensees of Oyster Creek and Nine Mile Point 1. Using the thickness obtained from ultrasonic thickness (UT) measurements of the drywell and torus shells at corroded areas, the licensees performed stress analyses of the shells. The stresses were found to be at or near the ASME Code allowables. Besides taking measures to eliminate or mitigate the corrosion, licensees of the two plants were required to perform periodic UT measurements to maintain the code-required shell thickness. As a final resolution of the corrosion problem of the Oyster Creek drywell, the licensee removed the sand from the sand cushion area and coated the shell in this area, thus removing the source of the corrosion and preventing further degradation. However, to assure that these measures are effective, the licensee is required to perform periodic UT measurements. In the meantime the licensee found that the drywell design pressure could be reduced from 62 to 44 psig. For Nine Mile Point 1, the licensee found that the condensation oscillation (CO) loads used in designing the torus could be lowered, thus reducing the required thickness of the torus shell; and on the basis of the rate of corrosion so far established, the torus should conform with the ASME Code requirements until year 2007. The staff reviewed and accepted the licensee's findings and obtained the licensee's commitments to conduct specified surveillance tests to ensure continued containment adequacy.

To alert licensees of other Mark I containments of the discovery that the Oyster Creek drywell was corroded, an information notice was issued. This was followed by a generic letter. To determine if the drywells of other similar Mark I plants had the same corrosion problems, the generic letter requested licensees of these plants to furnish pertinent information on the drywells.

On the basis of the information collected, a generic safety evaluation report was issued with the conclusion that the observed drywell corrosion was unique to Oyster Creek. For the corrosion of the torus at Nine Mile Point 1 , an information notice was issued to alert licensees of plants with Mark I steel tori of the problem. Since the torus at Nine Mile Point 1 is the only one with an uncoated inside face, the torus corrosion problem appear unique to Nine Mile Point 1 even though coatings have been found peeled off from the coated tori in several Mark I plants.

The discovery of the wetwell (torus) shell corrosion at Nine Mile Point 1 caused the staff to consider the need for a generic letter to require the licensees of plants with Mark I and Mark II steel containments to adopt a containment inspection program. The staff noted that the Appendix $J$ inspection is visual and by nature cursory and does not cover inaccessible areas of the containment. While these regulatory activities were underway, ASME was in the process of establishing the criteria for inspecting all types of containments. However, the ASME criteria could not be implemented without NRC rulemaking. 
The generic letter was published in the November 20, 1992, issue of the Federal Register. The Boiling Water Reactor Owners Group (BWROG) commented that the inspections recommended in the generic letter were too costly and not justifiable and gave the staff a model containment inspection plan (CIP), which, the BWROG claimed, would resolve the staff's concerns. The staff reviewed the CIP and had reservations on the CIP inspection requirements, especially the inspection frequency of more than 10 years.

The staff and BWROG were at an apparent impasse on the inspection program. However, both agreed that the inspection requirements in ASME Code Section XI Subsection IWE, which are mainly for steel containments, should be followed. The staff has been participating in the development of the ASME containment inspection criteria. The code group also has representatives from the industry, including the BWROG. NRC is in the process of completing the final rule to incorporate the ASME criteria for all types of containments into 10 CFR $50.55 \mathrm{a}$, and the endorsed portions of the Code will therefore apply to all types of steel containments. Because a rulemaking is preferable to a generic letter, the proposed generic letter was withdrawn.

While these activities to maintain the performance of Mark I containments were progressing, other measures to improve their performance were pursued. The Commission initiated probabilistic risk analysis (PRA) studies of the effect of failures of PWR and BWR containments on the health and safety of the general public. The studies are documented in NUREG-1150, "Severe Accident Risks: An Assessment for Five U.S. Nuclear Power Plants," and are the basis of the Commission's Containment Performance Improvement (CPI) program. For Mark I containments it was found that the risk to the public is dominated by early containment failure when the molten core attacks and melts through the steel shell. If this early mode of failure could be avoided, the large contribution of this scenario to the overall risk could be substantially reduced. Two important parts of the CPI program are (1) to assure the presence of water on the drywell floor to quench the molten core and prevent steel shell melt-through and (2) to provide vent paths that will vent the wetwell airspace to a high point release and relieve the drywell of high internal pressure. Hardened vents have been installed at all operating plants with Mark I containments. The venting pressure is close to the design basis pressure for most of the Mark I plants. With the venting procedure in place, the containment performance under severe accident conditions is not expected to be affected by the limited steel shell corrosion observed in the Oyster Creek drywell and the Nine Mile Point 1 torus. However, to assess the potential risk, Brookhaven National Laboratory (BNL), under contract with NRC, has studied the performance of a degraded containment. The study, which used the NUREG-1150 assumptions regarding the core debris melting through the containment shell, . shows that, with a high likelihood of the melt-through failure mode, the effect of containment degradation was not dominant for the overall release profile and hence the risk. Calculations using degraded material thicknesses but realistic material properties show that the containment pressure capability was still significantly higher than the design pressure. Therefore, it is probable that even if the likelihood of melt-through failures were reduced and overpressure failures became more important, the effect of containment degradation on the release profile would still be small with a venting pressure close to the design basis pressure. However, it should be noted that, if the venting pressure is set too low, the benefit of the inherent margin between containment design pressure and actual failure is lost. The details of this limited study by $B N L$ are contained in the appendix of this report. 


\section{ACKNOWLEDGEMENTS}

The authors acknowledge and appreciate the efforts of John Lehner of the Brookhaven National Laboratory (BNL) in formulating and developing the study in the appendix of this report on the effects of corrosion on severe accident performance of BWR Mark I steel containments. Richard Morrante, also of BNL, contributed to the fragility assessment of degraded containments. For doing system PSA (Probabilistic Safety Analysis) and adaptation of the NUREG 1150 model to the plants under study, thanks go to Chuen-Ching Lin.
The authors also thank the following NRC personel: William Beckner for suggesting various approaches for this study, Seung Lee for reviewing the probability analysis in the draft report of the BNL study, William Russell and Ashok Thadani for approving the BNL study, and Brian Sheron for explicating the regulatory history of the Mark I steel containment corrosion.

Special thanks to Serona Mosby (NRC, ECGB) for efficiently typing and compiling the report and to Paul Kleene (NRC, ADM) for editing it. 


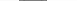




\section{ABBREVIATIONS}

$\mathrm{ADM}$

ASME

BNL

BWROG

$\mathrm{CO}$

CIP

CPI

DWHAL

DWHR

DWL

DWR

ECGB

EVNTRE

GL

GPU

IN

NEI

NUMARC (Now NEI)

PRA

PSA

PWR

UT

WWRaW

WWRbW
Office of Administration

American Society of Mechanical Engineers

Brookhaven National Laboratory

Boiling Water Reactor Owners Group

Condensation and Oscillation

Containment Inspection Program

Containment Performance Improvement

Drywell Head Flange Leak

Drywell Head Rupture

Drywell Leak

Drywell Rupture

Civil Engineering and Geosciences Branch

Event Tree (Name of a Computer Code)

Generic Letter

GPU Nuclear Corporation

Information Notice

Nuclear Energy Institute

Nuclear Management and Resources Council, Inc.

Probabilistic Risk Analysis

Probabilistic Safety Analysis

Pressurized Water Reactor.

Ultrasonic Testing

Wetwell Rupture Above Water

Wetwell Rupture Below Water 


\section{INTRODUCTION}

The study described in this report concerned the integrity of Mark I and Mark II steel containments for boiling-water reactor (BWR) plants, some of which have been found to be degraded during the normal operation of the plants. The containment structure is the last barrier against radioactive release to the environment and is essential to protect the health and safety of the general public. Therefore, its importance cannot be overemphasized. Containment structures are required to be designed and constructed with every care so that the high quality of their construction and in-service maintenance will ensure the integrity of containment function throughout the life of the plants. Their design, fabrication, and construction are governed by the ASME code that requires adherence to high quality in both design and construction with substantial margins of safety. To assure that the required high quality has been achieve, each containment after completion of construction is subjected to a structural integrity test typically at 1.15 times the design pressure. In addition, General Design Criterion 53 (10 CFR Part 50, Appendix A) requires that the containment be designed to permit appropriate periodic inspection of important parts, appropriate surveillance, and periodic testing. Appendix J to 10 CFR Part 50 gives the details of periodic testing of containments and among other things stipulates that, prior to a integrated leak rate test, a general inspection of the accessible interior and exterior surfaces of the containments be done to uncover any evidence of deterioration of structural or leak-tight integrity. The inspection is generally accomplished visually, since this method is most cost effective. Such an inspection is at best cursory and only detects obvious degradation. However, an experienced and observant inspector may uncover containment degradation by examining the conditions to which it is subjected, especially when direct visual observation is difficult. The requirements for designing, constructing, and inspecting containment structures, as delineated in GDC 50, 51,52 , and 53 , are mostly general and do not contain technical details. The technical guidelines in these areas were developed in Section III of the ASME Code, and were then issued and accepted by the regulatory agency and the industry. The ASME Section XI has recently (1992) developed criteria for comprehensive containment inspection for the steel (Subsection IWE) and the concrete (Subsection IWL) components. NRC has proposed a rule to endorse the criteria.

In spite of the stringent requirements and care in design and construction, steel containments have been found to be corroded, but not enough to put the public health and safety in question. An evaluation of the degraded containments reached this conclusion. In spite of being degraded, the containments were found to meet the ASME Code Criteria under the design conditions, with a small reduction in the margin of safety.

The Mark I containments are complex in that they use pressure suppression through the wetwell. The drywell and the shield wall in tandem can resist a pressure substantially higher than the design pressure. Consequently, a degradation of the drywell affects the Mark I containment performance for the design basis events less than the degradation of a wetwell. However, containment degradation can have more effect on the severe accident behavior. With this concern in mind, a study was conducted to compare the capability of degraded containments and undegraded ones under severe accident conditions. The purpose of this report is to summarize the NRC staff's effort in resolving the issues arising from the degradation of the steel containments, specifically the Mark I.

\section{HISTORY OF CORROSION}

\section{In November 1986, licensee of the Oyster Creek} Plant reported the discovery of corrosion of the drywell steel shell on the outside face in the sand cushion area, which was designed as a smooth transition for the drywell shell from a fixed to a free-standing condition. Water had been found in the torus room during refueling activities. The water came from the drains in the sand cushion area and led to the discovery of corrosion of the drywell shell in the sand cushion area. Nearly all the Mark I steel drywells for the first generation of BWR plants are of such a design. Fearing that the problem might be generic to all the Mark I steel drywells, the NRC issued Generic Letter 87-05 requiring the licensees of BWR plants to perform necessary inspections and report the results to NRC. From the information obtained under Generic Letter 87-05, it was concluded that 
the corrosion at Oyster Creek is unique; the insulation used during construction for the formation of the 3-inch gap between the steel shell and the concrete shield building contains chlorides and sulfides, which mix with the water leaking from the refueling pool and render it corrosive. The water leakage from the refueling pool at Oyster Creek is unique and was caused by the deformed flexible seal in the pool. This type of flexible seal was not used in other BWR plants.

In October 1988, the thickness of the steel torus shell of Nine Mile Point 1, which is the only steel torus with an uncoated inside surface, was found to be at or below the required thickness in localized areas because of corrosion. In BWR plants with coated tori there were instances of peeling-off of the coating and minor corrosion of the torus shell. Information Notice (IN) 88-82 was issued to alert licensees of BWR plants with Mark I containments of the potential corrosion problem in the torus.

Both the Oyster Creek drywell and the Nine Mile Point 1 torus were analyzed with reduced thicknesses, and the original loads and load combinations and found to be in conformance with requirements of ASME Code Section III, Subsection NE, with some reduction in the as-built margin of safety. How long the Code requirements will continue to be met depends on the rate of corrosion as estimated from ultrasonic test (UT) measurements. In view of this fact, licensees of Oyster Creek and Nine Mile Point 1 are required to periodically perform such measurements to determine if the rate of corrosion has changed.

\section{RESOLUTION EFFORT}

\section{Plant-Specific Activities}

Oyster Creek and Nine Mile Point 1 have design pressures of 62 and $35 \mathrm{psig}$ for the drywell and the wetwell (torus) vessels, respectively. All other later plants have the same design pressure for both the drywell and wetwell. It is known that the original Mark I containment design pressure.was conservatively established. This has been confirmed by tests and computer analysis. In view of this fact, by a letter dated July 22, 1991, GPU proposed to reduce the drywell pressure from 62 to 44 psig at Oyster Creek, and the NRC reviewed and approved the reduction. This led to reduction in the required thickness of the drywell shell for design basis loads. The NRC staff approved the reduction through license Amendment No. 165 on September 13, 1993. This extended the life of the Oyster Creek containment beyond the end of the current license. To reduce or eliminate further corrosion, GPU undertook to remove the sand cushion, clean and coat the area, and reanalyze the drywell without the sand cushion. The staff, with the help of Brookhaven National Laboratory, reviewed GPU's reanalysis and agreed with its conclusion that the effect of removing the sand cushion is very localized and the stresses in the affected region are within the allowable limits of ASME Section III Subsection NE for such a condition. As an assurance that the corrosion rate is slower than the rate obtained from previous UT measurements, GPU is committed to make the UT measurements periodically. On the basis of these studies, the staff believes that the Oyster Creek drywell corrosion problem is under control.

Information on a proposed reduction of the design pressure and hydrodynamic loads for the Nine Mile Point 1 torus was presented to the staff. The licensee requested that, on the basis of the information provided, staff review the effective load on the torus shell and approve a license amendment reducing the required minimum thickness of the torus shell from 0.447 to 0.431 inch. The request was reviewed and approved by the NRC by a letter dated August 25, 1992. This approval means that, at the rate of corrosion established to date through UT measurements, the torus is expected to meet the ASME Code requirements until approximately year 2007 without any modifications. Since the rate of corrosion is critical, the licensee is required to perform UT measurement periodically.

\section{Issuance of A Generic Letter}

The discovery of the corrosion of the drywell at Oyster Creek and of the torus at Nine Mile Point 1 caused the staff to consider the need for issuing a new generic letter to require the Mark I and Mark II plant licensees with steel containments to adopt an inspection program for such containments. The steel containment inspections are covered by ASME Section XI Subsection IWE. However, Subsection IWE at the 
time covered only the inspection of the welds, not the base metal or the inaccessible areas such as the sand cushion area of the drywell shell. The Mark I drywell and the Mark II containment design do not allow easy access to the exterior surfaces to conduct the basic visual examinations. Since the existing ASME Code was not suitable for use in inspection of Mark I steel drywell and Mark II steel containments, the staff proposed issuing a generic letter delineating the required inservice inspection procedures to be adopted by licensees of BWR plants with such containments.

While writing the generic letter, the staff held public meetings with the BWR Owners Group (BWROG) to gather comments on and input to the inspection criteria. The BWROG formal comments were provided in letters dated December 22, 89, June 7, 1991, and September 3, 1991. The draft generic letter for public comment was published in the November 20,1992, issue of the Federal Register (57 FR 54860). The proposed generic letter stated, "The staff, with industry assistance, has devised an inspection program which should produce the necessary information. This inspection program consisted of the inservice inspection of all Mark I and Mark II steel containments, refueling cavities, pools and associated drainage systems. Each licensee had to indicate whether it intended to adopt the staff's inspection program or an alternate equally effective inspection program." The staff received comments from 11 organizations: six utilities, one citizen group, two architect/engineers, NUMARC (now Nuclear Energy Institute), and BWROG. Among the comments, those of the BWROG were most detailed. The BWROG suggested an alternate inspection program, which it believed could resolve the staff's concerns, and outlined its program in general terms. On November 5, 1993, BWROG submitted to the staff its detailed Model Containment Inspection Program. The staff reviewed the program but had reservations about several aspects of the program.

While these activities specific to BWR steel containments were going on, a broad set of containment inspection criteria were being developed by the ASME Code Section XI for all containment types currently in operation. The NRC staff has actively participated in the ASME Code development activities and provided inputs for incorporation in the required criteria. The NRC staff's recommendations are based on the experience gained in licensing review. The NRC objective of the NRC staff's ASME effort is to have an ASME Section XI Code incorporate as many of the inspection requirements acceptable to NRC as possible. The Code criteria can be incorporated into $10 \mathrm{CFR} 50.55$ through endorsement by rulemaking. This is a better approach than the issuance of a generic letter on the basis of the containment type. Since the rulemaking on the endorsement of ASME Code Section XI Subsections IWE and IWL is in the final stage, the staff notified the BWROG on February 3, 1994 the termination of any further effort to issue the generic letter. The staff believes that the containment inspection requirement is better initiated by a rule rather than by generic letter. Furthermore, Appendix $J$ to $10 \mathrm{CFR}$ Part 50 contains the inspection requirement followed by the industry. Inspection mandated by this rule, though basically visual, has been reasonably effective in identifying containment problems known to date. However, for inaccessible areas of the containment, visual examination has to be supplemented by additional inspections, such as by ultrasonic thickness measurement or other methods of nondestructive examination. The discovery, at each refueling, of water in the torus room at Oyster Creek led to the discovery of the source of the water, and that led to the discovery of corrosion in the sand cushion area (through ultrasonic thickness measurements). Thus, it is important that licensees be alert and observant in such inspections.

\section{Other Activities}

Because of the importance of the containment to the health and safety of the general public, the NRC staff was pursuing other measures to improve containment performance so as to reduce significantly the likelihood of containment failure due to high pressure from severe accident sequences. In the NUREG-1150 studies of the severe accident risks for five representative nuclear power plants in the U.S., the Peach Bottom plant was used to represent a BWR plant with Mark I steel containment. The study found that improving certain areas of Mark I containment performance could substantially reduce the risk. Because of its risk importance, the Commission undertook an effort to implement the Mark I Containment Performance Improvement (CPI) program. Results of NUREG-1150 studies indicated that the risk to 
the public from plants with Mark I containments is dominated by early containment failure when molten core attacks and melts through the steel shell of the drywell. If this early failure mode could be avoided, the overall risk from severe accidents could be substantially reduced. On the basis of this finding, it became clear that the CPI program should consist of two elements:

(1) assuring presence of water on the drywell floor to quench the molten core and prevent steel shell melt through, and (2) providing vent paths to vent the wetwell airspace to a high point release and relieve the containment of high internal pressure. Containment purge and vent valves are already in place in operating plants but could not perform the function of venting under severe accident pressures. Consequently, "hardened vents" were necessary to implement this aspect of the CPI program. Hardened vents have been installed on all Mark I containments of all operating BWR plants. The venting pressures for most existing plants are close to the design basis pressure. For instance, venting pressure for Oyster Creek is 35 psig, which is the design pressure of the torus. With the venting procedure in place at all the Mark I steel containments, the corrosion so far observed in the drywell of Oyster Creek and in the torus of Nine Mile Point 1 is not expected to affect the performance of other Mark I steel containments under severe accident condition.

\section{Containment Inservice Degradation Assessment}

To confirm that the corrosion so far experienced in Oyster Creek and Nine Mile Point I containments would not significantly affect their performance under severe accident conditions, the staff asked the Brookhaven National Laboratory (BNL) to do a study using the same scenarios as the NUREG-1150 study but assuming a degraded containment.

One way to estimate the impact of containment degradation on the Peach Bottom plant is to repeat the accident progression analysis conducted for NUREG-1150; that is, use the established Peach Bottom EVNTRE computer code to generate the containment event tree, but substitute a reduced pressure capability to reflects a hypothetical degradation. The containment release profile generated with this method can then be compared with that generated in the NUREG-1150 study without degradation. Such an exercise was carried out as an intermediate step in the BNL study. However, the containment loads in a severe accident at Oyster Creek and Nine Mile Point 1 would be substantially different than the loads used in NUREG-1150 for Peach Bottom, because of differences in size and power among these plants, and Peach Bottom EVNTRE model had to be revised to take these differences into consideration.

BNL therefore modified the results of the comprehensive NUREG-1150 investigation of the Peach Bottom Mark I containment by considering not only the containment degradation but also plant size and containment venting pressures. The containment pressure source terms (e.g., steam and hydrogen production) were compared by rated power, and the containment pressure rise due to these source terms was scaled according to the ratio of rated power to containment volume.

Once the appropriate scaling factors were established and incorporated into the analysis, the containment release or performance profile for the Nine Point 1/Oyster Creek degraded containment was obtained by doing an EVNTRE analysis with both the undegraded and the degraded pressure capacity and comparing the plant release perimeters. BNL's assumptions were as follows:

1. Pressure capacities were based on three containment condition states: as-designed, current level of observed shell thickness corrosion, and postulated 25 percent additional shell thickness corrosion.

2. Three venting pressures were used: 100 psig, $43.4 \mathrm{psig}$, and $35 \mathrm{psig}$. For each venting pressure, the three condition states in 1 above were studied.

3. Six failure modes were considered: drywell head rupture (DWHR), drywell head flange leak (DWHL), drywell rupture (DWR), drywell leak (DWL), wetwell rupture below water-line (WWRbW), and wetwell rupture above water-line (WWRaW).

As an intermediate step, analyses were also done for Peach Bottom for three pressure capabilities: the NUREG-1150 value and 75 percent and 63 percent of the NUREG value. 
The results of this study showed that, although the effect of containment degradation of the type postulated for Oyster Creek and Nine Mile Point 1 is noticeable, and significant for some failure modes, it is not dominant for the overall release profile.

Several important failure modes for a Mark I containment are not affected by a reduction in containment pressure capability:

1. failure of the containment due to "liner melt-through" (the containment shell being attacked by molten core debris).

2. direct containment heating or other overpressurization resulting from a reactor breach at a pressure so high that the uncorroded containment will quickly fail, and

3. other scenarios such as containment bypass sequences and interfacing system loss-of-coolant accidents (LOCAs).

BNL's study shows that the degradation observed at Oyster Creek and Nine Mile Point 1 does not greatly affect performance of Mark 1 steel containments under severe accident conditions such as containment shell melt-through. However, the degradation can significantly affect containment scenarios with less conservative assumptions on shell melt-through than those used in NUREG-1150 and in the BNL study, such overpressurization failure will become dominant and the degradation could have a great effect on the containment performance. Nonetheless, calculations using degraded material thickness but realistic material properties showed that the containment pressure capability was still significantly higher than the design pressure and that the effect of containment degradation on the release profile would still be small if a venting pressure close to the design basis pressure were used. If the venting pressure is set too low, the benefit of the inherent margin between containment design pressure and actual failure is lost.

\section{CONCLUSION}

The staff has taken the necessary actions, generic as well as specific, to ensure that the Mark I and
Mark II steel containments will not be degraded under service conditions to a level at which their integrity is compromised. Staff actions to maintain and enhance the performance of Mark I containments, for example, the implementation of the Containment Performance Improvement (CPI) Program, were motivated by an awareness of the risk importance of various safety assurance measures. The corrosion experienced at Oyster Creek and Nine Mile Point 1 makes the need for containment inspection obvious. It may be argued that the Appendix $\mathrm{J}$ to Part 50 requirement to visually inspect the containment and the integrated leak rate tests met the need. It may be further argued that margins to overpressure failure in Mark I containments are substantial, as this assessment of the capability of the degraded containment under severe accident conditions shows. However, for inaccessible areas, visual inspection is not effective. Corrosion, if it continued undetected, will deplete the margin. Therefore, it is essential to put in place an inservice inspection program for these structures to assure that their integrity is maintained. This can be accomplished by a revision of 10 CFR 50.55a endorsing ASME Code Section XI criteria as part of the rules the licensees must comply with. The requirement in Appendix $J$ to $10 \mathrm{CFR}$ Part 50 to visually inspect the containment and do an integrated leak rate test may be considered as a complement to the inspection program.

\section{REFERENCES}

1. NRC 1986, Information Notice, IN 86-99, "Degradation of Steel Containments," December 1986.

2. NRC 1987, Generic Letter 87-05, "Request for Additional Information-Assessment of Licensee Measures to Mitigate and/or Identify Potential Degradation of Mark I Drywells," March 1987.

3. NRC 1987, Generic Staff Safety Evaluation Report (SER) of Licensee Responses to Generic Letter 87-05, November 1987.

4. NRC 1988, Regional Inspection Reports 50-220/88-09 (Nine Mile Point 1) and 50-410/88-09 (Nine Mile Point 2), April 1988.

5. NRC 1988, IN 88-82, "Torus Shells with Corrosion and Degraded Coatings in BWR Containments," October 1988. 
6. NRC 1989, SECY-89-017, "Mark I Containment Performance Improvement Program."

7. NRC 1989, Supplement to IN 88-82, May 1989.

8. NRC 1989, IN 89-16, "Installation of a Wetwell Hardened Vent," September 1989.

9. NRC 1989, IN 89-79, "Degraded Coatings and Corrosion of Steel Containment Vessels," December 1989.
10. NRC 1990, Supplement 1 to IN 89-79, June 1990.

11. NRC 1991, Supplement 1 to IN 86-99, February 1991.

12. NRC 1992, Federal Register Notice for Draft Generic Letter, "Augmented Inservice Inspection Requirements For Mark I and Mark II Steel Containments, Refueling Cavities and Associated Drainage System," (57 FR54864) November 1992. 
Appendix A 


\title{
CONTAINMENT INSERVICE DEGRADATION ASSESSMENT
}

\author{
J. Lehner, R. Morante, C.C. Lin and S. Nimnual \\ Accident Analysis Group \\ Safety and Risk Evaluation Division \\ and \\ Mechanical and Systems Engineering Group \\ Engineering Research and Application Division \\ Brookhaven National Laboratory \\ Upton, New York 11973
}

February 1995

Prepared for

Office of Nuclear Reactor Regulation U.S. Nuclear Regulatory Commission Washington, DC 20555

NRC FIN L-1521 



\begin{abstract}
Corrosion of the steel containment shell has been observed and measured at two older BWR Mark I plants, Oyster Creek and Nine Mile Point 1. A concern in regard to the degradation is the effect it may have on the containment performance in the unlikely event that a severe accident occurs. Should a severe accident take place, the degradation may affect the timing, location, and types of containment failure in a severe accident and thus the potential risk to the public. The objective of this report is to provide an estimate of the effect of inservice containment degradation, of the type experienced in Oyster Creek and Nine Mile Point 1, plus additional hypothetical corrosion, on the performance of a Mark I containment under severe accident loadings. To conserve resources, the approach chosen for this effort is one which builds on, and modifies, the results of the comprehensive NUREG-1150 investigation of the Peach Bottom Mark I containment in such a way as to account for containment degradation and make the analysis applicable to Oyster Creek and Nine Mile Point 1.
\end{abstract}





\section{CONTENTS}

Page

ABSTRACT $\ldots \ldots \ldots \ldots \ldots \ldots \ldots \ldots \ldots \ldots \ldots \ldots \ldots \ldots \ldots$ iii LIST OF FIGURES $\ldots \ldots \ldots \ldots \ldots \ldots \ldots \ldots \ldots \ldots \ldots \ldots \ldots \ldots$ LIST OF TABLES $\ldots \ldots \ldots \ldots \ldots \ldots \ldots \ldots \ldots \ldots \ldots \ldots \ldots \ldots \ldots \ldots \ldots$ EXECUTTVE SUMMARY $\ldots \ldots \ldots \ldots \ldots \ldots \ldots \ldots \ldots \ldots \ldots \ldots \ldots$ ix CORRECTION TO INITIAL DRAFT $\ldots \ldots \ldots \ldots \ldots \ldots \ldots \ldots \ldots \ldots$ xiii

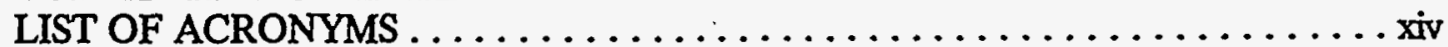

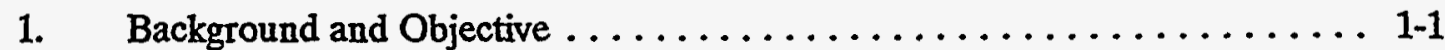

2. Approach .......................... 2-1

3. The Modified NUREG-1150 EVNTRE Methodology ............. 3-1

3.1 The EVNTRE Methodology $\ldots \ldots \ldots \ldots \ldots \ldots \ldots \ldots . \ldots . \ldots . \ldots .1$

3.2 Modifications to the Methodology for Application to

Containment Degradation in Nine Mile Point/Oyster Creek . . . . . . 3-3

4. Structural Evaluation of Early Mark I Containment Designs

for Various Levels of Shell Wall Corrosion . . . . . . . . . . . . . 4-1

4.1 Introduction . . . . . . . . . . . . . . . . . . .

4.2 Definition of Containment Condition States $\ldots \ldots \ldots \ldots \ldots \ldots$. . . . .

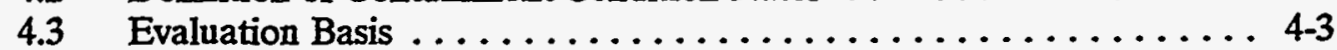

4.3.1 Failure Modes .......................... 4-3

4.3.2 Temperature States. . . . . . . . . . . . . . . . . . 4-3

4.3.3 . Containment Loading . . . . . . . . . . . . . . . . . . . . 4-4

4.4 Containment Structural Analysis . . . . . . . . . . . . 4-4

4.5 Development of Probability Distributions ............. 4-4

5. Results

5.1 The Effect of a Reduction in Containment Pressure Capability on the Peach Bottom Release Profile ................. 5-1

5.2 The Effect of a Reduction in Containment Pressure Capability on the Nine Mile Point 1/Oyster Creek Release Profile . . . . . . . . 5-2

6. Conclusions $\ldots \ldots \ldots \ldots \ldots \ldots \ldots \ldots \ldots \ldots \ldots \ldots \ldots$

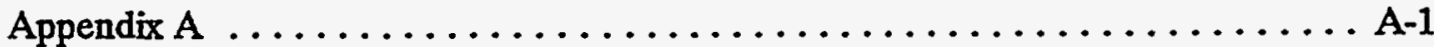

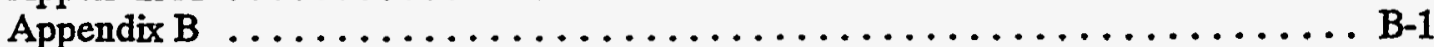

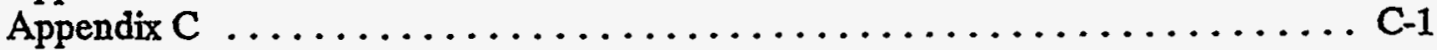

$\mathbf{v}$ 


\section{LIST OF TABLES}

Table

3-1 Comparison of Plant Parameters $\ldots \ldots \ldots \ldots \ldots \ldots \ldots \ldots \ldots \ldots \ldots . \ldots \ldots$

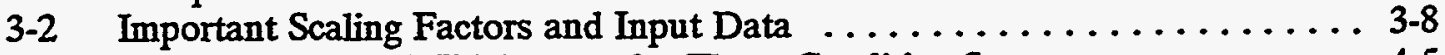

4-1 Containment Shell Thicknesses for Three Condition States .......... 4-5

4-2 Range of Shell Material Properties for Three Condition States . . . . . . . 4-6

4-3 Bolt and O-Ring Seal Data for Head Flange Analysis . . . . . . . . . . 4-7

4-4 Failure Pressures (PSI) for As-Designed Condition . . . . . . . . . . . . . . 4-8

4-5 Failure Pressures (PSI) for Current Condition . . . . . . . . . . . . 4-9

4-6 Failure Pressures (PSI) for Postulated Corroded Condition . . . . . . . . . 4-10

5-1 Peach Bottom Containment Performance with Different Pressure Capabilities 5-7

5-2 Nine Mile Point 1/Oyster Creek Containment Performance with Different Pressure Capabilities and 100 psig Venting Pressure . . . . . . . . . . 5-8

5-3 Nine Mile Point 1/Oyster Creek Containment Performance with Different Pressure Capabilities and 43.4 psig Venting Pressure . . . . . . . . . . 5 5

5-4 Nine Mile Point 1/Oyster Creek Containment Performance with Different

Pressure Capabilities and 35 psig Venting Pressure $\ldots \ldots \ldots \ldots \ldots \ldots$ 5-10 


\section{LIST OF FIGURES}

Figures

Page

3-1 NUREG-1150 Peach Bottom Accident Progression Analysis . . . . . . . . . 3-9

3-2 Conditional Probability of Collapsed APBs for Internal

PDSs (from NUREG-1150) . . . . . . . . . . . . . . . . 3-10

3-3 Accident Progression Analysis for OC/NMP .............. 3-11

4-1 Mark I Containment ....................... 4-11

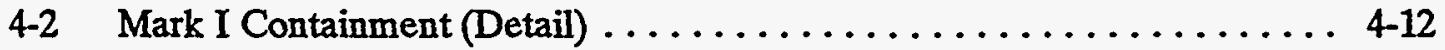

4-3 Drywell .............................. 4-13

4-4 Wetwell (Toroidal Suppression Chamber) . . . . . . . . . . . . . 4-14

4-5 Failure Probability, As-Designed (300 deg) $\ldots \ldots \ldots \ldots \ldots \ldots \ldots \ldots \ldots$. $\ldots \ldots$

4-6 Failure Probability, As-Designed (800 deg) $\ldots \ldots \ldots \ldots \ldots \ldots \ldots \ldots . . \ldots \ldots$

4-7 Failure Probability, Current (300 deg) ................. . 4-17

4-8 Failure Probability, Current $(800 \mathrm{deg}) \ldots \ldots \ldots \ldots \ldots \ldots \ldots \ldots . \ldots \ldots$

4-9 Failure Probability, Corroded (300 deg) ... . . . . . . . . . . . 4 4-19

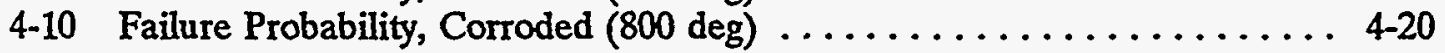

5-1 Effect of Containment Capability for Peach Bottom (PDS 1) . . . . . . 5-4

5-2 Effect of Containment Capability for Peach Bottom (PDS 5) ......... 5-5

5-3 Effect of Containment Capability for Peach Bottom (PDS 9) ......... 5-6

5-4 NMP/OC Design Condition Compared to PB 100\% and PB 75\% for PDS 1 5-11

5-5 NMP/OC Design Condition Compared to PB $100 \%$ and PB 75\% for PDS $5 \quad 5-12$

5-6 NMP/OC Design Condition Compared to PB 100\% and PB 75\% for PDS 9 5-13

5-7 NMP/OC Comparison, Effect of Containment Capability, PDS $1 \ldots \ldots$. . 5-14

5-8 NMP/OC Comparison, Effect of Containment Capability, PDS $5 \ldots \ldots$. . . 5-15

5-9 NMP/OC Comparison, Effect of Containment Capability, PDS $9 \ldots \ldots$. 5-16

5-10 Effect of Venting Pressure, NMP/OC Model, PDS $1 \ldots \ldots \ldots \ldots \ldots \ldots$ 5-17

5-11 Effect of Venting Pressure, NMP/OC Model, PDS $5 \ldots \ldots \ldots \ldots \ldots \ldots$ 5-18

5-12 Effect of Venting Pressure, NMP/OC Model, PDS $9^{-} \ldots \ldots \ldots \ldots \ldots \ldots . . .5-19$

6-1 Fractional Change of NCF Probability, Peach Bottom Model .......... 6-3

6-2 Fractional Change of NCF Probability, NMP/OC Model ........... 6-4

vii 



\section{EXECUTIVE SUMMARY}

\section{Objective and Approach}

Corrosion of the steel containment shell has been observed and measured at two older BWR Mark I plants, Oyster Creek and Nine Mile Point 1. The present level of corrosion is significant because initial design margins have been essentially exhausted at a number of locations in the containment structure. To address this problem, remedial actions are underway to prevent or minimize future corrosion. Loads are being re-evaluated to remove conservatism from the design basis calculations, and as-built material strength properties have been factored into the initial design calculations to demonstrate increased margins. The final resolution of these observed conditions for the remaining life of the affected Mark I containments is currently being developed jointly by the NRC and the licensees.

Another concern in regard to the degradation is the effect it may have on the containment performance should a severe accident occur. In the unlikely event that a severe accident does occur, the degradation may affect the timing, location, and types of containment failure and thus the potential risk to the public. Estimates of these parameters are needed to develop evacuation plans, activate radiological protective measures, and otherwise manage a severe accident.

The objective of the present work is to provide an estimate of the effect of inservice containment degradation, of the type experienced in Oyster Creek and Nine Mile Point 1 , on the performance of a Mark I containment under severe accident loadings. To conserve resources, the approach chosen for this effort is one which builds on, and modifies, the results of the comprehensive NUREG-1150 investigation of the Peach Bottom Mark I containment in such a way as to account for containment degradation and make the analysis applicable to Oyster Creek and Nine Mile Point 1.

To estimate the impact of hypothetical containment degradation on the Peach Bottom plant one can repeat the accident progression analysis conducted for NUREG-1150, i.e. use the EVNTRE computer code to generate the containment event tree, only substituting a reduced pressure capability which appropriately reflects the hypothetical degradation. The containment release profile generated with this method can then be compared with that generated in the NUREG-1150 study, which assumes as-built characteristics, and the impact of degradation will be apparent. Such an assessment of a degraded Peach Bottom containment was carried out as an intermediate step of the present study.

This simple approach will not work for Nine Mile Point and Oyster Creek since the containment loads in a severe accident would be substantially different than those used in

ix 
NUREG-1150 for Peach Bottom because these plants differ in size and power from Peach Bottom. To estimate the impact of the observed degradation, and/or additional potential degradation, in Nine Mile Point 1 and Oyster Creek, further modifications must be made to the Peach Bottom EVNTRE model to account for the differences in the design of these Mark I plants. Important differences for containment loading. i.e. the source of containment pressure, are the plant size and its venting pressure. In general, the containment pressure source terms (e.g., steam and hydrogen production) can be scaled according to the rated power, and the containment pressure rise due to these source terms can be scaled according to the ratio of rated power to containment volume.

Once appropriate scaling factors have been established and incorporated into the analysis, an assessment of the containment release or performance profile for the Nine Mile Point/Oyster Creek degraded containment can be obtained by performing an EVNTRE analysis with both the undegraded and degraded pressure capability and comparing the plant release profile for the two cases.

One of the key inputs to accident analysis is the internal pressure capacity of the containment. Because of the probabilistic nature of accident analysis, it is insufficient and highly conservative to assume loss of the containment pressure boundary when the containment design pressure is reached. In addition, different modes of containment "failure" have different consequences in the accident analysis.

The structural part of this study generated probabilistic distributions of failure pressure for six (6) specified Mark I Containment failure modes using a combination of Nine Mile Point and Oyster Creek parameters, for three (3) specified condition states. The condition states are:

1. as-designed

2. current level of observed shell thickness corrosion

3. postulated $25 \%$ additional shell thickness corrosion

The failure modes considered are:

- Drywell Head Rupture (DWHR)

- $\quad$ Drywell Head Flange Leak (DWHL)

- Drywell Rupture (DWR)

- Drywell Leak (DWL)

- Wetwell Rupture below Waterline (WWRbW)

- Wetwell Leak above Waterline (WWLaW)

Modifications were then made to the EVNTRE code so that results for the following cases could be obtained and compared for the below stated conditions $a, b$ and $c$ within each case. 
1) Peach Bottom model with a 100 psig venting pressure:
a. pressure capability equal to NUREG-1150 values.
b. pressure capability equal to $75 \%$ of NUREG-1150 values.
c. pressure capability equal to $63 \%$ of NUREG- 1150 values.

2) Nine Mile Point/Oyster Creek (NMP/OC) model with 100 psig venting pressure:
a. pressure capability equal to original design values.
b. pressure capability based on current observed conditions.
c. pressure capability with postulated $25 \%$ additional shell corrosion.

3) NMP/OC model with 43.4 psig venting pressure:
a. pressure capability equal to original design values.
b. pressure capability based on current observed conditions.
c. pressure capability with postulated $25 \%$ additional shell corrosion.

4) NMP/OC with 35 psig venting pressure:
a. pressure capability equal to original design values.
b. pressure capability based on current observed conditions.
c. pressure capability with postulated $25 \%$ additional shell corrosion.

\section{Results}

The results of this study show that while the effect of containment degradation of the type postulated for Nine Mile Point 1 and Oyster Creek is noticeable, and significant for some failure modes, it is not dominant for the overall release profile.

There are a number of important failure modes for a Mark I containment which are unaffected by a reduction in containment pressure capability. The most significant of these is failure due to "liner melt-through" where the containmentshell is attacked and penetrated by molten core debris flowing out of a breached vessel and across the drywell floor. Obviously containment pressure capability is irrelevant for this kind of failure. If liner meltthrough failure is given less likelihood than is assigned in the NUREG-1150 type approach used here, pressure failures would become more important, and the effect of degradation on the overall release profile can be expected to be more significant.

Another failure mode which will not be significantly affected by degradation in containment pressure capability is that associated with direct containment heating or other over-pressurization resulting from a reactor vessel breach at high pressure. The 
containment pressures generated in such a scenario are likely to be so high that even the uncorroded containment will quickly fail and therefore degradation will not play a role.

Other scenarios, such as containmentbypass sequences and certain interfacing system LOCAs are unaffected by changes in containment pressure capability as well.

Another observation that can bë made based on the results is that lower containment venting pressures do not influence the failure probabilities very much, but can increase releases because most of the vented sequences with the 43 and 35 psig venting pressures would have been no containment failure sequences if a higher (100 psig) venting pressure were used.

In summary, it appears that based on this limited study, for the Mark I containments investigated, the degradation postulated can be significant for certain scenarios but does not cause a major change in containment performance under severe accident conditions. 


\section{CORRECTION TO INITIAL DRAFT}

During the course of BNL's review of NRC staff comments on the initial draft of this report, an omission in the definition of the "conditional probability of failure vs. pressure" distributions was noted by one of the report authors. These distributions are derived from the structural analysis results and are required input for the release profile calculations. Subsequent investigation, based on a comparison of the initial and modified Oyster Creek/Nine Mile Point 1 release profiles for the 100 psig venting pressure case showed this omission had negligible effect on the results and conclusions of the study. In fact, the comparison indicated that the release profiles, and therefore the general conclusions of this study are insensitive to modest variations in the "conditional probability of failure vs. pressure" distributions.

These findings are documented in an attachment to a letter of December 8, 1994 from J.R. Lehner, BNL/SRED/AAG to C.P. Tan NRC/NRR/ECGB.

Appendix B of this final draft of the report has been updated to show the corrected formulation of the conditional probability of failure vs. pressure distribution. However, because of the negligible effect on results noted above, the figures and tables in the main report and Appendix $C$ were left unchanged from the earlier draft. 


\section{LIST OF ACRONYMS}

$\begin{array}{ll}\text { ADS } & \text { Automatic Depressurization System } \\ \text { APBs } & \text { Accident Progression Bins } \\ \text { APET } & \text { Accident Progression Event Trees } \\ \text { ASME } & \text { American Society of Mechanical Engineers } \\ \text { ASTM } & \text { American Society of Testing Materials } \\ \text { ATWS } & \text { Anticipated Transient Without Scram } \\ \text { BNL } & \text { Brookhaven National Laboratory } \\ \text { BWR } & \text { Boiling Water Reactor } \\ \text { CPF } & \text { Cumulative Probability of Failure } \\ \text { CRD } & \text { Control Rod Drive } \\ \text { EOPs } & \text { Emergency Operating Procedures } \\ \text { HPCI } & \text { High Pressure Coolant Injection } \\ \text { HPSW } & \text { High Pressure Service Water } \\ \text { LOCAs } & \text { Loss of Coolant Accidents } \\ \text { NCF } & \text { No Containment Failure } \\ \text { NMP/OC } & \text { Nine Mile Point 1/Oyster Creek } \\ \text { NPSH } & \text { Net Positive Suction Head } \\ \text { NRC } & \text { Nuclear Regulatory Commission } \\ \text { PB } & \text { Peach Bottom } \\ \text { PCPL } & \text { Primary Containment Pressure Limit } \\ \text { PCS } & \text { Power Conversion System } \\ \text { PDS } & \text { Plant Damage States } \\ \text { RCIC } & \text { Reactor Core Isolation Cooling } \\ \text { RCS } & \text { Reactor Coolant System } \\ \text { RPV } & \text { Reactor Pressure Vessel } \\ \text { SBO } & \text { Station Blackout } \\ \text { SLC } & \text { Standby Liquid Control } \\ \text { SRVs } & \text { Safety Relief Valves } \\ \text { VB } & \text { Vessel Breach } \\ & \end{array}$

All pressures in psig unless otherwise noted. 


\section{Background and Objective}

Corrosion of the steel containment shell has been observed and measured at two older BWR Mark I plants, Oyster Creek and Nine Mile Point 1. The present level of corrosion is significant because initial design margins have been essentially exhausted at a number of locations in the containment structure. To address this problem, remedial actions are underway to prevent or minimize future corrosion. Loads are being re-evaluated to remove conservatism from the design basis calculations, and as-built material strength properties have been factored into the initial design calculations to demonstrate increased margins. The final resolution of these observed conditions for the remaining life of the affected Mark I containments is currently being developed jointly by the NRC and the licensees.

Another concern in regard to the degradation is the effect it may have on the containment performance in the event of a severe accident. Should a severe accident occur, the degradation may affect the timing, location, and types of containment failure and thus the potential risk to the public. Estimates of these parameters are needed to develop evacuation plans, activate radiological protective measures, and otherwise manage a severe accident.

In the past, both NRC and the nuclear industry performed numerous studies of containment performance under severe accident challenges. One of the largest studies of this kind, sponsorèd by NRC, was documented in NUREG-1150, "Severe Accident Risks: An Assessment for Five Nuclear Power Plants." One of the plants analyzed in NUREG1150 was a BWR Mark I plant, i.e. the twin units Peach Bottom 2,3. However, NUREG1150 and all the other severe accident risk studies to date have implicitly assumed asdesigned conditions. for the containment. No consideration to degradation has been given in these studies when containment strength and containment failure probabilities were estimated.

The objective of the present.work is to provide an estimate of the effect of inservice containment degradation, of the type experienced in Oyster Creek and Nine Mile Point 1, on the performance of a Mark I containment under severe accident loadings. To conserve resources, the approach chosen for this effort is one which builds on, and modifies, the results of the comprehensive NUREG-1150 investigation of the Peach Bottom Mark I containment in such a way as to account for containment degradation and make the analysis applicable to Oyster Creek and Nine Mile Point 1. 


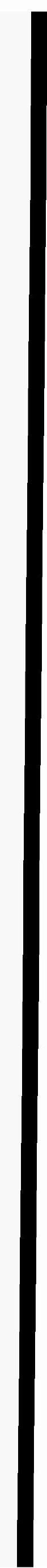




\section{Approach}

As noted above, included in the NUREG-1150 study was a detailed analysis of the Peach Bottom BWR Mark I plant, including a comprehensive containment performance investigation. A common tool for containment performance assessment is the containment event tree, or accident progression tree, which tracks the possible paths along which a severe accident can evolve once core damage has occurred. The containment event tree describes the containment response to a core melt accident and accounts for system interactions, operator actions, and key phenomenological issues. The tree usually starts with the plant damage states, i.e. plant states into which core damage sequences with certain common characteristics can be binned, and progresses to containment failure and fission product release. In NUREG-1150 the containment event tree, or accident progression event tree as it is called there, is an unusually comprehensive tree, processed and quantified using the EVNTRE computer code. The tree contains 145 containment related questions, many with several branch points.

As the accident progresses the integrity of the containment is challenged by various pressure loads and other phenomena which occur as a result of the accident. The ability of the containment to withstand pressure loads is determined by its pressure capability. It is the pressure capability which is impacted by the containment degradation of concern here, i.e. the observed corrosion in the steel shell of the containment. A containment with reduced pressure capability may experience earlier or more frequent failures and different failure modes than an undegraded containment subjected to the same pressure loads. The pressure loads themselves are, of course, the same for a degraded as well as an undegraded containment.

To estimate the impact of hypothetical containment degradation on the Peach Bottom plant one can repeat the EVNTRE analysis conducted for NUREG-1150, only substituting a reduced pressure capability which appropriately reflects the hypothetical degradation. The containment release profile generated with this method can then be compared with that generated in the NUREG-1150 study, which assumes as-designed characteristics, and the impact of degradation will be apparent.

This simple approach will not work for Nine Mile Point and Oyster Creek since the containment loads in a severe accident would be substantially different than those used in NUREG-1150 for Peach Bottom because these plants differ in size and power from Peach Bottom. To estimate the impact of the observed degradation, and/or additional potential degradation, in Nine Mile Point 1 and Oyster Creek, further modifications must be made to the Peach Bottom EVNTRE model to account for the differences in the design of these Mark I plants. Important differences for containment loading. i.e. the source of containment pressure, are the plant size and its venting pressure. In general, the containment pressure source terms (e.g., steam and hydrogen production) can be scaled according to the rated power, and the containment pressure rise due to these source terms can be scaled according to the ratio of rated power to containment volume. 
Once appropriate scaling factors have been established and incorporated into the analysis, an assessment of the containment release or performance profile for the Nine Mile Point/Oyster Creek degraded containment can be obtained by performing an EVNTRE analysis with both the undegraded and degraded pressure capability and comparing the plant release profile for the two cases.

Based on the above discussion, the following approach was used to asses the impact of degradation on the performance of the Nine Mile Point/Oyster Creek containment:

1. The pressure loads (distributions) at key phases of a severe accident used in the NUREG-1150 Peach Bottom EVNTRE model were obtained.

2. The Peach Bottom EVNTRE model was reviewed to identify those questions which are important to containment pressure load definition (i.e., questions which define pressure source terms and pressure rises resulting from these source terms). Examples are the parameters that affect the hydrogen production during core melt and the parameters that affect the progression of core-concrete interaction. The parameters in these questions were examined, and the appropriate scaling factors for these parameters were determined.

3. The values of the scaling factors between Oyster Creek/Nine Mile Point 1 and Peach Bottom were determined based on the plant parameters, and the Peach Bottom EVNTRE model was modified to reflect these differences.

4. The venting pressure (i.e. the PCPL in the EOPs) was obtained from the utilities operating Nine Mile Point 1 and Oyster Creek.

5. Containment pressure capabilities and the associated failure modes for both the original design and the degraded containment were obtained. These containment pressure capabilities are the mean pressures with appropriate distributions to characterize the uncertainties.

6. The modified pressure load distributions and the new pressure capabilities were used as input to the EVNTRE calculation. The release profiles for both the original design and the degraded containment were obtained using the modified EVNTRE model and the effect of containment degradation on the release profile was assessed.

As an intermediate step, the performance of a hypothetical degraded Peach Bottom containment was assessed by performing only steps 5 and 6 above.

The above six steps provide the basis for the remaining sections of this report. Section 3 describes the NUREG-1150 EVNTRE based methodology for containment 
performance analysis and the modifications needed to apply the methodology to the containment degradation problem. Section 4 describes step five above, i.e. obtaining the modified pressure capabilities. This is the single biggest step in the above list. The results of the analysis are presented in Section 5. Conclusions are stated in Section 6. 



\section{The Modified NUREG-1150 EVNTRE Methodology}

\subsection{The EVNTRE Methodology}

Both the containment pressure loading as well as the containment pressure capability and failure mode are described in the NUREG-1150 study, and incorporated in the EVNTRE code, as probability functions. The containment pressure capability is estimated for two temperature conditions, $300^{\circ} \mathrm{F}$ and $800^{\circ} \mathrm{F}$, since, during some phases of the accident, the drywell can be at very high temperature. Where data was lacking, cumulative distribution functions were obtained via expert opinion elicitation.

The containment release profile (or containment failure mode) is characterized in NUREG-1150 by the definition of accident progression bin (APB) groups. The accident progression event tree (APET), quantified with EVNTRE, is used to obtain the conditional probability of each APB for important plant damage states (PDSs). The magnitude of the containment pressure loading, as an APET question, is asked at various phases of a severe accident and its value is compared with the containment pressure capability to determine whether the containment would fail. If a failure occurs, the mode of failure (i.e., the APB) is established as well. The accident progression is divided into a number of phases, including the early phase (before vessel breach), the vessel breach phase (during and shortly after vessel breach, VB), and the late phase. Each phase has its important pressure load sources. These include the mass and energy discharge to the containment due to decay heat and core degradation during the early phase, the pressure load mechanism associated with high pressure melt ejection and steam explosion during the vessel breach phase, and the mass and energy generation due to corium-concrete interaction and decay heat during the late phase. The APET for Peach Bottom progresses through the phases of the accident using 145 questions, many with more than two branch points.

Figure 3-1 shows the main elements of the NUREG-1150 accident progression analysis for Peach Bottom. Further details of the NUREG-1150 methods for the Peach Bottom containment analysis can be found in NUREG/CR-4552, Volume 4, Parts 1 and 2.

Figure 3-2 summarizes the results of that analysis. The figure shows the conditional probability of each accident progression bin group for the important plant damage states. Starting with a particular PDS the figure shows the likelihood with which the accident progresses to one of the ten APB groups listed on the left hand side of the figure: (1) an early wetwell failure with the RCS pressure at vessel breach greater than 200 psi, (2) an early wetwell failure with the RCS pressure at vessel breach less than $200 \mathrm{psi}$, (3) an early drywell failure with the RCS pressure at vessel breach greater than $200 \mathrm{psi}$, (4) an early drywell failure with the RCS pressure at vessel breach less than $200 \mathrm{psi}$, (5) a late wetwell failure with vessel breach, (6) a late dry well failure with vessel breach, (7) containment venting with vessel breach, (8) no containment failure, (9) no vessel breach, and (10) no core damage. 
The nine plant damage states shown in the figure have the following designations as described in NUREG/CR-4552:

PDS Group 1 - LOCA

PDS Group 2 - Fast Transient

PDS Group 3 - Fast Transient

PDS Group 4 - Fast SBO

PDS Group 5 - Slow SBO
This PDS represents two scenarios: (1) a large LOCA followed by immediate loss of all injection, and (2) a medium LOCA with initial HPCI success but almost immediate failure as the vessel depressurizes below HPCI working pressure, all other injection has failed. CRD and containment heat removal are available. Venting is available.

This PDS represents four different scenarios involving four different transient initiators followed by two stuck open SRVs. HPCI works initially but fails when the vessel depressurizes below HPCI working pressure. All other injection has failed and early core damage results with the vessel at low pressure. CRD and containment heat removal are working but steam is directed through SRVs to the suppression pool, not the drywell as in PDS-1. Venting is available.

This PDS is similar to PDS-2 except that containment heat removal is not working and CRD may not be working. HPSW failed due to operator failure and can be recovered during core degradation.

This PDS is a short-term station blackout with DC power failed. It consists of two scenarios: one with a stuck open SRV (8.8\%) and one without (91.2\%). Early core damage results from the immediate loss of all injection. The vessel may or may not be at low pressure depending on the SRV split. Venting is possible if AC power is restored.

This PDS is a long-term station blackout It is composed of two scenarios. High pressure injection is initially working. AC power is not recovered and either: (1) the batteries deplete, resulting in injection failure, re-closure of the ADS valves, and re-pressurization of the RPV (in those cases where an SRV is not stuck open), followed by boil-off of the primary coolant and core damage at high or low RPV pressure depending on whether an SRV is stuck open or not, or (2) HPCI and RCIC fail on high suppression pool temperature or high 
PDS Group 6 - Fast ATWS

PDS Group 7 - ATWS

PDS Group 8 - ATWS

PDS Group 9 - ATWS containment pressure, respectively, followed by boil-off and core damage at low RPV pressure (since if DC has not failed, ADS would still be possible, or an SRV is stuck open). The containment is at high pressure but less than or equal to the saturation pressure corresponding to the temperature at which HPCI will fail (i.e., about 40 psig at the start of core damage).

This PDS is an ATWS with SLC working. HPCI works and the vessel is not manually depressurized. Injection fails on high suppression pool temperature and early core damage ensues. Venting is available.

This PDS is an ATWS with failure of SLC, the initiator is a stuck open SRV. High pressure injection fails on high suppression pool temperature and the reactor is either: (1) not manually depressurized or (2) the operator depressurizes and uses low pressure injection systems until the injection valves fail due to excessive cycling or the containment fails (or is vented) and the injection systems fail due to harsh environments in the reactor building or loss of NPSH.

This PDS is an ATWS sequence with loss of an AC bus or PCS followed by a failure to scram. Otherwise it is the same as PDS 7.

This PDS is an ATWS with failure of SLC, the initiator is a loss of off-site power. However, other AC is available. Otherwise, this PDS is the same as PDS-8.

\subsection{Modifications to the Methodology for Application to Containment Degradation in Nine Mile Point/Oyster Creek}

In order to take advantage of the NUREG-1150 work for the present study, significant modifications must be made to the Peach Bottom EVNTRE model. First of all, the pressure load distributions referred to in the approach described in Section 2 are not available in the standard output of the Peach Bottom EVNTRE model for the NUREG1150 calculation. Modifications to the EVNTRE model are required to make these data available. More significantmodifications are those which are needed to model containment degradation and the differences among the Mark I plants.

Modifications in the Peach Bottom EVNTRE model calculations are necessary in the pressure capability for the purpose of assessing a hypothetically degraded Peach Bottom 
containment. To assess the degraded Oyster Creek and Nine Mile Point 1 containments, modifications must be made in both the pressure loadings and the pressure capability to account for the design differences between Peach Bottom and these Mark I plants. Figure 3-3 shows schematically how the EVNTRE model is modified.

These design differences may cause a change in accident progression and consequently in the risk profile. Important differences include plant systems, e.g., isolation condenser, plant size (The rated MWe is 1050 for Peach Bottom and 600 for Oyster Creek and Nine Mile Point) and containment venting pressure (i.e., primary containment pressure limit, PCPL).

In the analysis performed for this study it was not possible to account for the differences in plant systems and their availability, since this was beyond the scope of this project. However, differences in pressure loading and pressure capability, as well as PCPL were accounted for.

In general, the containment pressure source terms (e.g., steam and hydrogen production) can be scaled according to the rated power, and the containment pressure rise due to these source terms can be scaled according to the ratio of rated power to containment volume. Other scaling factors, such as one for hydrogen production based on the amount of zircalloy, can also be determined. Table 3-1 lists a comparison of important plant parameters between Peach Bottom and Oyster Creek. In summary, scaling factors based on plant parameters are used to make modifications to values used in the APET questions, values in the distribution data input to the APET, values in the user functions in the APET, and in input to the Latin Hypercube Sampling used as part of the modeling. Table 3-2 shows important scaling factors and other input data used to modify the EVNTRE analysis. The table lists the parameters modified, the scaling factor (where applicable), the basis for the change, and the part of the EVNTRE model which was affected by the change.

The venting pressure, i.e., the Primary Containment Pressure Limit, PCPL, for Peach Bottom used in NUREG-1150 was 100 psig. The venting pressures for Oyster Creek and Nine Mile Point 1 were obtained from the utilities. The PCPL is a function of torus pressure and primary containment water level. In Oyster Creek for instance, it can vary from 55 psig at low water level to 35 psig at high level.

A reduced pressure capability for a hypothetically degraded Peach Bottom containment was established by simply reducing the capability used in NUREG-1150 by 25 percent. In other words, all pressure distributions related to containment strength and failure mode were shifted so that failure would occur at $75 \%$ of the NUREG-1150 pressure value. There are obvious shortcomings in this assumption since the different types and amounts of degradation will affect the different failure modes differently. However, for our purposes in this study of comparison with the Nine Mile Point and Oyster Creek 
degradation assessment, this simplified reduction in the Peach Bottom pressure capability will suffice.

The estimate of the reduced pressure capability of the degraded Nine Mile Point 1 and Oyster Creek containments constituted a major part of the effort of this study and is described in detail in Section 4 and in Appendices A and B. As a simplification, the Nine Mile Point 1 and Oyster Creek containments were modeled as a single containment which combined the areas of actual corrosion observed separately in each of these plants. Postulated additional corrosion, defined in Section 4, was also modeled with the combined containment.

To summarize, modifications (described here and in Section 4) were made to the EVNTRE code so that results for the following cases could be obtained and compared for the below stated conditions $a, b$ and $c$ within each case (Section 5):

1) Peach Bottom model with a 100 psig venting pressure:

a) pressure capability equal to NUREG-1150 values. (This was a repeat of the NUREG-1150 calculation and was used to verify that the EVNTRE code was being implemented correctly for the current study.)

b) pressure capability equal to $75 \%$ of NUREG-1150 values.

c) pressure capability equal to $63 \%$ of NUREG-1150 values.

2) Nine Mile Point/Oyster Creek (NMP/OC) model with 100 psig venting pressure:

a) pressure capability equal to original design values.

b) pressure capability based on current observed conditions.

c) pressure capability with postulated $25 \%$ additional shell corrosion.

3) NMP/OC model with 43.4 psig venting pressure:

a) pressure capability equal to original design values.

b) pressure capability based on current observed conditions.

c) pressure capability with postulated $25 \%$ additional shell corrosion. 
4) NMP/OC with 35 psig venting pressure:

a) pressure capability equal to original design values.

b) pressure capability based on current observed conditions.

c) pressure capability with postulated $25 \%$ additional shell corrosion. 


\begin{tabular}{|c|c|c|}
\hline Parameter & Peach Bottom & Oyster Creek \\
\hline $\begin{array}{l}\text { Thermal Power (MWt) } \\
\text { Amount of Zircalloy }(\mathrm{Kg}) \\
\text { Volumes } \\
\text { Drywell Free Volume }\left(\mathrm{ft}^{3}\right) \\
\text { Wetwell Free Volume }\left(\mathrm{ft}^{3}\right) \\
\text { Suppression Pool Volume }\left(\mathrm{ft}^{3}\right) \\
\text { Design Pressures } \\
\text { Drywell Design Pressure (psig) } \\
\text { Wetwell Design Pressure (psig) } \\
\text { Blowdown Pressures } \\
\text { Drywell Pressure (psig) } \\
\text { Wetwell Pressure (psig) } \\
\text { Reactor Pedestal Volume }\left(\mathrm{m}^{3}\right) \\
\text { Vent Pressure (psig) }\end{array}$ & $\begin{array}{r}167726 \\
111935 \\
123000 \\
56 \\
56 \\
33 \\
20 \\
245 \\
100\end{array}$ & $\begin{array}{r}1930 \\
46639 \\
180000 \\
126000 \\
87000\end{array}$ \\
\hline
\end{tabular}




\begin{tabular}{|l|c|l|l|}
\hline \multicolumn{1}{|c|}{ Parameter } & $\begin{array}{c}\text { Scaling Factor or } \\
\text { Input Data }\end{array}$ & \multicolumn{1}{|c|}{ Basis } & Modification \\
\hline \hline $\begin{array}{l}\text { Containment Pressure from Steam } \\
\text { Blowdown }\end{array}$ & 0.75 & Blowdown Pressure & Questions 19 and 27 \\
Hydrogen Generation & 0.7 & Amount of Zircaloy \\
Pressure Rise at VB & 0.73 & $\begin{array}{l}\text { Average of Above Two } \\
\text { Values } \\
\text { Pedestal Volume and } \\
\text { Pressure Risk at VB }\end{array}$ & Questions and DIST.DAT \\
Question 94 \\
$\begin{array}{l}\text { Pedestal Pressure Load } \\
\text { Initial Conditions (Moles of Gases) }\end{array}$
\end{tabular}




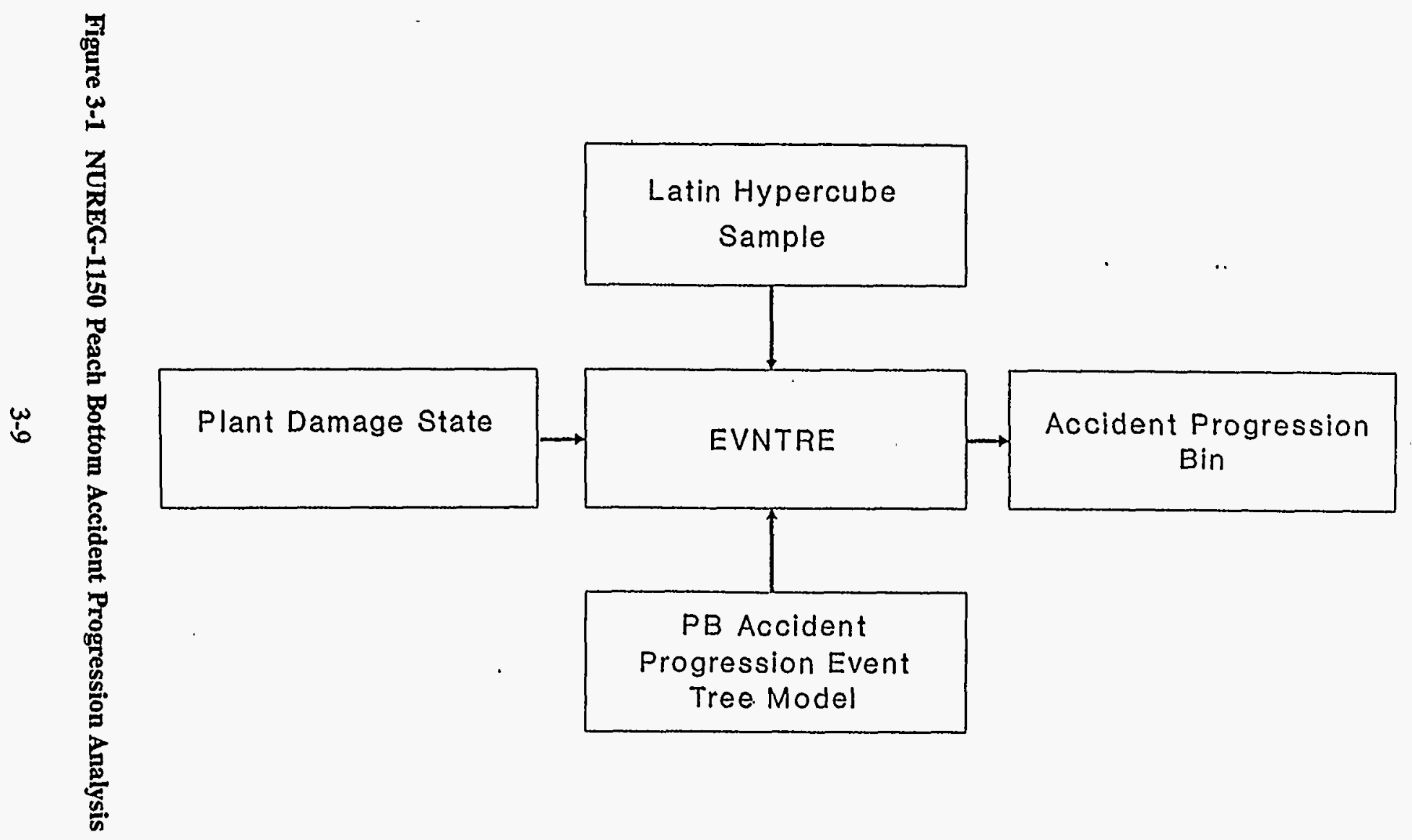

厹 


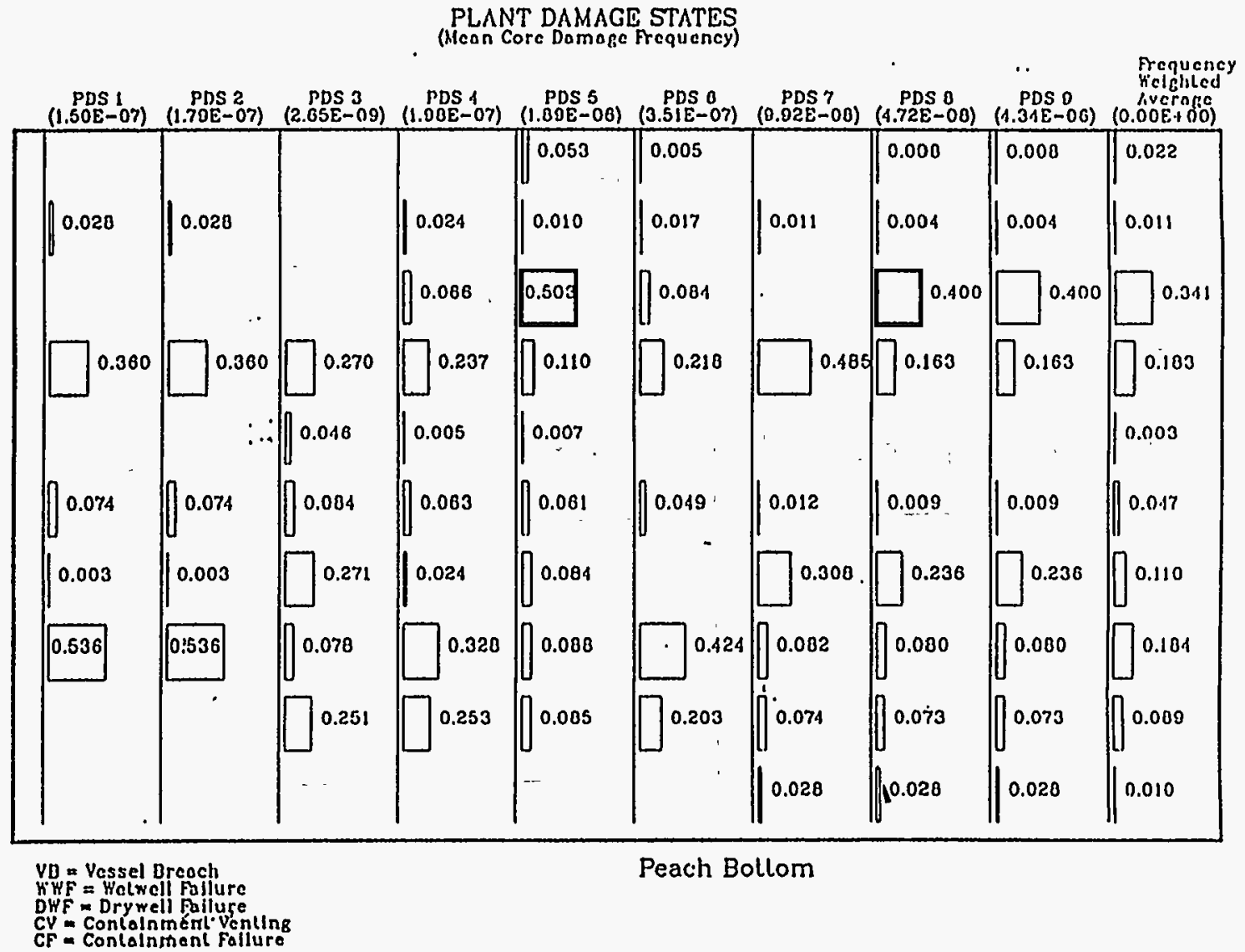




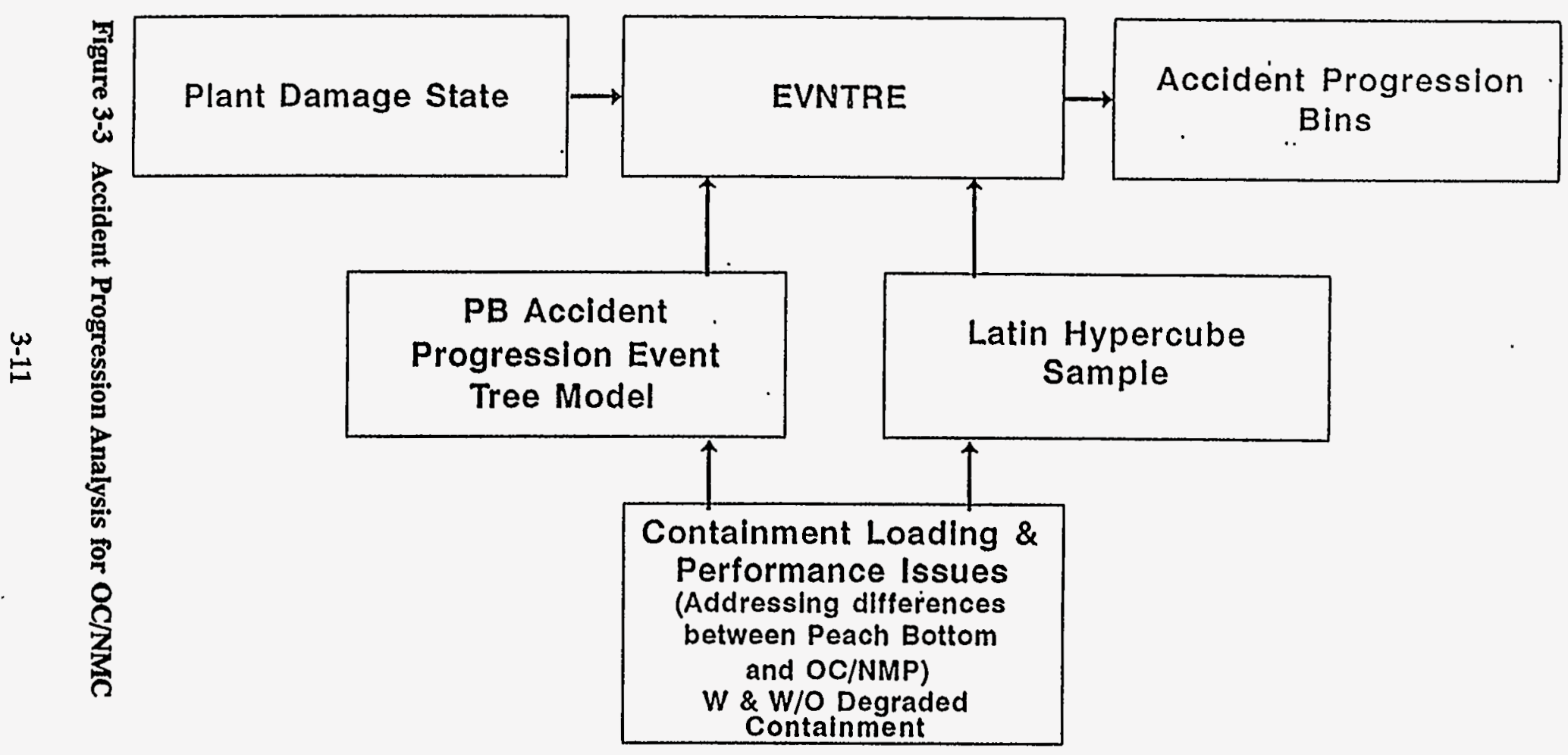

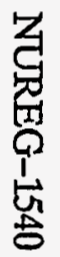




\section{STRUCTURAL EVALUATION OF EARLY MARK I CONTAINMENT DESIGNS FOR VARIOUS LEVELS OF SHELL WALL CORROSION}

\subsection{Introduction}

One of the key inputs to accident analysis is the internal pressure capacity of the containment. Because of the probabilistic nature of accident analysis, it is insufficient and highly conservative to assume loss of the containment pressure boundary when the containment design pressure is reached. In addition, different modes of containment "failure" have different consequences in the accident analysis.

The objective of this structural evaluation is to generate reasonable, physically-based probabilistic distributions of failure pressure for six (6) specified Mark I Containmentfailure modes, for three (3) specified condition states. The condition states are:

1. as-designed

2. current level of observed shell thickness corrosion

3. postulated $25 \%$ additional shell thickness corrosion

The results of the structural evaluation are input to the accident analysis. By conducting three accident analyses, one for each of the three condition states, the sensitivity of the radioactive release profile to corrosion of the steel containment can be evaluated.

It is important to note that the structural evaluation was limited in scope and the results represent the work of a single analyst. Because of the comparative nature of this study, the differences in the release profiles between the three condition states are the significant results. It was necessary to utilize simplifying approximations in order to generate the large amount of data needed for the accident analyses. An important objective was to maintain consistency in the methodology applied to each of the three condition states, so that the sensitivity of the release profile to the three condition states could be accurately predicted.

\subsection{Definition of Containment Condition States}

The three condition states analyzed have been designated the As-Designed Condition, the Current Condition and the Postulated Corroded Condition. A description of each condition is provided below. Figures 4-1 through 4-4 show the geometry of the Mark I containment. Tables 4-1 and 4-2 list the shell thickoesses and material properties for each condition state. Table 4-3 lists the bolt and O-ring seal data used for all three condition states. 
This model was selected for analysis in order to provide a "baseline" for comparison to the other conditions. The containment model assumes nominal design shell thicknesses for the drywell and wetwell and material yield strength per ASME Code Section III. In the development of probability distributions for the as-designed condition, the code-specified yield strength was considered to be a lower bound since it is the minimum for the material grade. The median was assumed to be $120 \%$ of the code value; the upper bound was assumed to be $140 \%$ of the code value. This is a reasonable distribution, based on historic test results for actual vs. code specified yield strength.

\section{Current Condition}

This model was developed to represent the current corroded condition of several existing Mark I containments, utilizing the worst condition currently observed in the various regions of the drywell and wetwell. Although measured corrosion is not uniform within a region, the minimum measured shell thickness within each region was assumed to be the uniform thickness of the region. This is a conservative simplification which facilitated analysis using axisymmetric computer models and closed form solutions.

The actual mean yield strength, available from vendor reports and licensee submittals, was assumed to be the median yield strength. Based on statistical analysis performed by the licensees, the lower bound was assumed to be $90 \%$ of the mean and the upper bound was assumed to be $110 \%$ of the mean. As shown in Table 4-2, this results in higher values of yield strength than for the "as-designed" condition. Based on the information available, a symmetric distribution of yield strength was assumed (i.e., mean = median).

\section{Postulated Corroded Condition}

This condition was defined to assess the effect of additional significant corrosion, beyond the current condition. For each region of the containment, the shell thickness was assumed to be $75 \%$ of the current condition thickness. The failure pressure vs. probability distributions for this condition were obtained by multiplying the current condition pressure distribution by 0.75 . The underlying assumption is that failure pressure is a linear function of shell thickness. This is valid for shell membrane failure modes, but will tend to overpredict the failure pressure for modes influenced by local shell bending behavior. However, the procedure used is considered sufficient to test the sensitivity of the release profile to significant additional containment corrosion. 


\subsection{Evaluation Basis}

\subsubsection{Failure Modes}

To parallel the NUREG-1150 study for Peach Bottom, it was necessary to generate probabilistic distributions of failure pressure which are comparable to the data presented in Draft B of NUREG/CR-4551 (Vol. 2, Part 3, Structural Response, 15-JUN-90) for the Peach Bottom Containment. Ten (10) structural failure modes were initially specified for the Peach Bottom containment study. Based on the results of that study the current accident analysis utilizes only six (6) of the structural failure modes. The failure modes considered are:

- Drywell Head Rupture (DWHR)

- Drywell Head Flange Leak (DWHL)

- Drywell Rupture (DWR)

- Drywell Leak (DWL)

- Wetwell Rupture below Waterline (WWRbW)

- Wetwell Leak above Waterline (WWLaW)

The differentiation between rupture and leak is based on the size, location, and estimated progression of a postulated breech in the containment boundary.

A leak is assumed to arrest any additional pressure buildup, and to have a total area of 10 to $260 \mathrm{in}^{2}$. Typical leak locations are the bolted head flange and areas of localized high strain. A rupture is assumed to result in rapid depressurization of containment and to have a total area greater than $260 \mathrm{in}^{2}$. Gross membrane failure of the shell is considered a rupture.

\subsubsection{Temperature States}

The accident analysis considers both low temperature äccident scenarios ( $\left.300^{\circ} \mathrm{F}\right)$ and high temperature accident scenarios $\left(800^{\circ} \mathrm{F}\right)$. Therefore, probabilistic distributions of failure pressure had to be generated for two (2) different temperature states. The low temperature state was defined as uniform $300^{\circ} \mathrm{F}$ in both the drywell and wetwell. The high temperature state was defined as uniform $800^{\circ} \mathrm{F}$ in the drywell and uniform $300^{\circ} \mathrm{F}$ in the wetwell. Due to condensation in the suppression pool, the wetwell temperature was estimated to remain at $300^{\circ} \mathrm{F}$ for the case where the drywell achieves a temperature of $800^{\circ} \mathrm{F}$.

The actual material property data for the current and postulated corroded conditions are at room temperature $\left(\approx 70^{\circ} \mathrm{F}\right)$. Therefore, this data had to be scaled for $300^{\circ} \mathrm{F}$ and $800^{\circ} \mathrm{F}$ temperature states. Scaling was performed based on the tabulated values of yield stress as a function of temperature from ASME Section III, for the containment materials. 


\subsubsection{Containment Loading}

The evaluation assumes a uniform quasi-static buildup of internal pressure inside containment. No dynamic effects or pressure gradient effects are considered. This is consistent with the approach used in the Peach Bottom study.

\subsection{Containment Structural Analysis}

Appendix A describes the methodology employed to select the specific failure locations and to develop the range of failure pressure for the thirty six (36) different combinations of containment condition state, failure mode and temperature state. The general approach used was to estimate a lower bound failure pressure, a median failure pressure and an upper bound failure pressure, considering the uncertainties associated with material strength properties and limitations of the analytical methods to predict actual failure mechanisms.

Tables 4-4, 4-5, and 4-6 list the failure pressure predictions for the three containment condition states.

\subsection{Development of Probability Distributions}

To cast the failure pressure predictions in the form of probabilistic distributions, the lower bound prediction was assumed to be the $5 \%$ probability failure pressure, the median prediction was assumed to be the $50 \%$ probability failure pressure, and the upper bound prediction was assumed to be the $95 \%$ probability failure pressure. Continuous distributions of cumulative probability of failure vs. pressure were then developed for each of the thirty six (36) combinations described above. The details of this procedure and the additional steps to generate the necessary input data for the accident analysis are described in Appendix B.

The results for cumulative probability of failure vs. prēssure are illustrated in Figures 4-5 through 4-10.

The generated probability distributions are smooth functions. However, because the number of pressure input values was specified to be the same as used in the Peach Bottom study, several of the distributions in the figures appear to have discontinuous slopes. This is strictly due to the limited number of pressure input values.

It is also pointed out that in the Peach Bottom study probabilistic distributions were developed from the independent input of three (3) structural experts, and then the three distributions were averaged (i.e., $(A+B+C) / 3$ ). The approach does not represent a rigorous probability analysis. The current approach is based on reasonable approximations which facilitated generation of the large data base of probabilistic input needed for the accident analysis. It also is not intended to represent a rigorous probability analysis. 
Table 4-1 Containment Shell Thicknesses for Three Condition States

\begin{tabular}{||l||c|c|c||}
\hline \multicolumn{1}{|c||}{$\begin{array}{c}\text { CONTAINMENT } \\
\text { REGION }\end{array}$} & $\begin{array}{c}\text { AS-DESIGNED } \\
\text { (NOMINAL } \\
\text { SPECIFIED) }\end{array}$ & $\begin{array}{c}\text { CURRENT } \\
\text { (LOWEST } \\
\text { MEASURED) }\end{array}$ & $\begin{array}{c}\text { POSTULATED } \\
\text { CORRODED } \\
\text { (75\% OF } \\
\text { CURRENT) }\end{array}$ \\
\hline \hline $\begin{array}{l}\text { DRYWELL - } \\
\text { ELLIPTICAL HEAD }\end{array}$ & 1.1875 & 1.1875 & 0.891 \\
\hline DRYWELL - CYLINDER & 0.640 & 0.619 & 0.464 \\
\hline $\begin{array}{l}\text { DRYWELL - } \\
\text { TRANSITION KNUCKLE }\end{array}$ & 2.5625 & 2.5625 & 1.922 \\
\hline $\begin{array}{l}\text { DRYWELL - } \\
\text { UPPER SPHERE }\end{array}$ & 0.722 & 0.677 & 0.508 \\
\hline $\begin{array}{l}\text { DRYWELL - } \\
\text { MID SPHERE }\end{array}$ & 0.770 & 0.723 & 0.542 \\
\hline $\begin{array}{l}\text { DRYWELL - } \\
\text { LOWER SPHERE }\end{array}$ & 1.154 & 1.154 & 0.866 \\
\hline $\begin{array}{l}\text { DRYWELL - } \\
\text { SANDBED AREA }\end{array}$ & 1.154 & 0.736 & 0.552 \\
\hline \begin{tabular}{l} 
WETWELL - TORUS \\
\hline
\end{tabular} & 0.460 & 0.440 & 0.330 \\
\hline
\end{tabular}


Table 4-2 Range Shell Material Properties for Three Condition States.

\begin{tabular}{|c|c|c|c|c|c|c|}
\hline & \multicolumn{3}{|c|}{ YIELD STRESS (ksi) } & \multicolumn{3}{|c|}{$\begin{array}{l}\text { ULTIMATE TENSILE STRESS } \\
\text { (ksi) }\end{array}$} \\
\hline & $\begin{array}{l}\text { Lower } \\
\text { Bound }\end{array}$ & Median & $\begin{array}{l}\text { Upper } \\
\text { Bound }\end{array}$ & $\begin{array}{l}\text { Lower } \\
\text { Bound }\end{array}$ & Median & $\begin{array}{l}\text { Upper } \\
\text { Bound }\end{array}$ \\
\hline \multicolumn{7}{|l|}{ Drwell'@300\% } \\
\hline - As-Designed Condition & 33.7 & 40.4 & 47.2 & 70 & 77 & 85 \\
\hline $\begin{array}{l}\text { - Current and Postulated } \\
\text { Corroded Conditions }\end{array}$ & 40.5 & 45.0 & 49.5 & 70 & 77 & 85 \\
\hline \multicolumn{7}{|l|}{ Drymell ${ }^{1} @ 800^{\circ} \mathrm{F}$} \\
\hline - As-Designed Condition & 25.3 & 30.4 & 35.4 & 64.3 & 70.7 & 78 \\
\hline $\begin{array}{l}\text { - Current and Postulated } \\
\text { Corroded Conditions }\end{array}$ & 30.4 & 33.8 & 37.2 & 64.3 & 70.7 & 78 \\
\hline \multicolumn{7}{|l|}{ Wetrell (Torus) ${ }^{2} @ 300^{\circ} \mathrm{F}$} \\
\hline - As-Designed Condition & 28.3 & 34.0 & 39.6 & 60 & 66 & 72 \\
\hline $\begin{array}{l}\text { - Current and Postulated } \\
\text { Corroded Conditions }{ }^{3}\end{array}$ & 35.1 & 39.0 . & 42.9 & $60^{-}$ & 66 & 72 \\
\hline
\end{tabular}

Notes:

1) Original ASTM Designation: Current ASME Designation:

A212 Grade B, FBX to A300 SAS16 Grade 70

2) Original ASTM Designation: Current ASME Designation:

A201 Grade B, FBX to A300 SAS16 Grade 60

3) Actual Yield Stress, measured at Room Temperature, is multiplied by 0.89 to define Yield Stress at $300 \%$, and by 0.67 to define Yield Stress at $800^{\circ} \mathrm{F}$. Reduction factors are based on ASME Section III tabulated Yield Stress for $70^{\circ} \mathrm{F}, 300^{\circ} \mathrm{F}$, and $800^{\circ} \mathrm{F}$.

4) The ranges of Ultimate Tensile Stress are taken from the original ASTM Specifications and are assumed to be the same for all three condition states:

A212 Grade B $\quad 70-85 \mathrm{ksi}$

A201 Grade B $\quad 60-72$ ksi

Per ASME Section III Tables, Utimate Tensile Stress is constant up to $700^{\circ} \mathrm{F}$. For $800 \mathrm{~F}$ in the Drywell, Ultimate Tensile Stress is reduced by $8 \%$. 
Table 4.3 Bolt and O-Ring Seal Data for Head Flange Analysis

Bolt Material: $\quad$ ASME SA-320 Grade L43

\begin{tabular}{l|c|c|c} 
& $100^{\circ} \mathrm{F}$ & $300^{\circ} \mathrm{F}$ & $800^{\circ} \mathrm{F}$ \\
\hline Yield Stress (ksi) & 105 & 95.7 & 72.6 \\
Ultimate Tensile Stress (ksi) & 125 & - & - \\
Elastic Modulus (10 $\left.10^{6} \mathrm{psi}\right)$ & 27.8 & 26.7 & 23.0
\end{tabular}

Bolt Preload: $\quad 92,000 \mathrm{lb} / \mathrm{bolt}$, applied at room temperature, using load cell for tight control of preload.

Number of Bolts: $\quad 96$

Initial O-Ring Seal Compression: $\quad 0.1875^{n}$

Seal Rebound Characteristics asstimed for analysis:

\begin{tabular}{l||c|c|c}
\multicolumn{1}{c||}{$\begin{array}{c}\text { DRYWELL } \\
\text { TEMPERATURE }\end{array}$} & \multicolumn{3}{c}{$\begin{array}{c}\text { HOURS OF NORMAL OPERATION (200\%) } \\
\text { AFTER SEAL INSTALLATION, PRECEDING } \\
\text { ACCIDENT }\end{array}$} \\
\hline \hline & $3,000 \mathrm{hrs}$ & $6,000 \mathrm{hrs}$ & $9,000 \mathrm{hrs}$ \\
& $60-80 \%$ & $50-70 \%$ & $40-60 \%$ \\
$300^{\circ} \mathrm{F}$ (initial) & $40-70 \%$ & $30-60 \%$ & $20-50 \%$ \\
$300^{\circ} \mathrm{F}$ (70 hrs) & $0 \%$ & $0 \%$ & $0 \%$
\end{tabular}


Table 4-4 Failure Pressures (PSI) for As-Designed Condition

\begin{tabular}{||c||c|c|c||c|c|c|}
\hline $\begin{array}{c}\text { FAILURE } \\
\text { MODE }\end{array}$ & \multicolumn{3}{c|}{$\begin{array}{c}\text { LOW TEMP } \\
\text { (300\% ALL) }\end{array}$} & \multicolumn{3}{c|}{$\begin{array}{c}\text { HIGH TEMP } \\
\left(800^{\circ} \text { F DW/300' WW }\right)\end{array}$} \\
\hline & $\begin{array}{c}\text { LOWER } \\
\text { BOUND }\end{array}$ & MEDIAN & $\begin{array}{c}\text { UPPER } \\
\text { BOUND }\end{array}$ & $\begin{array}{c}\text { LOWER } \\
\text { BOUND }\end{array}$ & MEDIAN & $\begin{array}{c}\text { UPPER } \\
\text { BOUND }\end{array}$ \\
\hline DWHR & 202 & 254 & 310 & 152 & 191 & 233 \\
\hline DWHL & 120 & 170 & 220 & 60 & 70 & 80 \\
\hline DWR & 219 & 271 & 323 & 167 & 203 & 239 \\
\hline DWL & 100 & 126 & 154 & 75 & 95 & 116 \\
\hline WWRbW & 100 & 118 & 136 & 100 & 118 & 136 \\
\hline WWLaW & 93 & 109 & 125 & 93 & 109 & 125 \\
\hline
\end{tabular}


Table 4-5 Failure Pressures (PSI) for Current Condition

\begin{tabular}{||c||c|c|c||c|c|c||}
\hline \multirow{2}{*}{$\begin{array}{c}\text { FAILURE } \\
\text { MODE }\end{array}$} & \multicolumn{3}{|c||}{$\begin{array}{c}\text { LOW TEMP } \\
\left(300^{\circ} \mathrm{F} \text { ALL }\right)\end{array}$} & \multicolumn{3}{c||}{$\begin{array}{c}\text { HIGH TEMP } \\
\left(800^{\circ} \mathrm{F} \text { DW/300 } \mathrm{F} \text { WW }\right)\end{array}$} \\
\cline { 2 - 7 } & $\begin{array}{c}\text { LOWER } \\
\text { BOUND }\end{array}$ & MEDIAN & $\begin{array}{c}\text { UPPER } \\
\text { BOUND }\end{array}$ & $\begin{array}{c}\text { LOWER } \\
\text { BOUND }\end{array}$ & MEDIAN & $\begin{array}{c}\text { UPPER } \\
\text { BOUND }\end{array}$ \\
\hline DWHR & 223 & 284 & 327 & 163 & 213 & 245 \\
\hline DWHL & 120 & 170 & 220 & 60 & 70 & 80 \\
\hline DWR & 142 & 166 & 190 & 107 & 125 & 163 \\
\hline DWL & 120 & 140 & 162 & 90 & 105 & 122 \\
\hline WWRbW & 116 & 128 & 140 & 116 & 128 & 140 \\
\hline WWLaW & 106 & 118 & 130 & 106 & 118 & 130 \\
\hline
\end{tabular}


Table 4-6 Failure Pressures (PSD for Postulated Corroded Condition

\begin{tabular}{|c|c|c|c|c|c|c|}
\hline \multirow[t]{2}{*}{$\begin{array}{l}\text { FAILURE } \\
\text { MODE }\end{array}$} & \multicolumn{3}{|c|}{$\begin{array}{l}\text { LOW TEMP } \\
\left(300^{\circ} \mathrm{F} \text { ALL }\right)\end{array}$} & \multicolumn{3}{|c|}{$\begin{array}{c}\text { HIGH TEMP } \\
\left(800^{\circ} \mathrm{F} \mathrm{DW} / 300^{\circ} \mathrm{F} \text { WW }\right)\end{array}$} \\
\hline & $\begin{array}{l}\text { LOWER } \\
\text { BOUND }\end{array}$ & MEDIAN & $\begin{array}{l}\text { UPPER } \\
\text { BOUND }\end{array}$ & $\begin{array}{l}\text { LOWER } \\
\text { BOUND }\end{array}$ & MEDIAN & $\begin{array}{l}\text { UPPER } \\
\text { BOUND }\end{array}$ \\
\hline DWHR & 172 & 213 & 245 & 117 & 160 & 184 \\
\hline DWHL & 120 & 170 & 220 & 60 & 70 & 80 \\
\hline DWR & 107 & 125 & 143 & 80 & 94 & 117 \\
\hline DWL & 90 & 105 & 122 & 68 & 79 & 92 \\
\hline WWRbW & 87 & 96 & 105 & 87 & 96 & 105 \\
\hline WWLaW & 80 & 89 & 98 & 80 & 89 & 98 \\
\hline
\end{tabular}




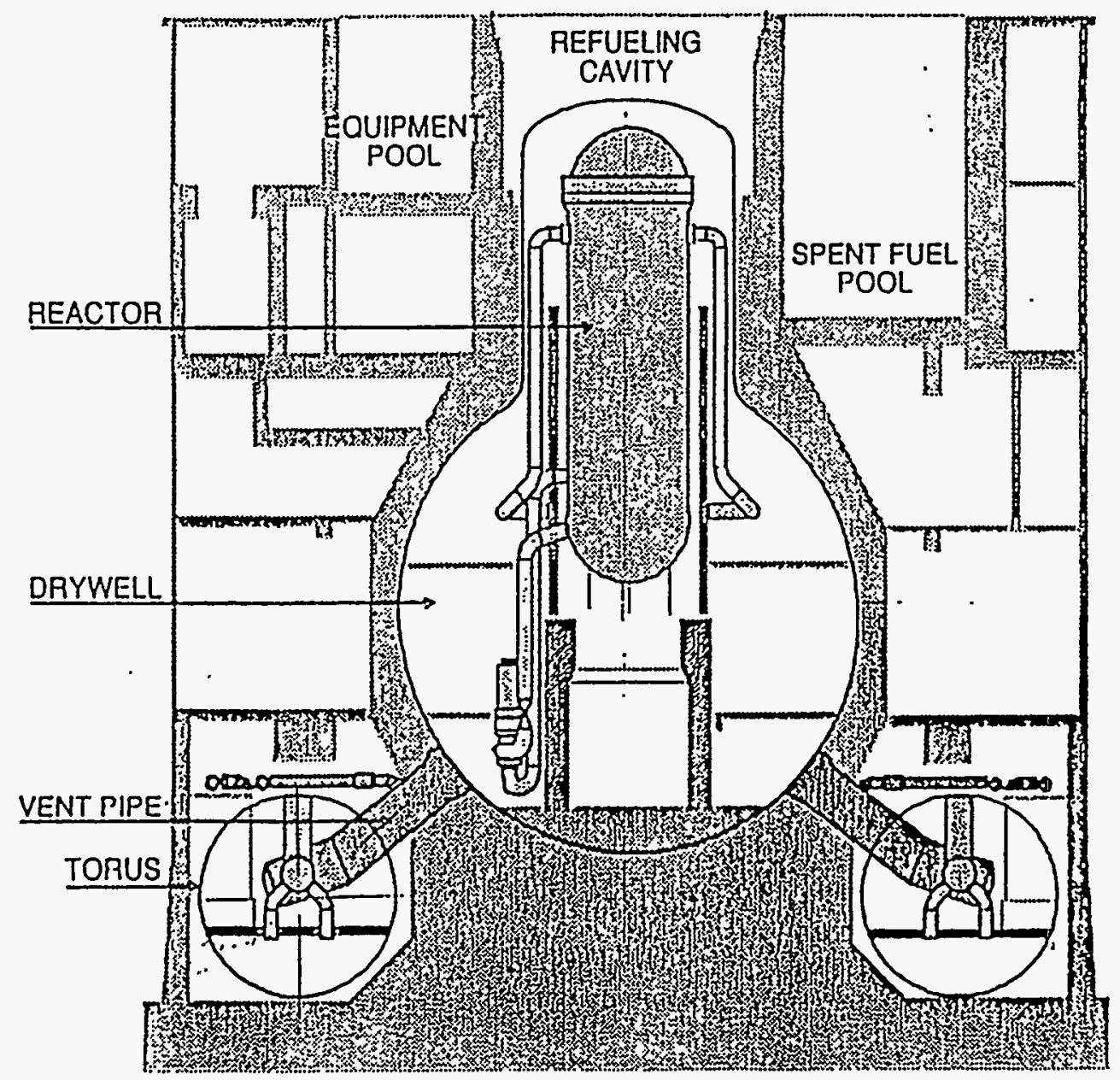

Figure 41 Mark I Containment

4-11 


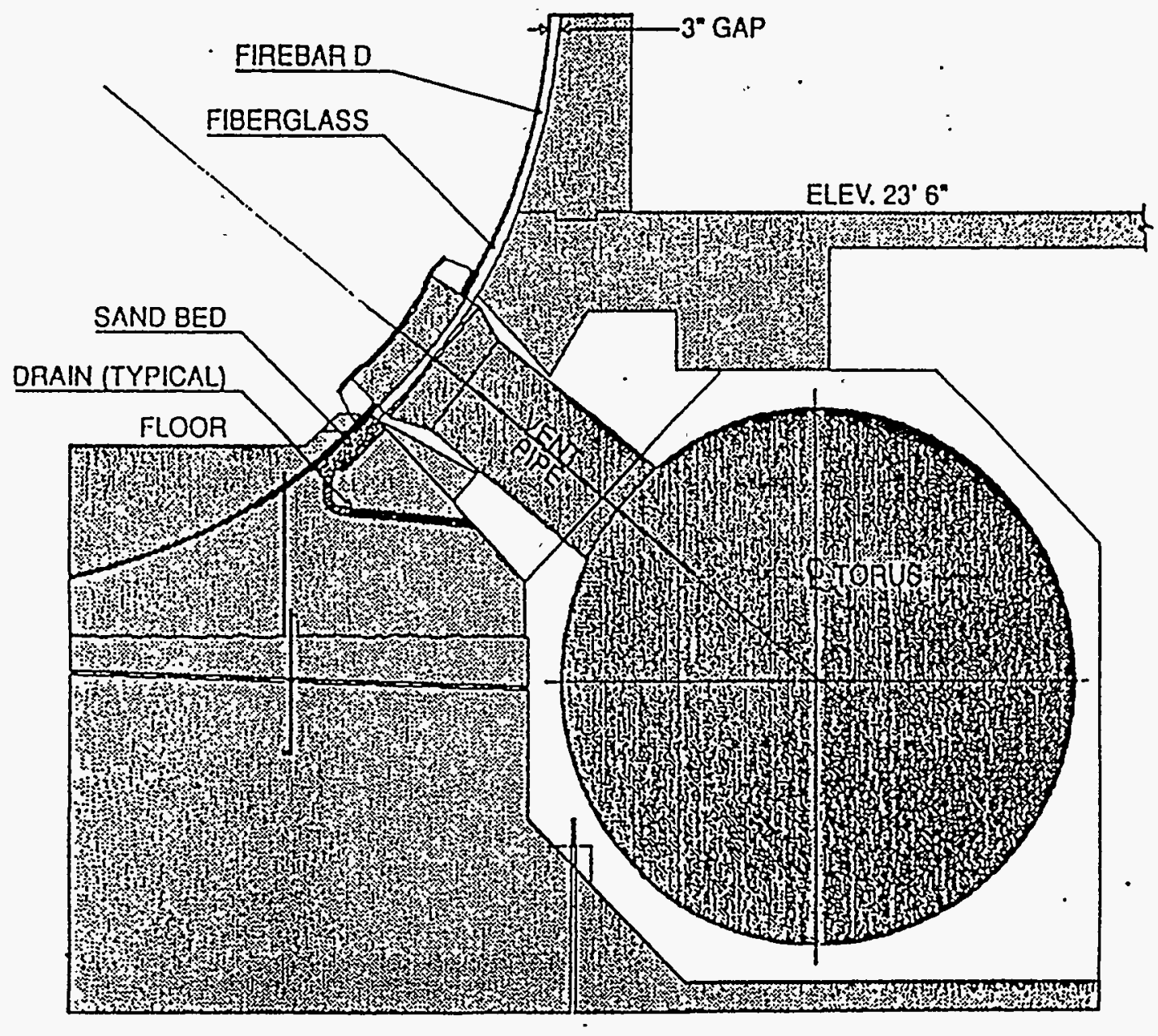

Figure 4-2 Mark I Containment

4-12 


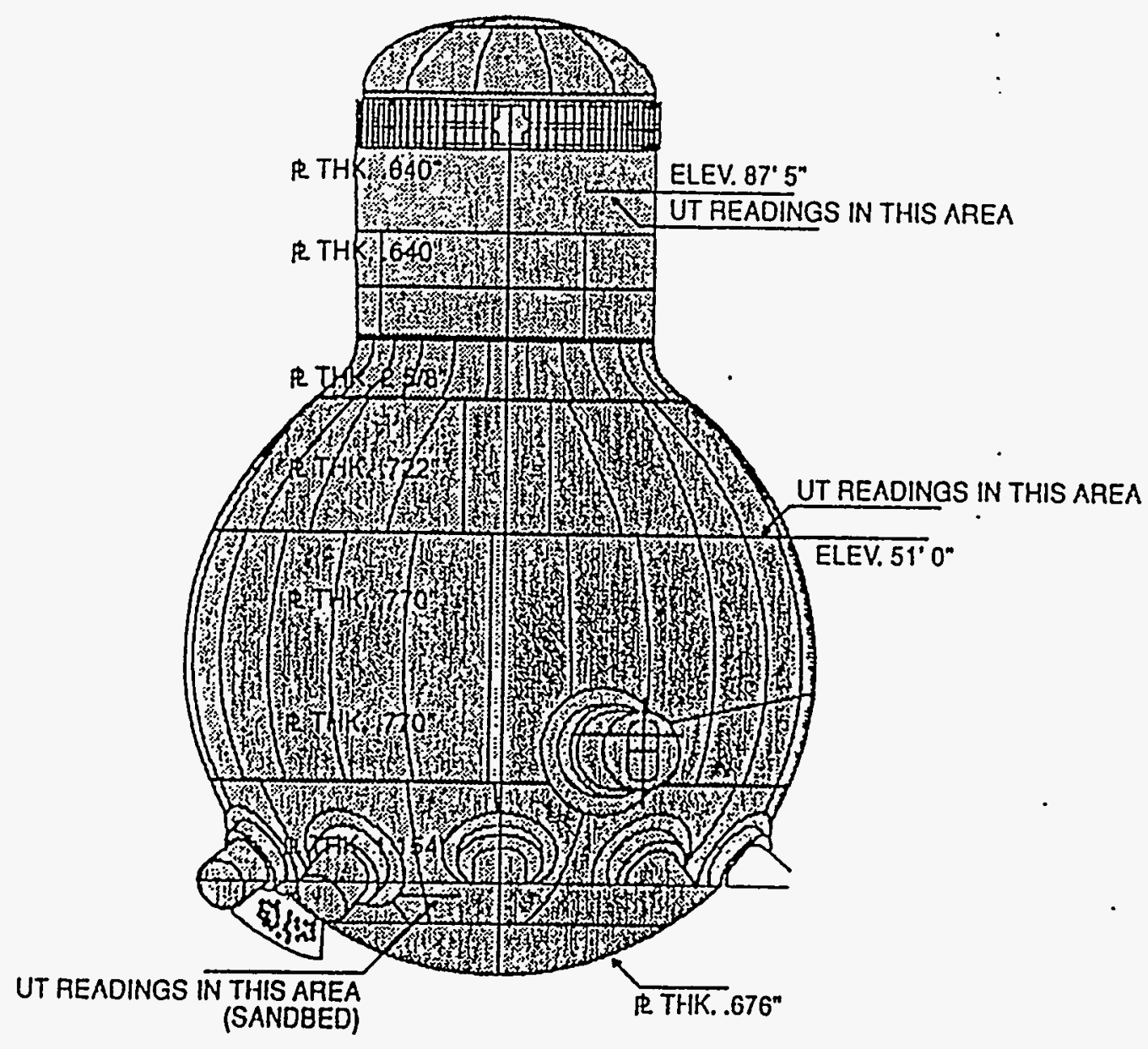

Figure 4-3 Drywell

4-13 
$D I-b$

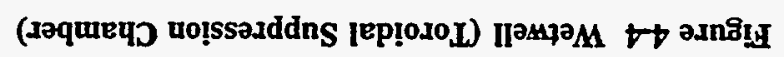

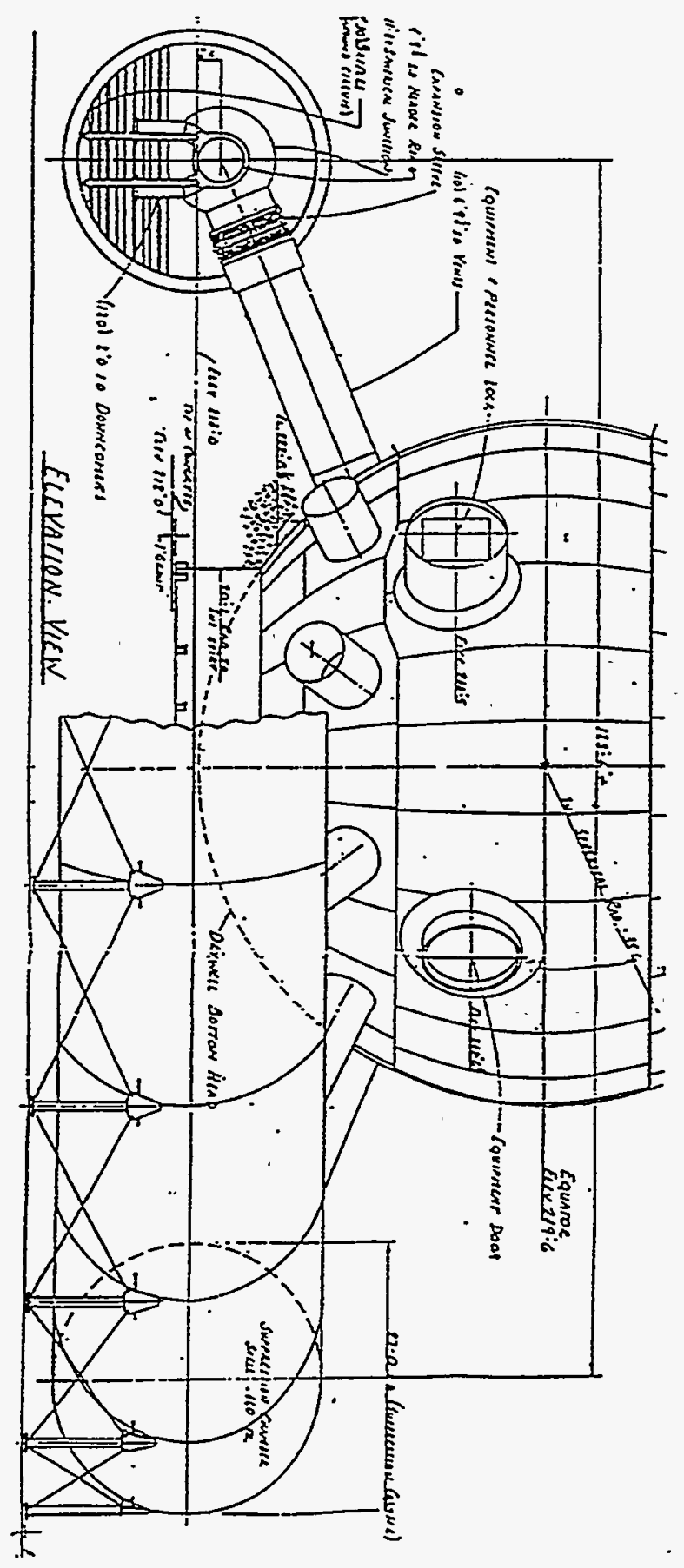


SI-t

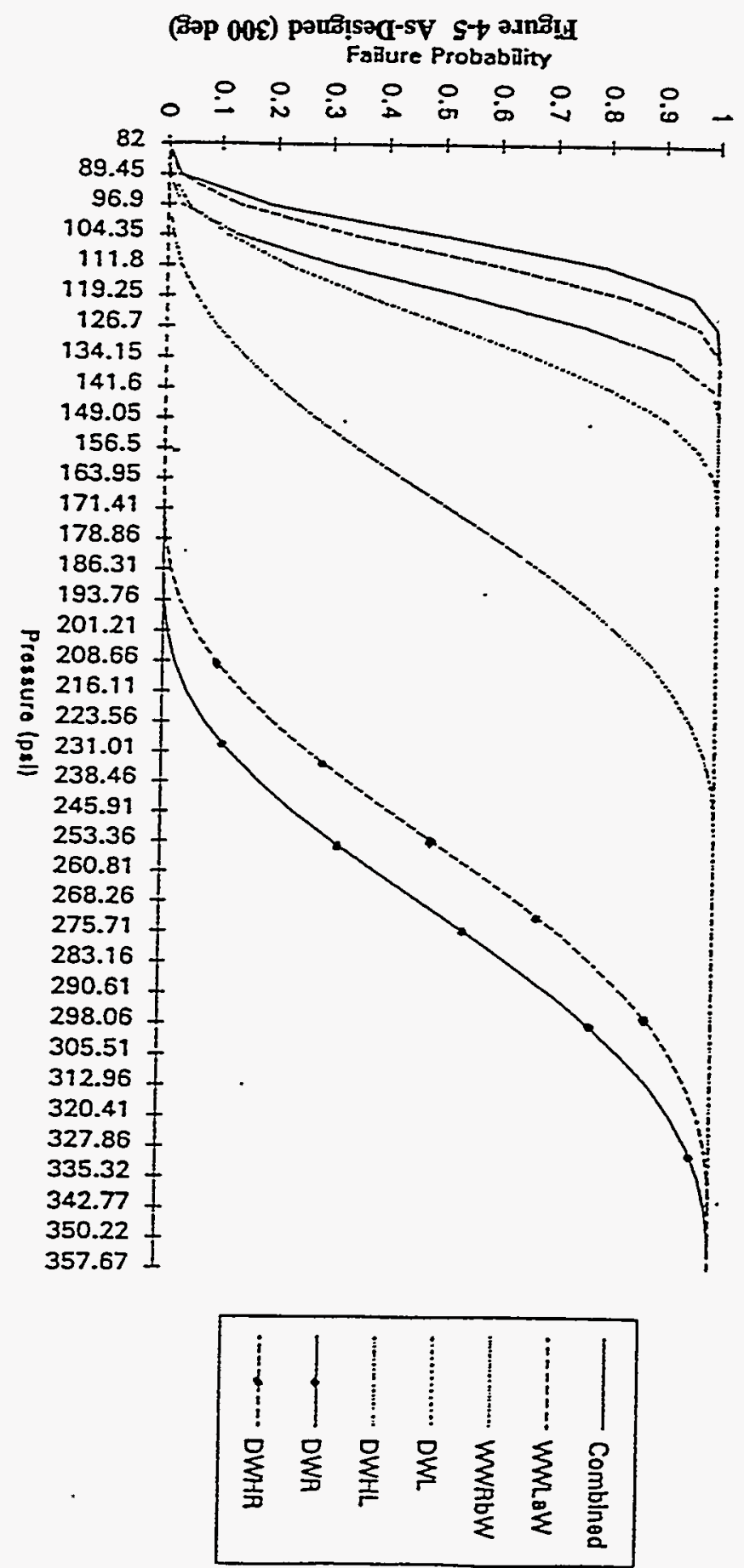



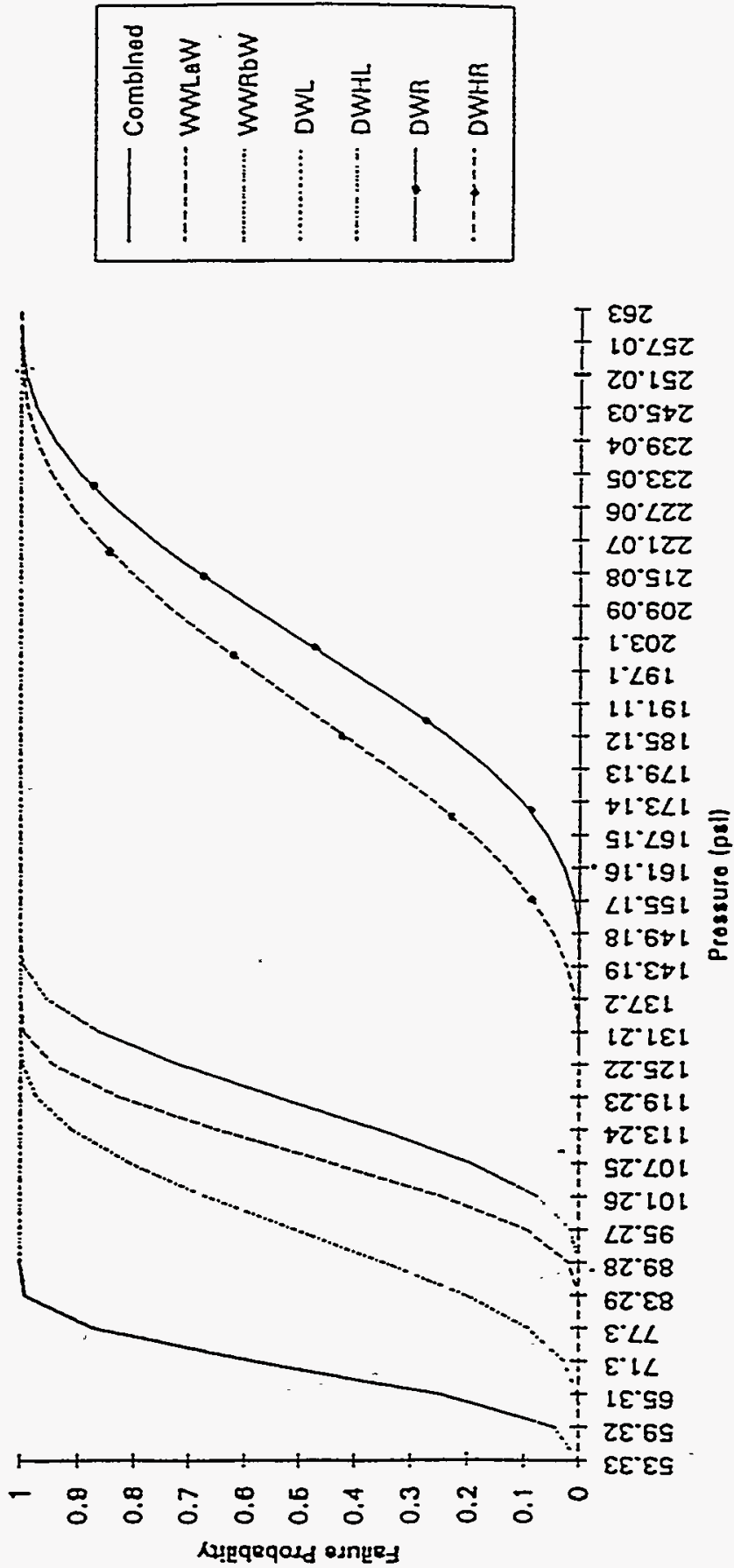

Figure 4-6 As-Designed (800 deg) 

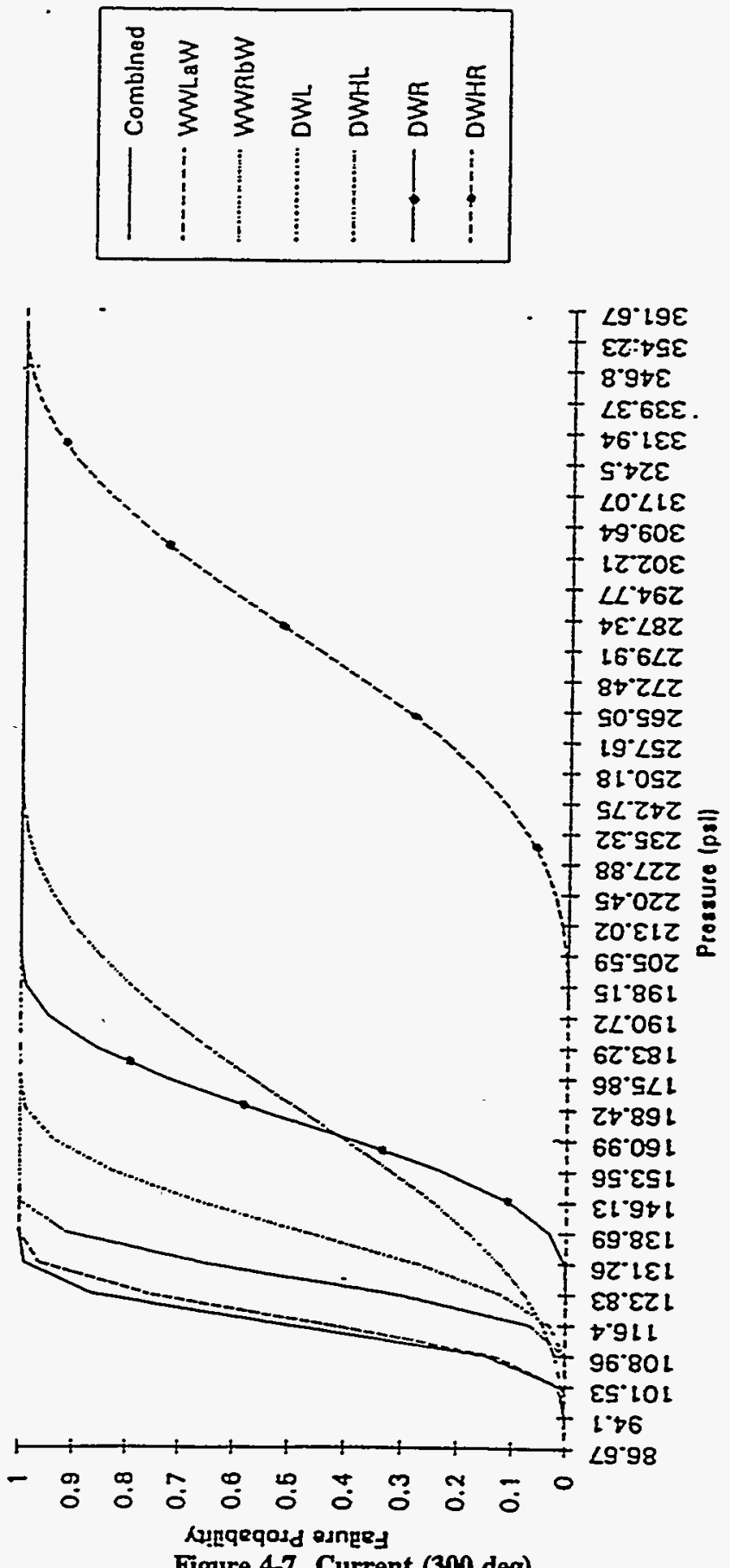

Figure 4-7 Current (300 deg)

4-17 
$8 I-7$

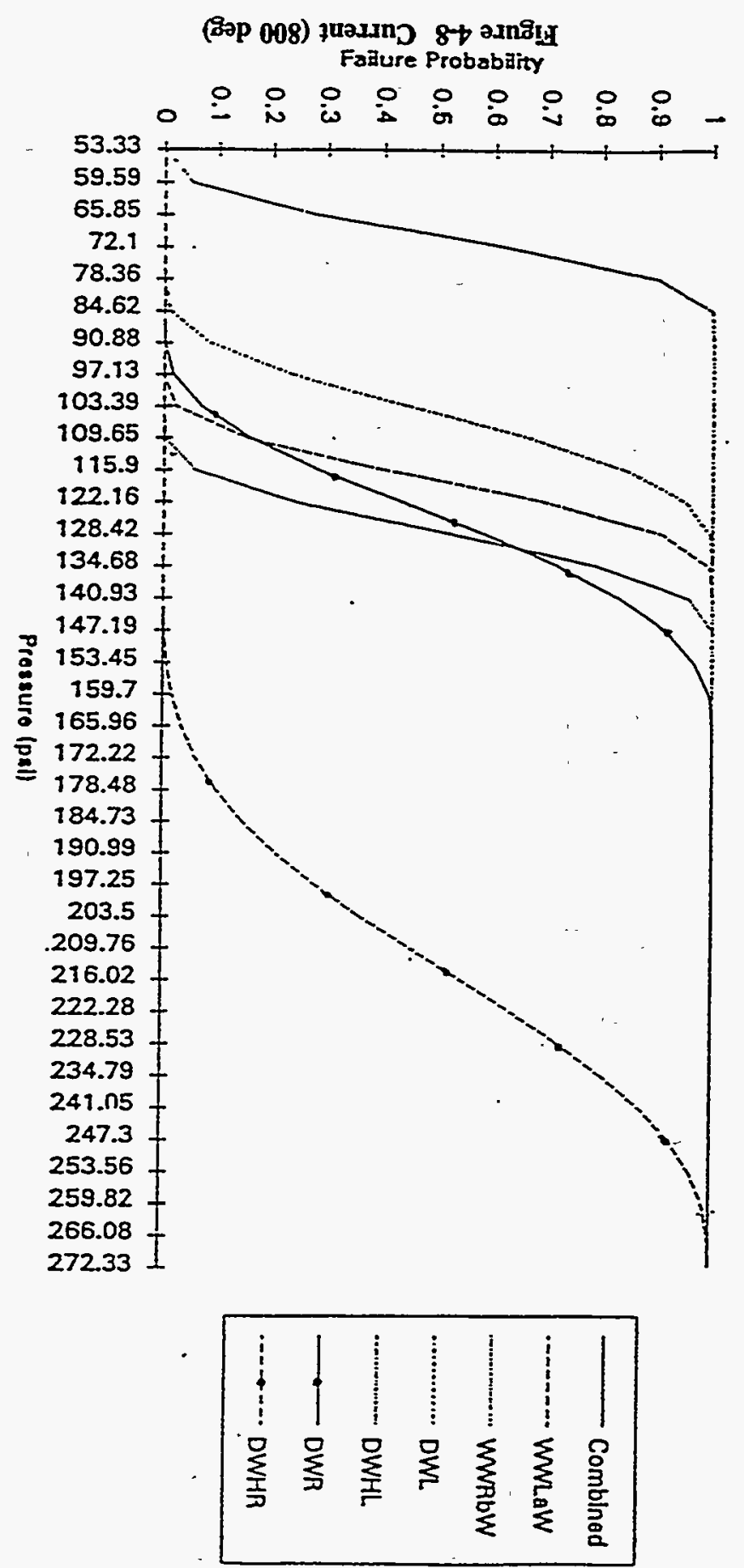



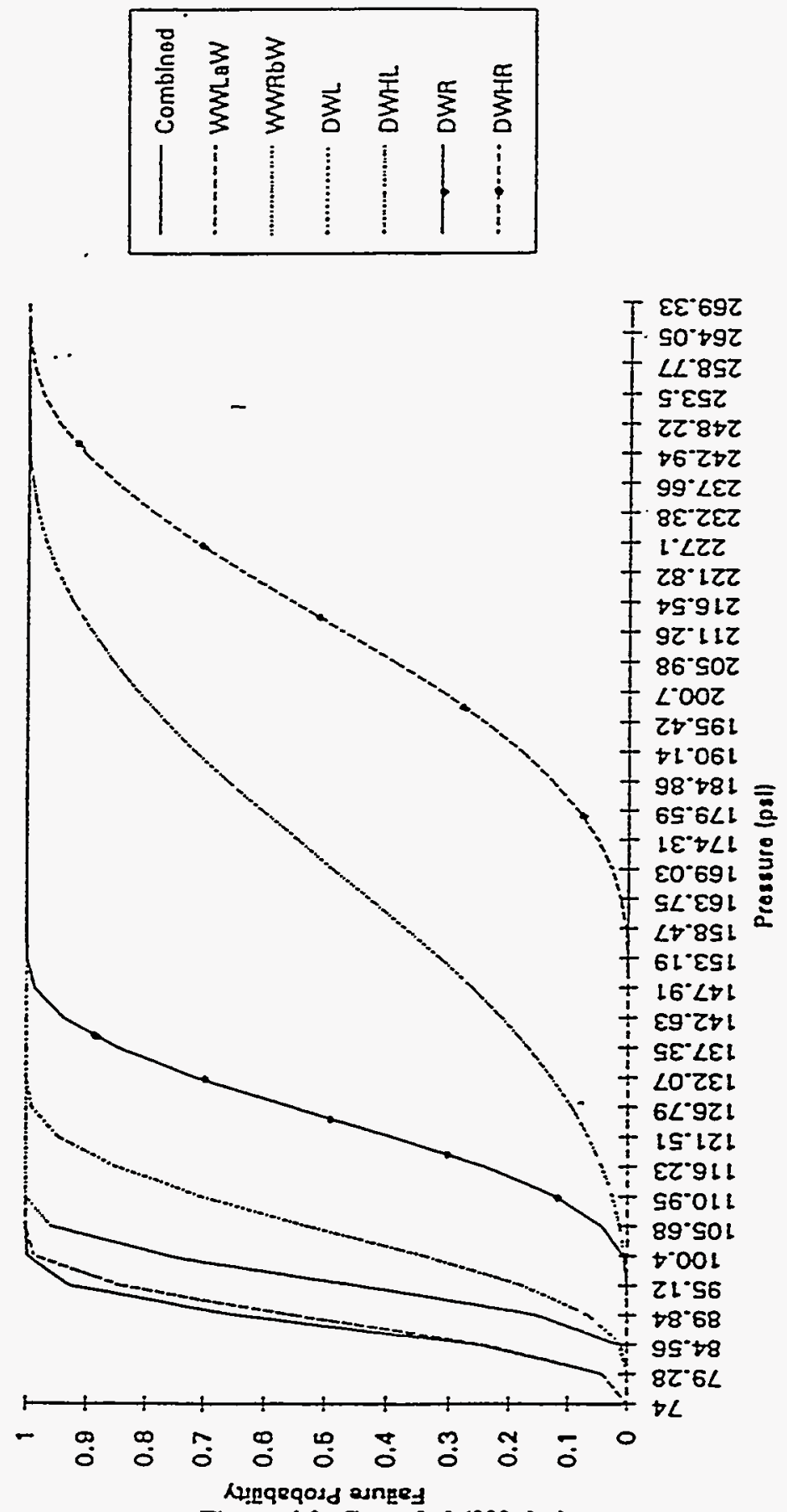

Figure 4-9 Corroded (300 deg) 

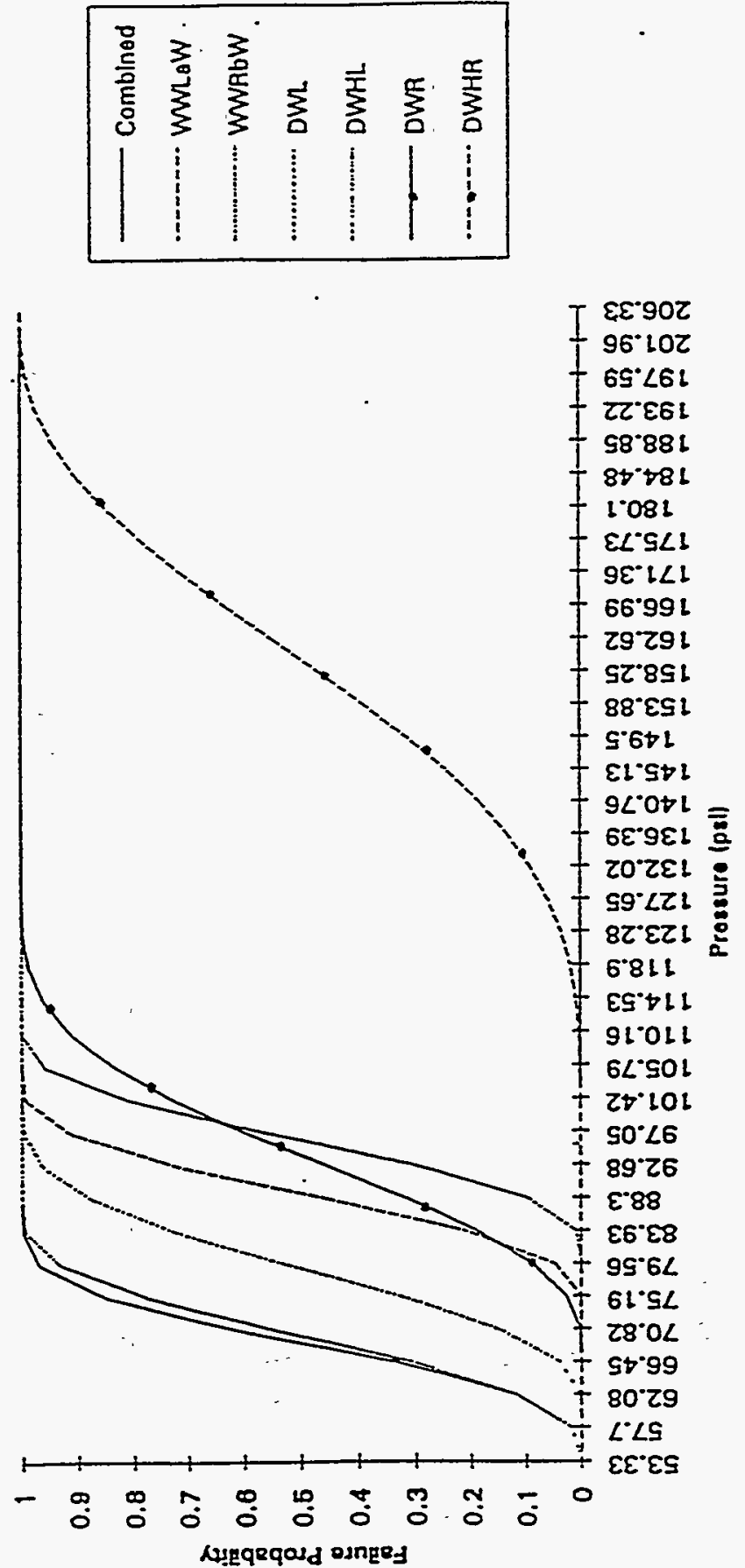

Figure 4-10 Corroded (800 deg) 


\section{5. . RESULTS}

\subsection{The Effect of a Reduction in Containment Pressure Capability on the Peach Bottom Release Profile}

The modified EVNTRE code can now be used to calculate the cases outlined in Subsection 3.2. A containment release profile similar to that shown in Figure 3-2 is obtained for each of the three conditions, a,b and c, under each case and these profiles are compared to determine how containment degradation affects the allocation of each significant plant damage state into the accident progression bins. This will show, for instance, whether degradation has caused a shift from late failures to early failures, an increase in failures, or other changes such as in the failure location (wetwell or drywell), etc.

As indicated in Subsection 3.2, the first case analyzed was that of a Peach Bottom containment with an hypothetical reduction in pressure capability. Three conditions were compared: (a) pressure capability equal to that used in NUREG-1150 (this condition also was used to confirm that the EVNTRE code was being correctly implemented for the present study since the results obtained were identical to those presented in NUREG-1150), (b) pressure capability equal to $75 \%$ of (a), and pressure capability equal to $63 \%$ of (a).

The complete results for this case are listed in Table 5-1 where the allocation of each of the nine PDSs into the ten APBs is given for each of conditions $a, b$, and $c$. Figures C-1 through C-18 of Appendix C show these results graphically for each of the nine plant damage states, for conditions $a$ and $b$. Comparing the changes in the conditional probability of APBs for selected PDSs across conditions $a, b$, and $c$ is illustrative of the effect of containment degradation for this case.

Figure 5-1 shows the comparison for PDS Group 1, LOCA. As the figure indicates, both early drywell failures (APB 2) and early wetwell failures (APB 4) increase with increasing containment degradation, as do late drywell failures (APB 6). Late wetwell failures (APB 5) also start to appear with a degraded contäinment. As expected, all of these increased failures occur at the expense of the no containment failure APB, APB 8. For this PDS Group the conditional probability of no containment failure drops from 0.536 at full containment strength, to 0.442 at $75 \%$ pressure capability and to 0.28 at $63 \%$ pressure capability. So for this PDS Group, at $63 \%$ capability the conditional probability of no containment failure is reduced to half of what it is at $100 \%$.

Figure 5-2 shows the comparison for PDS Group 5, Slow SBO. Again both early wetwell failures (APBs 1 and 2) and early drywell failures (APBs 3 and 4) increase while late wetwell failures remain almost unchanged. Late drywell failures (APB 6), containment venting (APB 7), and no containment failure (APB 8) all decrease, while no vessel breach (APB 9) remains unchanged. However, none of the shifts in this PDS Group are very significant, with the largest change in conditional probability of any APB between $100 \%$ strength and $63 \%$ strength equal to only .045 . 
The three containment conditions are compared for PDS Group 9, an ATWS Group, in Figure 5-3. As expected, and similar to the previously discussed PDS Groups, conditional probabilities of early and late failures, both in the drywell and wetwell, increase with containment degradation (APBs 1 through 6), while those for containment venting (APB 7), no containment failure (APB 8), and no core damage (APB 10) decrease. Somewhat unexpected is the significant shift in early drywell failure from the high pressure APB 3 to the low pressure APB 4 when the pressure capability is reduced from $75 \%$ to $63 \%$.

The reason for this shift appears to be due to the lowered containment strength leads to more frequent containment failure at a pressure low enough to avoid reclosure of the reactor safety relief valves. In the EVNTRE code, when containment pressure reaches 85 psig a forced reclosure of the relief valves is assumed. In some ATWS scenarios, where a high containment pressure capability exists, the 85 psig can be reached before core melt or vessel breach, causing a reclosure of the relief valves and a subsequent failure at high RCS pressure. Apparently attainment of the 85 psig is still likely with the $75 \%$ pressure capability but unlikely once the containment is degraded to $63 \%$. In the latter case, therefore, more of the sequences are at low RCS pressure. The slight increase in APB 9, no vessel breach, and APB 10, no core damage, with $63 \%$ pressure capability for this PDS Group, also seems to be due to the increased probability of the relief valves remaining open.

\subsection{The Effect of a Reduction in Containment Pressure Capability on the Nine Mile} Point 1/Oyster Creek Release Profile

The second case analyzed is the comparison of the containment response with design, current and corroded pressure capability (as defined in Section 4) of the Nine Mile Point/Oyster Creek (NMP/OC) model using 100 psig venting pressure.

Before proceeding with this comparison, however, the results for the NMP/OC design condition were compared to the results of the Peach Bottom (PB) $100 \%$ pressure capability condition and the PB 75\% condition. This comparison was conducted as a further check that the additional modifications made to the EVNTRE code to obtain a NMP/OC model yielded reasonable results. Figures 5-4, 5-5 and 5-6 show the comparison for PDS Groups 1,5 and 9 respectively. As can be seen, the NMP/OC containment as designed shows a similar response to the PB containment when subjected to the same type of loads but with load magnitude scaled down to NMP/OC conditions.

The results of the actual containment performance comparison of Case 2, i.e. between design, current, and corroded conditions for NMP/OC, are listed in Table 5-2. Complete graphical results are shown in figures C-19 through C-45 of Appendix C. Figures 5-7, 5-8, and 5-9 give the comparisons for PDS Groups 1 (LOCA), 5 (Slow SBO) and 9 (ATWS) respectively. As these figures show, the trends are the same as for the PB containment performance of Case 1 , but less pronounced, i.e differences in conditional probability among the three conditions in each APB are smaller than for Case 1. This is likely due to the fact that the differences in containment pressure capability are less severe 
for Case 2 than for Case 1. In the NMP/OC model the current and design conditions are not that far apart, with the current condition being the stronger for most failure modes (See Section 4). The corroded condition of the NMP/OC model is also not as severe as the 75\% condition for $\mathrm{PB}$, since in $\mathrm{PB}$ the $25 \%$ reduction in pressure capability is across the board for all failure modes, while in NMP/OC the $25 \%$ reduction is in the shell thickness and so does not affect the seal failure mode, for instance.

Qualitatively, however, the shifts in conditional probability in the APBs are the same for Case 2 as they are for Case 1. Even the shift from APB 3 to APB 4 for PDS Group 9, noted for the $63 \%$ PB condition in Case 1 , is repeated in Case 2 for the NMP/OC corroded condition. This is because the NMP/OC containment pressure capability is low enough under this condition to make the attainment of 85 psig containment pressure (the relief valve reclosure pressure) unlikely.

Case 3 compares the same NMP/OC conditions as Case 2 but with the containment venting pressure reduced to 43.4 psig. Complete results for case 3 are listed in Table 5-3 and shown in Figures C-46 through C-72 of Appendix C. Case 4 is a repeat of Case 3 but with the containment venting pressure reduced even further to $35 \mathrm{psig}$. Results for Case 4 are given in Table 5-4 and in Figures C-73 through C-99 of Appendix C.

The effect of changes in containment venting pressure can best be seen by making comparisons among Cases 2,3 and 4 for particular PDS Groups, at a particular condition. Figure 5-10 shows the effect of venting pressure on PDS Group 1 (LOCA) with current containment pressure capability. Not surprisingly, for this PDS Group reducing the venting pressure shifts a large portion of the sequences that would not have led to containment failure, i.e. APB 8, to sequences where the containment is vented, APB 7. This is the sole effect for this PDS Group and no difference is discerned for a venting pressure of 43 or 35 psig.

The effect of different containment venting pressures on PDS Group 5 (Slow SBO) is slightly more complicated, as shown in Figure 5-11. The major effect is again a shift from APB 9, no containment failure, to APB 8, containment vented. However, there is also a slight decrease in early wetwell failures, early high pressure drywell failures, and late drywell failures, associated with the lower venting pressures. The conditional probability for low pressure drywell failures, APB 4, increases slightly with lower venting pressure, as does APB 9 , no vessel breach. The latter probably occurs because some RCIC and HPCI failures due to high containment pressure are avoided at the lower containment venting pressures. However, as Figure 5-11 shows, the changes in conditional probability associated with different venting pressures in all the APBs except 7 and 8 are slight for this PDS Group.

The effect of different venting pressures on PDS Group 9 (ATWS) is similar to that for Group 1 discussed above. It is shown in figure 5-12. The only significant change is a shift from APB 8, no containment failure, to APB 7, vented containment. 


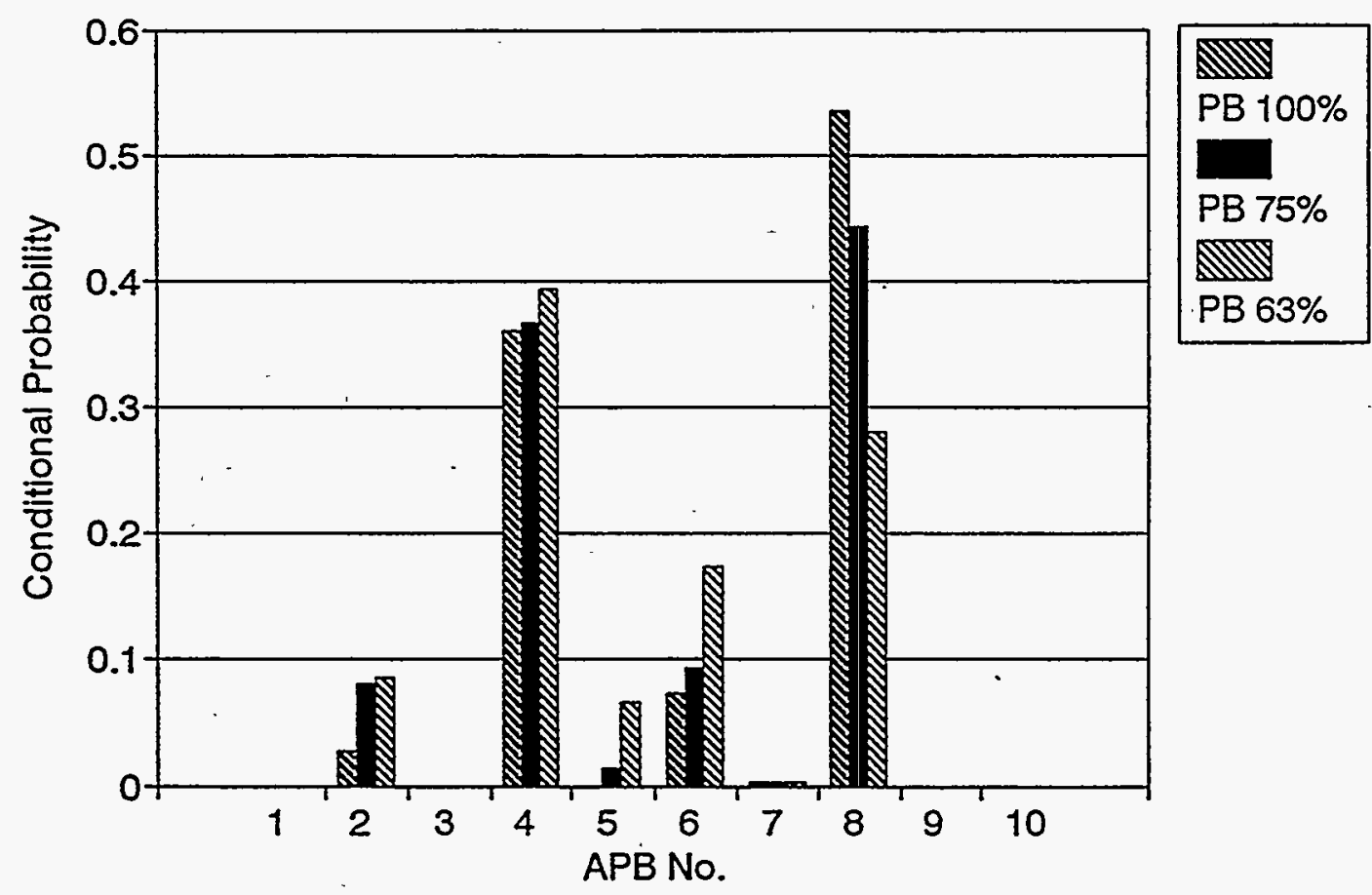

Figure 5-1 Effect of Containment Capability for Peach Bottom (PDS 1)

$5-4$ 


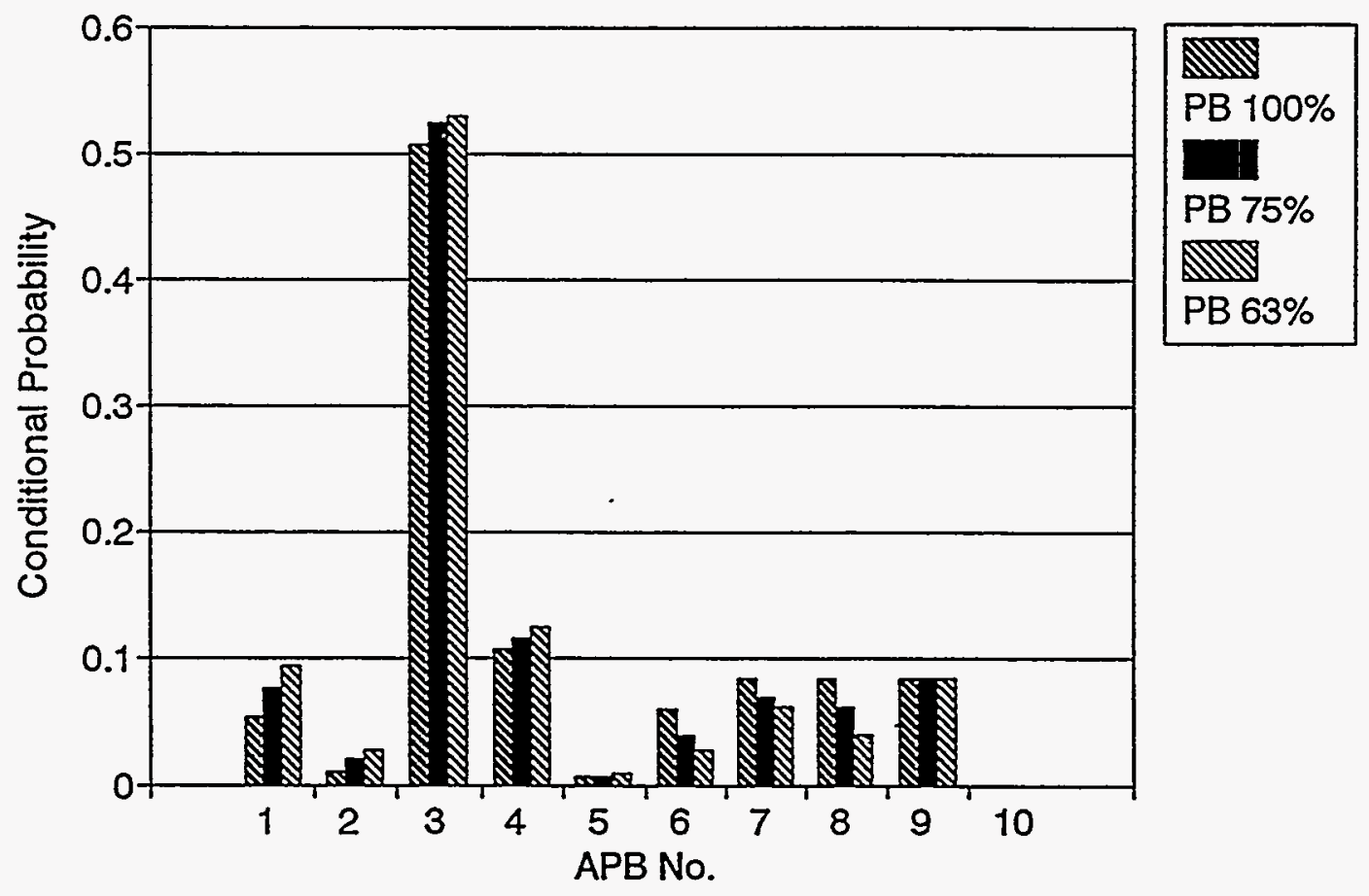

Figure 5-2 Effect of Containment Capability for Peach Bottom (PDS 5)

5-5 


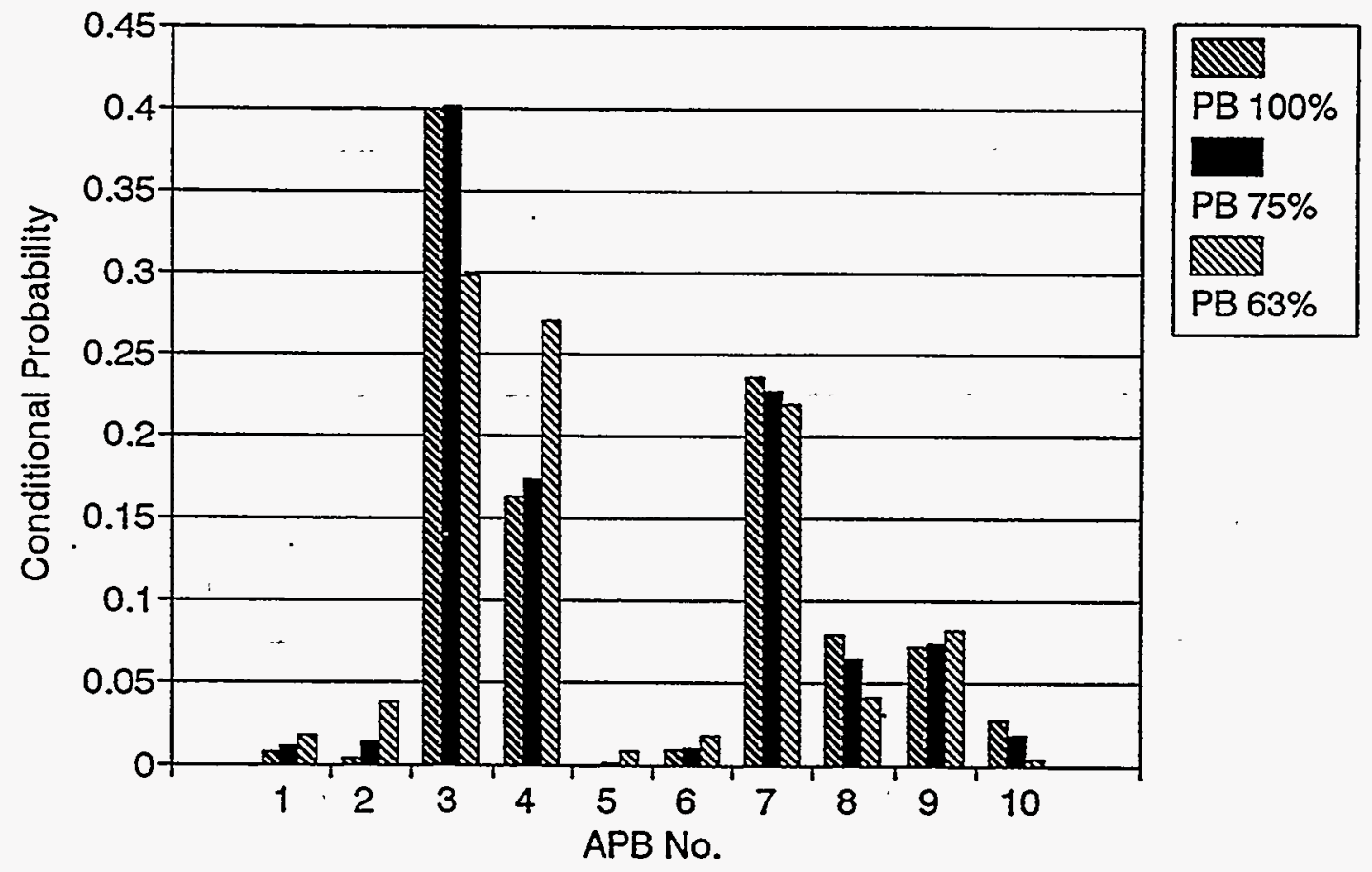

Figure 5-3 Effect of Containment Capability for Peach Bottom (PDS 9)

5-6 
Table 5-1 Peach Bottom Containment Performance with Different Pressure Capabilities

\begin{tabular}{|c|rrrrrrrrrr|}
\hline & \multicolumn{10}{|c|}{ APB (Peach Bollom) } \\
\cline { 2 - 11 } PDS & 1 & 2 & 3 & 4 & 5 & 6 & 7 & 8 & 9 & 10 \\
\hline 1 & $0.00 \%$ & $2.78 \%$ & $0.00 \%$ & $36.00 \%$ & $0.00 \%$ & $7.37 \%$ & $0.28 \%$ & $53.57 \%$ & $0.00 \%$ & $0.00 \%$ \\
2 & $0.00 \%$ & $2.78 \%$ & $0.00 \%$ & $36.00 \%$ & $0.00 \%$ & $7.37 \%$ & $0.28 \%$ & $53.57 \%$ & $0.00 \%$ & $0.00 \%$ \\
3 & $0.00 \%$ & $0.00 \%$ & $0.00 \%$ & $27.00 \%$ & $4.64 \%$ & $8.36 \%$ & $27.10 \%$ & $7.78 \%$ & $25.12 \%$ & $0.00 \%$ \\
4 & $0.06 \%$ & $2.36 \%$ & $6.63 \%$ & $23.66 \%$ & $0.49 \%$ & $6.26 \%$ & $2.36 \%$ & $32.83 \%$ & $25.34 \%$ & $0.00 \%$ \\
5 & $5.34 \%$ & $1.01 \%$ & $50.68 \%$ & $10.79 \%$ & $0.69 \%$ & $6.03 \%$ & $8.49 \%$ & $8.48 \%$ & $8.49 \%$ & $0.00 \%$ \\
6 & $0.51 \%$ & $1.69 \%$ & $8.35 \%$ & $21.79 \%$ & $0.03 \%$ & $4.86 \%$ & $0.04 \%$ & $42.44 \%$ & $20.30 \%$ & $0.00 \%$ \\
7 & $0.00 \%$ & $1.12 \%$ & $0.00 \%$ & $48.52 \%$ & $0.00 \%$ & $1.22 \%$ & $30.75 \%$ & $8.19 \%$ & $7.38 \%$ & $2.80 \%$ \\
8 & $0.75 \%$ & $0.42 \%$ & $40.01 \%$ & $16.28 \%$ & $0.00 \%$ & $0.93 \%$ & $23.57 \%$ & $7.96 \%$ & $7.26 \%$ & $2.80 \%$ \\
9 & $0.75 \%$ & $0.42 \%$ & $40.01 \%$ & $16.28 \%$ & $0.00 \%$ & $0.93 \%$ & $23.57 \%$ & $7.96 \%$ & $7.26 \%$ & $2.80 \%$ \\
\hline
\end{tabular}

\begin{tabular}{|c|c|c|c|c|c|c|c|c|c|c|}
\hline \multirow[b]{2}{*}{ PDS } & \multicolumn{6}{|c|}{ APB (75\% Peach Botlom) } & \multirow[b]{2}{*}{7} & \multirow[b]{2}{*}{8} & \multirow[b]{2}{*}{$y$} & \multirow[b]{2}{*}{$10^{\circ}$} \\
\hline & 1 & 2 & 3 & 4 & 5 & 6 & & & & \\
\hline 1 & $0.00 \%$ & $8.04 \%$ & $0.00 \%$ & $36.65 \%$ & $1.46 \%$ & $9.34 \%$ & $0.28 \%$ & $44.23 \%$ & $0.00 \%$ & $0.00 \%$ \\
\hline 2 & $0.00 \%$ & $8.04 \%$ & $0.00 \%$ & $36.65 \%$ & $1.46 \%$ & $9.34 \%$ & $0.28 \%$ & $44.23 \%$ & $0.00 \%$ & 0.007 \\
\hline 3 & $0.00 \%$ & $0.00 \%$ & $0.00 \%$ & $27.00 \%$ & $4.34 \%$ & $8.79 \%$ & $27.10 \%$ & $7.65 \%$ & $25.12 \%$ & $0.00 \%$ \\
\hline 4 & $0.23 \%$ & $5.54 \%$ & $6.69 \%$ & $23.88 \%$ & $0.96 \%$ & $6.81 \%$ & $2.11 \%$ & $28.43 \%$ & $25.34 \%$ & $0.00 \%$ \\
\hline $\mathbf{5}$ & $7.75 \%$ & $2.01 \%$ & $52.43 \%$ & $11.62 \%$ & $0.66 \%$ & $3.93 \%$ & $6.93 \%$ & $6.19 \%$ & $8.44 \%$ & $0.00 \%$ \\
\hline 6 & $1.39 \%$ & $4.89 \%$ & $8.50 \%$ & $22.17 \%$ & $0.94 \%$ & $5.95 \%$ & $0.04 \%$ & $35.81 \%$ & $20.30 \%$ & $0.00 \%$ \\
\hline 7 & $0.00 \%$ & $3.16 \%$ & $0.00 \%$ & $49.46 \%$ & $0.16 \%$ & $1.39 \%$ & $29.56 \%$ & $6.74 \%$ & $7.67 \%$ & $1.85 \%$ \\
\hline 8 & $1.20 \%$ & $1.44 \%$ & $40.14 \%$ & $17.37 \%$ & $0.13 \%$ & $1.07 \%$ & $22.79 \%$ & $6.52 \%$ & $7.48 \%$ & $1.85 \%$ \\
\hline 9 & $1.20 \%$ & $1.44 \%$ & $40.14 \%$ & $17.37 \%$ & $0.13 \%$ & $1.07 \%$ & $22.79 \%$ & $6.52 \%$ & $7.48 \%$ & $1.85 \%$ \\
\hline
\end{tabular}

\begin{tabular}{|c|rrrrrrrrrr|}
\hline & \multicolumn{10}{|c|}{ APB (63\% Peach Boltom) } \\
\cline { 2 - 12 } & 1 & 2 & 3 & 4 & 5 & \multicolumn{1}{c|}{6} & 7 & \multicolumn{1}{c|}{8} & 9 & 10 \\
\hline 1 & $0.00 \%$ & $8.51 \%$ & $0.00 \%$ & $39.37 \%$ & $6.62 \%$ & $17.25 \%$ & $0.28 \%$ & $27.97 \%$ & $0.00 \%$ & $0.00 \%$ \\
2 & $0.00 \%$ & $8.51 \%$ & $0.00 \%$ & $39.37 \%$ & $6.62 \%$ & $17.25 \%$ & $0.28 \%$ & $27.97 \%$ & $0.00 \%$ & $0.00 \%$ \\
3 & $0.00 \%$ & $0.00 \%$ & $0.00 \%$ & $27.00 \%$ & $3.78 \%$ & $9.35 \%$ & $27.10 \%$ & $7.65 \%$ & $25.12 \%$ & $0.00 \%$ \\
4 & $0.36 \%$ & $6.89 \%$ & $6.80 \%$ & $24.89 \%$ & $3.52 \%$ & $11.35 \%$ & $1.96 \%$ & $18.87 \%$ & $25.34 \%$ & $0.00 \%$ \\
5 & $0.41 \%$ & $2.74 \%$ & $52.89 \%$ & $12.56 \%$ & $0.91 \%$ & $2.79 \%$ & $6.18 \%$ & $4.00 \%$ & $8.48 \%$ & $0.00 \%$ \\
6 & $1.77 \%$ & $5.61 \%$ & $8.74 \%$ & $23.69 \%$ & $5.42 \%$ & $10.08 \%$ & $0.04 \%$ & $24.35 \%$ & $20.30 \%$ & $0.00 \%$ \\
7 & $0.00 \%$ & $6.54 \%$ & $0.00 \%$ & $49.45 \%$ & $1.06 \%$ & $2.27 \%$ & $27.46 \%$ & $4.12 \%$ & $8.66 \%$ & $0.43 \%$ \\
8 & $1.78 \%$ & $3.88 \%$ & $29.79 \%$ & $27.04 \%$ & $0.90 \%$ & $1.81 \%$ & $21.94 \%$ & $4.19 \%$ & $8.23 \%$ & $0.43 \%$ \\
9 & $1.78 \%$ & $3.88 \%$ & $29.79 \%$ & $27.04 \%$ & $0.90 \%$ & $1.81 \%$ & $21.94 \%$ & $4.19 \%$ & $8.23 \%$ & $0.43 \%$ \\
\hline
\end{tabular}

$5-7$ 
Table 5-2 Nine Mile Point 1/Oyster Creek Containment Performance with Different Pressure Capabilities and 100 psig Venting Pressure

\begin{tabular}{|c|c|c|c|c|c|c|c|c|c|c|}
\hline \multirow[b]{2}{*}{ IIIS } & \multicolumn{10}{|c|}{ APB (100 psig vent pressure, Corroded Condilion) } \\
\hline & 1 & 2 & .3 & 4 & 5 & 6 & 7 & 8 & 9 & 10 \\
\hline 1 & & $6.74 \%$ & & $36.41 \%$ & $2.12 \%$ & $7.06 \%$ & & $47.67 \%$ & & \\
\hline 2 & & $6.74 \%$ & & $36.41 \%$ & $2.12 \%$ & $7.06 \%$ & & $47.67 \%$ & & \\
\hline 3 & & & & $27.00 \%$ & $5.48 \%$ & $7.65 \%$ & $27.10 \%$ & $7.65 \%$ & $25.12 \%$ & $\cdot$ \\
\hline 4 & $0.15 \%$ & $4.18 \%$ & $6.65 \%$ & $23.53 \%$ & $1.06 \%$ & $6.37 \%$ & $2.19 \%$ & $30.51 \%$ & $25.34 \%$ & \\
\hline 5 & $7.99 \%$ & $3.52 \%$ & $50.36 \%$ & $11.87 \%$ & $0.71 \%$ & $4.57 \%$ & $2.81 \%$ & $8.87 \%$ & $9.26 \%$ & \\
\hline 6 & $1.19 \%$ & $3.26 \%$ & $8.45 \%$ & $21.93 \%$ & $1.40 \%$ & $4.74 \%$ & & $3 \ddot{8} .73 \%$ & $20.30 \%$ & \\
\hline$T$ & & $1.95 \%$ & & $47.67 \%$ & $0.26 \%$ & $1.18 \%$ & $29.67 \%$ & $7.50 \%$ & $8.09 \%$ & $3.68 \%$ \\
\hline 8 & $0.68 \%$ & $1.31 \%$ & $28.73 \%$ & $25.14 \%$ & $0.23 \%$ & $0.90 \%$ & $23.87 \%$ & $7.38 \%$ & $8.08 \%$ & $3.68 \%$ \\
\hline 9 & $0.58 \%$ & $1.31 \%$ & $28.731: 0$ & $25.1 .1 \%$ & $0.23 \%$ & $0.90 \%$ & $23.87 \%$ & $7.3 A_{i}$ & B.08\% & $3.68 \pi$ \\
\hline
\end{tabular}

\begin{tabular}{|c|c|c|c|c|c|c|c|c|c|c|}
\hline \multirow[b]{2}{*}{ ?DS } & \multicolumn{8}{|c|}{ APB (100 psig vent pressure, Current Condition) } & \\
\hline & 1 & 2 & 3 & 1 & 5 & 6 & 7 & 8 & 9 & 10 \\
\hline 1 & & $1.54 \%$ & & $36.27 \%$ & & $7.14 \%$ & & $55.04 \%$ & & \\
\hline 2 & & $1.54 \%$ & & $36.27 \%$ & & $7.14 \%$ & & $55.04 \%$ & & \\
\hline 3 & & & - & $27.00 \%$ & $5.49 \%$ & $7.64 \%$ & $27.10 \%$ & $7.65 \%$ & $25.12 \%$ & \\
\hline 4 & $0.04 \%$ & $1.13 \%$ & $6.63 \%$ & $23.91 \%$ & $0.48 \%$ & $6.17 \%$ & $2.38 \%$ & $33.91 \%$ & $25.34 \%$ & \\
\hline 5 & $5.98 \%$ & $1.41 \%$ & $48.97 \%$ & $11.31 \%$ & $0.17 \%$ & $7.35 \%$ & $3.93 \%$ & $11.64 \%$ & $9.22 \%$ & \\
\hline 6 & $0.36 \%$ & $0.69 \%$ & $8.37 \%$ & $22.22 \%$ & & $4.73 \%$ & & $43.31 \%$ & $20.30 \%$ & \\
\hline 7 & & $0.97 \%$ & & $48.53 \%$ & & $1.20 \%$ & $30.50 \%$ & $8.57 \%$ & $7.38 \%$ & $2.84 \%$ \\
\hline 8 & $0.59 \%$ & $0.38 \%$ & $39.87 \%$ & $16.38 \%$ & & $0.92 \%$ & $23.26 \%$ & $8.37 \%$ & $7.36 \%$ & $2.84 \%$ \\
\hline 9 & $0.59 \%$ & $0.38 \%$ & $39.87 \%$ & $16.38 \%$ & & $0.92 \%$ & $23.26 \%$ & $-8.37 \%$ & $7.36 \%$ & $2.84 \%$ \\
\hline
\end{tabular}

\begin{tabular}{|c|rrrrrrrrrr|}
\hline & \multicolumn{7}{|c|}{ APB (100 psig venl pressurc, Design Condition) } \\
\cline { 2 - 12 } & 1 & 2 & 3 & 4 & 5 & 6 & 7 & 8 & 9 & $: 10$ \\
\hline 1 & & $2.78 \%$ & & $36.27 \%$ & & $7.14 \%$ & & $53.80 \%$ & & $\cdots$ \\
2 & & $2.78 \%$ & & $36.27 \%$ & & $7.14 \%$ & & $53.80 \%$ & & \\
3 & & & & $27.00 \%$ & $4.92 \%$ & $8.21 \%$ & $27.10 \%$ & $7.65 \%$ & $25.12 \%$ & \\
4 & $0.05 \%$ & $2.38 \%$ & $6.65 \%$ & $23.80 \%$ & $0.41 \%$ & $6.20 \%$ & $2.30 \%$ & $32.85 \%$ & $25.34 \%$ & \\
5 & $6.26 \%$ & $1.90 \%$ & $49.81 \%$ & $11.28 \%$ & $0.16 \%$ & $6.59 \%$ & $3.57 \%$ & $11.15 \%$ & $9.23 \%$ & \\
6 & $0.52 \%$ & $1.69 \%$ & $8.37 \%$ & $21.93 \%$ & & $4.73 \%$ & & $42.46 \%$ & $20.30 \%$ & \\
7 & & $1.19 \%$ & & $48.49 \%$ & $0.02 \%$ & $1.19 \%$ & $30.44 \%$ & $8.36 \%$ & $7.39 \%$ & $2.91 \%$ \\
8 & $0.65 \%$ & $0.55 \%$ & $39.73 \%$ & $16.50 \%$ & $0.02 \%$ & $0.92 \%$ & $23.17 \%$ & $8.14 \%$ & $7.37 \%$ & $2.91 \%$ \\
9 & $0.65 \%$ & $0.55 \%$ & $39.73 \%$ & $16.50 \%$ & $0.02 \%$ & $0.92 \%$ & $23.17 \%$ & $8.14 \%$ & $7.37 \%$ & $-2.91 \%$ \\
\hline
\end{tabular}


Table 5-3 Nine Mile Point 1/Oyster Creek Containment Performance with Different Pressure Capabilities and 43.4 psig Venting Pressure

\begin{tabular}{|c|c|c|c|c|c|c|c|c|c|c|}
\hline \multirow[b]{2}{*}{ PIS } & \multicolumn{10}{|c|}{ APB (43.4 psig vent pressure, Corrode Condition) } \\
\hline & 1 & 2 & 3 & 4 & 5 & 6 & 7 & 8 & 9 & 10 \\
\hline 1 & & $6.74 \%$ & & $36.41 \%$ & $0.42 \%$ & $7.06 \%$ & $32.55 \%$ & $16.81 \%$ & & \\
\hline 2 & & $6.74 \%$ & & $36.41 \%$ & $0.42 \%$ & $7.06 \%$ & $32.55 \%$ & $16.81 \%$ & & \\
\hline 3 & & & & $27.00 \%$ & $5.48 \%$ & $7.65 \%$ & $27.10 \%$ & $7.65 \%$ & $25.12 \%$ & \\
\hline 4 & $0.14 \%$ & $4.18 \%$ & $6.65 \%$ & $23.53 \%$ & $0.57 \%$ & $6.15 \%$ & $21.85 \%$ & $11.57 \%$ & $25.34 \%$ & \\
\hline 5 & $6.84 \%$ & $1.78 \%$ & $49.43 \%$ & $12.32 \%$ & $0.30 \%$ & $3.90 \%$ & $13.75 \%$ & $2.05 \%$ & $9.60 \%$ & \\
\hline 6 & $1.19 \%$ & $3.26 \%$ & $8.45 \%$ & $21.93 \%$ & $0.28 \%$ & $4.73 \%$ & $22.56 \%$ & $17.30 \%$ & $20.30 \%$ & \\
\hline 7 & & $1.47 \%$ & & $47.66 \%$ & $0.05 \%$ & $1.09 \%$ & $35.70 \%$ & $2.25 \%$ & $8.09 \%$ & $3.68 \%$ \\
\hline$B$ & $0.58 \%$ & $0.92 \%$ & $28.70 \%$ & $25.15 \%$ & $0.05 \%$ & $0.84 \%$ & $29.26 \%$ & $2.72 \%$ & $8.08 \%$ & $3.68 \%$ \\
\hline 2 & $0.58 \%$ & $0.92 \%$ & $28.70 \%$ & $25.15 \%$ & $0.05 \%$ & $0.8 .4 \%$ & $29.26 \%$ & $2.72 \%$ & $8.08 \%$ & 3.683 \\
\hline
\end{tabular}

\begin{tabular}{|c|cccccccccc|}
\hline & \multicolumn{8}{|c|}{ APB (43.4 psig vent pressure, Currenl Condition) } \\
\cline { 2 - 11 } PDS & 1 & 2 & 3 & 1 & 5 & 6 & 7 & 8 & 9 & 10 \\
\hline 1 & & $1.51 \%$ & & $36.27 \%$ & & $7.14 \%$ & $36.07 \%$ & $18.97 \%$ & & \\
2 & & $1.54 \%$ & & $36.27 \%$ & & $7.14 \%$ & $36.07 \%$ & $18.97 \%$ & \\
3 & & & & $27.00 \%$ & $5.49 \%$ & $7.64 \%$ & $27.10 \%$ & $7.65 \%$ & $25.12 \%$ & \\
4 & $0.04 \%$ & $1.13 \%$ & $6.63 \%$ & $23.91 \%$ & $0.48 \%$ & $6.16 \%$ & $23.68 \%$ & $12.62 \%$ & $25.34 \%$ & \\
5 & $4.95 \%$ & $0.79 \%$ & $48.15 \%$ & $12.05 \%$ & $0.11 \%$ & $6.28 \%$ & $15.45 \%$ & $2.57 \%$ & $9.61 \%$ \\
6 & $0.36 \%$ & $0.69 \%$ & $8.37 \%$ & $22.22 \%$ & & $4.73 \%$ & $24.29 \%$ & $19.02 \%$ & $20.30 \%$ & \\
7 & & $0.77 \%$ & & $48.59 \%$ & & $1.10 \%$ & $36.80 \%$ & $2.50 \%$ & $7.38 \%$ & $2.84 \%$ \\
8 & $0.51 \%$ & $0.26 \%$ & $39.83 \%$ & $16.46 \%$ & & $0.86 \%$ & $28.84 \%$ & $3.01 \%$ & $7.37 \%$ & $2.84 \%$ \\
3 & $0.51 \%$ & $0.26 \%$ & $39.83 \%$ & $16.46 \%$ & & $0.86 \%$ & $28.84 \%$ & $3.01 \%$ & $7.37 \%$ & $2.84 \%$ \\
\hline
\end{tabular}

\begin{tabular}{|c|c|c|c|c|c|c|c|c|c|c|}
\hline \multirow[b]{2}{*}{ POS } & \multicolumn{8}{|c|}{ APB (43.4 psi vent pressure, Design Condition) } & \multirow[b]{2}{*}{9} & \multirow[b]{2}{*}{.10} \\
\hline & 1 & 2 & 3 & 4 & 5 & 6 & 7 & 8 & & \\
\hline$!$ & & $2.78 \%$ & & $36.27 \%$ & & $7.14 \%$ & $35.24 \%$ & $18.56 \%$ & & $\therefore$ \\
\hline 2 & & $2.78 \%$ & & $36.27 \%$ & & $7.14 \%$ & $35.24 \%$ & $18.56 \%$ & & \\
\hline 3 & & & & $27.00 \%$ & $4.92 \%$ & $8.21 \%$ & $27.10 \%$ & $7.65 \%$ & $25.12 \%$ & \\
\hline 4 & $0.05 \%$ & $2.38 \%$ & $6.65 \%$ & $23.80 \%$ & $0.11 \%$ & $6.20 \%$ & $22.90 \%$ & $12.26 \%$ & 25.347 & \\
\hline 5 & $5.21 \%$ & $1.05 \%$ & $48.83 \%$ & $12.04 \%$ & $0.10 \%$ & $5.59 \%$ & $15.05 \%$ & $2.47 \%$ & $9.63 \%$ & \\
\hline 6 & $0.52 \%$ & $1.69 \%$ & $8.37 \%$ & $21.93 \%$ & & $4.73 \%$ & $23.79 \%$ & $18.67 \%$ & $20.30 \%$ & \\
\hline 7 & & $0.92 \%$ & & $48.55 \%$ & & $1.10 \%$ & $36.65 \%$ & $2.46 \%$ & $7.39 \%$ & $2.91 \%$ \\
\hline 8 & $0.57 \%$ & $0.37 \%$ & $39.67 \%$ & $16.58 \%$ & & $0.86 \%$ & $28.69 \%$ & $2.95 \%$ & $7.38 \%$ & 2.91 त्न \\
\hline 9 & $0.57 \%$ & $0.37 \%$ & $39.67 \%$ & $16.58 \%$ & & $0.86 \%$ & $28.69 \%$ & $2.95 \%$ & $7.38 \%$ & : 2.91영 \\
\hline
\end{tabular}


Table 5-4 Nine Mile Point 1/Oyster Creek Containment Performance with Different Pressure Capabilities and 35 psig Venting Pressure

\begin{tabular}{|c|c|c|c|c|c|c|c|c|c|c|}
\hline \multirow[b]{2}{*}{ PDS } & \multicolumn{10}{|c|}{ APB (35 psig vent pressure, Corroded Condition) } \\
\hline & 1 & 2 & 3 & 4 & 5 & 6 & 7 & 8 & 9 & 10 \\
\hline 1 & & $6.74 \%$ & & $36.41 \%$ & $0.42 \%$ & $7.06 \%$ & $32.55 \%$ & $16.81 \%$ & & \\
\hline 2 & & $6.74 \%$ & & $36.41 \%$ & $0.42 \%$ & $7.06 \%$ & $32.55 \%$ & $16.81 \%$ & & \\
\hline 3 & & & & $27.02 \%$ & $5.48 \%$ & $7.63 \%$ & $27.17 \%$ & $7.598 \%$ & $25.12 \%$ & - \\
\hline 4 & $0.14 \%$ & $4.18 \%$ & $6.65 \%$ & $23.53 \%$ & $0.57 \%$ & $6.15 \%$ & $21.93 \%$ & $11.49 \%$ & $25.34 \%$ & \\
\hline 5 & $6.83 \%$ & $1.64 \%$ & $49.44 \%$ & $12.41 \%$ & $0.29 \%$ & $3.74 \%$ & $14.23 \%$ & $1.78 \%$ & $9.60 \%$ & \\
\hline 6 & $1.19 \%$ & $3.26 \%$ & $8.45 \%$ & $21.93 \%$ & $0.28 \%$ & $4.73 \%$ & $22.56 \%$ & $17.30 \%$ & $20.30 \%$ & \\
\hline 7 & & $1.38 \%$ & & $47.75 \%$ & $0.05 \%$ & $1.00 \%$ & $35.95 \%$ & $2.09 \%$ & $8.09 \%$ & $3.68 \%$ \\
\hline 8 & $0.54 \%$ & $0.87 \%$ & $28.70 \%$ & $25.21 \%$ & $0.05 \%$ & $0.79 \%$ & $29.53 \%$ & $2.55 \%$ & $8.08 \%$ & 3.687 \\
\hline 9 & $0.5 .1 \%$ & $0.87 \%$ & $28.70 \%$ & $25.21 \%$ & $0.05 \%$ & $0.79 \%$ & $29.53=$ & $3.35 \pi$ & $8.108 \%$ & $3.688 \mathrm{~d}$ \\
\hline
\end{tabular}

\begin{tabular}{|c|c|c|c|c|c|c|c|c|c|c|}
\hline \multirow[b]{2}{*}{ PDS } & \multicolumn{8}{|c|}{ APB (35 psig vent pressure, Current Condition) } & \\
\hline & 1 & 2 & 3 & 4 & 5 & 6 & $i$ & B & 9 & 10 \\
\hline 1 & & $1.51 \%$ & . & $36.27 \%$ & & $7.14 \%$ & $36.07 \%$ & $18.97 \%$ & & \\
\hline 2 & & $1.54 \%$ & & $36.27 \%$ & & $7.14 \%$ & $36.07 \%$ & $18.97 \%$ & & \\
\hline 3 & & & & $27.02 \%$ & $5.48 \%$ & $7.63 \%$ & $27.17 \%$ & $7.58 \%$ & $25.12 \%$ & \\
\hline 4 & $0.04 \%$ & $1.13 \%$ & $6.63 \%$ & $23.91 \%$ & $0.48 \%$ & $6.16 \%$ & $23.76 \%$ & $12.54 \%$ & $25.34 \%$ & \\
\hline 5 & $4.94 \%$ & $0.73 \%$ & $48.16 \%$ & $12.16 \%$ & $0.10 \%$ & $6.11 \%$ & $15.87 \%$ & $2.28 \%$ & $9.61 \%$ & \\
\hline 6 & $0.36 \%$ & $0.69 \%$ & $8.37 \%$ & $22.22 \%$ & & $4.73 \%$ & $24.29 \%$ & $19.02 \%$ & $20.30 \%$ & ' \\
\hline 7 & & $0.70 \%$ & & $48.68 \%$ & & $1.02 \%$ & $37.04 \%$ & $2.32 \%$ & $7.38 \%$ & $2.84 \%$ \\
\hline 8 & $0.50 \%$ & $0.21 \%$ & $39.84 \%$ & $16.52 \%$ & & $0.80 \%$ & $29.09 \%$ & $2.81 \%$ & $7.37 \%$ & $2.84 \%$ \\
\hline 9 & $0.50 \%$ & $0.21 \%$ & $39.84 \%$ & $16.52 \%$ & & $0.80 \%$ & $29.09 \%$ & $2.81 \%$ & $7.37 \%$ & $2.84 \%$ \\
\hline
\end{tabular}

\begin{tabular}{|c|c|c|c|c|c|c|c|c|c|c|}
\hline \multirow[b]{2}{*}{ PDS } & \multicolumn{10}{|c|}{ APB (35 psi vent pressure, Design Condition) } \\
\hline & 1 & 2 & 3 & 4 & 5 & 6 & 7 & 8 & .9 & $: 10$ \\
\hline 1 & & $2.78 \%$ & & $36.27 \%$ & & $7.14 \%$ & $35.24 \%$ & $18.56 \%$ & & . \\
\hline 2 & $\cdot$ & $2.78 \%$ & & $36.27 \%$ & & $7.14 \%$ & $35.24 \%$ & $18.56 \%$ & & \\
\hline 3 & & 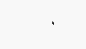 & & $27.02 \%$ & $4.92 \%$ & $8.19 \%$ & $27.17 \%$ & $7.58 \%$ & $25.12 \%$ & \\
\hline 4 & $0.05 \%$ & $2.38 \%$ & $6.65 \%$ & $23.80 \%$ & $0.41 \%$ & $6.19 \%$ & $22.99 \%$ & $12.17 \%$ & $25.34 \%$ & \\
\hline 5 & $5.20 \%$ & $0.99 \%$ & $48.84 \%$ & $12.15 \%$ & $0.09 \%$ & $5.42 \%$ & $15.47 \%$ & $2.18 \%$ & $9.63 \%$ & \\
\hline 6 & $0.52 \%$ & $1.69 \%$ & $8.37 \%$ & $21.93 \%$ & & $4.73 \%$ & $23.79 \%$ & $18.67 \%$ & $20.30 \%$ & \\
\hline 7 & & $0.84 \%$ & & $48.64 \%$ & & $1.01 \%$ & $36.90 \%$ & $2.29 \%$ & $7.39 \%$ & $2.91 \%$ \\
\hline 8 & $0.55 \%$ & $0.32 \%$ & $39.68 \%$ & $16.63 \%$ & & $0.80 \%$ & $28.95 \%$ & $2.76 \%$ & $7.38 \%$ & $2.91 \%$ \\
\hline 9 & $0.55 \%$ & $0.32 \%$ & $39.68 \%$ & $16.63 \%$ & & $0.80 \%$ & $28.95 \%$ & $2.76 \%$ & $7.38 \%$ & $2.91 \%$ \\
\hline
\end{tabular}




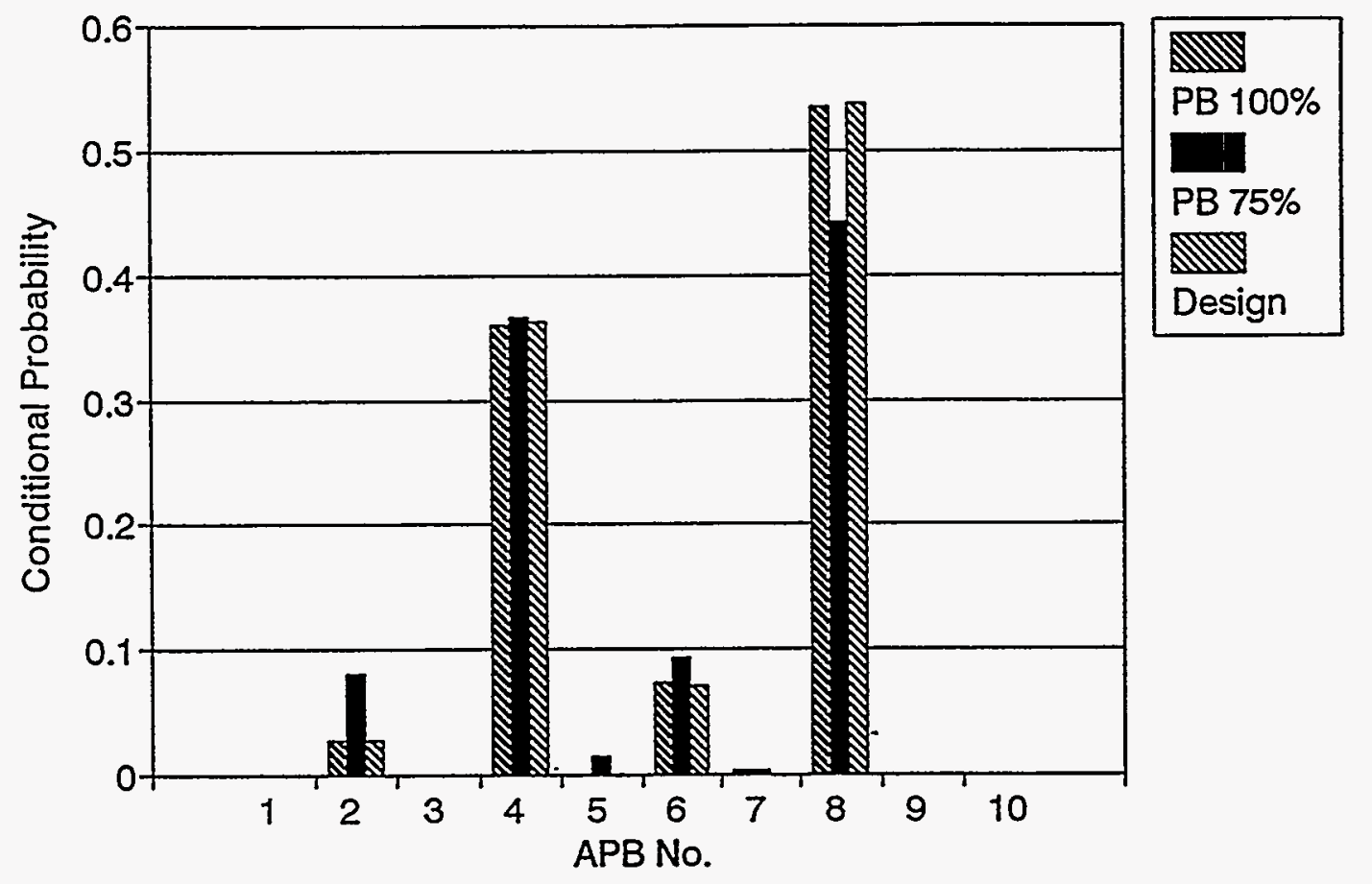

Figure 5.4 NMP/OC Design Condition Compared to PB 100\% and PB 75\% for PDS 1

$5-11$

A-49 


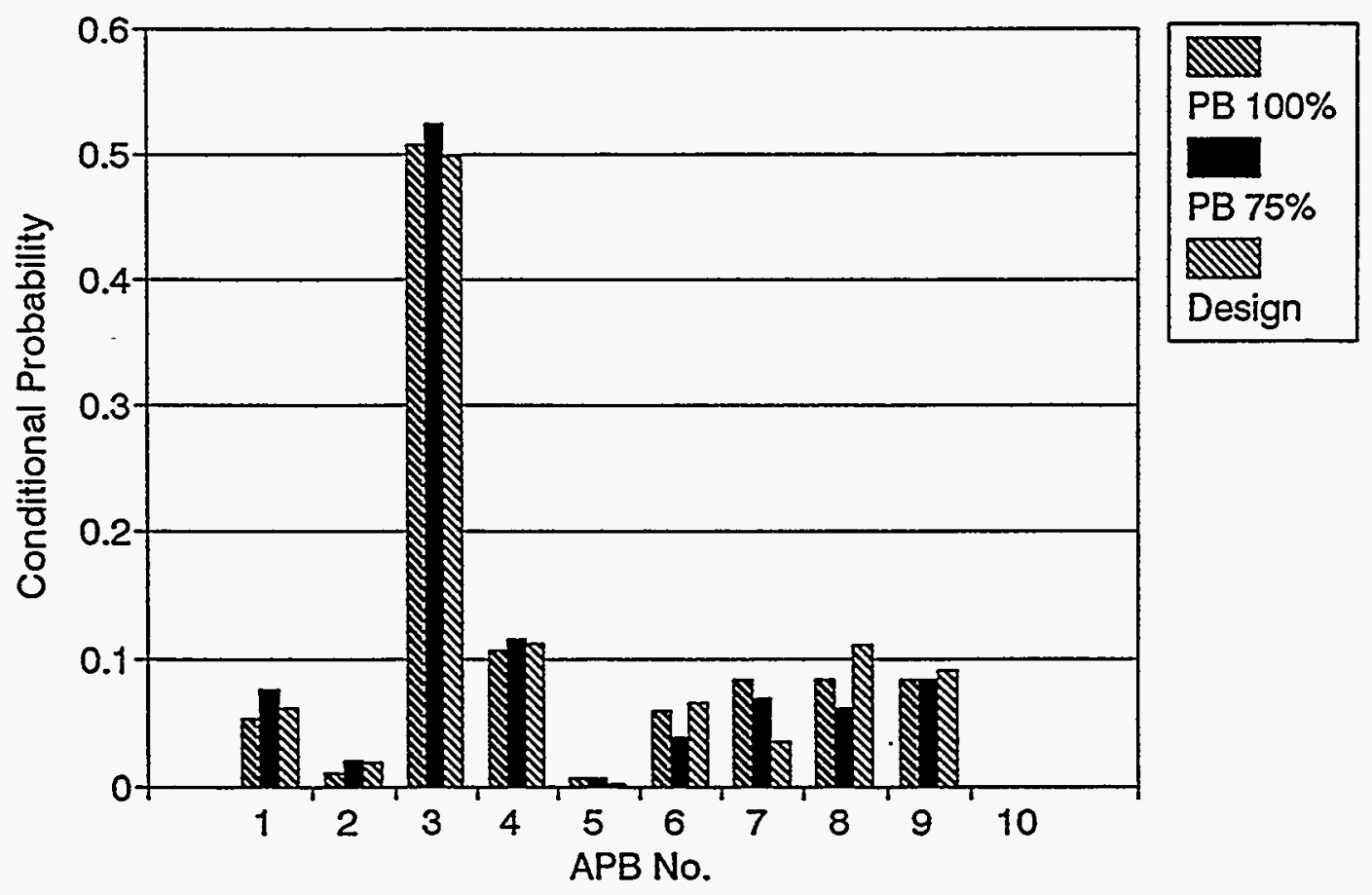

Figure 5-5 NMP/OC Design Condition Compared to PB 100\% and PB 75\% for PDS 5 


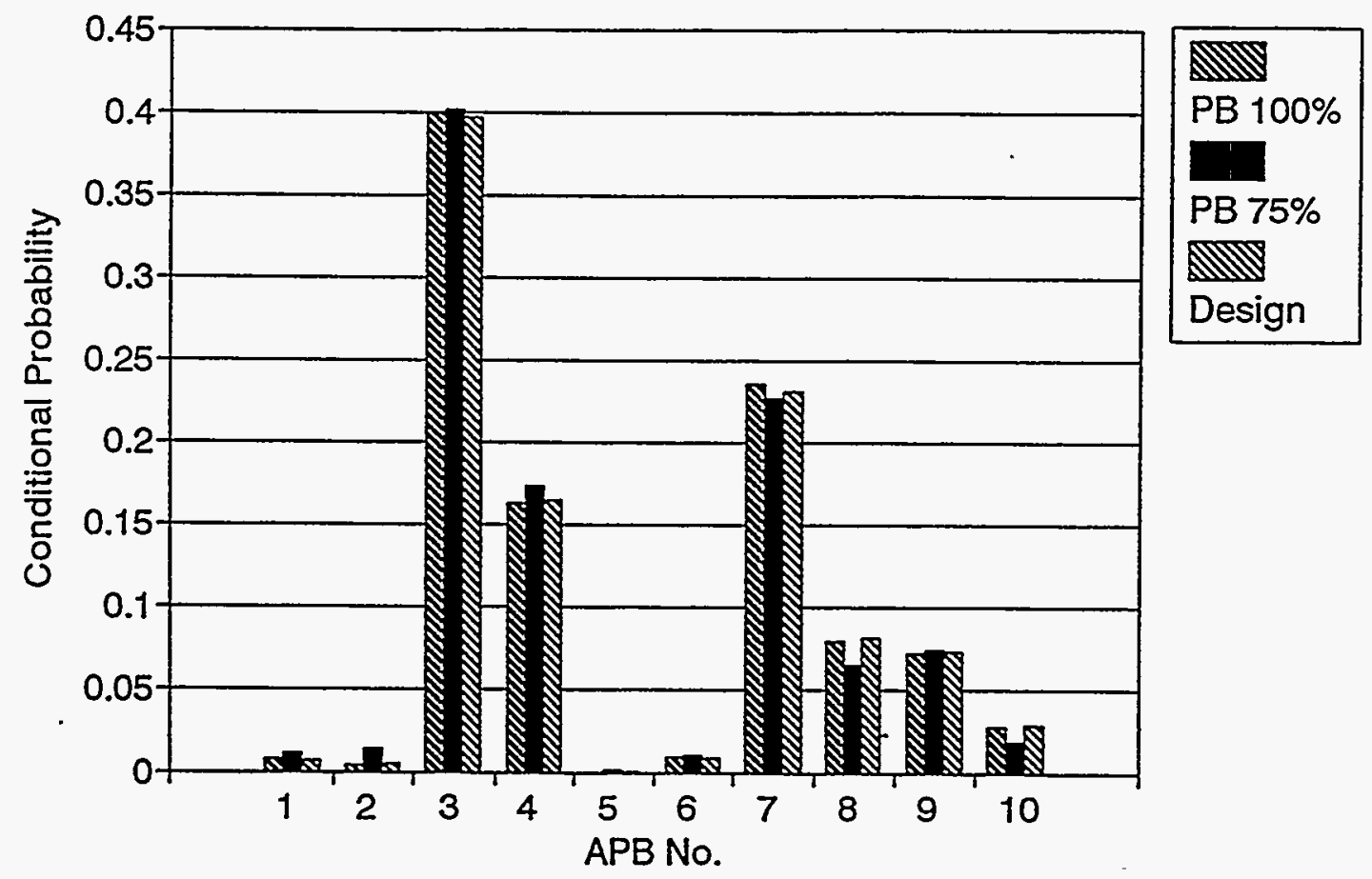

Figure 5-6 NMP/OC Design Condition Compared to PB 100\% and PB 75\% for PDS 9

$5-13$ 


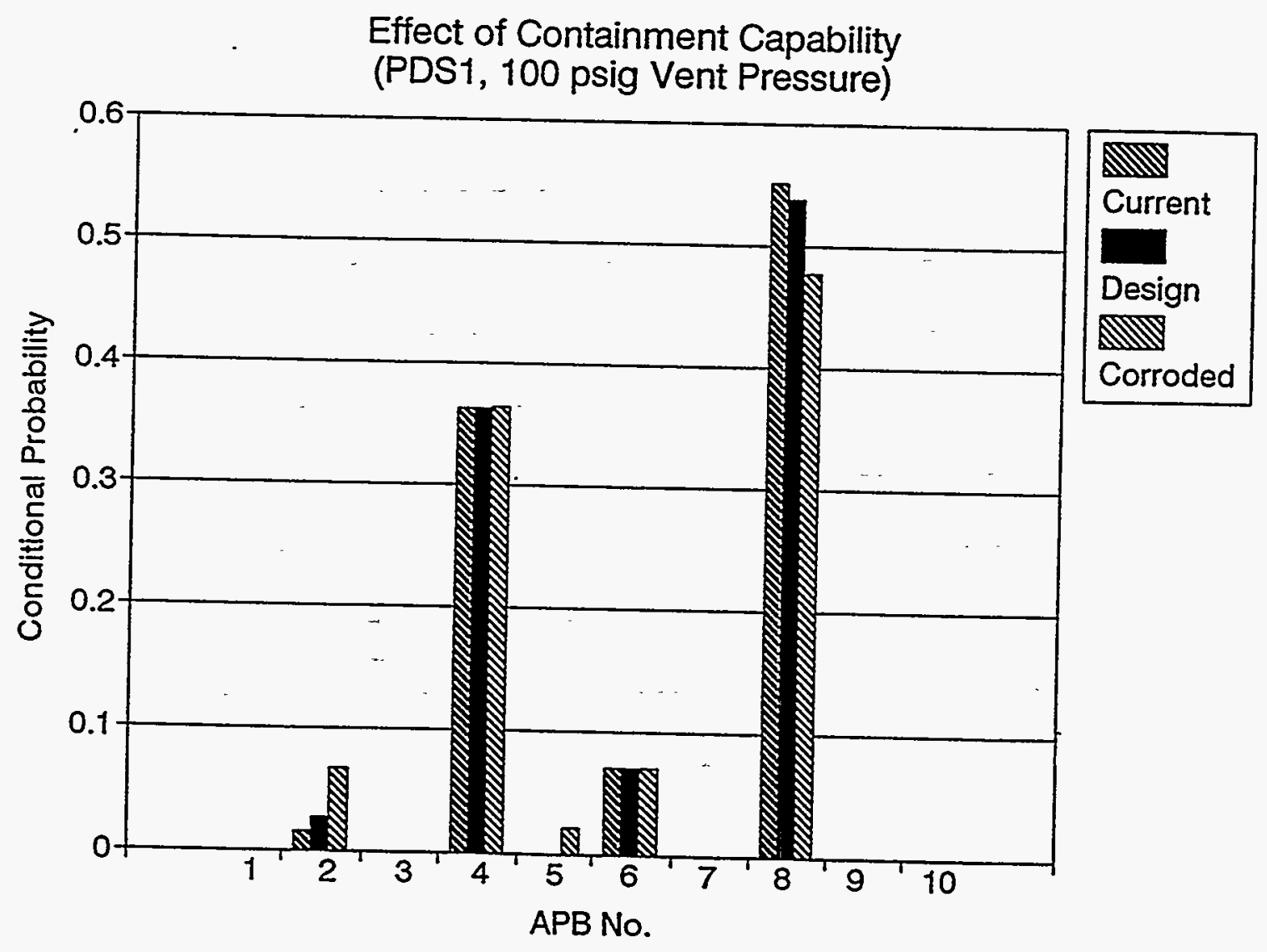

Figure 5-7 NMP/OC Comparison

5-14 


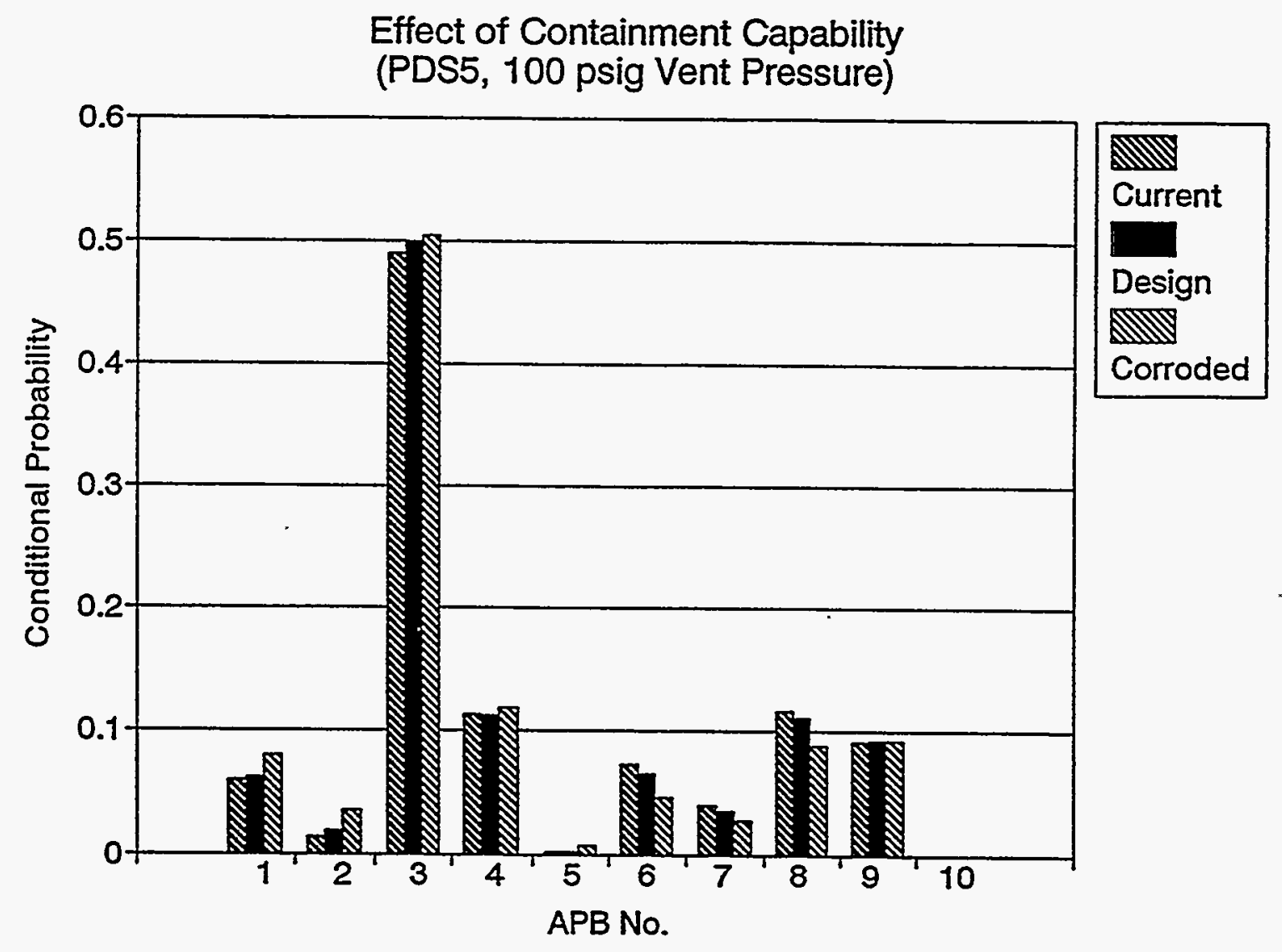

Figure 5-8 NMP/OC Comparison

5-15 


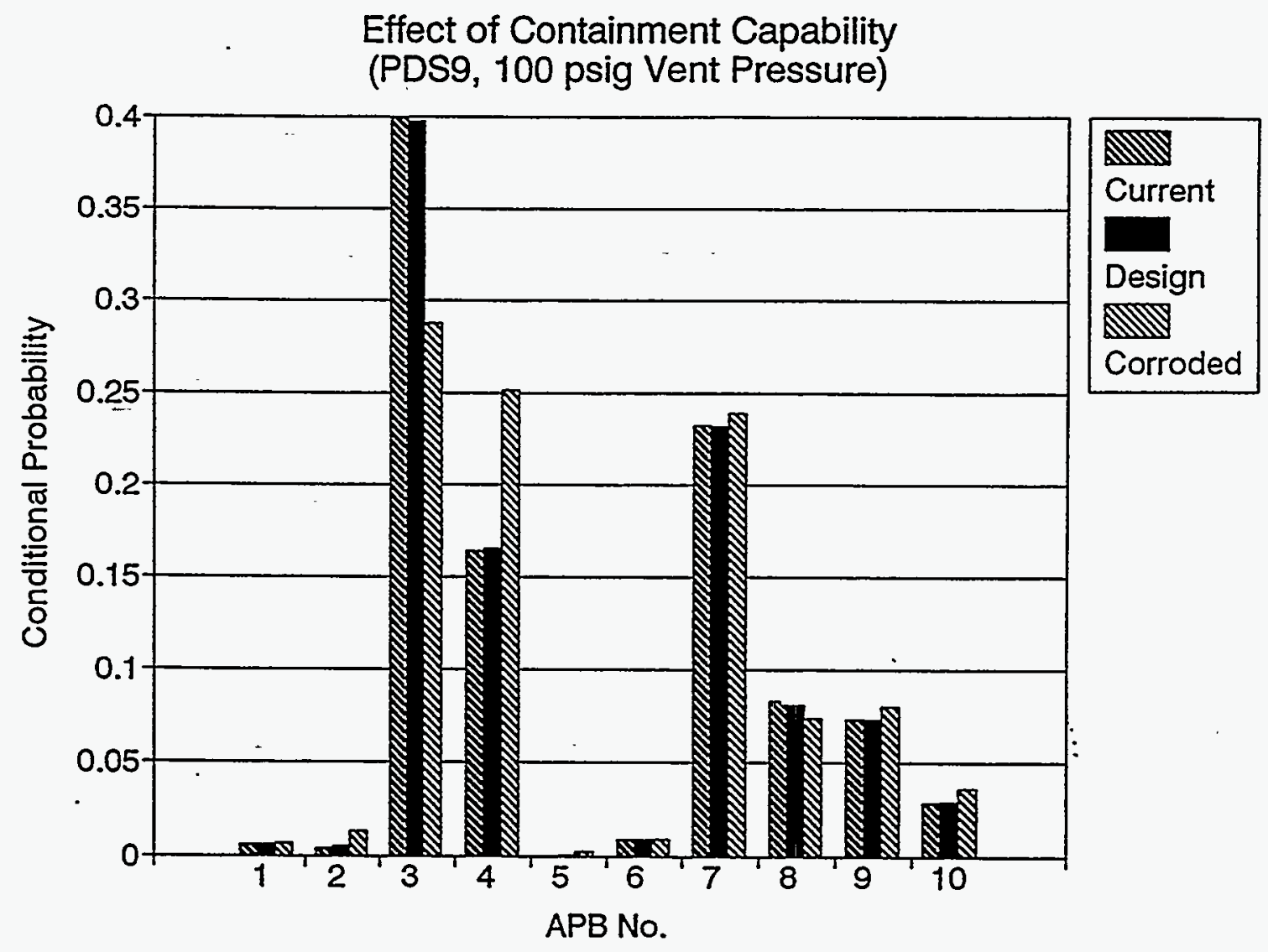

Figure 5-9 NMP/OC Comparison

$5-16$ 


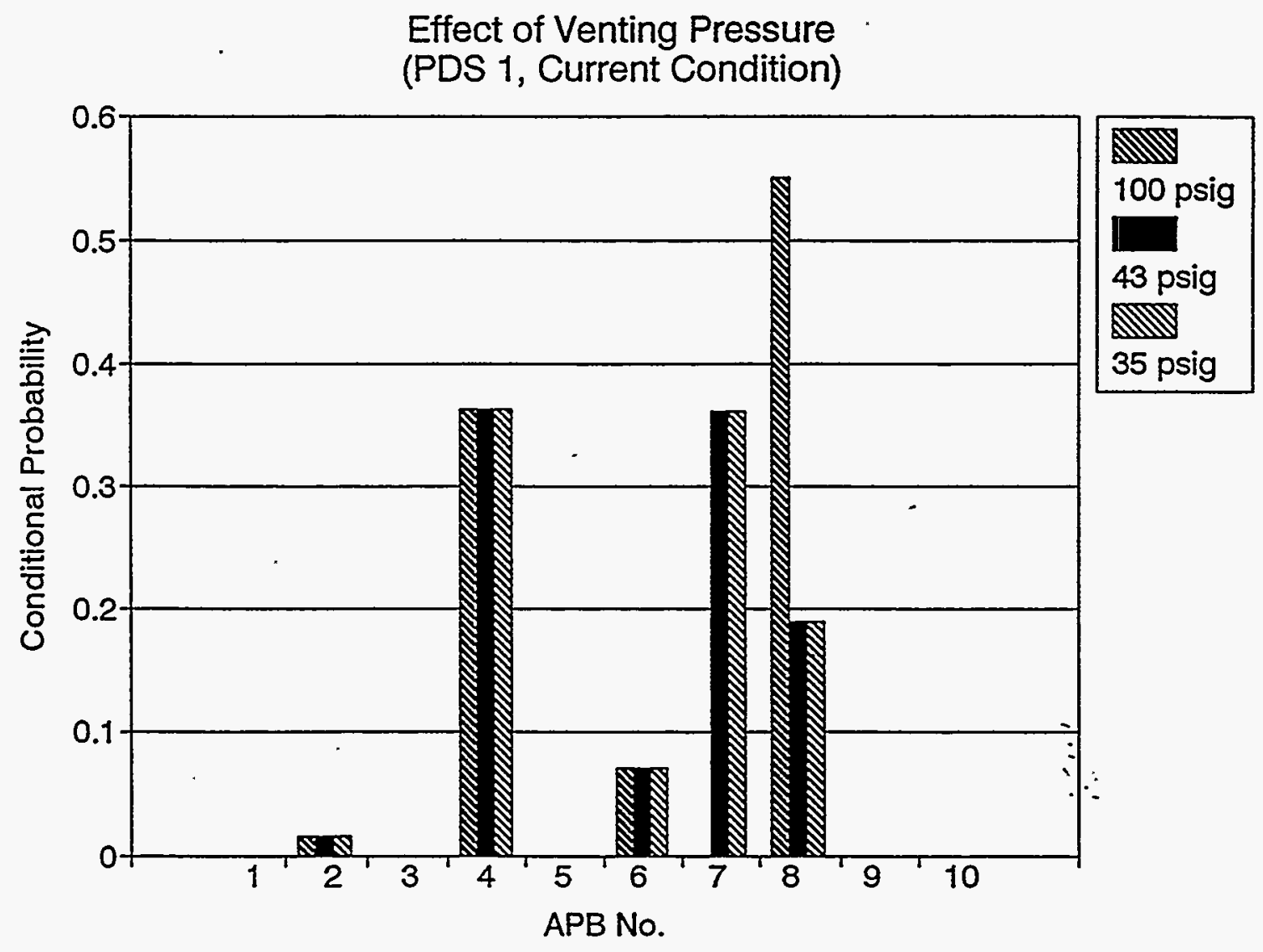

Figure 5-10 NMP/OC Model

5-17 


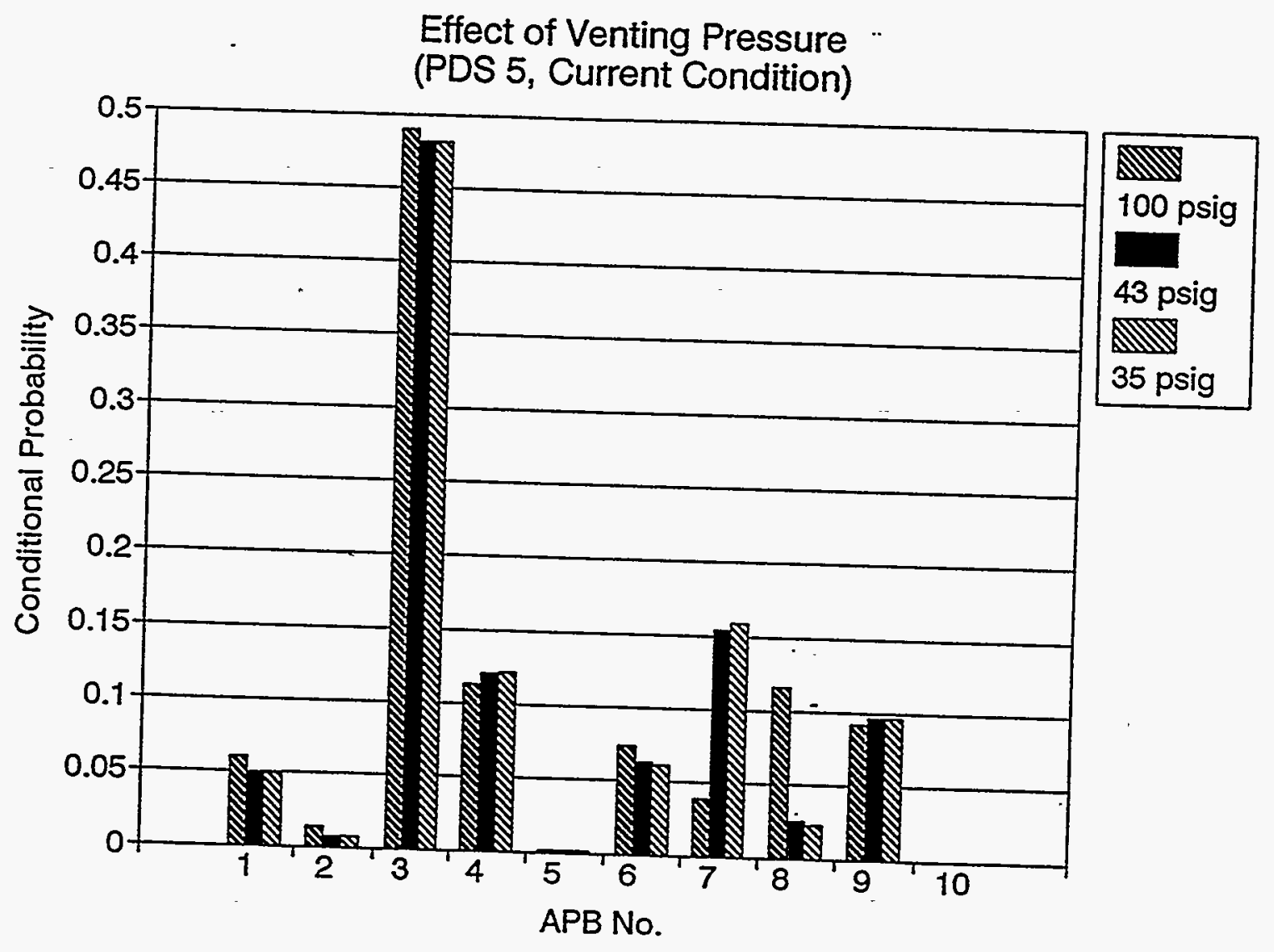

Figure 5-11 NMP/OC Model 


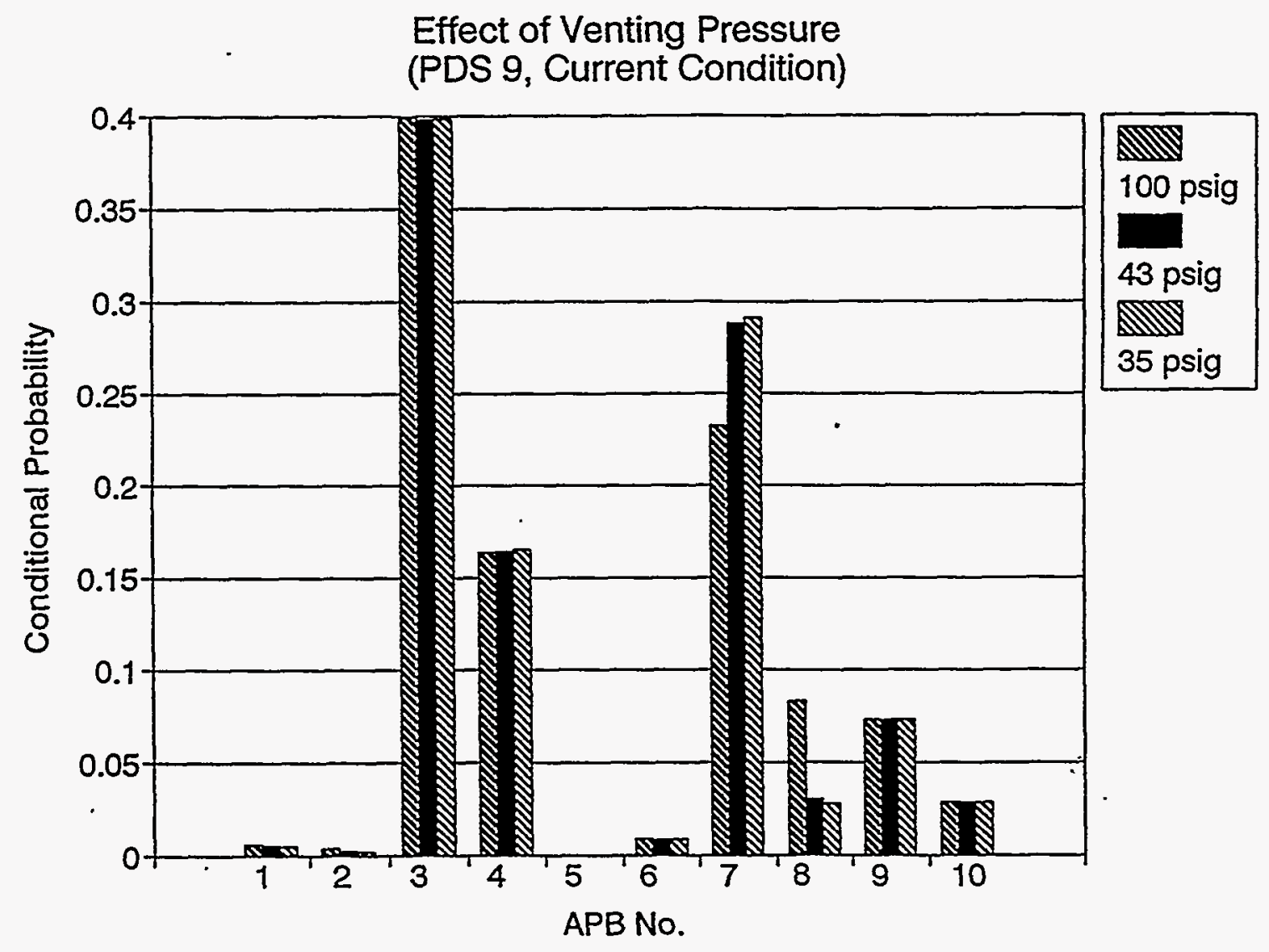

Figure 5-12 NMP/OC Model 



\section{CONCLUSIONS}

The results discussed in Section 5, and further documented in Appendix C, show that while the effect of containment degradation of the type postulated for Nine Mile Point 1 and Oyster Creek is noticeable, and for some PDS Groups significant, it is not dominant for the overall release profile.

There are a number of important failure modes for a Mark I containment which are unaffected by a reduction in containment pressure capability. The most significant of these is failure due to "liner melt-through" where the containment shell is attacked and penetrated by molten core debris flowing out of a breached vessel and across the drywell floor. This mode is a dominant contributor to the drywell failures of APBs 3 and 4 which play an important role in most of the PDS Groups for all the cases considered. Obviously containment pressure capability is irrelevant for this kind of failure. If liner melt-through failure is given less likelihood than is assigned in the NUREG-1150 type approach used here, pressure failures would become more important, and the effect of degradation on the overall release profile can be expected to be more significant.

Another failure mode which will not be significantly affected by degradation in containment pressure capability is that associated with direct containment heating or other over-pressurization resulting from a reactor vessel breach at high pressure. The containment pressures generated in such a scenario are likely to be so high that even the uncorroded containment will quickly fail and therefore degradation will not play a role.

Other scenarios, such as containmentbypass sequences and certain interfacing system LOCAs are unaffected by changes in containment pressure capability as well.

However, as the results of Section 5 also show, containment degradation will, in general, lead to a reduction in the "no containment failure" outcomes characterized by APB 8 , and this can be very significant for some PDS Groups. One such Group is PDS 1 (LOCA) shown in Figure 5-1 for PB and in Figure 5-7 for NMP/OC.

To show the reduction in no containment failure outcomes, i.e. increase in containment failure, the fractional change in the no containment failure (NCF) probability of APB 8 is shown for the nine PDS Groups in Figure 6-1 for Peach Bottom. The figure shows that the NCF probability for the PB $75 \%$ condition is, on average only about $80 \%$ of what it is for the PB $100 \%$ condition. That is, the conditional probability of NCF at a containment pressure capability of $75 \%$ divided by the conditional probability of NCF at $100 \%$ pressure capability is 0.8 . For the PB $63 \%$ condition the NCF probability is only about $50 \%$, on average, of what it is at the $100 \%$ capability.

Figure 6-2 shows this same ratio for the NMP/OC model across the nine PDS Groups. Here the reductions are less dramatic since the corrosion is not as severe as that hypothesized for Peach Bottom. The design and current conditions assign an-almost identical conditional probability to $\mathrm{NCF}$, while the corroded condition results in a reduction 
in NCF, on average, to about $85 \%$ of the probability at the current condition. The most significant drop is shown for PDS Group 5 (Slow SBO) where the NCF for the corroded condition is lowered to about 75\% of the current value. However, as shown in Figure 5-8, the actual conditional probability of NCF is small for both conditions, i.e. .116 for the current and .089 for the corroded condition. As noted above, if the liner melt-through failures were assigned a smaller likelihood these conditional probabilities would be expected to be bigger and change more significantly.

Another observation that can be made based on the results of Section 5 is that lower containment venting pressures do not influence the failure probabilities very much, but can increase releases because most of the vented sequences with the 43 and 35 psig venting pressures would have been no containment failure sequences if a higher (100 psig) venting pressure were used. This is indicated by Figures 5-10, 5-11, and 5-12.

In summary, it appears that based on this limited study, for the Mark I containments investigated, the degradation postulated can be significant for certain scenarios but does not cause a major change in containment performance under severe accident conditions. 
Fractional Change of No Containment

Failure Probability for Various PDSs

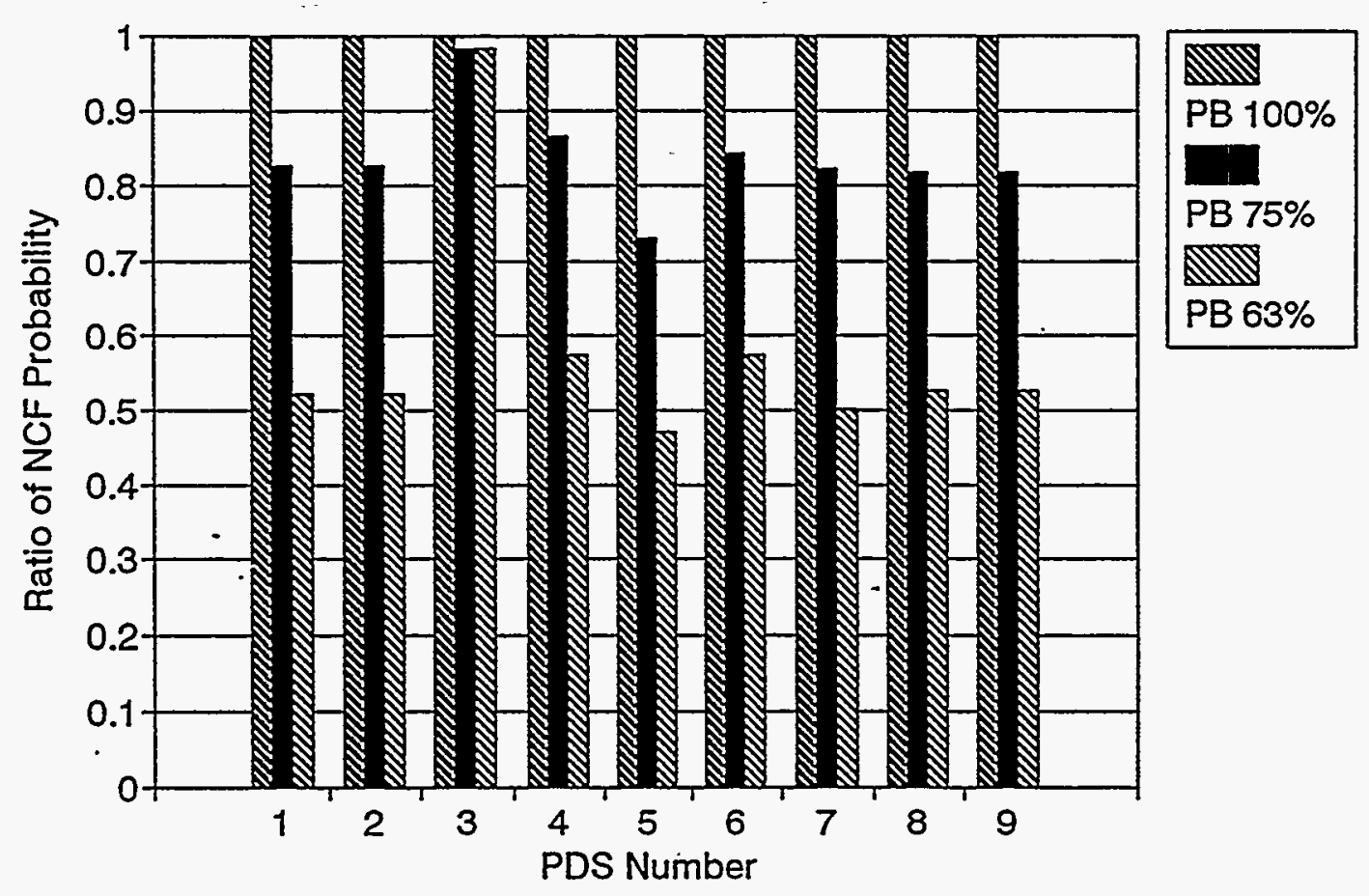

Figure 6-1 Peach Bottom Model

$6-3$ 
Fractional Change of No Containment

Failure Probability for Various PDSs

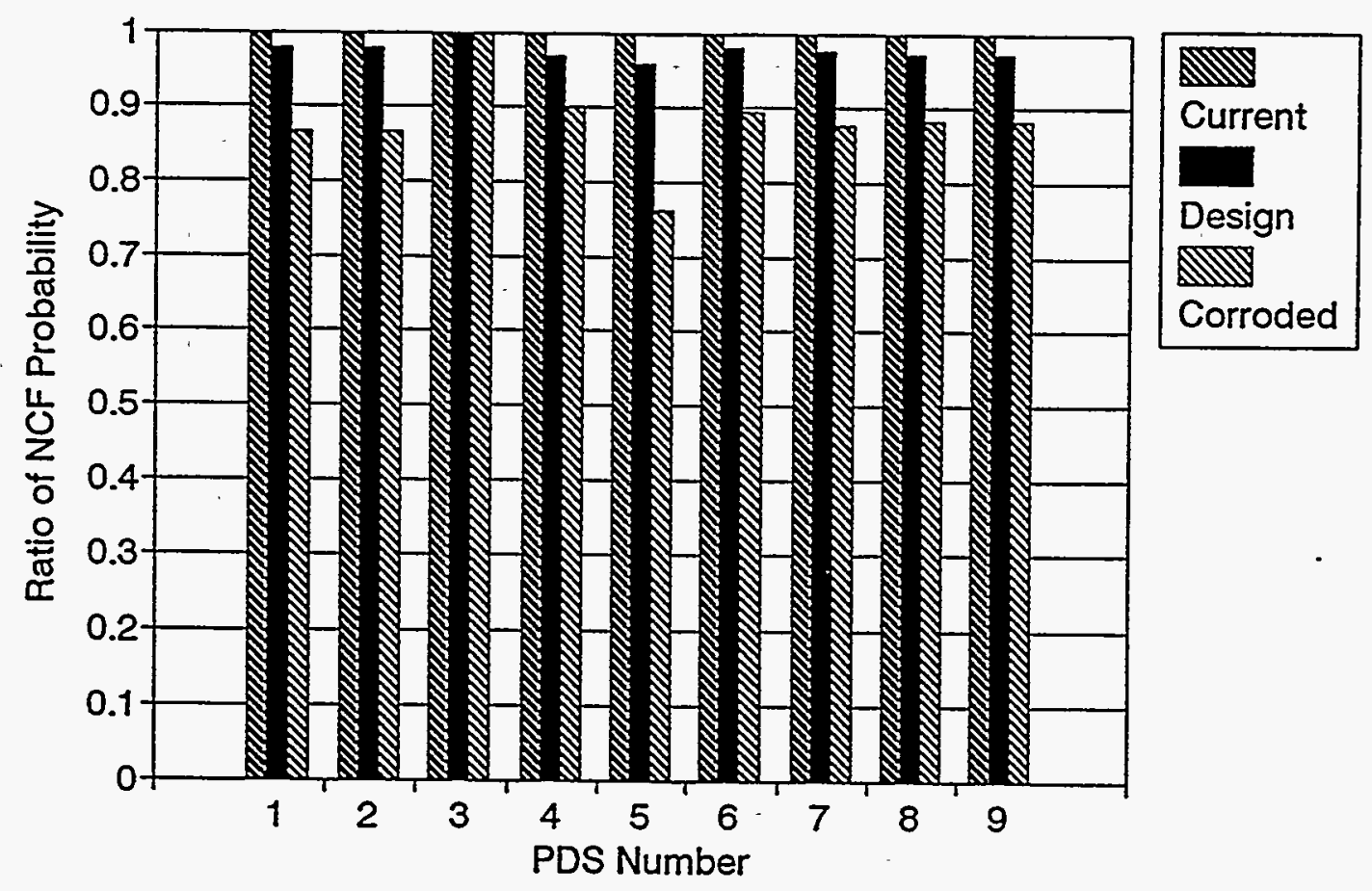

Figure 6-2 NMP/OC Model

6-4 


\section{APPENDIX A}

\section{Containment Structural Analysis}

\section{A.1 INTRODUCTION}

To provide the required input for the accident analyses of the three (3) defined condition states, it was necessary to estimate the range of failure pressure for thirty-six distinct cases:

3 states $\times 2$ temperatures $\times 6$ failure modes $=36$ cases

The estimated failure pressures are listed in Tables 4-4 through 4-6 of the report.

The failure pressure estimates are based on a combination of hand calculations, computer analysis using the BOSOR4 and BOSOR5 programs, and scaling of calculated results to account for thickness and/or yield stress variations. modes:

Certain assumptions were made in defining the three condition states and the failure

1. Because they are easily replaced at each refueling outage if evidence of degradation is found, the head flange bolt and 0-ring seal properties are assumed to be the same for all three condition states; i.e., the same range of failure pressure for the Drywell Head Flange Leak (DWHL) is assigned to all three condition states.

2. The Vent Line Expansion Bellows was initially selected as a candidate location for the Wetwell Leak above the Waterline (WWLaW), based on a preliminary BOSOR4 analysis of the bellows. However, leakage through expansion bellows was not addressed in the Peach Bottom Study. Therefore, this location was eliminated from further consideration, in order to maintain consistency between this analysis and the Peach Bottom Study.

As part of the NRC Containment Integrity Program, expansion bellows were recently tested to determine their behavior at extreme pressure and extension/compression. Based on a preliminary understanding of these results, it appears that undegraded expansion bellows are not candidate locations for containment leaks. However, this data should be studied in greater detail, to assess whether the effects of degraded bellows should be considered in subsequent accident analysis.

3. The Postulated Corroded Condition is hypothetical and was included to assess the sensitivity of the release profile to a significant reduction in containment shell thickness. As discussed in Chapter 4 of the report, the failure pressures 
were defined as $75 \%$ of the failure pressures estimated for the Current Condition. This corresponds approximately to a $25 \%$ reduction in shell thickness. As discussed in (1) above, this does not apply to the DWHL mode of failure.

4. In defining the shell thicknesses for the Current Condition, the minimum reported shell thickness in each region of the containment was assumed to be the uniform thickness of the region. No corrosion was reported for the Drywell elliptical head or transition knuckle. Consequently, the nominal design thicknesses were assumed for these regions.

A detailed discussion of the analysis methodology is presented only for the AsDesigned Condition. For the Current Condition, the evaluation of the corroded sandbed region of the drywell is included. No further discussion of the Postulated Corroded Condition is required.

\section{A.2 COMPUTER ANALYSES CONDUCTED}

Since the overall MARK I Containment geometry is axisymmetric, it was possible to evaluate the pressure capacity by primarily utilizing closed form solutions and axisymmetric shell computer models. Two of the most versatile and widely-used computer codes for axisymmetric shells are BOSOR4 for elastic analysis and BOSOR5 for elastic-plastic analysis. These codes were originally developed in the late 1960's and early 1970's by Dr. David Bushnell of Lockheed Applied Mechanics Laboratory, Palo Alto, CA, and have been enhanced to improve usability over the past twenty years. These computer programs were obtained directly from Dr. Bushnell and installed on BNL's VAX 780, for use on a different project. The installation at BNL was verified by execution of an extensive sample problem set provided with the program. The analyst who conducted the BOSOR4 and BOSOR5 analyses of the MARK I Containment has ten years previous experience with these computer codes.

The following computer analyses were conducted utilizing BOSOR4 and BOSOR5 in support of the evaluation of containment pressure capacity:

\section{BOSOR4 Elastic Analysis}

- Detailed Analysis of Bolted Head Flange Connection for Pre-load and Internal Pressure

- Overall Analysis of Drywell Shell for As-Designed Thicknesses; Internal Pressure Loading

- Overall Analysis of Drywell Shell for Current Thicknesses, including changes in the Sandbed region; Internal Pressure Loading 
- Analysis of Ventline Expansion Bellows for Internal Pressure and Axial Displacement (not used in final evaluation)

- Overall Analysis of Wetwell Shell (based on Toroidal Geometry) for AsDesigned Thickness; Internal Pressure Loading and Uniform Temperature Rise

- $\quad$ Analysis of Wetwell Shell between Ring/Saddle Supports (based on Cylinder Geometry) for As-Designed Thickness; Internal Pressure Loading

BOSOR5 Elastic-Plastic Analysis

- Detailed Analysis of the Drywell Transition Knuckle for As-Designed Thicknesses and Lower Bound Stress-Strain Properties; Internal Pressure Loading

- Analysis of Wetwell Shell between Ring/Saddle Supports using a Cylinder Model, for Current Median Stress-Strain Properties; Internal Pressure Loading

\section{A.3 CONTAINMENT FAILURE MODES}

In the Peach Bottom Study, ten (10) failure modes were originally specified. In addition to the six (6) investigated here, the following four (4) failure modes were initially considered:

- Catastrophic Drywell Rupture (CDWR)

- $\quad$ Catastrophic Wetwell Rupture (CWWR)

- Wetwell Leak below Waterline (WWLbW)

- Wetwell Rupture above Waterline (WWRaW)

Based on the responses of the three experts solicited for the Peach Bottom Study, the CDWR and CWWR failure modes were perceived to be either redundant DWR and WWR failure modes or unimportant because of extremely high failure pressures. Consequently, these two (2) failure modes were not considered in this present study.

Based on their relative importance in the accident analysis of the three condition states, BNL selected only the WWRbW and WWLaW failure modes for the Wetwell, instead of considering all four (4) Wetwell failure modes originally specified in the Peach Bottom Study. The two failure modes selected for the present study were judged to adequately represent the contribution of wetwell failure to the radioantive releace nrnfile

\section{A.3.1 Containment Rupture Modes}

Containment shell rupture is postulated in three (3) regions: 
- $\quad$ Drywell Elliptical Head (DWHR)

- Drywell Cylinder/Sphere (DWR)

- Wetwell Torus below Waterline (WWRbW)

Rupture is associated with a relatively large area of excessive membrane stress (strain) caused by internal pressure loading. In ASME Section III terminology, this stress would be categorized as a General Primary Membrane Stress. In design calculations it would typically be limited to the lesser of $2 / 3$ times the code-specified yield strength or $1 / 3$ times the code-specified tensile strength. Therefore, it is evident that the containment design pressure is an unrealistically conservative estimate of the containment failure pressure.

A201 and A212 are carbon-silicon steels; in specimen tests they exhibit a fairly welldefined yield point, followed by a region of almost "perfectly plastic" behavior up to 3-5\% strain, and then significant strain hardening up to a tensile strength of approximately twice the yield strength, at about $25 \%$ strain. These materials are extremely ductile, providing a very significant design safety margin.

For the purpose of this study, a limit of $3 \%$ general membrane strain was imposed as a "rupture" criterion. Up to $3 \%$ membrane strain, these materials behave essentially elastic/perfectly plastic; once the yield pressure is attained, only a minor increase in pressure capacity is achievable at $3 \%$ membrane strain. For all practical purposes, the yield pressure is the "rupture" pressure, unless a secondary pressure-resisting structure restricts the radial expansion to less than $3 \%$ membrane strain.

For the drywell cylinder/sphere, the reinforced concrete biological shield wall completely encases it the 3 inch gap between drywell shell and shield wall corresponds to a $1.5 \%$ radial strain in the cylindrical region and $0.7 \%$ radial strain in the spherical region. Consequently, the prediction of rupture pressure for the drywell cylinder/sphere is based on the combined capacity of the drywell shell at yield stress and of the reinforced concrete biological shield wall at yielding of the hoop direction rebar.

"Rupture" pressure predictions for the Drywell Elliptical Head and the Wetwell Torus Shell are directly correlated with calculated yield pressures, since no secondary structural elements provide additional pressure capacity. For an elliptical head subject to internal pressure, there is a region of hoop compressive membrane stress above the flanged end. The potential for shell buckling exists in this area. However, based on prior calculations for Mark I containments, it was concluded that local shell buckling occurs at pressures higher than the yield pressure. Therefore, it is not the controlling rupture mode in this study. However, if a strain limit greater than $3 \%$ had been specified as a "rupture" criterion, such that significantstrain hardening behavior was permissible, then local inelastic shell buckling would be the controlling rupture mode for the drywell elliptical head.

The ventlines between the drywell and the wetwell were also considered for containment rupture. However, preliminary calculations indicated that the ventline rupture 
pressure would exceed both the Drywell Rupture Pressure (DWR) and the Wetwell Rupture Pressure (WWRbW). Based on this initial assessment, no additional analysis of the ventlines was conducted.

\section{A.3.2 Containment Leak Modes}

Containment leaks are postulated at three (3) locations:

- Drywell Head Flange (DWHL)

- $\quad$ Drywell Transition Knuckle (DWL)

- Wetwell above the Waterline (WWLaW)

Leaks develop either by loss of sealing at the Head Flange or by localized breeches of containment at locations of high combined membrane plus bending stress. Based on a BOSOR4 elastic analysis of the drywell shell, the highest such stress occurs at the transition knuckle between the cylindrical and spherical regions of the drywell, on the spherical shell side of the junction. Local yielding would initiate at relatively low pressure. In the wetwell, the periodic stiffening rings at each saddle support provide significantconstraint to the shell, leading to high local bending stresses in the shell. For the purpose of this study, a limit of $5 \%$ surface strain was imposed as a "leak" criterion. The selected locations for the Drywell Leak (DWL) and Wetwell Leak above Waterline (WWLaW) were both analyzed using BOSOR5 to evaluate the relationship between internal pressure and local surface strain.

A leak of the Drywell Head Flange (DWHL) is expected when the internal pressure is sufficiently high to first overcome bolt preload and then to stretch the bolt an amount just greater than the rebound capability of the $O$-ring seal. The pressure required to overcome bolt preload can be calculated in a straightforward manner. However, the additional pressure required to cause a leak at the head flange is difficult to predict because of the large uncertainty associated with seal rebound behavior.

It is noted that there are major access penetrations, ventline penetrations, and primary piping penetrations in the drywell. These reinforced openings are potential locations for the development of a drywell leak. In addition, leaks may develop around access hatches at high internal pressure. The evaluation of these structural details is beyond the scope of this study. However, previous evaluations of Mark I containments have concluded that the penetrations are conservatively designed and are not considered the likely location of first failure. Also, as noted in A.1, expansion bellows have been eliminated from consideration as potential leak locations.

\section{A.4 EVALUATION OF AS-DESIGNED CONDITION}

The containment geometry, shell thicknesses and material strength properties are presented in the Chapter 4 Tables and Figures. Additional dimensional data, such as lengths and radii, will be specified where used. 


\section{A.4.1 Drywell Head Rupture (DWHR) Evaluation}

The drywell head is a 2:1 ellipse with major radius equal to $198^{\prime \prime}$. The maximum general membrane stress due to internal pressure occurs at the apex (axis of revolution). From the BOSOR4 elastic analysis of the drywell, the General Membrane Stress at the apex for 100 psi internal pressure is:

$$
\sigma_{M}=16,675 p s i
$$

The range of failure pressure, based on the as-designed material yield strengths from Table 4-2 is:

\begin{tabular}{|c|c|c|c|c|c|}
\hline & $300^{\circ} \mathrm{F}$ & & $\underline{800^{\circ} \mathrm{F}}$ & & \\
\hline & Ire (psi) & & & re (psi) & \\
\hline Lower & Median & Upper & Lower & Median & Upper \\
\hline 202 & 242 & 282 & 152 & 182 & 212 \\
\hline
\end{tabular}

To account for other uncertainties, such as minor strain hardening effects up to $3 \%$ membrane strain, the median prediction is increased by $5 \%$ and the upper prediction is increased by $10 \%$.

The final estimated failure pressures, as listed in Table 4-4, are:

$\underline{300^{\circ} \mathrm{F}}$

Pressure (psi)

Lower Median

202
254
Upper

310

\section{$\underline{800^{\circ} \mathrm{F}}$}

Pressure (psi)

Lower

Median

Upper

152

191 


\section{A.4.2 Drywell Rupture (DWR) Evaluation}

Two regions of the drywell were evaluated to estimate the rupture pressure. The first is the cylindrical region, with radius equal to $198^{\mathrm{n}}$ and the second is the upper spherical region, with radius equal to $420 "$. The maximum General Membrane Stress for 100 psi internal pressure, based on either closed form solution or the BOSOR4 analysis is:

$$
\text { Cyl: } \quad \sigma_{\mathrm{M}}=30,940 \mathrm{psi}
$$

Sphere: $\sigma_{M}=29,085$ psi

The range of failure pressure, based on the as-designed material yield strengths from Table 4-2 is:

\begin{tabular}{|c|c|c|c|c|c|c|}
\hline & & $\underline{300^{\circ} \mathrm{F}}$ & & . & $\underline{800^{\circ} \mathrm{F}}$ & \\
\hline & & Ire (psi) & & & Pressure & \\
\hline & Lower & Median & Upper & Lower & Median & Upper \\
\hline Cyl: & 109 & 131 & 153 & 82 & 98 & 114 \\
\hline Sphere: & 116 & 139 & 162 & 87 & 104 & 122 \\
\hline
\end{tabular}

As discussed in A.3.1, additional pressure resistance is provided by the reinforced concrete biological shield wall, which is separated from the drywell shell by a 3 inch gap.

The pressure resistance capacity is calculated based on yielding of the steel reinforcement in the hoop direction. No credit is taken for the concrete strength. Based on the design parameters for a representative Mark I Biological Shield Wall, the following additional pressure resistance was estimated:

\section{$\underline{300^{\circ} \mathrm{F}} \quad \underline{800^{\circ} \mathrm{F}}$}

Pressure (psi) $\quad$ Pressure (psi)

$\begin{array}{lllllll} & \text { Lower } & \text { Median } & \text { Upper } & \text { Lower } & \text { Median } & \text { Upper } \\ \text { Cyl: } & 110 & 140 & 170 & 85 & 105 & 125 \\ \text { Sphere: } & 125 & 155 & 185 & 95 & 115 & 135\end{array}$


Combining the shell and shield wall resistances, the final estimated failure pressures are:

\begin{tabular}{|c|c|c|c|c|c|c|}
\hline & & $300^{\circ} \mathrm{F}$ & & & & \\
\hline & Pres & Ire (psi) & & & re (psi) & \\
\hline & & Median & Upper & Lower & Median & Upper \\
\hline Cyl: & 219 & 271 & 323 & 167 & 203 & 239 \\
\hline Sphere: & 241 & 294 & 347 & 182 & 219 & 257 \\
\hline
\end{tabular}

The cylinder results are listed in Table 4-4 for DWR.

\section{A.4.3 Wetwell Rupture (WWRbW) Evaluation}

The "toroidal" suppression chamber is actually an assemblage of cylinders with mitered joints at the ring stiffener/saddle support locations. The major radius of the "torus" is $740^{\prime \prime}$; the cylindrical radius is $162^{\prime \prime}$; the axial length of the cylinders between stiffening rings is $232^{\prime \prime}$. Two different axisymmetric elastic models were used to analyze the wetwell:

- equivalent torus model

- cylinder model between ring stiffeners

From the cylinder model, the maximum general membrane stress (in the cylinder hoop direction) for $100 \mathrm{psi}$ internal pressure is:

$$
\sigma_{M}=35,220 \mathrm{psi}
$$

From the equivalent torus model, the maximum general membrane stress (in the torus meridional direction $=$ the cylinder hoop direction) for $100 \mathrm{psi}$ internal pressure is:

$$
\sigma_{M}=40,150 \mathrm{psi}
$$

which occurs on the horizontal centerline at $r=740^{\prime \prime}-162^{n}=578^{n}$.

The waterline is below the horizontal centerline. To drain the torus, the rupture would have to occur near the bottom. At the bottom, the equivalent torus model predicts the same general membrane stress as the cylinder model. Therefore, to account-for the 
effect of the toroidal geometry on the general membrane stress, and at the same time considering that the postulated rupture location is near the bottom, an average of the two stresses listed above is assumed at the rupture location $[(35,220+40.150) / 2=37,685 \mathrm{psi}]$ for 100 psi internal pressure. This represents a $7 \%$ increase over the cylinder model prediction.

An elastic-plastic analysis utilizing BOSOR5 was conducted for the cylinder model. Based on the VonMises Yield Criterion and the lower As-Designed Yield Strength, the onset of membrane yielding occurs at 92 psi. The elastic-plastic solution remained stable up to 5\% membrane strain, at which point the analysis was terminated. At this strain a large radial deflection $\left(\approx 7^{*}\right)$ develops at midbay between the stiffening rings; because of nonlinear geometric effects, there is an effective stiffening which the cylinder axial direction provides to the cylinder hoop direction. Interpolation of the results for successive pressure increments yields a pressure at $3 \%$ membrane strain equal to 107 psi.

To account for the effect of toroidal geometry, discussed above, it is necessary to reduce the $107 \mathrm{psi}$ prediction from the cylinder model by $7 \%$. The final estimated lower bound failure pressure for the As-Designed Condition is then $100 \mathrm{psi}$.

The failure pressures for the median and upper bound were estimated based on the yield strengths from Table 4-2. Only the $300^{\circ} \mathrm{F}$ temperature state is needed for the wetwell. The values of failure pressure, as listed in Table 4-4 are:

\section{$\underline{300^{\circ} \mathrm{F}}$}

Pressure (psi)

$\begin{array}{lll}\text { Lower } & \text { Median } & \text { Upper } \\ 100 & 118 & 136\end{array}$

\section{A.4.4 Drywell Head Flange Leak (DWHL)Evaluation}

In order to estimate the range of pressures which would initiate a leak at the bolted head flange assembly, a series of BOSOR4 elastic analyses were conducted. The objective of the analyses was to determine the local deformation of the bolted flange assembly, and the pressure at which loss of sealing occurs for different assumed percentages of seal rebound. The model is axisymmetric; the bolts are represented by an equivalent orthotropic cylinder with only axial extensional and bending stiffness. The stiffener plates attached to the drywell shell are "smeared" to create an orthotropic material, stiffened in the axial direction. The techniques employed are common to analyses of such assemblies. Bolt preload is applied by imposition of a fictitious temperature decrease in the bolt cylinder; its magnitude is determined by iteration to produce the desired axial tension. Then a series 
of analyses for internal pressure are executed, iterating on the point of contact just prior to separation of the sealing surfaces. Then the separation of the sealing surfaces at the O-ring locations is determined as internal pressure is increased.

Table 4-3 provides key data for the bolts and O-ring seals. The initial $92,000 \#$ bolt preload applied at room temperature is reduced to $88,000 \#$ at $300^{\circ} \mathrm{F}$ and $76,000 \#$ at $800^{\circ} \mathrm{F}$ due to temperature dependent decrease in the Modulus of Elasticity. Because the coefficients of thermal expansion for the drywell shell and bolt materials are well matched, there is only negligible change in bolt preload due to differential thermal expansion at elevated temperatures.

The pressures at which leaks are estimated to occur are well below the pressure which would initiate yielding of the bolts. Therefore, bolt yielding is not a consideration in this evaluation.

Based on the results of the analyses conducted, initial separation of the sealing surfaces is estimated to occur at $85 \mathrm{psi}$ for the $300^{\circ} \mathrm{F}$ case and $70 \mathrm{psi}$ for the $800^{\circ} \mathrm{F}$ case. Because of the approximations used in the analysis, a range of $\pm 10 \mathrm{psi}$ is assigned to the best estimate prediction. Therefore, for loss of preload, the following pressures were assumed:

\begin{tabular}{llllll} 
& \multicolumn{2}{c}{$\underline{300^{\circ} \mathrm{F}}$} & \multicolumn{2}{c}{$\underline{800^{\circ} \mathrm{F}}$} \\
& Pressure (psi) & \multicolumn{3}{c}{ Pressure (psi) } \\
Lower & Median & Upper & Lower & Median & Upper \\
75 & 85 & 95 & 60 & 70 & 80
\end{tabular}

Based on relative deformation between the sealing surfaces after loss of preload, the following additional pressure resistance is attributed to seal rebound:

$\begin{array}{lllll}\text { Seal Rebound (\%) } & 0 & 25 & 50 & 75 \\ \text { Pressure (psi) } & 0 & 45 & 85 & 125\end{array}$

Assuming the likely range of seal rebound is $25-75 \%$ for the $300^{\circ} \mathrm{F}$ case and $0 \%$ for the $800^{\circ} \mathrm{F}$ case, the final estimated leak pressures for the bolted flange assembly are: 
$\underline{300^{\circ} \mathrm{F}}$

Pressure (psi) $\underline{800^{\circ} \mathrm{F}}$

Pressure (psi)

Lower

Median

Upper

170

220

Lower

Median

120

220

60

70

Upper

80

These values are listed in Table 4-4, 4-5, and 4-6 for DWHL. As discussed in A.1, no degradation is assumed for this mode.

\section{A.4.5 Drywell Leak (DWL) Evaluation}

A BOSOR4 elastic analysis of the Drywell, for internal pressure loading, indicated that the highest local bending stress and local membrane stress occur at the juncture of the toroidal knuckle with the spherical shell below. Localized yielding is initiated below 100 psi.

Plastic deformation at the juncture will be limited by the presence of the Concrete Shield Wall only $3^{\prime \prime}$ from the shell. Consequently, it is not likely that a rupture would develop at this location. However, localized failure is a possibility prior to the shell encountering the restraining effect of the shield wall. Therefore, a drywell leak is postulated to occur at this location.

Based on the results of a BOSOR5 elastic-plastic analysis of the transition region, the estimated range of pressures for leak initiation is:

\begin{tabular}{|c|c|c|c|c|c|}
\hline & $\underline{300^{\circ} \mathrm{F}}$ & & \multicolumn{2}{|c|}{$\underline{800^{\circ} \mathrm{F}}$} & \\
\hline \multicolumn{3}{|c|}{ Pressure (psi) } & \multicolumn{3}{|c|}{ Pressure (psi) } \\
\hline Lower & Median & Upper & Lower & Median & Upper \\
\hline 100 & 126 & 154 & 75 & 95 & 116 \\
\hline
\end{tabular}

The criterion used was $5 \%$ local surface strain at the juncture between the $0.722^{\prime \prime}$ spherical shell and the $2.5625^{n}$ toroidal transition knuckle. These values are listed in Table 4-4.

The estimated pressures for $5 \%$ local surface strain are very close to the pressures which initiated general membrane yielding in the cylindrical and spherical regions of the drywell. 


\section{A.4.6 Wetwell Leak (WWLaW) Evaluation}

A leak in the wetwell is assumed to occur at a stiffening ring/saddle support location. The constraint imposed at these locations causes very high local bending stresses in the shell wall. The BOSOR5 elastic-plastic cylinder model assumes complete radial and rotational constraint at the stiffening ring/saddle support. Therefore, the local bending stresses predicted by the analysis are an upper bound. The 5\% local strain limit imposed as the "leak" criterion is reached at approximately 93 psi internal pressure, for the As-Designed Condition lower bound yield strength. Based on the yield strength range listed in Table 4-2 for the As-Designed Condition, the following failure pressures are estimated for the WWLaW mode:

$\begin{array}{lll} & & \underline{300^{\circ} \mathrm{F}} \\ & & \\ & \text { Pressure }(\mathrm{psi}) & \\ \text { Lower } & \text { Median } & \text { Upper } \\ 93 & 109 & 125\end{array}$

Only the $300^{\circ} \mathrm{F}$ case is considered for the wetwell.

\section{A.5 EVALUATION OF CURRENT CONDITION}

The estimated failure pressures for the Current Condition employ the same methodology utilized for the As-Designed Condition, with appropriate adjustment of thickness and yield strength as specified in Tables 4-1 and 4-2.

One additional evaluation - the sandbed region - was required to assess the effect of observed severe corrosion and subsequent remedial actions on the expected failure modes of the drywell. This evaluation is described below. ,

\section{A.5.1 Drywell Rupture (DWR) Evaluation}

Corrosion in the sandbed region at the bottom of the Drywell (see Figures 4-2 and 4-3) has been observed to reduce the shell thickness from a nominal 1.154" to $0.736^{\prime \prime}$ at the worst location. As part of the proposed remedial actions to eliminate future corrosion, the sand is to be removed, leaving a gap of approximately $15^{\mathrm{n}}$ between the shell wall and the concrete foundation mat. This evaluation examines the stress state in this region, considering the reduced thickness and the lack of a secondary structural restraint.

The evaluation assumes a uniform shell thickness of $0.736^{\prime \prime}$ over a meridional arc length of about $60^{\prime \prime}$ and completely around the circumference. This is a worst case scenario for the current corroded condition. A BOSOR4 elastic analysis was conducted of the 
Drywell using the shell thicknesses listed in Table 4-1 for the Current Condition. The General Membrane Stress in the sandbed region for 100 psi internal pressure is:

$$
\sigma_{\mathrm{M}}=28,530 \mathrm{psi}
$$

Based on the Current Condition Yield Strengths from Table 4-2, the range of failure pressures is:

\begin{tabular}{|c|c|c|c|c|c|}
\hline & $\underline{300^{\circ} \mathrm{F}}$ & \multicolumn{4}{|c|}{$800^{\circ} \mathrm{F}$} \\
\hline \multicolumn{3}{|c|}{ Pressure (psi) } & \multicolumn{3}{|c|}{ Pressure (psi) } \\
\hline Lower & Median & Upper & Lower & Median & Upper \\
\hline 142 & 158 & 173 & 107 & 119 & 130 \\
\hline
\end{tabular}

With a $15^{\prime \prime}$ gap created by removal of the sand, a $3.5 \%$ plastic strain would have to develop before the steel shell pressed against the adjacent concrete. Therefore, with the 3\% membrane strain limit, no secondary pressure resistance can be counted in this case.

To account for other uncertainties, such as minor strain hardening effects up to $3 \%$ membrane strain, the median prediction is increased by $5 \%$ and the upper prediction is increased by $10 \%$. The final estimated failure pressures for DWR for the Current Condition are:

$\underline{300^{\circ} \mathrm{F}}$

Pressure (psi)

Lower Median

142 166

Upper

Lower

$\underline{800^{\circ} \mathrm{F}}$

Pressure (psi)

From the BOSOR4 Drywell Analysis for the current condition, it was verified that the highest local stresses occur at the junction of the toroidal transition knuckle and the spherical shell below it. Therefore, the postulated location for drywell leak (DWL) does not change for the current condition

\section{A.6 EVALUATION OF POSTULATED CORRODED CONDITION}

The estimated failure pressures for all failure modes except DWHL were obtained directly from the Current Condition estimates, as discussed in A.1. 


\section{APPENDIX B}

\section{B.1 DEVELOPMENT OF CUMULATIVE PROBABILITY OF FAILURE VS PRESSURE DISTRIBUTION FOR EACH FAILURE MODE}

Previously calculated:

Estimate of pressure for 5\%, 50\% and 95\% Cumulative Probability of Failure (designated $\mathrm{p}_{.05}, \mathrm{p}_{5}, \mathrm{p}_{.95}$ ).

\section{Approximation 1:}

The shape of a representative cumulative probability of failure (CPF) curve can be approximated by a sixth order polynomial (see Figures $4-5$ through 4-10):

$$
\begin{array}{ll}
\mathrm{CPF}(\mathrm{x}) & =\mathrm{Ax}^{6}+\mathrm{Bx}^{5}+\mathrm{Cx}^{4}+\mathrm{Dx}^{3}+\mathrm{Ex}^{2}+\mathrm{Fx}+\mathrm{G} \\
\text { where } \mathrm{x} & =\left(\mathrm{p}-\mathrm{p}_{0}\right) /\left(\mathrm{p}_{1}-\mathrm{p}_{0}\right) \\
\mathrm{p}_{0} & =\mathrm{p} \text { at } \mathrm{CPF} \equiv 0 \\
\mathrm{p}_{1} & =\mathrm{p} \text { at } \mathrm{CPF} \equiv 1
\end{array}
$$

(Range of $x$ is 0 to 1 )

subject to the following conditions:

$$
\begin{aligned}
& \mathrm{CPF} \quad=0 \text { at } \mathrm{x}=0 \quad(\rightarrow \mathrm{G} \equiv 0) \\
& \mathrm{CPF} \quad=1.0 \text { at } \mathrm{x}=1.0(\rightarrow 1=\mathrm{A}+\mathrm{B}+\mathrm{C}+\mathrm{D}) \\
& \mathrm{d}(\mathrm{CPF})=0 \text { at } \mathrm{x}=0 \quad(\rightarrow \mathrm{F} \equiv 0) \\
& \mathrm{dx} \quad \text { at } \mathrm{x}=1.0(\rightarrow 0=6 \mathrm{~A}+5 \mathrm{~B}+4 \mathrm{C}+3 \mathrm{D}) \\
& \mathrm{d}^{2}(\mathrm{CPF})=0 \text { at } \mathrm{x}=0 \quad(\rightarrow \mathrm{E} \equiv 0) \\
& \frac{\mathrm{dx}^{2}}{\mathrm{dx}^{2}} \text { at } \mathrm{x}=1.0(\rightarrow 0=30 \mathrm{~A}+20 \mathrm{~B}+12 \mathrm{C}+6 \mathrm{D}) \\
& C P F=0.5 \text { at } x=x_{.5}=\frac{\left(p_{.5}-p_{0}\right)}{\left(p_{1}-p_{0}\right)} \\
& {\left[-0.5=A\left(x_{.5}\right)^{6}+B\left(x_{.5}\right)^{5}+C\left(x_{.5}\right)^{4}+D\left(x_{.5}\right)^{3}\right]}
\end{aligned}
$$

B-1 
Solving for A, B, C, D yields

$$
\begin{aligned}
& A=\left[.5-\left\{6\left(x_{s}\right)^{5}-15\left(x_{s}\right)^{4}+10\left(x_{s}\right)^{3}\right\}\right] /\left\{\left(x_{s}\right)^{6}-3\left(x_{s}\right)^{5}+3\left(x_{s}\right)^{4}-\left(x_{s}\right)^{3}\right\} \\
& B=6-3 A \\
& C=3 A-15 \\
& D=10-A
\end{aligned}
$$

\section{Approximation 2:}

To define $\mathrm{p}_{\mathrm{o}}$ and $\mathrm{p}_{1}$, it was assumed that

$$
\begin{aligned}
& x_{.95}=\frac{p_{.95}-p_{0}}{p_{1}-p_{0}}=0.8 \\
& x_{.05}=\frac{p_{.05}-p_{0}}{p_{1}-p_{0}}=0.2
\end{aligned}
$$

Solving for $\mathrm{p}_{\mathrm{o}}$ and $\mathrm{p}_{1}$ yields

$$
\begin{aligned}
& p_{0}=p_{.05}-1 / 3\left(p_{.95}-p_{.05}\right) \\
& p_{1}=p_{.95}+1 / 3\left(p_{.95}-p_{.05}\right)
\end{aligned}
$$

This approximation is based on a symmetric distribution, which reasonably fits the estimates of pressure for $5 \%, 50 \%, 95 \%$ probability of failure.

\section{B.2 DEVELOPMENT OF COMBINED CUMULATIVE PROBABILITY OF FAILURE VS PRESSURE DISTRIBUTION, CONSIDERING ALL SIX FAILURE MODES}

The Combined Cumulative Probability of Failure (CCPF) vs Pressure Distribution is required input for the Accident Analysis.

Given the individual CPF's for each of the six failure modes, the CCPF is calculated as follows:

1) Let $\mathrm{CPF}_{\mathrm{i}}, \mathrm{i}=1$ to 6 , be the CPF's for the individual failure modes.

B-2 
2) Then, the CCPF at any value of pressure is given by

$$
\begin{aligned}
\mathrm{CCPF}(\mathrm{p})=1.0 & -\left[1.0-\mathrm{CPF}_{1}(\mathrm{p})\right]^{*}\left[1.0-\mathrm{CPF}_{2}(\mathrm{p})\right] \\
& *\left[1.0-\mathrm{CPF}_{3}(\mathrm{p})\right]^{*}\left[1.0-\mathrm{CPF}_{4}(\mathrm{p})\right] \\
& *\left[1.0-\mathrm{CPF}_{5}(\mathrm{p})\right] *\left[1.0-\mathrm{CPF}_{6}(\mathrm{p})\right]
\end{aligned}
$$

\section{B.3 DEVELOPMENT OF CONDITIONAL PROBABILITY OF FAILURE VS PRESSURE DISTRIBUTION FOR EACH FAILURE MODE}

The Conditional Probability of Failure (CONPF) vs Pressure Distribution, for each Failure Mode, is required input for the Accident Analysis.

The specific definition of this quantity, as used in the original Peach Bottom Accident Analysis, is somewhat unclear. It has been defined here as follows:

Assuming that failure occurs in the pressure interval $p$ to $p+\Delta p$, where $\Delta p$ is small, what is the probability that the failure occurs in a specific failure mode.

To quantify CONPF for each failure mode the following procedure was followed:

1) Let $\operatorname{CONPF}_{\mathrm{i}}, \mathrm{i}=1$ to 6 , be the CONPF's for the individual failure modes.

2) Then $\mathrm{CONPF}_{\mathrm{i}}$ at any value of pressure is given by

$$
\operatorname{CONPF}_{i}(p)=\left(\frac{d C P F_{i}}{d p}\right)_{p} / \sum_{i=1}^{6}\left(\frac{d C P F_{i}}{d p}\right)_{p}
$$

The numerator $\left(\frac{d C P F_{i}}{d p}\right)_{p}$ is the Probability Density for failure

mode $i$ at pressure $p$.

The denominator $\sum_{i=1}^{6}\left(\frac{d C P F_{i}}{d p}\right)_{p}$ is the

sum of the Probability Densities for all failure modes at pressure p. 
The denominator normalizes the result, such that

$$
\sum_{i=1}^{6} \operatorname{CONPF}_{i}(p) \equiv 1.0
$$

B-4 


\section{B.4 FORTRAN COMPUTER PROGRAM FOR PROBABILITY CALCULATIONS}

The required probability calculations were performed by writing a FORTRAN computer program.

The PROB program listing follows. See B.5 for intermediate output and B.6 for final output. Also, see Figures 4-5 through 4-10 of report for plots of the CPF's.

B-5 
program prob

c This program is to calculate CDF \& conditional probability c for containment of MARK I'BHR. written $6 / 25 / 93$ by Y.Park \& R.Morante at BNL

dimension ntitle(5),plm(10), pum (1ø), prm(10), pi (186),

$1 \operatorname{cdfm}(10,10 \sigma), \operatorname{cdft}(106), \operatorname{pdfm}(10,10 \theta), \operatorname{conpm}(10,16 \theta)$ 
$\operatorname{pdfm}(i, j)=6.0 * c a * x=5+5+5.6 * c b * x * * 4+4.6 * c c * x * * 3+3.0 * c d * x * 2$

if (pdfm(i,j). (t. $1 . e-64) \operatorname{pdfm}(i, j)=0.6$

delp $=$ pum (i) - plm(i)

$\operatorname{pdfm}(i, j)=\operatorname{pdfm}(i, j) / \operatorname{del} p$.

56. $\operatorname{cdfm}(i, j)=c a * x * * 6+c b * x * * 5+c c * x * * 4+c d * x * * 3$.

160 continue

c

c calculate cdft(j)

c

do $268 j=I$; $n p$

ppt $=1$.

do $156 i=1$, nmode

$p=1 .-\operatorname{cdfm}(i, j)$

ppt=ppt:p

150 continue

cont inue $(j)=1$. -ppt

280

continue

c

c calculate $\operatorname{conpm}(i, j)$

c

do $389 \mathrm{j}=1$, np

sum $=8.8$

do 250 i=1, nmode

250 sum=sum+pdfm $(i, j)$

if (sum.eq.ø. .) sum=1.0

do $275 i=1$, nmode

$275 \operatorname{conpm}(i, j)=\operatorname{pdfm}(i, j) / \operatorname{sum}$

368 continue

c

output

c

c in file prob1.out.....tables for pi,cdft, conpm

c in file prob2.out.....tables for pim, pum, pmn

pi,cdft,cdfm write $(3,598)$ ntitle

580 format $(5 a 4)$

write $(3,518) \quad(i, i=1$, nmode)

510 format (" pressure', $16(i 5,2 x)$ )

write $(3,526)$ ( $\operatorname{lm}(i), i=1$, nmode)

write $(3,521)$ (pum $(i), i=1$, nmode)

write $(3,522)$ (pmm (i), $i=1$, nmode)

520 format (' lower $p$, IgfT.2)

521 format (' upper $p,, 16 f 7.2)$

522 format (' median $\left.p^{\prime}, 16 f 7.2\right)$

c

write $(3,536) \quad(i, i=1$, nmode $)$

536 format (' pressure ',' cdft', 18(I5,2x))

do $466 j=1, n p$

$4 B B$ write $(3,532)$ pi $(j), \operatorname{cdft}(j),(\operatorname{cdfm}(i, j), i=1$, nmode $)$

532 format $(f 10.2,12 f 7.4)$

do $68 g \mathrm{j}=1, \mathrm{np}$

686 write $(3,61 \theta)$ (pdfm $(i, j), i=1$, nmode)

610 format $(16 f 12.9)$

c

write $(2,508)$ ntitle

write $(2,54 \theta) \quad(i, i=1$, nmode $)$

546 format (' pressure',' edf ', $16(i 5,2 x))$

do $458 j=1$, $n p$

450

write $(2,542)$

$(p i(j)+14.7) / 14.5838, \operatorname{cdft}(j)$,

(conpm $(i, j), i=1$, nmode) 
542 format $(f 9.2,1 x, 11 f 7.4)$ stop end 


\section{B.5 . INTERMEDIATE OUTPUT}

"pressure" is in psi

"cdft" is the combined cumulative probability of failure (CCPF)

" 1 " is the cumulative probability of failure (CPF) for WWLaW

" 2 " is the cumulative probability of failure (CPF) for WWRbW

" 3 " is the cumulative probability of failure (CPF) for DWL

" 4 " is the cumulative probability of failure (CPF) for DWHL

"5" is the cumulative probability of failure (CPF) for DWR

"6" is the cumulative probability of failure (CPF) for DWHR

NOTE: The second set of data, with no headings, are the probability densities for the six (6) failure modes.

$$
\left(\frac{d C P F_{i}}{d p}\right)
$$


3EEDEG - DESIGN

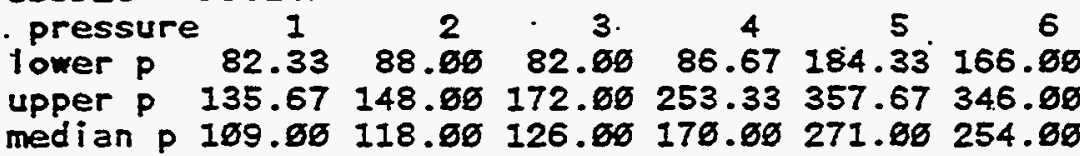
pressure cdft $1 \quad 2 \quad 2 \quad 3 \quad 4 \quad 4 \quad 5$ $82.80 \quad 0.6800 \quad 0.6560 \quad 0.6060 \quad 0.8600 \quad 0.8060 \quad 0.86000 .6006$

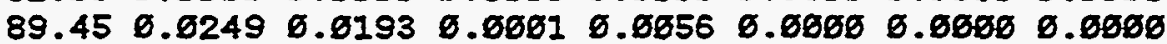
$\begin{array}{lllllllll}96.90 & 0.1862 & 0.1294 & 0.0258 & 0.0384 & 0.0621 & 0.0600 & 0.0000\end{array}$ $\begin{array}{llllllllllll}184.35 & 0.4935 & 0.3399 & 0.1287 & 0.1165 & 0.0161 & 0.0600 & 0.0060\end{array}$ $\begin{array}{lllllllll}111.80 & 0.7982 & 0.5978 & 0.3117 & 0.2211 & 0.6270 & 0.0608 & 0.6080\end{array}$ $\begin{array}{llllllllll}119.25 & 0.9517 & 0.8265 & 0.5391 & 0.3608 & 0.6545 & 0.06080 & 0.0600\end{array}$ $\begin{array}{lllllllllll}126.70 & 0.9961 & 0.9637 & 0.7571 & 0.5147 & 0.6935 & 0.0060 & 0.0600\end{array}$ $\begin{array}{llllllllll}134.15 & 1.0686 & 0.9998 & 0.9157 & 0.6658 & 0.1437 & 0.0008 & 0.0606\end{array}$

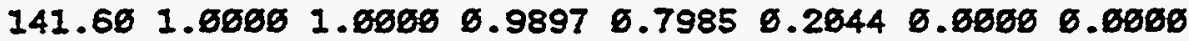

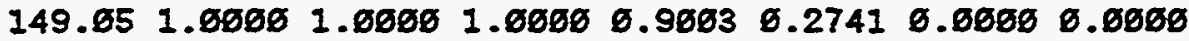

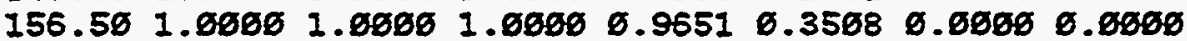
$\begin{array}{llllllll}163.95 & 1.6060 & 1.8000 & 1.0600 & 0.9945 & 0.4322 & 0.0600 & 0.0600\end{array}$

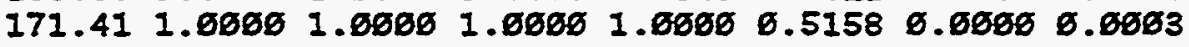

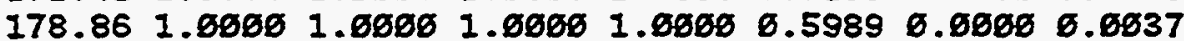

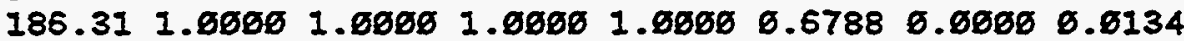
$\begin{array}{llllllll}193.76 & 1.0060 & 1.0600 & 1.0060 & 1.0600 & 0.7531 & 0.0015 & 6.0317\end{array}$ $201.211 .60001 .00001 .60001 .0600 \quad 0.8196 \quad 0.06790 .6598$

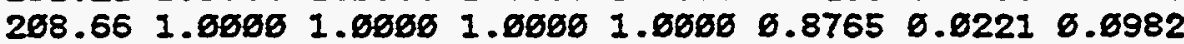

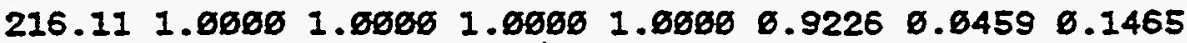
$223.561 .60601 .6006 \quad 1.60601 .0600 \quad 0.9572 \quad 0.6801 \quad 0.2039$

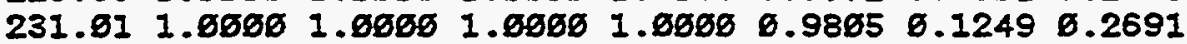
$238.46 \quad 1.80001 .06001 .00001 .0600 \quad 0.9938 \quad 0.1797 \quad 0.3484$ $245.91 \quad 1.68601 .66001 .66001 .8600 \quad 0.9992 \quad 0.2434 \quad 0.4159$ 253.361 .0000 I. $260.811 .00001 .00001 .00001 .06001 .00600 .3968 \quad 0.5707$

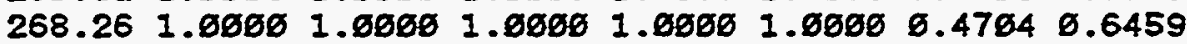
275.71 I.8500 1.6000 I.

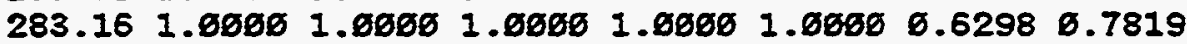

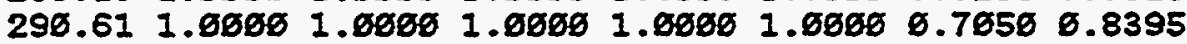

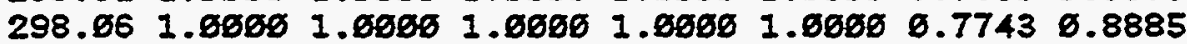
$385.511 .80001 .60001 .00601 .00001 .0000 \quad 0.8357 \quad 0.9282$

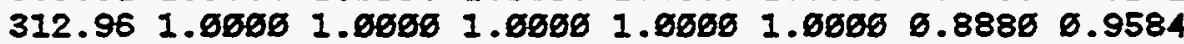

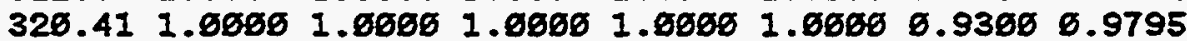

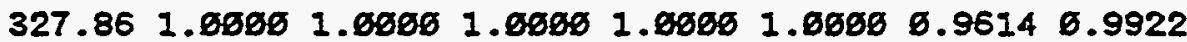
$335.321 .06801 .080601 .00601 .06001 .60606 .9825 \quad 0.9983$ 342.77 I. 0000 I. 350.221 .06001 .00001 .00001 .00001 .00080 .99931 .00000

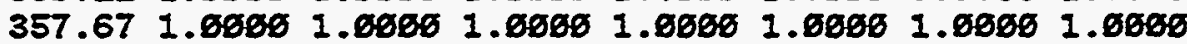

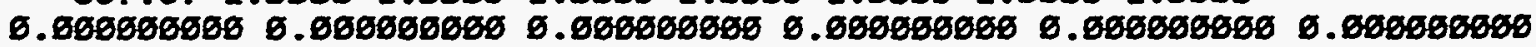

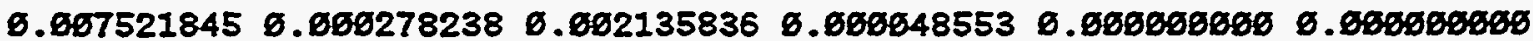

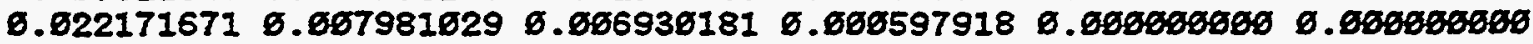

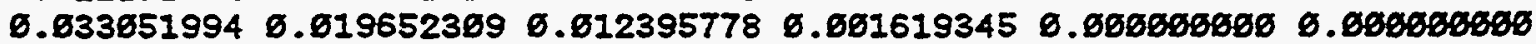

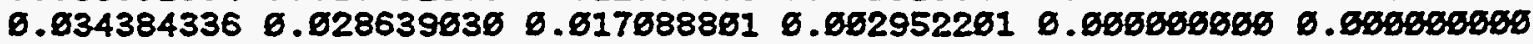

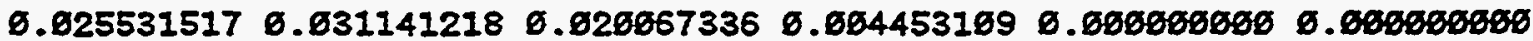

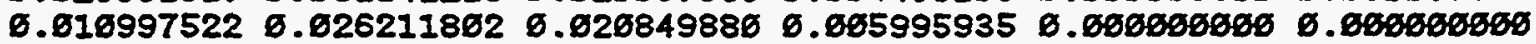

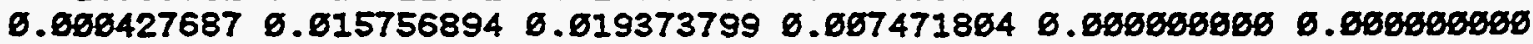

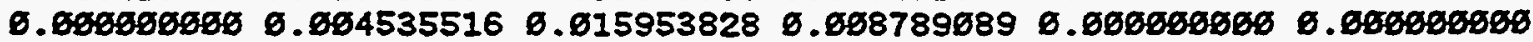

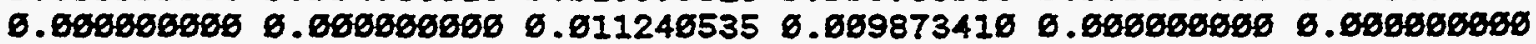

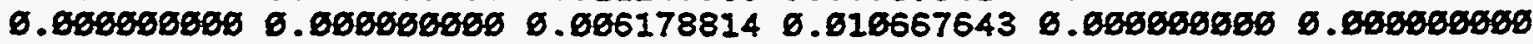

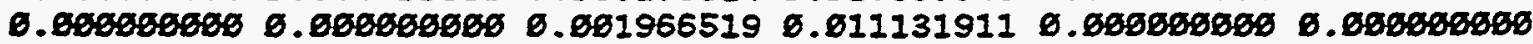

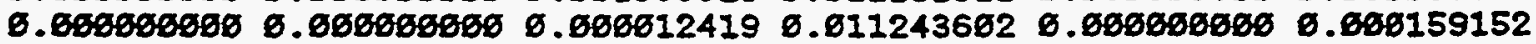

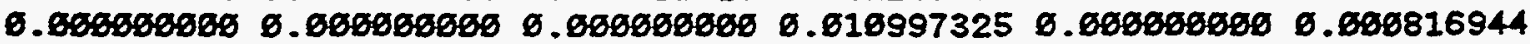

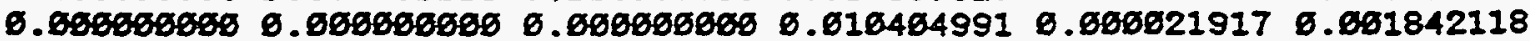

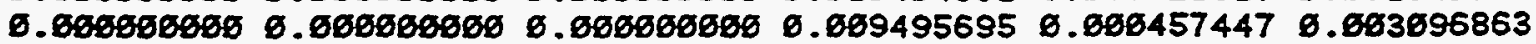




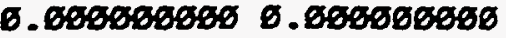
6.86866868000
6. Б686865680
6.856808685
6.668315849
$0.061336427 \quad 0.064461179$

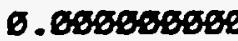

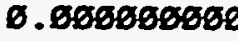
.
0.066929671
0.062518942
D. 68686686656
0.6868686568
0.686605686
0.085416248
0.863879257
0.085832222

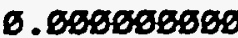
0.050000008
8.863875587
6. 865365817
0.667123668
G. B868686868
פ. 6906868060

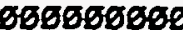
6.062422268
0.866761242
0.688265849
0.688686860
D.
(1)
פ.061189121
0.067982338
0.689201188
6. B868686868

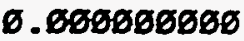
0.0686858688
8.086325973
0.069686881
6.689891168
B. 60868868888
6. Б886806508
.
0.8686868608
0.069939537
0.618388454
6.6868686868
0.806006060
6.6860606688
๑. 6660686680
0.816526339
0.016795715
0.018439462

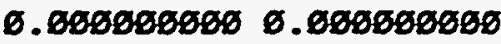
6.606886808
6.808080008
8.016753466
.818283316
0.0868686868
$0.898086 \sigma 88$
6.8060806060
B. 6666606656
0.816395445
0.069851186
0.686086060
6.686868600
6.
Б. 8685885680
0.889737734
D. 669165244
0.8686866686
D. 6980606800
6.8086868698
6.
g. 688816575
.
g.

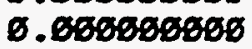
0.86808686
6.686868688
g. g97658354 0.685956828
0.8086886868
Ø. 8086886868
(5)
0.068606060
0.604693381
0.088686860
8.680868680
0.980909090
6.080808068
g.
ஏ.663426266
B. 6856565080
9. 6808080868
Б.
3.0666606860
0.883588253
0.602241378
0.608686868
9. Б686Б58688
6. 9868686800
B. 8868686880
$0.083588253 \quad 0.681222250$

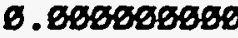
6. Б686868680
0.086080808
6.8686868680
$0.661658625 \quad 0.6666045264$
๑. В86Б6Б6860

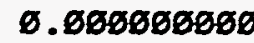
0.968586589
0.806586580
$0.688292878 \quad 0.608608680$

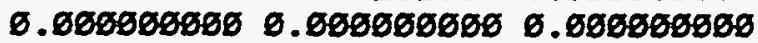


8EODEG - DESIGN

$\begin{array}{lllllll}\text { pressure } & 1 & 2 & 3 & 4 & 5 & 6\end{array}$

\begin{tabular}{lrrrrrr} 
lower P & 82.33 & 88.68 & 61.33 & 53.33 & 143.89 & 125.86 \\
\hline lpper & 135.67 & 148.86 & 129.67 & 86.67 & 263.09 & 269.96
\end{tabular}

median $p 169.60118 .00 \quad 95.60 \quad 70.05203 .05191 .00$

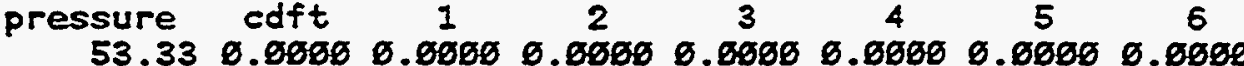

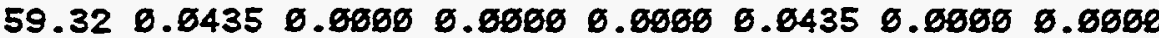

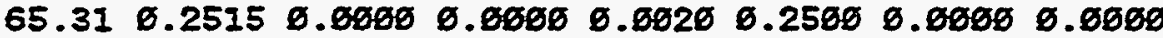

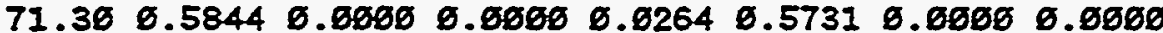

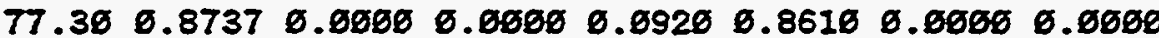

$83.29 \quad 0.9929 \quad 0.6501 \quad 0.6080 \quad 0.2614 \quad 0.9911 \quad 0.0680 \quad 0.0600$

$89.281 .0600 \quad 0.6180 \quad 0.6081 \quad 0.34541 .0000 \quad 0.0606 \quad 0.8600$

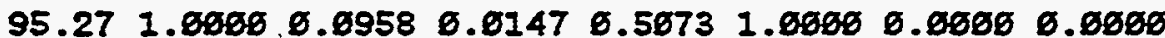

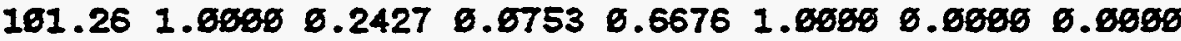

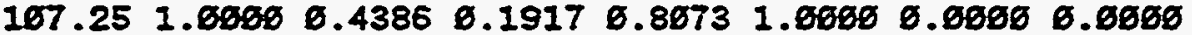

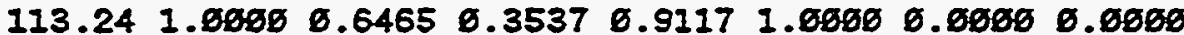

$\begin{array}{llllllllll}119.23 & 1.0606 & 0.8259 & 0.5384 & 6.9739 & 1.8060 & 0.0660 & 0.0660\end{array}$

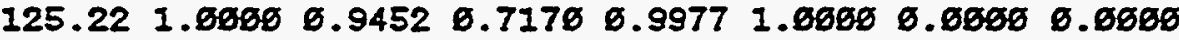

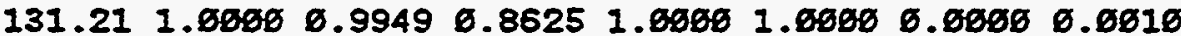

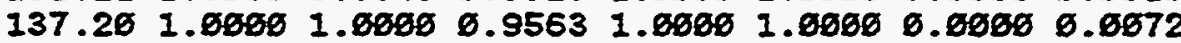

$143.191 .05001 .0080 \quad 0.99541 .00001 .80800 .8080 \quad 0.0219$

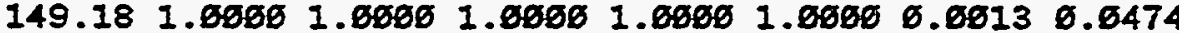

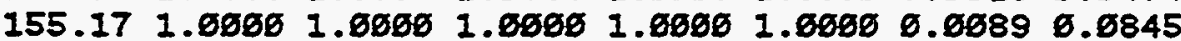

$161.161 .00001 .00001 .00081 .00001 .0000 \quad 0.02730 .1333$

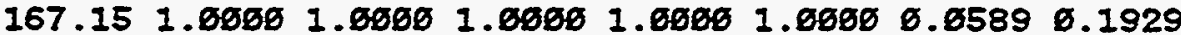

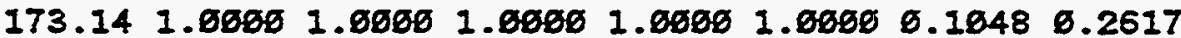

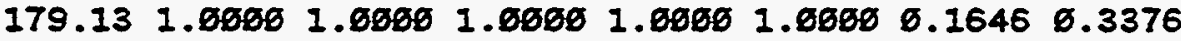

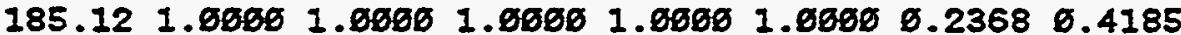

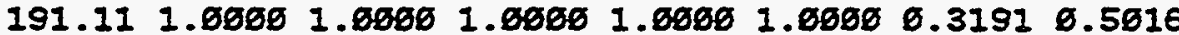

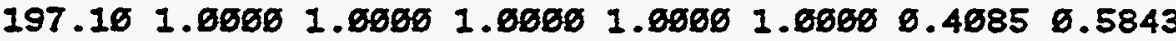

$203.101 .06001 .06001 .86801 .08001 .00800 .5815 \quad 0.6641$

$209.691 .06061 .06861 .06601 .00001 .0000 \quad 0.5944 \quad 0.7386$

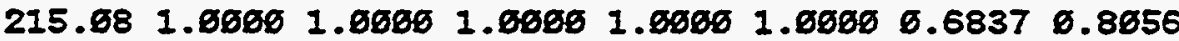

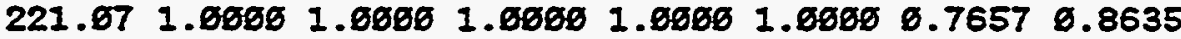

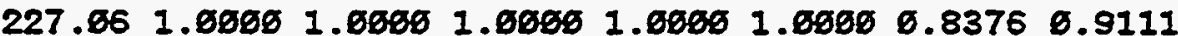

233.051 .06001 .00601 .80001 .00001 .00000 .89690 .9478

$239.041 .06801 .06061 .06001 .00001 .60600 .9423 \quad 0.9738$

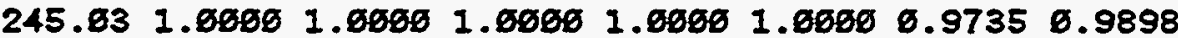

$251.021 .08001 .00001 .00001 .00081 .00000 .9915 \quad 0.9977$

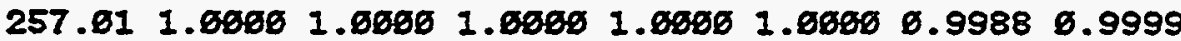

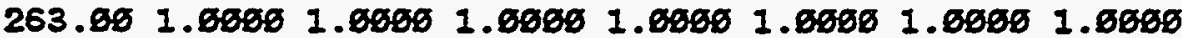

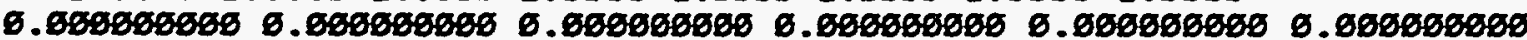

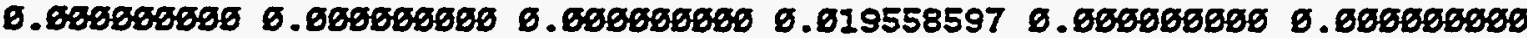

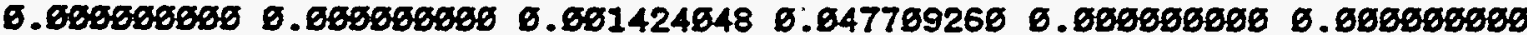

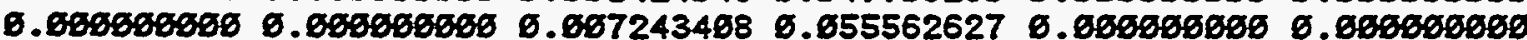

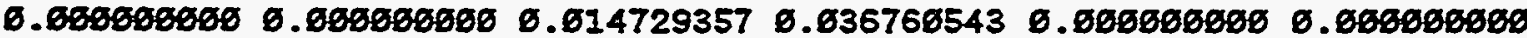

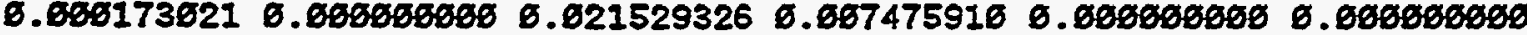

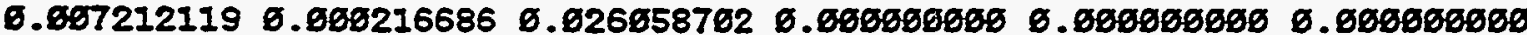

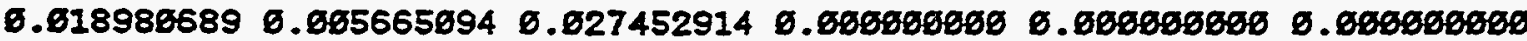

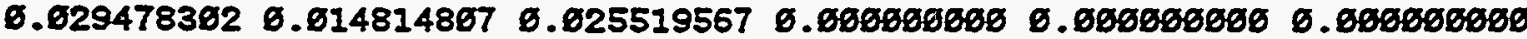

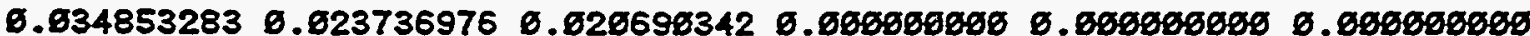

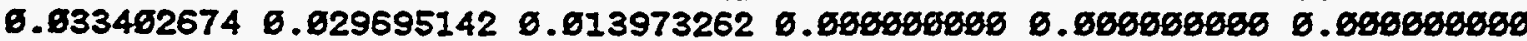

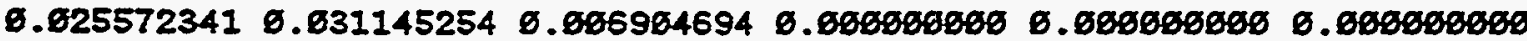

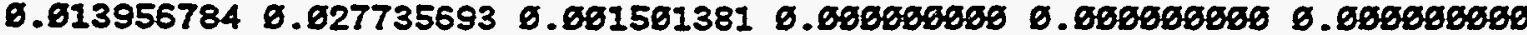

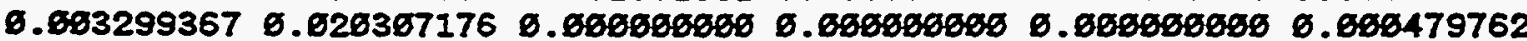

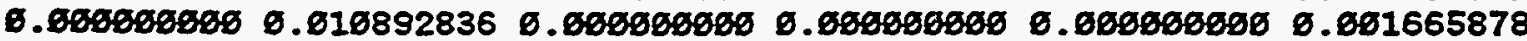

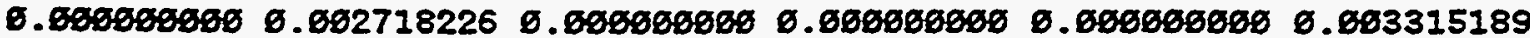

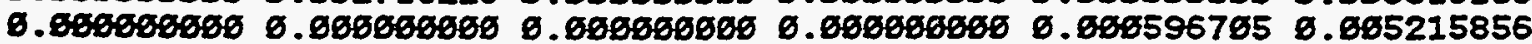

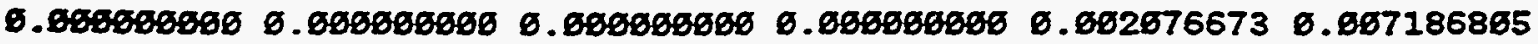




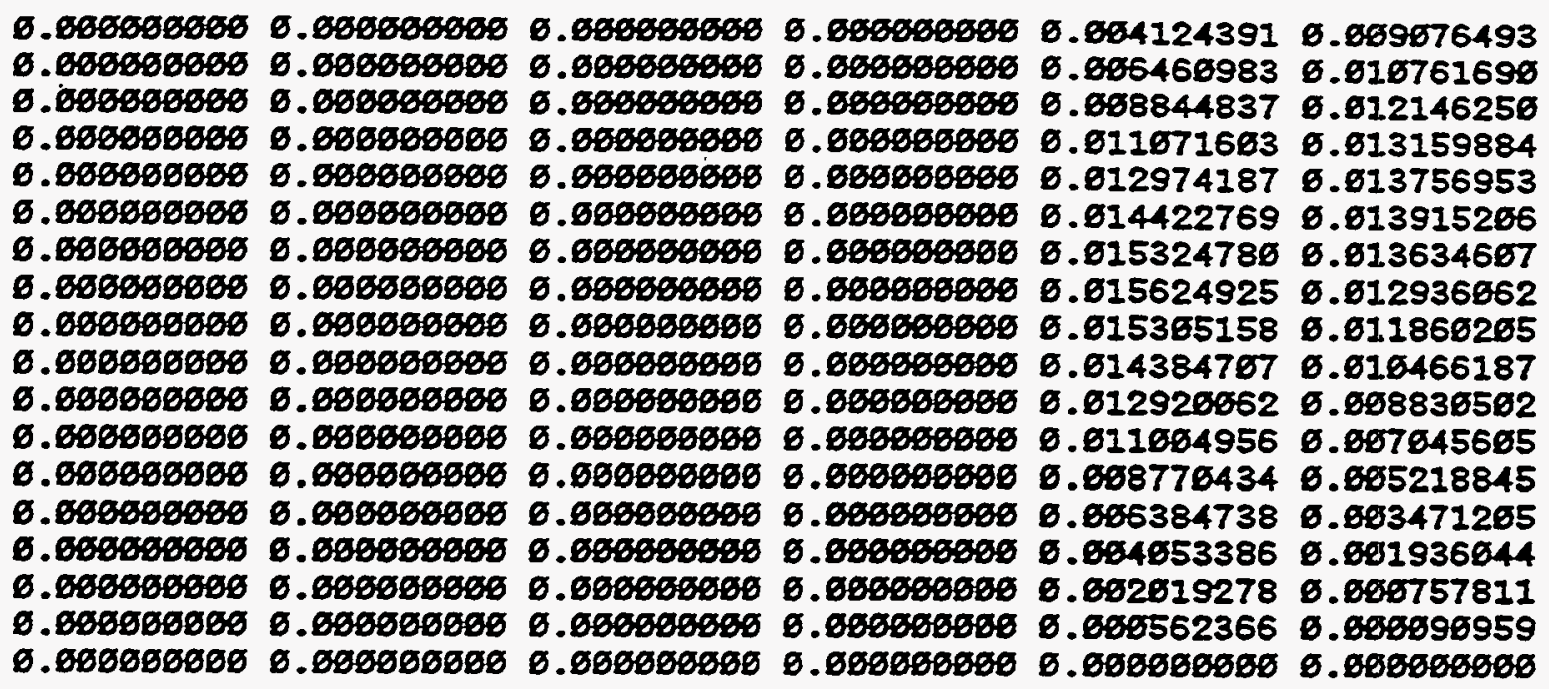


3EBDEG - CURRENT

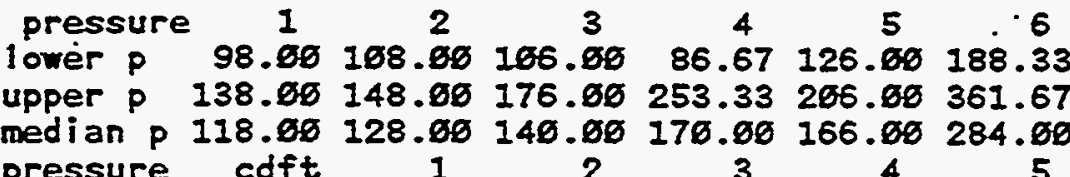
$86.67 \quad 0.0600 \quad 0.6000 \quad 0.0500 \quad 0.6060 \quad 0.0060 \quad 0.6060 \quad 0.6060$

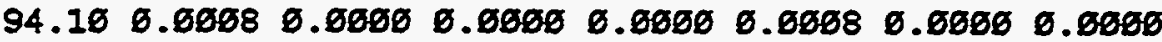
$181.53 \quad 0.0121 \quad 0.0650 \quad 0.0600 \quad 0.0600 \quad 0.0062 \quad 0.0060 \quad 0.0660$ $\begin{array}{llllllllll}188.96 & 0.1482 & 0.1365 & 0.0681 & 0.0668 & 0.0194 & 0.6000 & 0.0600\end{array}$

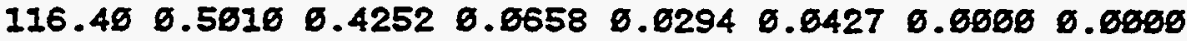
$\begin{array}{llllllllll}123.83 & 0.8645 & 6.7581 & 0.3181 & 0.1283 & 0.6771 & 0.0686 & 0.8660\end{array}$ $\begin{array}{llllllllll}131.26 & 0.9919 & 0.9635 & 0.6502 & 0.2734 & 0.1229 & 0.0026 & 0.086 \emptyset\end{array}$ $\begin{array}{llllllllll}138.69 & 1.6680 & 1.6080 & 0.9139 & 0.4649 & 0.1795 & 0.8310 & 0.8686\end{array}$ $\begin{array}{llllllll}146.13 & 1.6690 & 1.6080 & 0.9996 & 0.6665 & 0.2458 & 0.1652 & 0.6660\end{array}$ $\begin{array}{lllllllll}153.56 & 1.0600 & 1.0680 & 1.0600 & 0.8264 & 0.3198 & 0.2267 & 0.0680\end{array}$ $\begin{array}{llllllll}168.99 & 1.6060 & 1.6060 & 1.0060 & 0.9386 & 0.3994 & 0.3838 & 0.0666\end{array}$

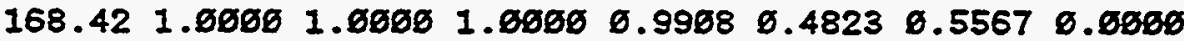

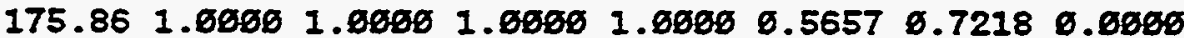

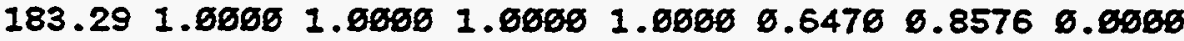

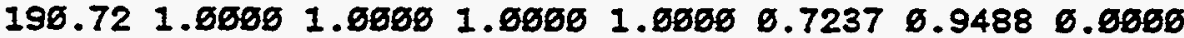
$\begin{array}{llllllll}198.15 & 1.6000 & 1.6000 & 1.0000 & 1.0600 & 0.7934 & 0.9919 & 0.0607\end{array}$

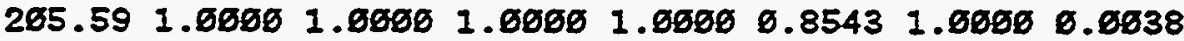

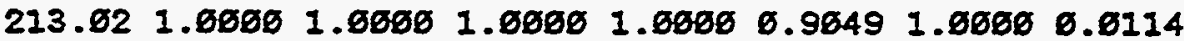

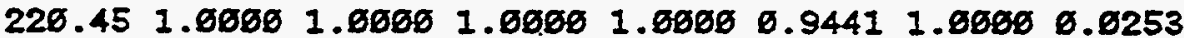

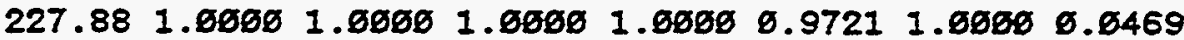

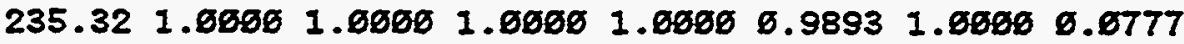

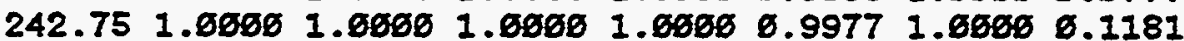

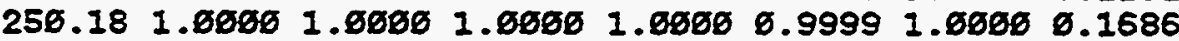
257.611 .68001 .08001 .80001 .00801 .00001 .00800 .2286

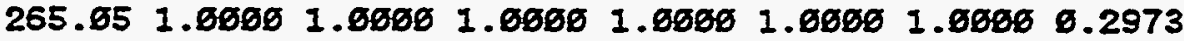

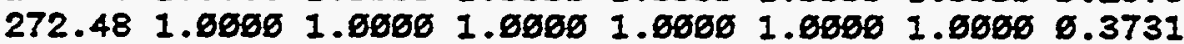

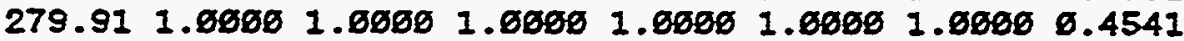

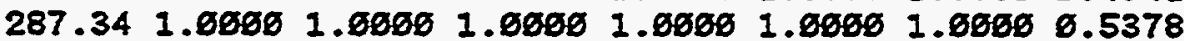

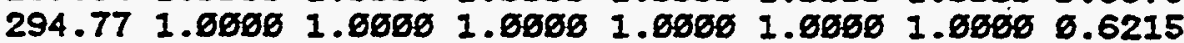

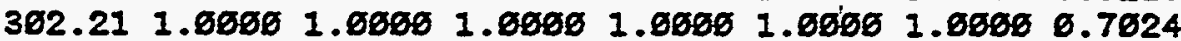

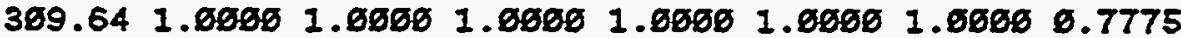

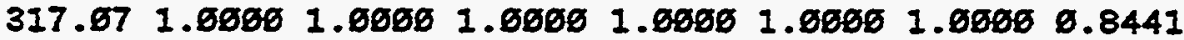

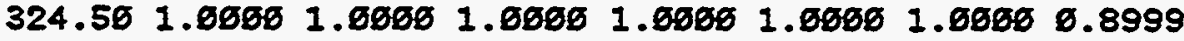

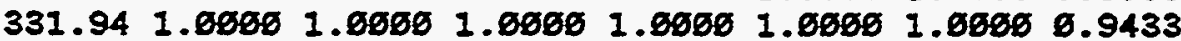
339.371 .66861 .06601 .06001 .06061 .00601 .60800 .9736

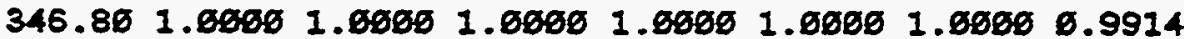

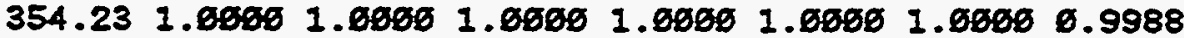

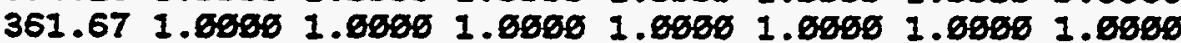

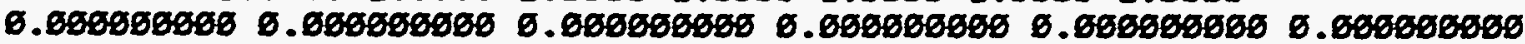

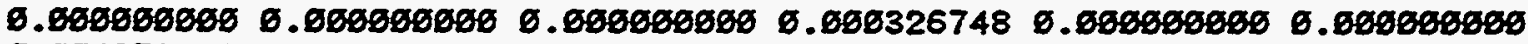

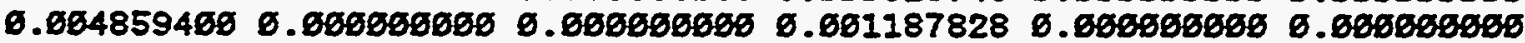

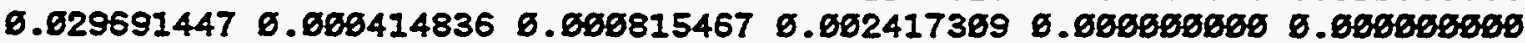

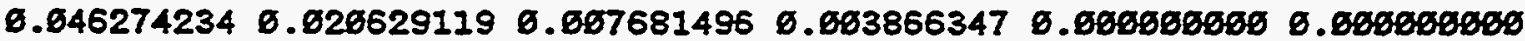

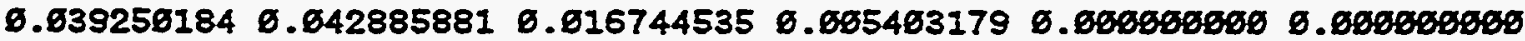

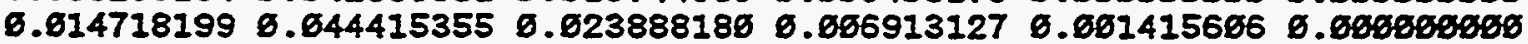

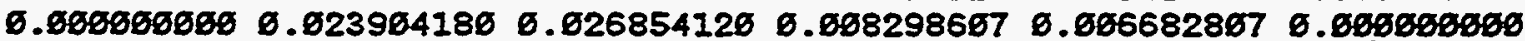

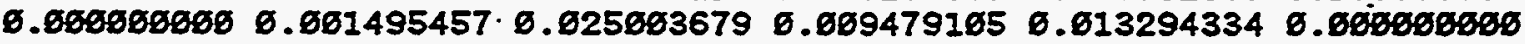

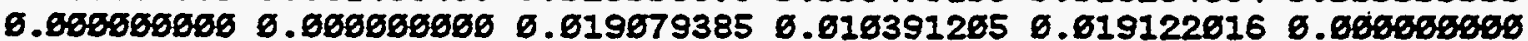

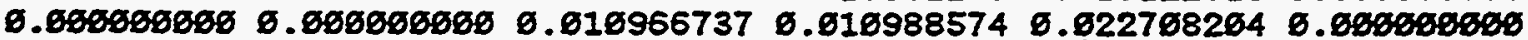

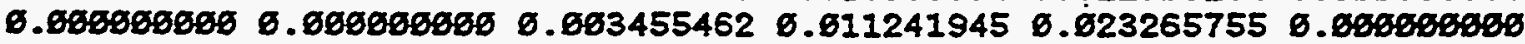

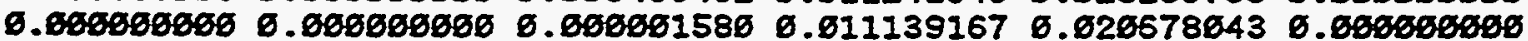

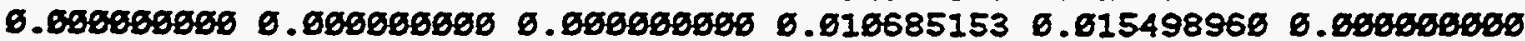

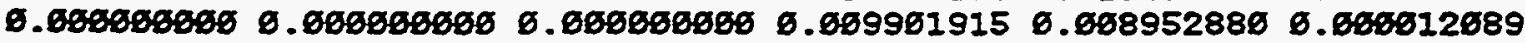

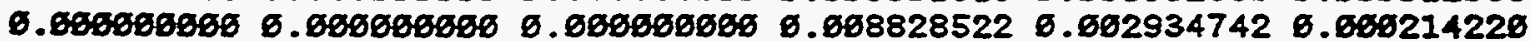




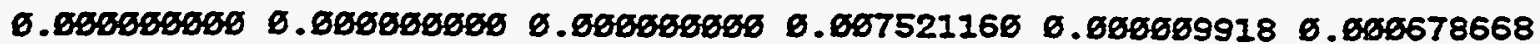

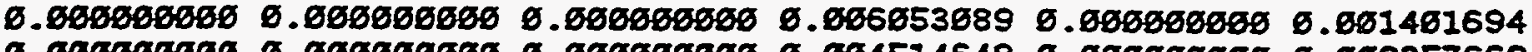

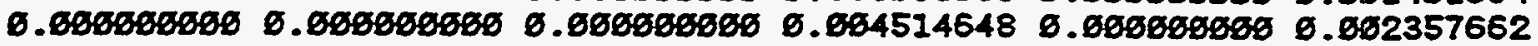

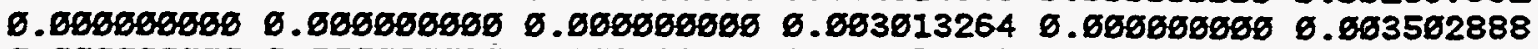

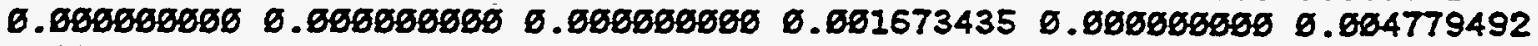

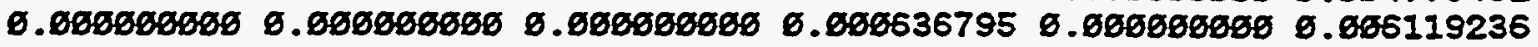

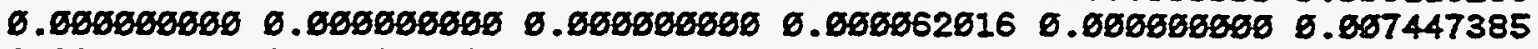

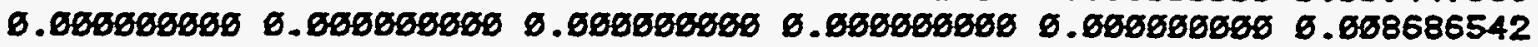

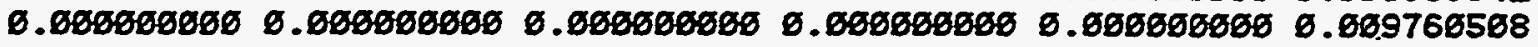

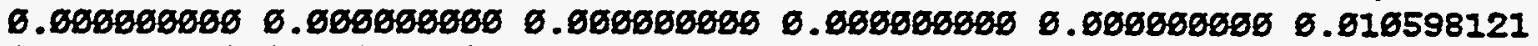

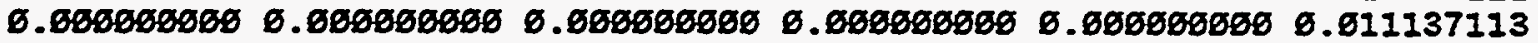

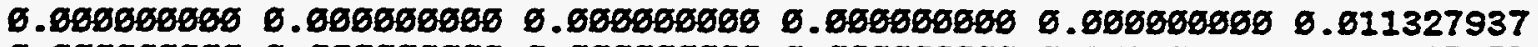

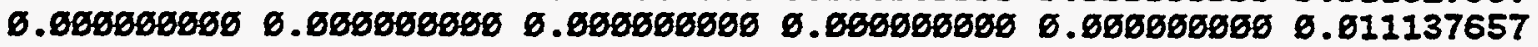

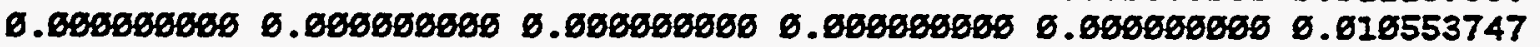

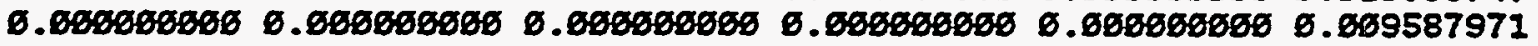

6.

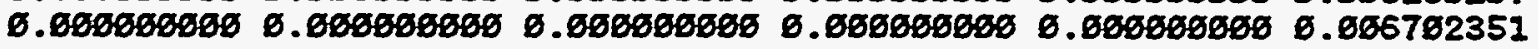

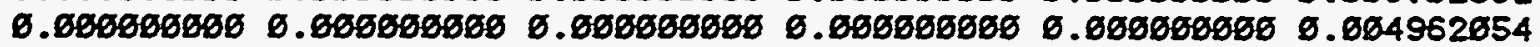

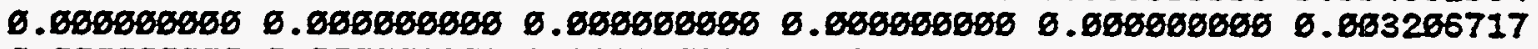

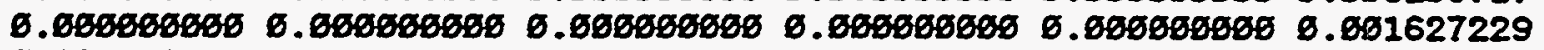

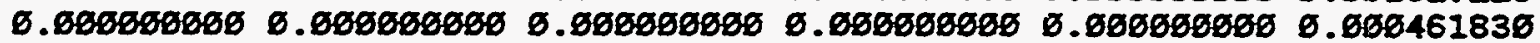

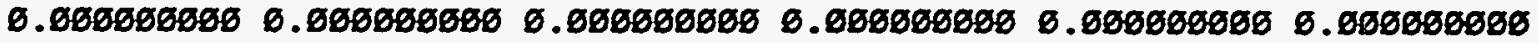


8EDDEG -CURRENT

\begin{tabular}{ccccccc}
$\begin{array}{c}\text { pressure } \\
\text { lower }\end{array}$ & 1 & 2 & 3 & 4 & 5 & 6 \\
\hline & 98.60 & 198.60 & 79.33 & 53.33 & 88.33 & 135.67
\end{tabular}

$\begin{array}{llllllll} & \text { upper p } & 138.06 & 148.06 & 132.67 & 86.67 & 181.67 & 272.33\end{array}$

median p $118.60128 .00165 .00 \quad 70.00125 .00 \quad 213.00$

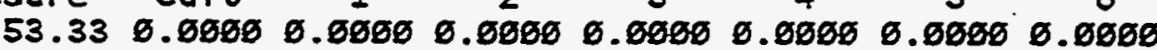

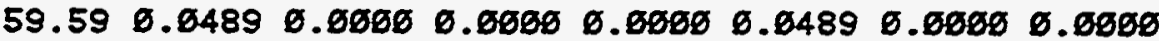

$\begin{array}{lllllllll}65.85 & 0.2759 & 0.8000 & 0.0000 & 0.0800 & 0.2759 & 0.0060 & 0.0600\end{array}$

$\begin{array}{lllllllllll}72.10 & 0.6171 & 0.0600 & 0.0680 & 0.0060 & 0.6171 & 0.0600 & 0.0080\end{array}$

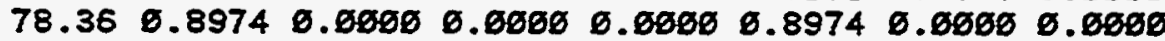

$\begin{array}{lllllllllll}84.62 & 6.9979 & 0.0680 & 0.0080 & 0.0160 & 0.9979 & 0.0860 & \emptyset .0606\end{array}$

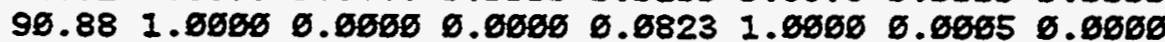

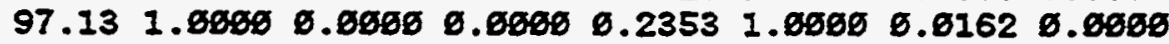

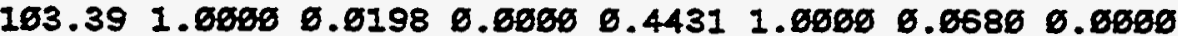

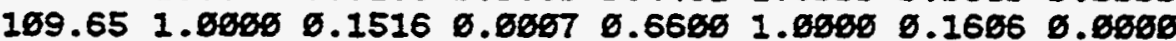

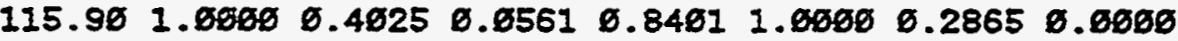

$\begin{array}{lllllllll}122.16 & 1.0660 & 0.6895 & 0.2415 & 0.9533 & 1.0600 & 0.4320 & 0.0680\end{array}$

$\begin{array}{llllllllllll}128.42 & 1.8686 & 0.9672 & 0.5196 & 0.9964 & 1.0680 & 0.5807 & 0.08860\end{array}$

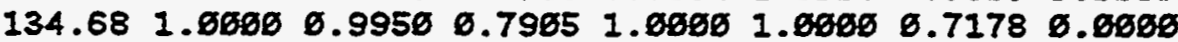

$146.93 \quad 1.06601 .0000 \quad 0.9584 \quad 1.06061 .60600 .8315 \quad 0.0061$

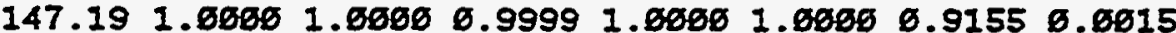

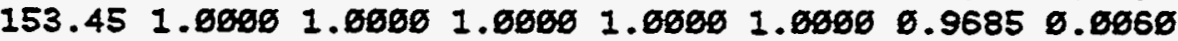

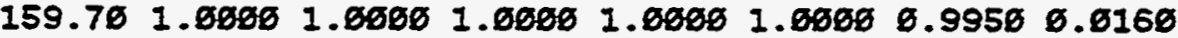

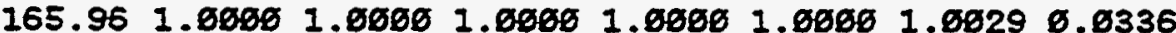

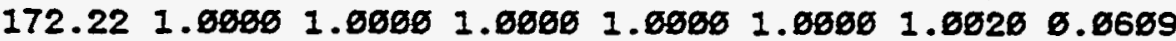

$178.481 .00001 .00001 .06001 .00001 .00001 .0001 \quad 0.0991$

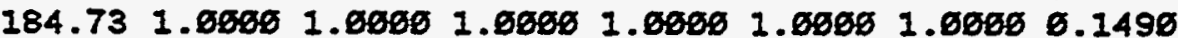

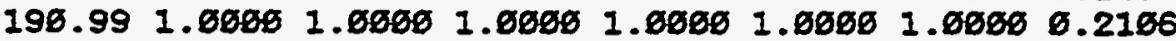

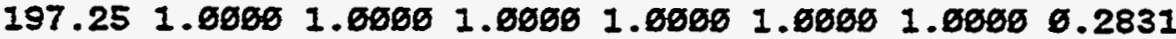

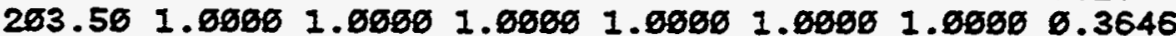

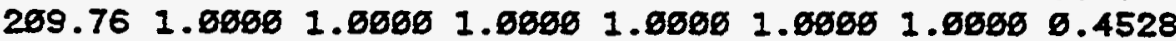

216.021 .00001 .06001 .00001 .00001 .600001 .00000 .5445

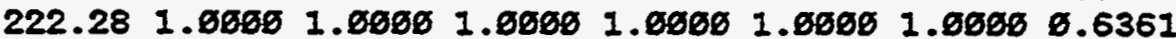

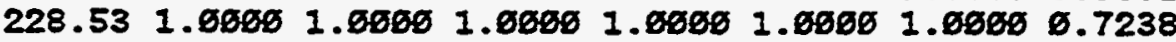

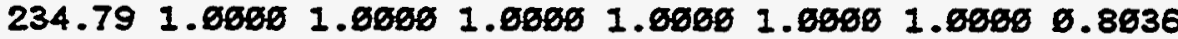

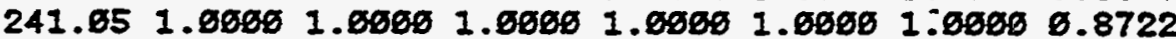

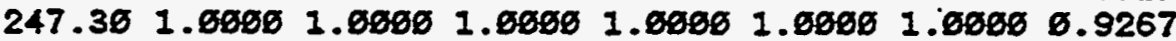

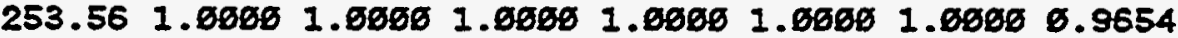

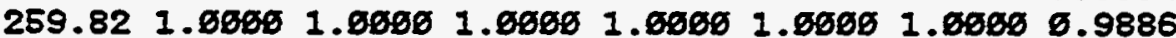

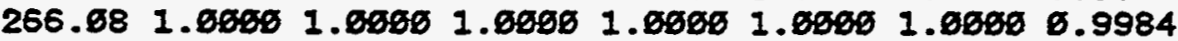

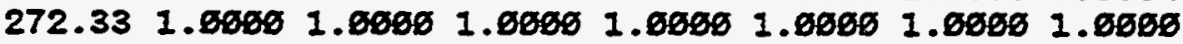

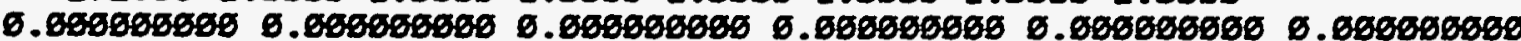

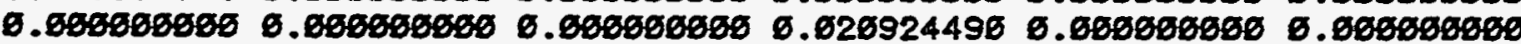

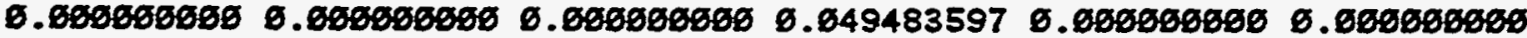

D.

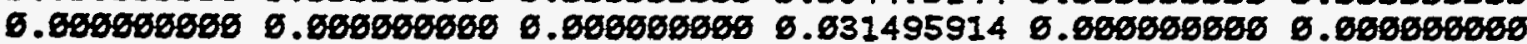

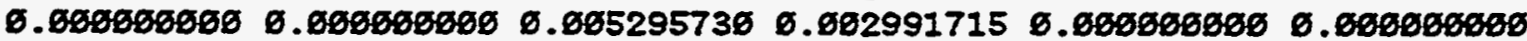

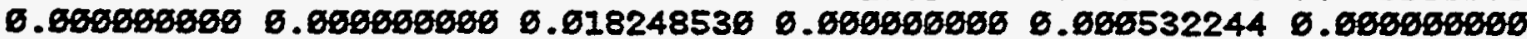

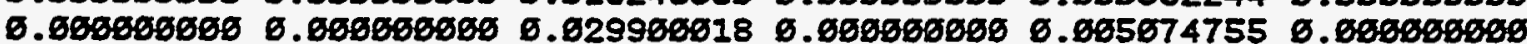

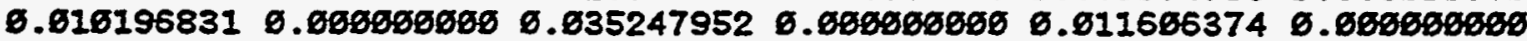

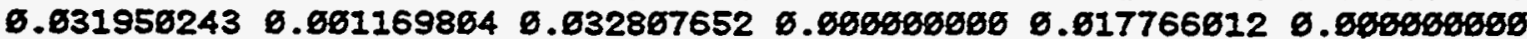

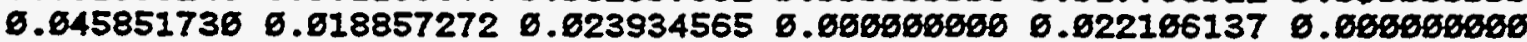

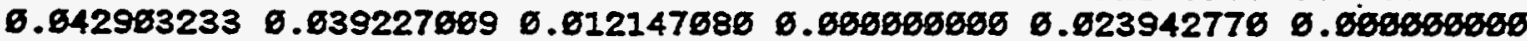

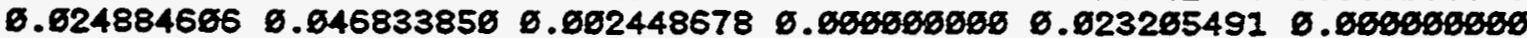

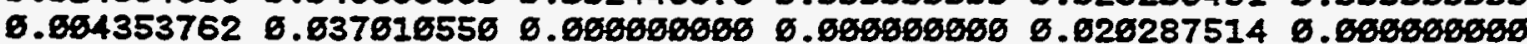

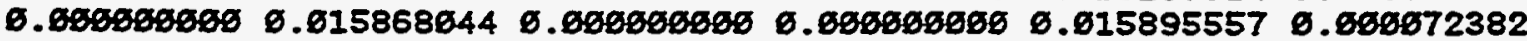

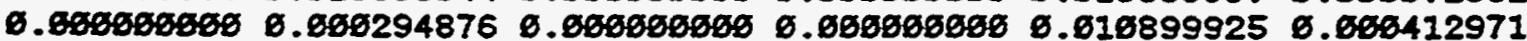

б.

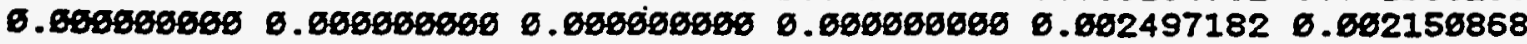



B. 6686868688
0.668656865
9.68608060800
0.0606068688
6.868298650
0.083539896
B. B68608006ర
6.
0.0888808080
0.086868686
0.6866505080
0.885199923
0.6686868686

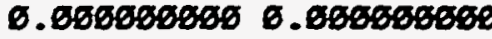
0.6886866868
0.6686806000
0.067634641

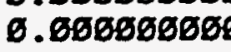
0.6586608080
0.8688589898
0.966868666
0.6865050080
0.888926552
0.668890800
0. 8686060660
8. 686808088
0.686860686
6.
0.016745718
6. 6686868068

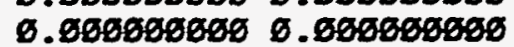
0.868868686
0.086858580
0.012358491

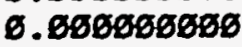

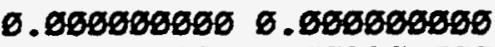
.080680688
0.080800880
0.013636215
0.660606800

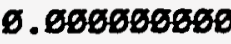
๑. Б668б56888
$0.000 \cos$
8.8666060000
0.014463996
0.086086080
0.6606080808
6.6868686880
0.085895656
0.6866866080
ஏ.814749355
6. B60680808
0.68666066868
0.6668686086
0.806066800
0.068086888
0.014431829
B. Б56506058
0.060808060
5.
0.608680680

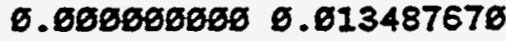
0.606008080
8.880886888
8.686886888
0.888868686
6.0606806086
0.011946524

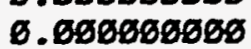

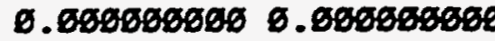
0.068088888
$6.686068660 \quad 0.869892241$
6.0606866868

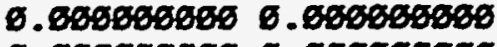
0. 8060808580
0.865606860
0.867475584
6.658089680

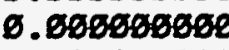
0.6868686898
0.8089808680
Q. 698686868
0.084921879
0.8568650608
0.6080006080
0.0868698858
0.86898660868
6. 6668686668
0.802548358
0.860868080
0.0860868060
6.860868885
8. 868880088
0.6606060600 .686680600 
3GEDEG -CORRODE

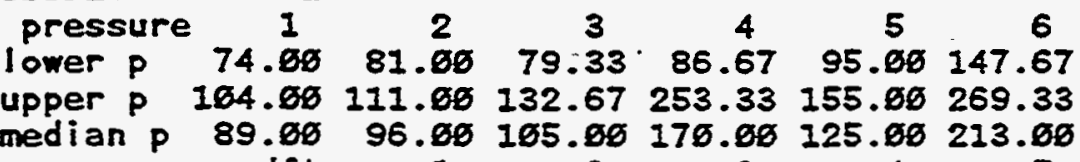

median P $89.60 \quad 96.00165 .06 \quad 170.06 \quad 125.00 \quad 213.00$

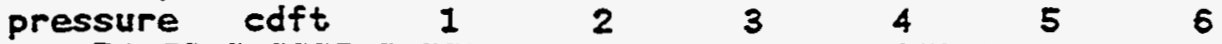

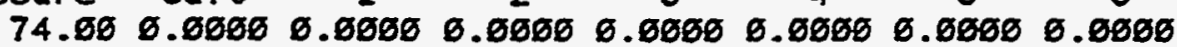

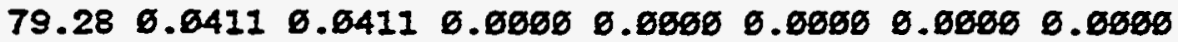

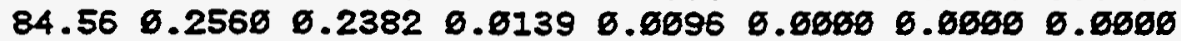
$89.84 \quad 0.6465 \quad 0.5523 \quad 0.1560 \quad 0.0645 \quad 0.0661 \quad 0.060800 .0868$ $95.12 \quad 0.9280 \quad 0.8420 \quad 0.4449 \quad 0.1782 \quad 0.6012 \quad 0.0680 \quad 0.6600$ $\begin{array}{lllllllllll}166.46 & 0.9977 & 0.9856 & 6.7594 & 0.3395 & 0.6049 & 0.0653 & 0.0608\end{array}$ $\begin{array}{lllllllllll}165.68 & 1.0808 & 1.0600 & 0.9579 & 0.5239 & 0.6124 & 0.8424 & 0.0080\end{array}$

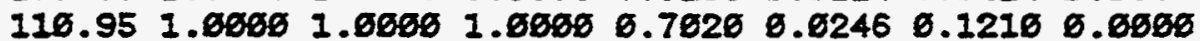
$116.231 .06001 .8600 \quad 1.6000 \quad 0.8479 \quad 0.6420 \quad 0.2413 \quad 0.0600$ $121.511 .060601 .60601 .6000 \quad 0.9450 \quad 0.8651 \quad 0.3920 \quad 0.0600$

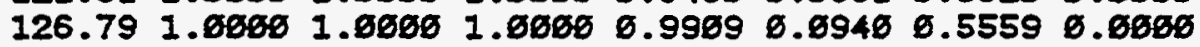

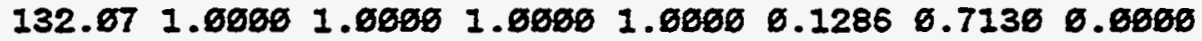

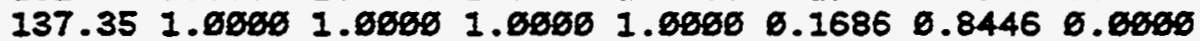

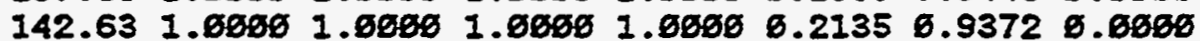

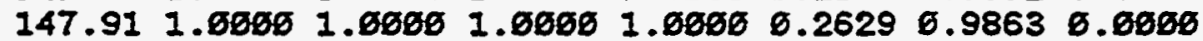

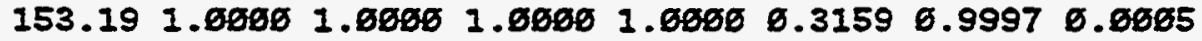

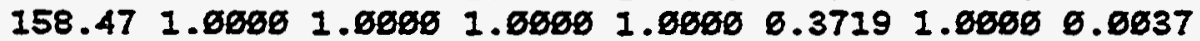

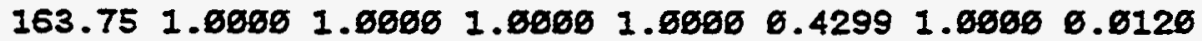

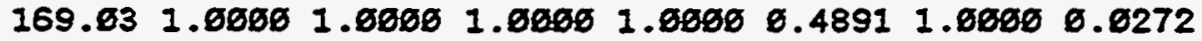
$174.311 .06001 .00001 .00001 .00000 .54841 .6060 \quad 0.6510$

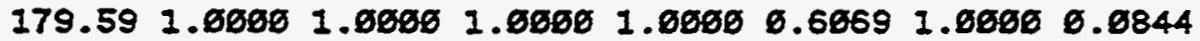

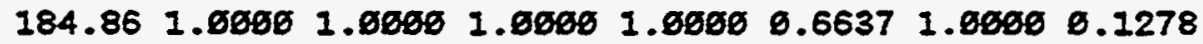

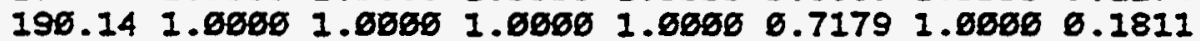

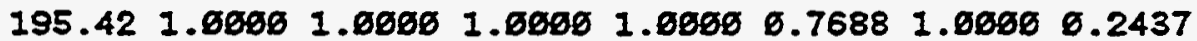

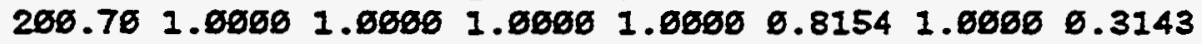

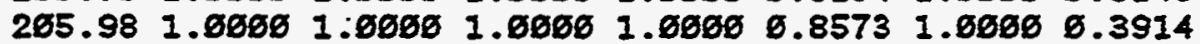
$211.261 .06001 .06001 .06001 .00600 .89391 .0800 \quad 0.4727$ 216.541 .08001 .08001 .06001 .60600 .92491 .80606 .5559

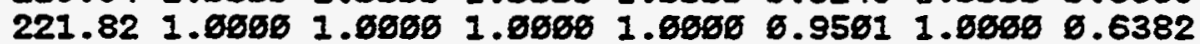
227.101 .68001 .80601 .60001 .60000 .96961 .08600 .7169

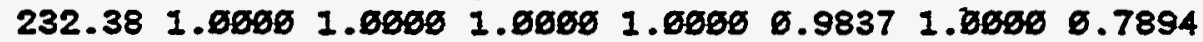

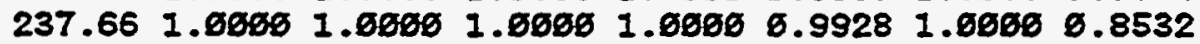
$242.941 .06001 .06061 .60001 .60606 .9978 \quad 1.0060 \quad 0.9662$ $248.221 .06061 .00601 .00001 .00000 .9997 \quad 1.00060 .9471$

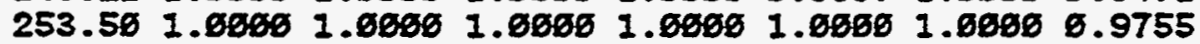

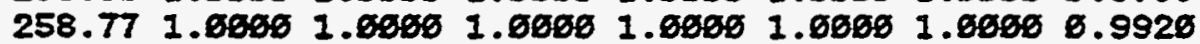

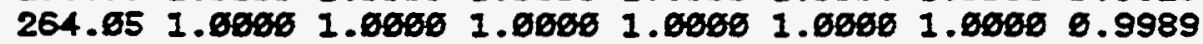

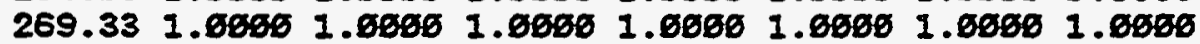

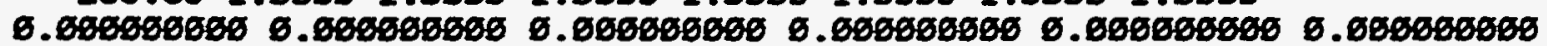

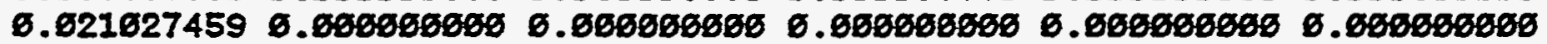

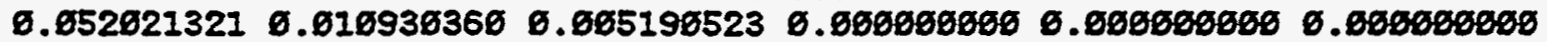

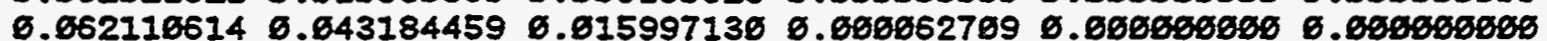

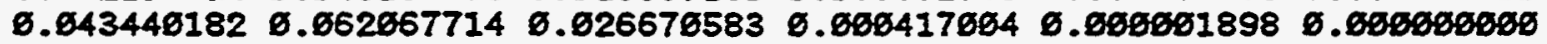

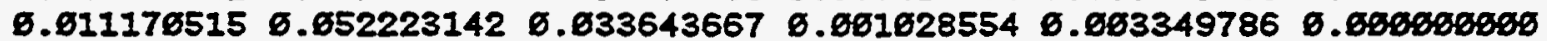

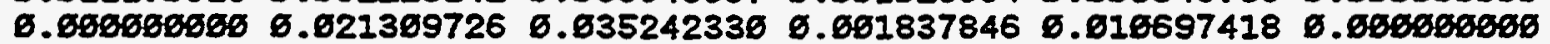

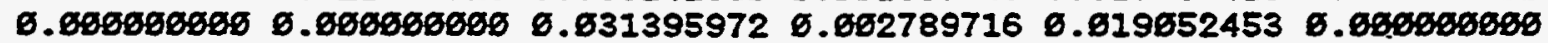

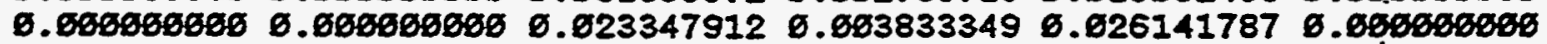

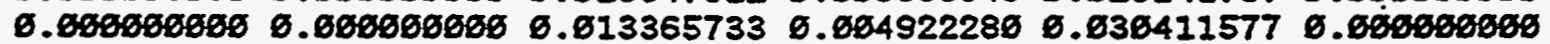

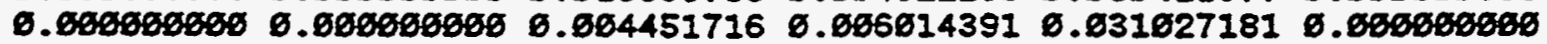

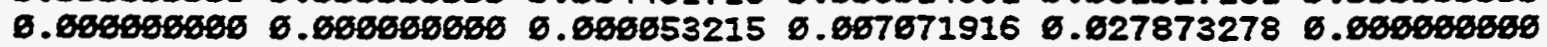

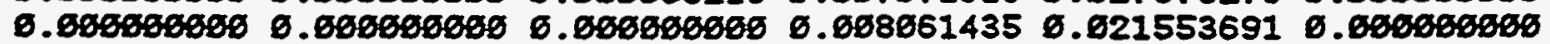

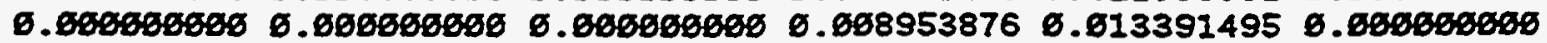

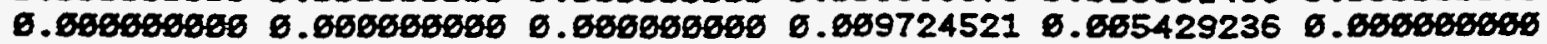

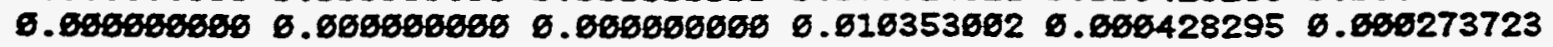




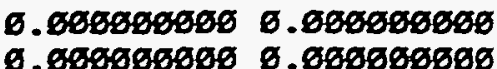
0.868686869
0.818823285
0.0600600000 .061817117

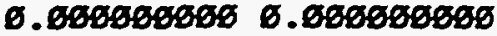
.885868658
8.811123786
0.0000000000
0.062171268
0.
0. 85886868688
0.011246933
6.
0.003658916

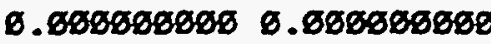
פ. B8868685656
0.011189995
.8686805659
Б.6165389091

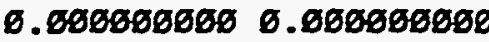
6.088080808
B.816545461
0.9808586890
0.057261201
0.8668680860
0.6868686806
6.688686868
0.069973657
0.806080606
0.689169131

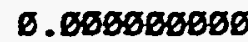
0.0060600000
0.86868686868
0.069253275
0.0080606050
0.011865327
0.668060680
5.
0.6886868686
6.068463687
๑. 868686065
6.012664895
0. 868608608

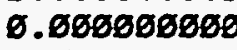
0.868068608
0.067446198
0.8060808000
0.814649693

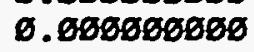

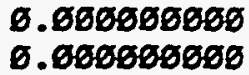
0.868686860
פ. 666416676
0.0606508000
0.015672419

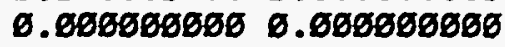
8.6060080600
0.065326538
0.0868086080
6.015668783

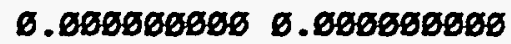
0.068668656
0.684231784
0.06866806808
0.915761296
6.6868686888 6.868686868
8. 868068088
0.863166268
0.086606860
6.815343764

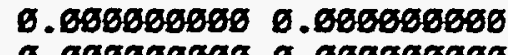
8.8886868688
0.082174964
0.0866606868
0.814485191

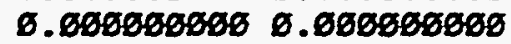
פ. 6868608650
0.681386858
9.8868688868
0.612973955
0.600506008
0.6808606868
6.006068606
0.866615738
0.086696656
0.011113686
0.
6. 608686068
0.0808088680
.
8.086808868
0.068927559

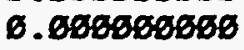

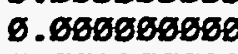
0.8808000800
0.8686858686
6. 86868686868
6.666562332
0.6088068080
0.080808080
0.086068698
B. $80606 B 668$
8.8868868680
0.684212437
0.85888080808

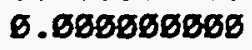
D. .
0.880808808
0. .

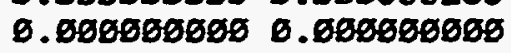




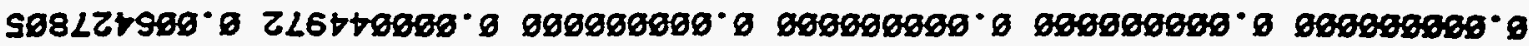

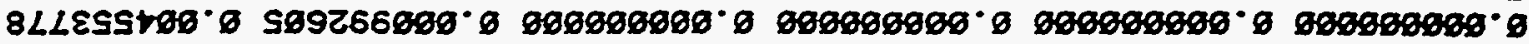

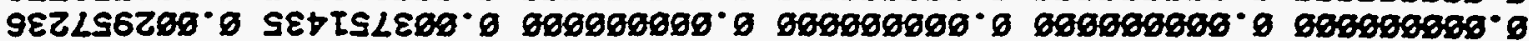

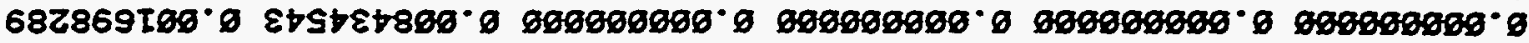

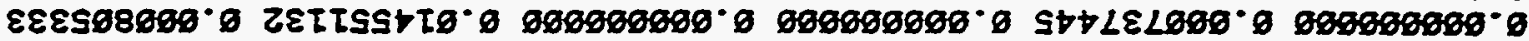

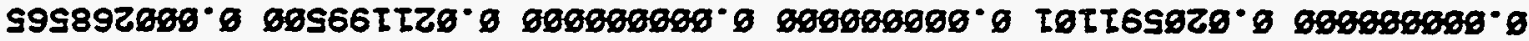

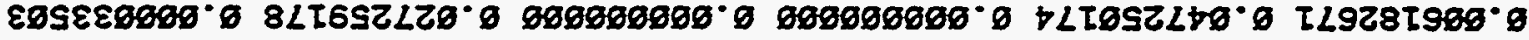

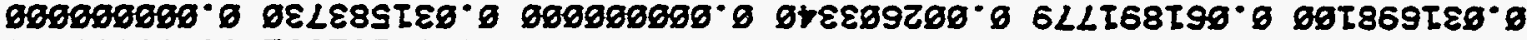

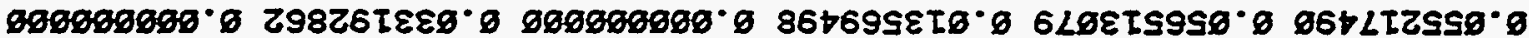

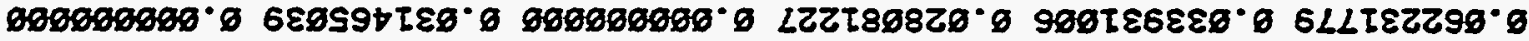

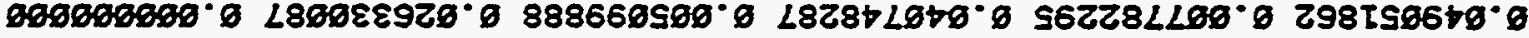

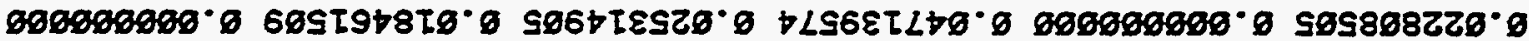

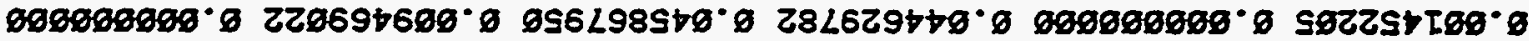

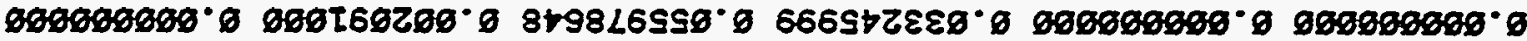

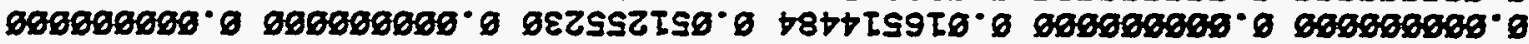

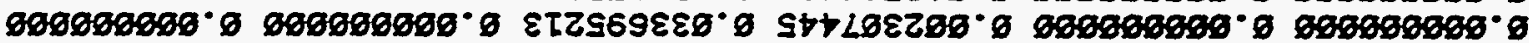

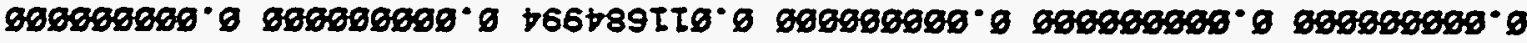

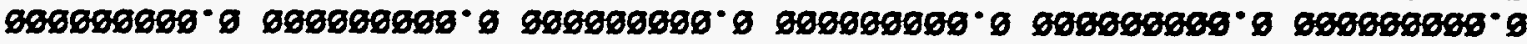

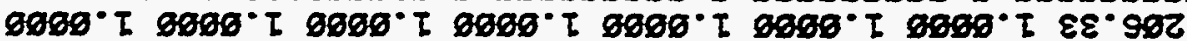

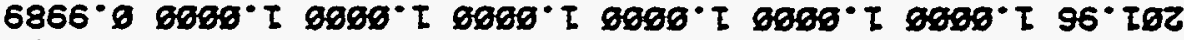

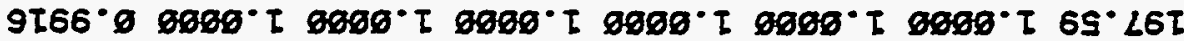

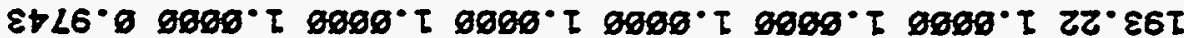

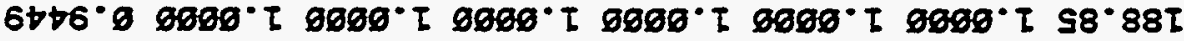

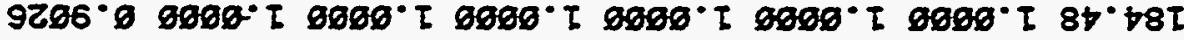

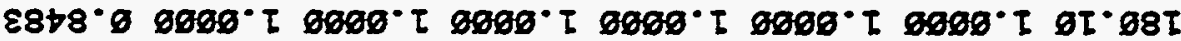

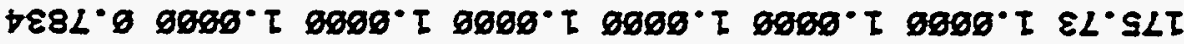

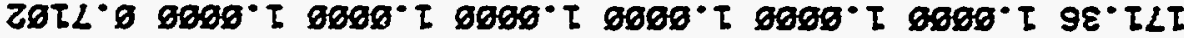

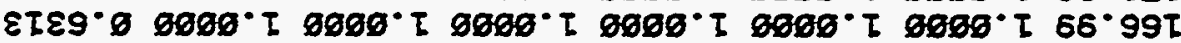

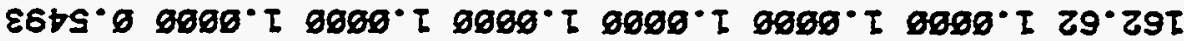

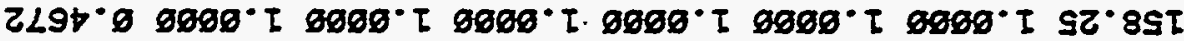

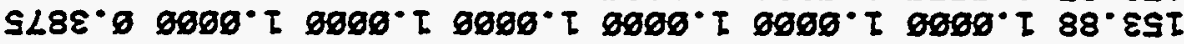

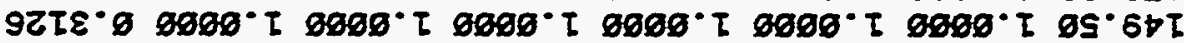

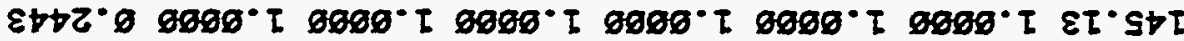

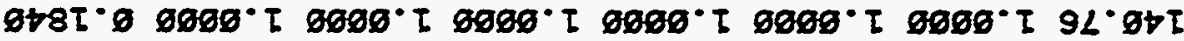

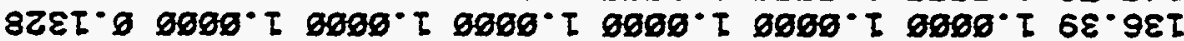

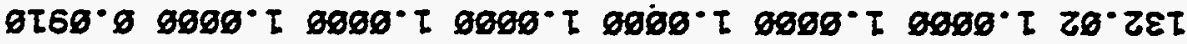

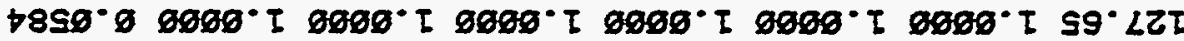

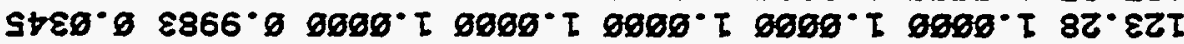

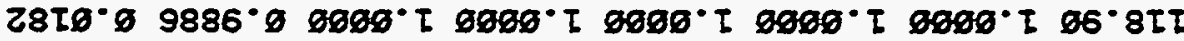

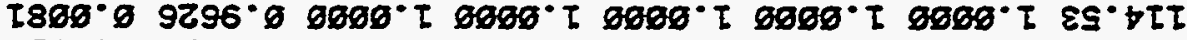

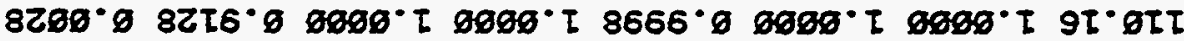

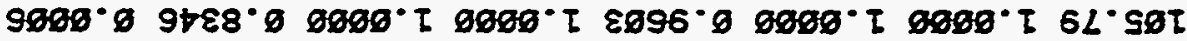

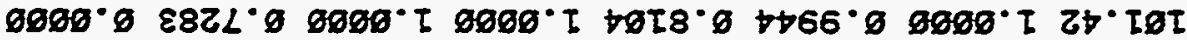

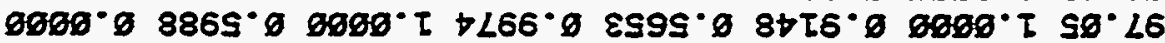

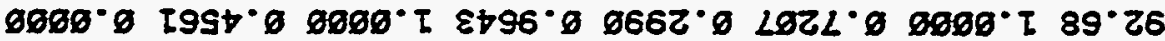

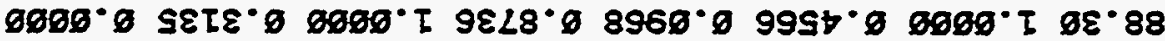

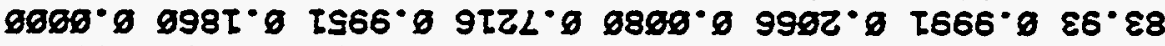

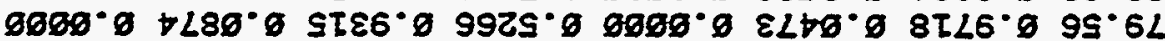

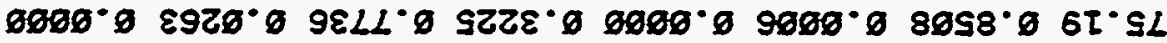

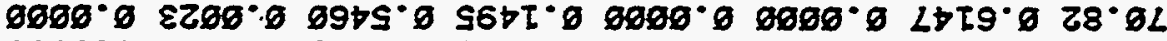

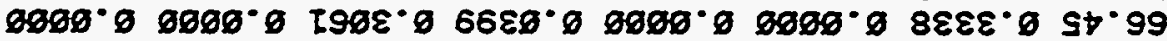

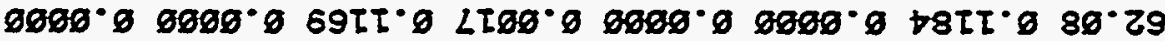

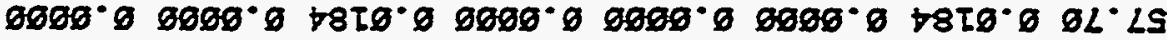

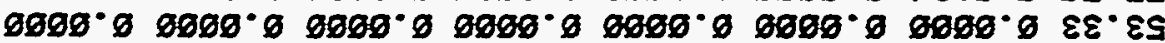

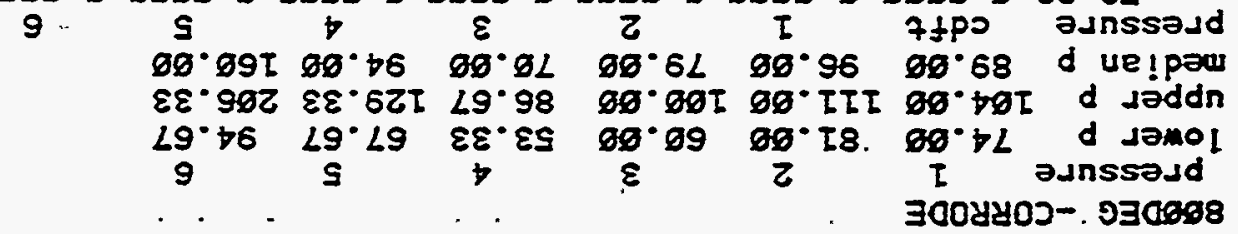



Б.
0.6806060600
6.
6.
0.68656586880
6.868493979
B. 68656565658
6. 80868689808
6. 8386808080
0.860808688
D. 8686868686
0.018648210

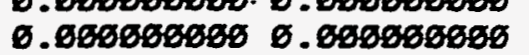
6.068668608
0.8608686880
0.6668685850
6.012774142

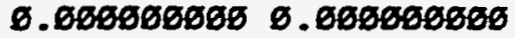
0.0886860885
0.656065658

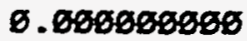
0.014749642
6.8680686865
0.088686880
0.000800080
5.

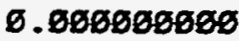
0.816453266

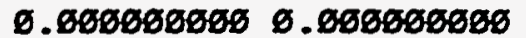
9.808060806
0.868086860
0.0868668655
0.017776769
0.608868688
0.068668688
0.8868686865
0.0686865658
0.0665605608
0.018601578

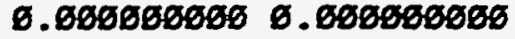
פ. Б686568568
9.680808868
$8.8668 B B 8668$
0.018865258
0.6686866668
0.8086685868
0.080606080
0.6698686668
0.080666666
6.018567970
6. 6065868668
0.088686868
0.6806060650
6.617569995
0.8608686808
0.060680605
๑. Б66056650
6.
0.015887467

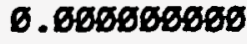
0.0850608000
0.086066868
0.0668696860
6.688808688
0.013768145

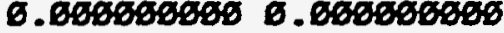
б.
0.0868686800
0.011688688
0.66606868680 .086686868
0.8086868660
б. 866808686

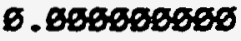
0.888265717

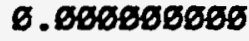
8.085686688
0.689868680

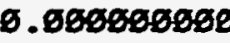
0.8688686606
6.865381275
.

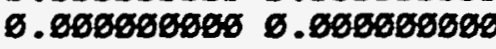
$9.686686865 \square$
8.868886860
0.062689607
6.680608686
0.0608060600
0.088688060
6.6668680860
9.0908008080
0.080763295
0.808686680 


\section{B.6 FINAL OUTPUT FOR ACCIDENT ANALYSIS}

"pressure" is in bars

"cdf" is the combined cumulative probability of failure (CCPF)

" 1 " is the conditional probability of failure (CONPF) for WWLaW

" 2 " is the conditional probability of failure (CONPF) for WWRbW

" 3 " is the conditional probability of failure (CONPF) for DWL

"4" is the conditional probability of failure (CONPF) for DWHL

" 5 " is the conditional probability of failure (CONPF) for DWR

"6" is the conditional probability of failure (CONPF) for DWHR 


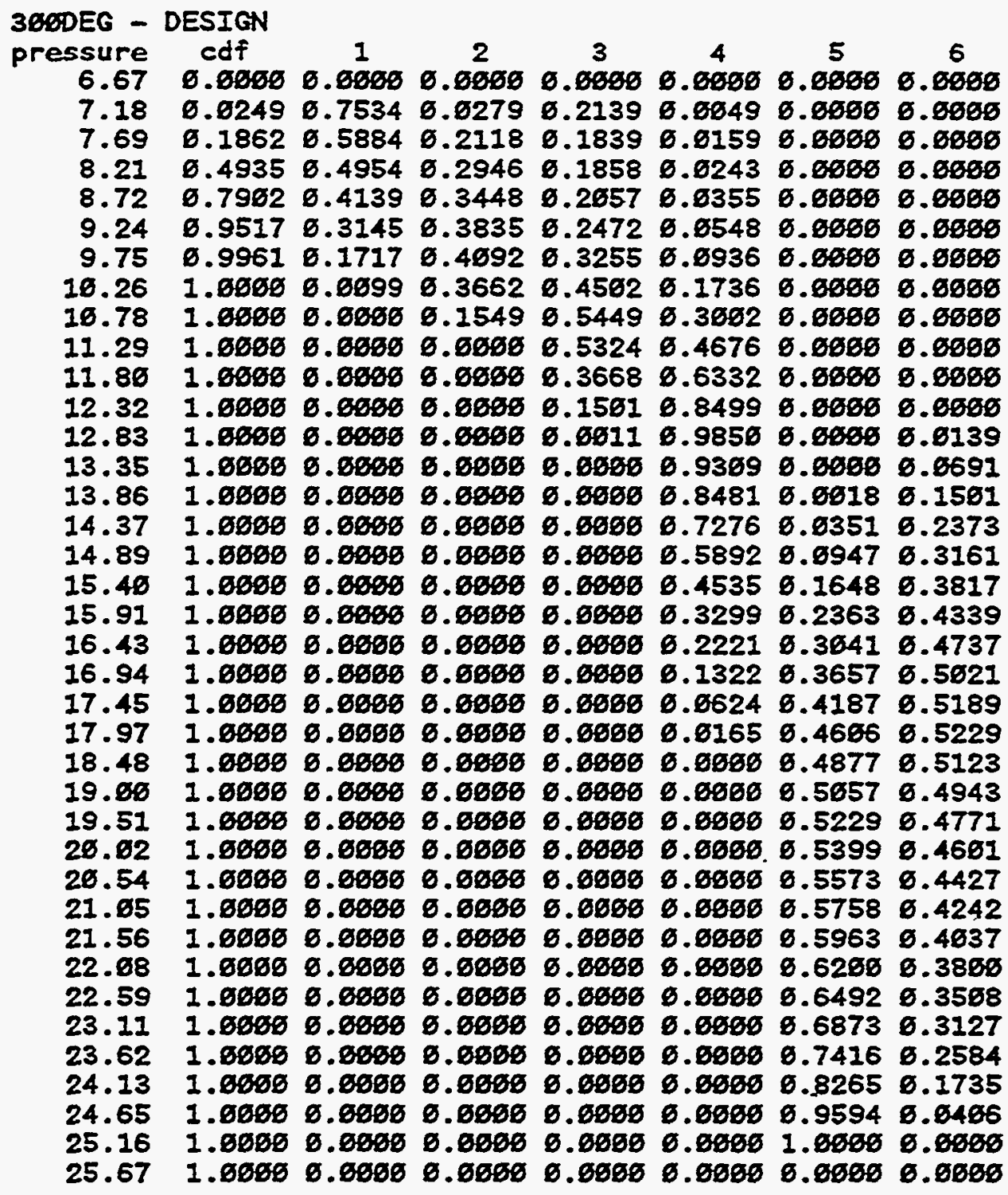




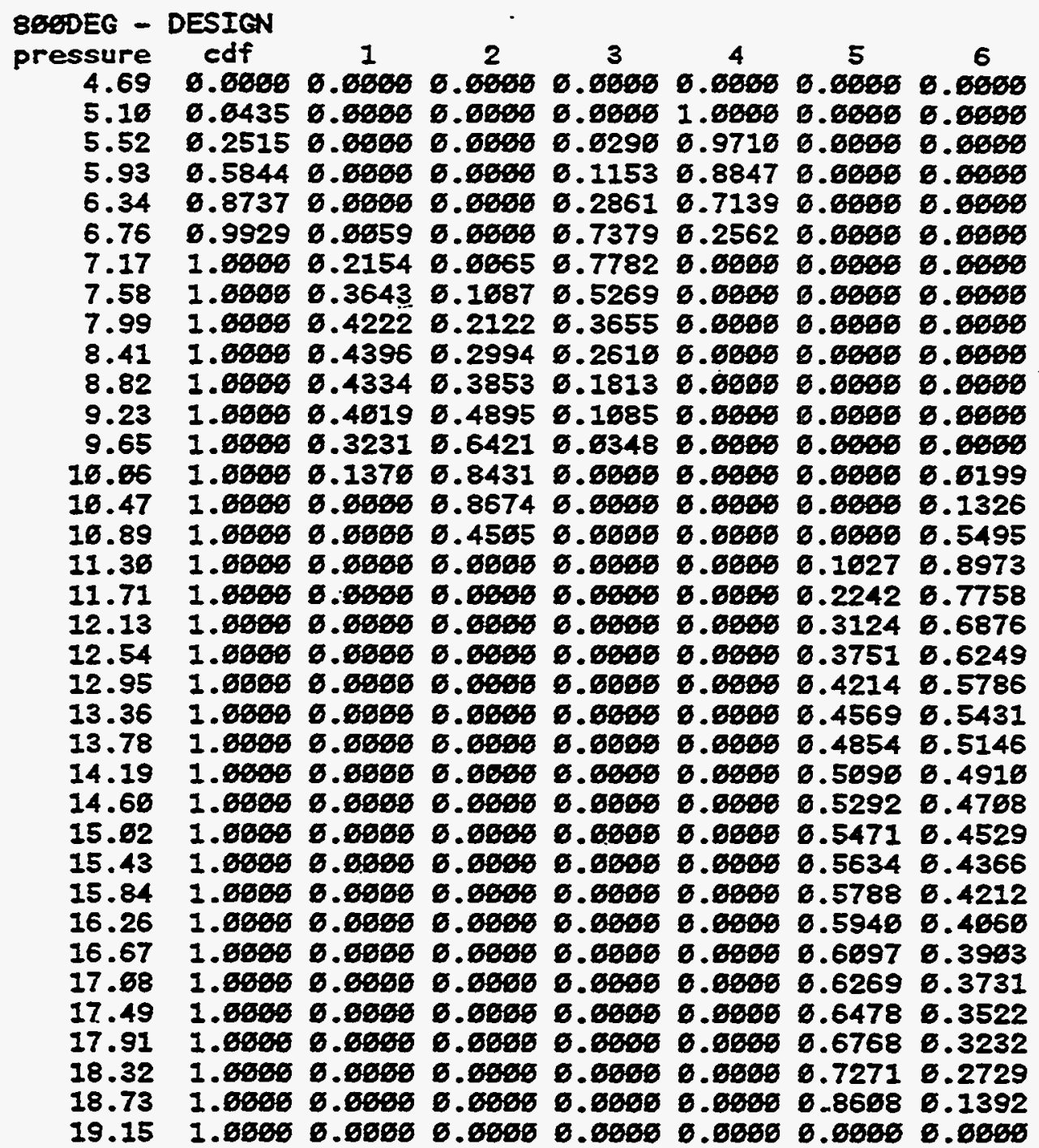




\begin{tabular}{|c|c|c|c|c|c|c|c|}
\hline $\begin{array}{r}\text { essure } \\
6.99 \\
7.56 \\
8.81 \\
8.53 \\
9.84 \\
9.55 \\
16.86 \\
10.58 \\
11.89 \\
11.68 \\
12.11 \\
12.63 \\
13.14 \\
13.65 \\
14.16 \\
14.68 \\
15.19 \\
15.76 \\
16.21 \\
16.73 \\
17.24 \\
17.75 \\
18.26 \\
18.78 \\
19.29 \\
19.86 \\
26.31 \\
26.83 \\
21.34 \\
21.85 \\
22.36 \\
22.87 \\
23.39 \\
23.96 \\
24.41 \\
24.92 \\
05.91\end{array}$ & 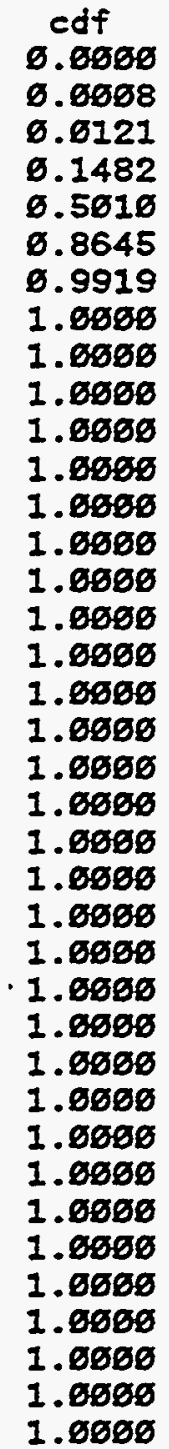 & 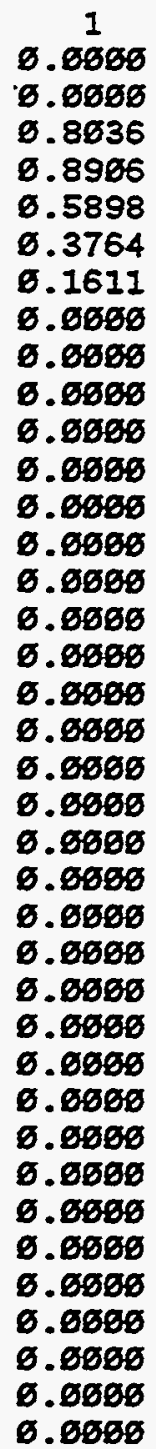 & 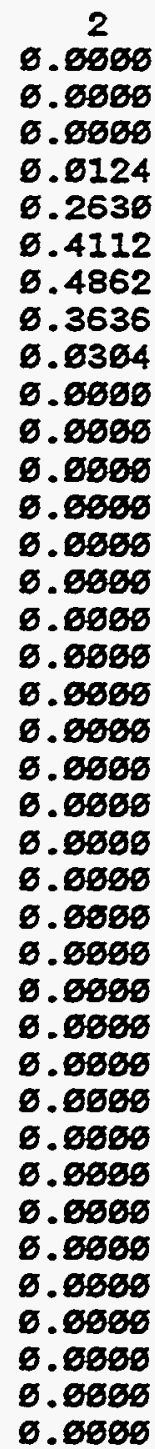 & 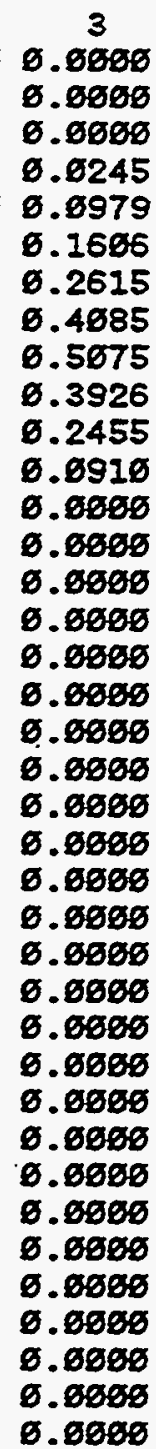 & 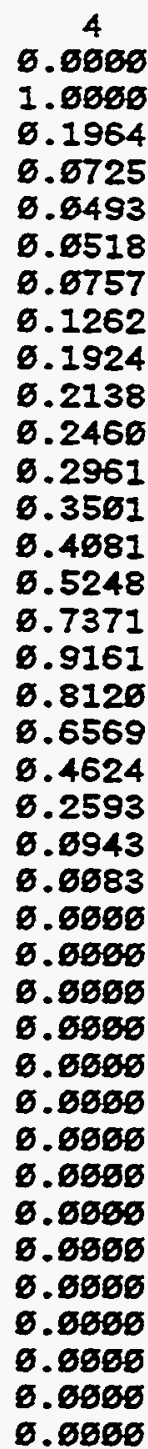 & 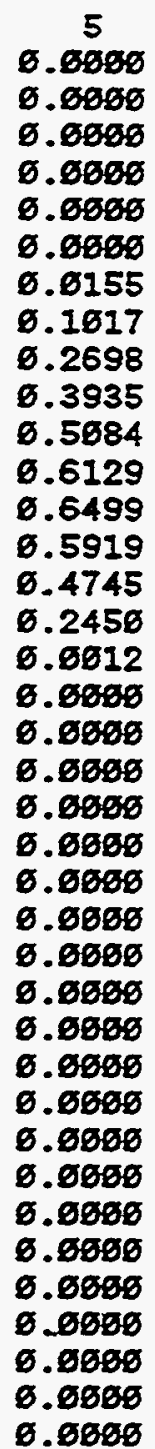 & 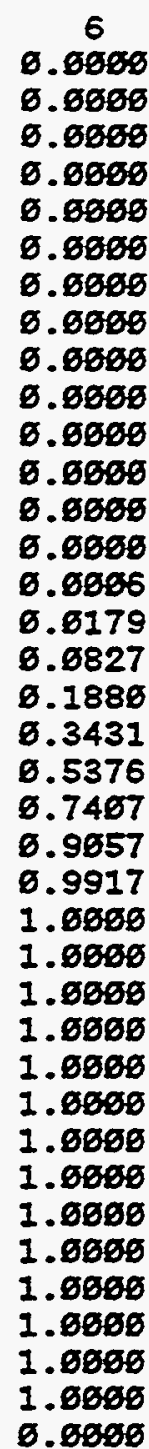 \\
\hline
\end{tabular}




\begin{tabular}{|c|c|c|c|c|c|c|c|}
\hline $\begin{array}{r}\text { essure } \\
4.69 \\
5.12 \\
5.55 \\
5.98 \\
6.42 \\
6.85 \\
7.28 \\
7.71 \\
8.14 \\
8.57 \\
9.89 \\
9.44 \\
9.87 \\
16.39 \\
16.73 \\
11.16 \\
11.59 \\
12.82 \\
12.46 \\
12.89 \\
13.32 \\
13.75 \\
14.18 \\
14.61 \\
15.84 \\
15.48 \\
15.91 \\
16.34 \\
16.77 \\
17.26 \\
17.63 \\
18.86 \\
18.58\end{array}$ & 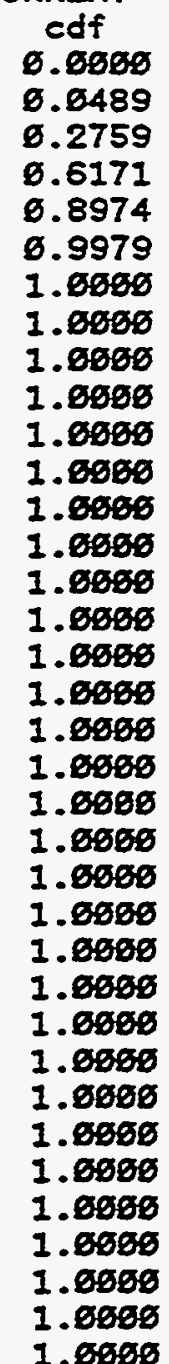 & 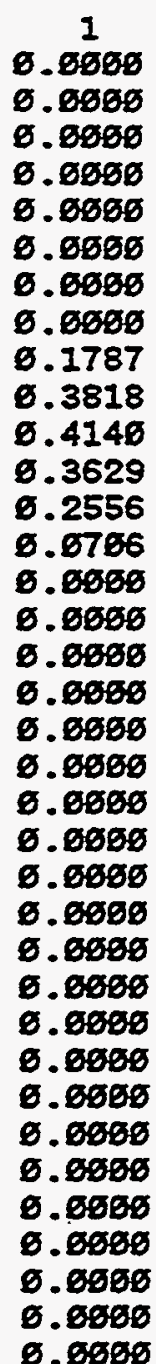 & 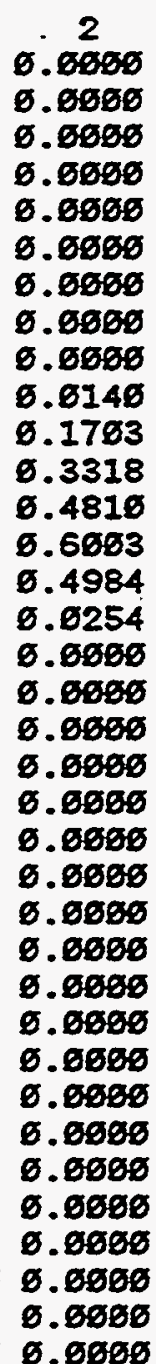 & 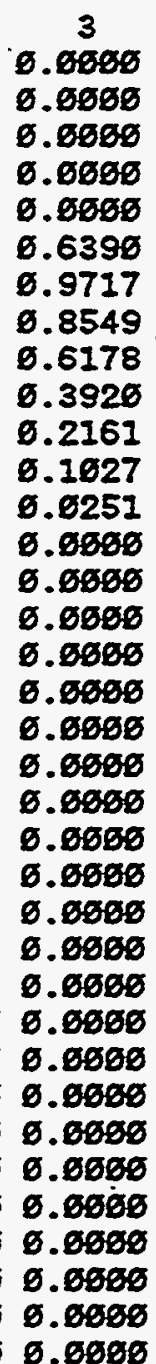 & 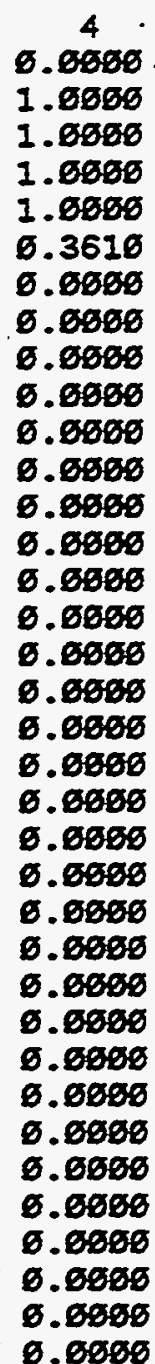 & 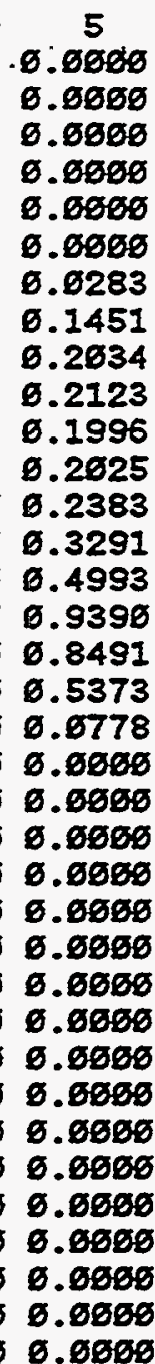 & 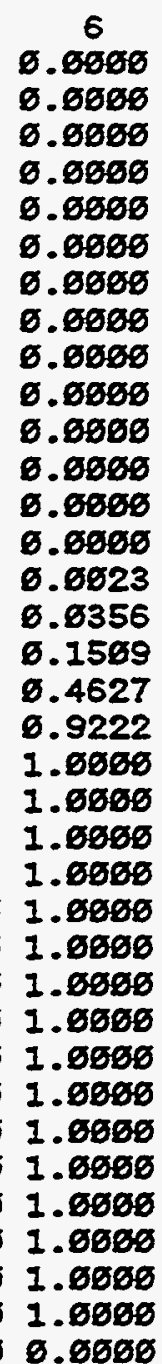 \\
\hline
\end{tabular}




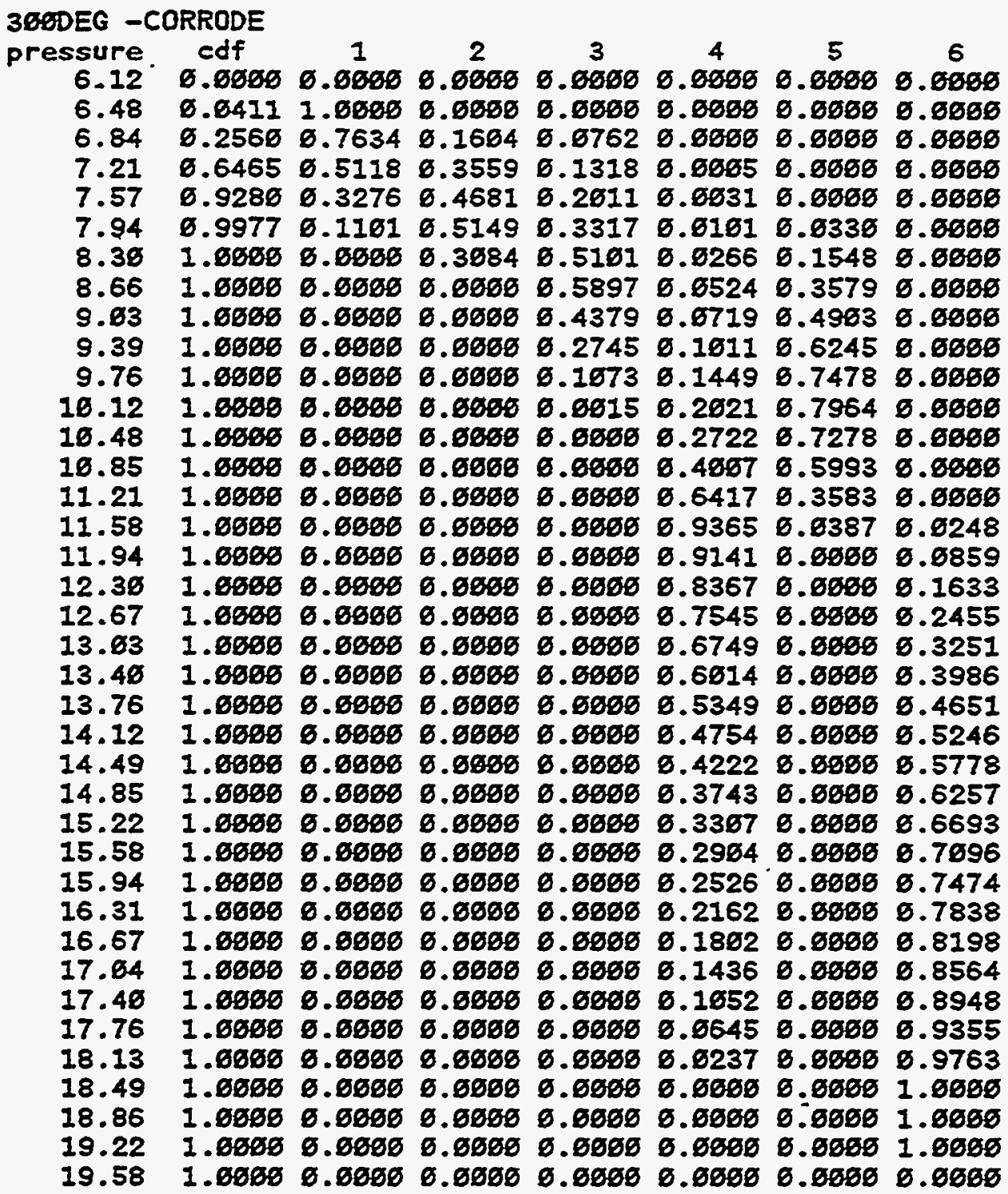




\begin{tabular}{|c|c|c|c|c|c|c|c|}
\hline $\begin{array}{r}25 s u r e \\
4.69 \\
4.99 \\
5.29 \\
5.59 \\
5.96 \\
6.29 \\
6.50 \\
6.80 \\
7.10 \\
7.46 \\
7.76 \\
8.91 \\
8.31 \\
8.61 \\
8.91 \\
9.21 \\
9.51 \\
9.81 \\
19.12 \\
16.42 \\
19.72 \\
11.62 \\
11.32 \\
11.62 \\
11.92 \\
12.23 \\
12.53 \\
12.83 \\
13.13 \\
13.43 \\
13.73 \\
14.83 \\
14.34 \\
14.64 \\
11.04\end{array}$ & 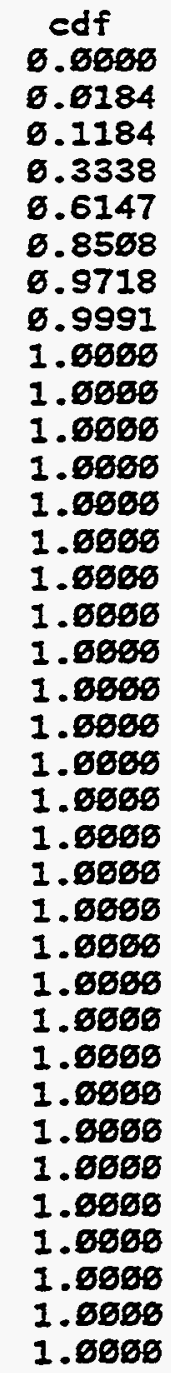 & 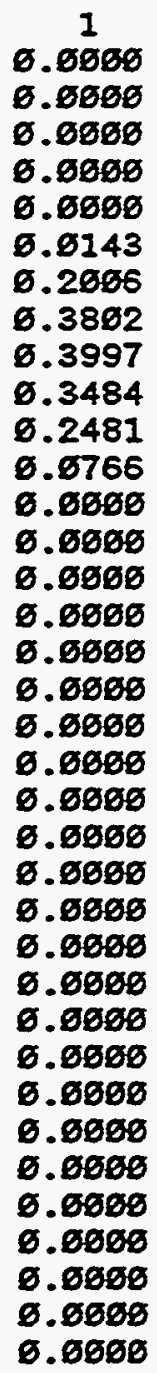 & 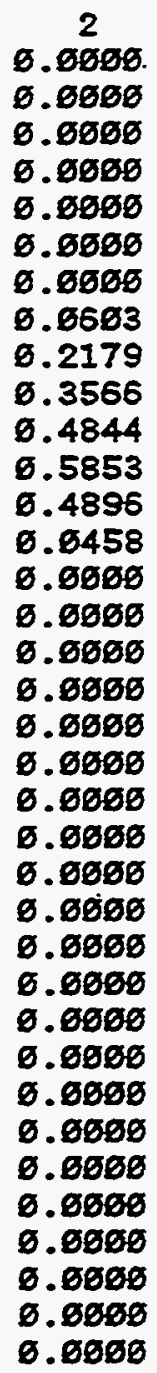 & 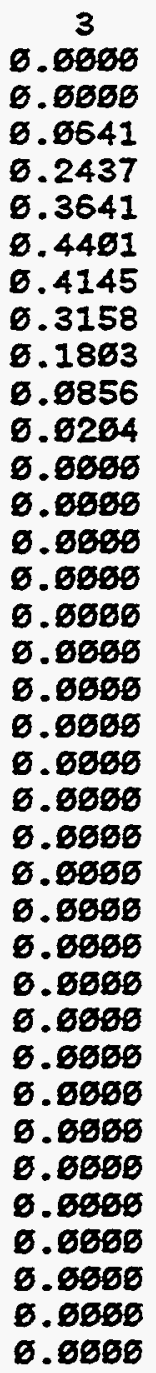 & 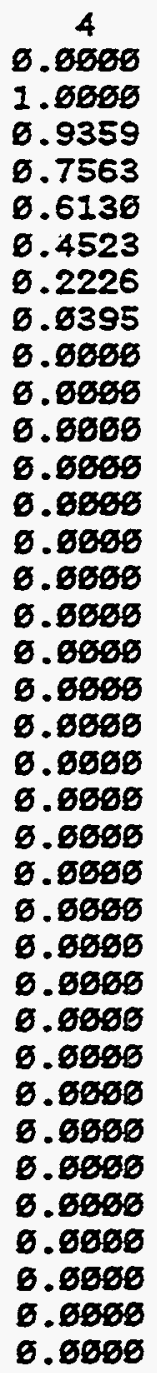 & 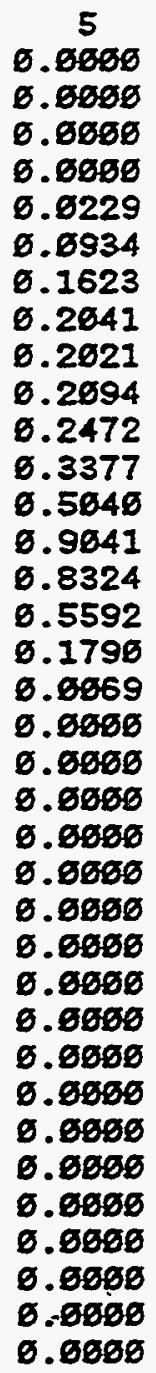 & 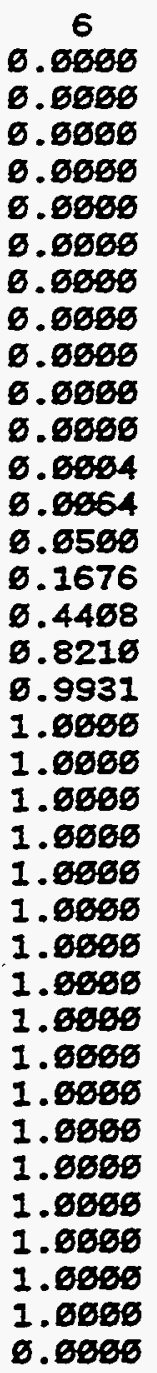 \\
\hline
\end{tabular}




\section{APPENDIX C}

\section{EVNTRE Results}

The attached figures show the EVNTRE results for each of the nine Plant Damage State Groups for the various cases considered in this report.

Figures C-1 to C-9: $\quad$ Peach Bottom containment with $100 \%$ pressure capability

Figures C-10 to C-18: Peach Bottom containment with $75 \%$ pressure capability

Figures C-19 to C-27: Nine Mile Point/Oyster Creek containment with 100 psig venting pressure and design pressure capability

Figures C-28 to C-36: Nine Mile Point/Oyster Creek containment with 100 psig venting pressure and current pressure capability

Figures C-37 to C-45: Nine Mile Point/Oyster Creek containment with 100 psig venting pressure and corroded pressure capability

Figures C-46 to C-54: Nine Mile Point/Oyster Creek containment with 43.4 psig venting pressure and design pressure capability

Figures C-55 to C-63: Nine Mile Point/Oyster Creek containment with 43.4 psig venting pressure and current pressure capability

Figures C-64 to C-72: Nine Mile Point/Oyster Creek containment with 43.4 psig venting pressure and corroded pressure capability

Figures C-73 to C-81: Nine Mile Point/Oyster Creek containment with 35 psig venting pressure and design pressure capability

Figures C-82 to C-90: Nine Mile Point/Oyster Creek containment with 35 psig venting pressure and current pressure capability

Figures C-91 to C-99: Nine Mile Point/Oyster Creek containmentwith 35 psig venting pressure and corroded pressure capability

C-1 


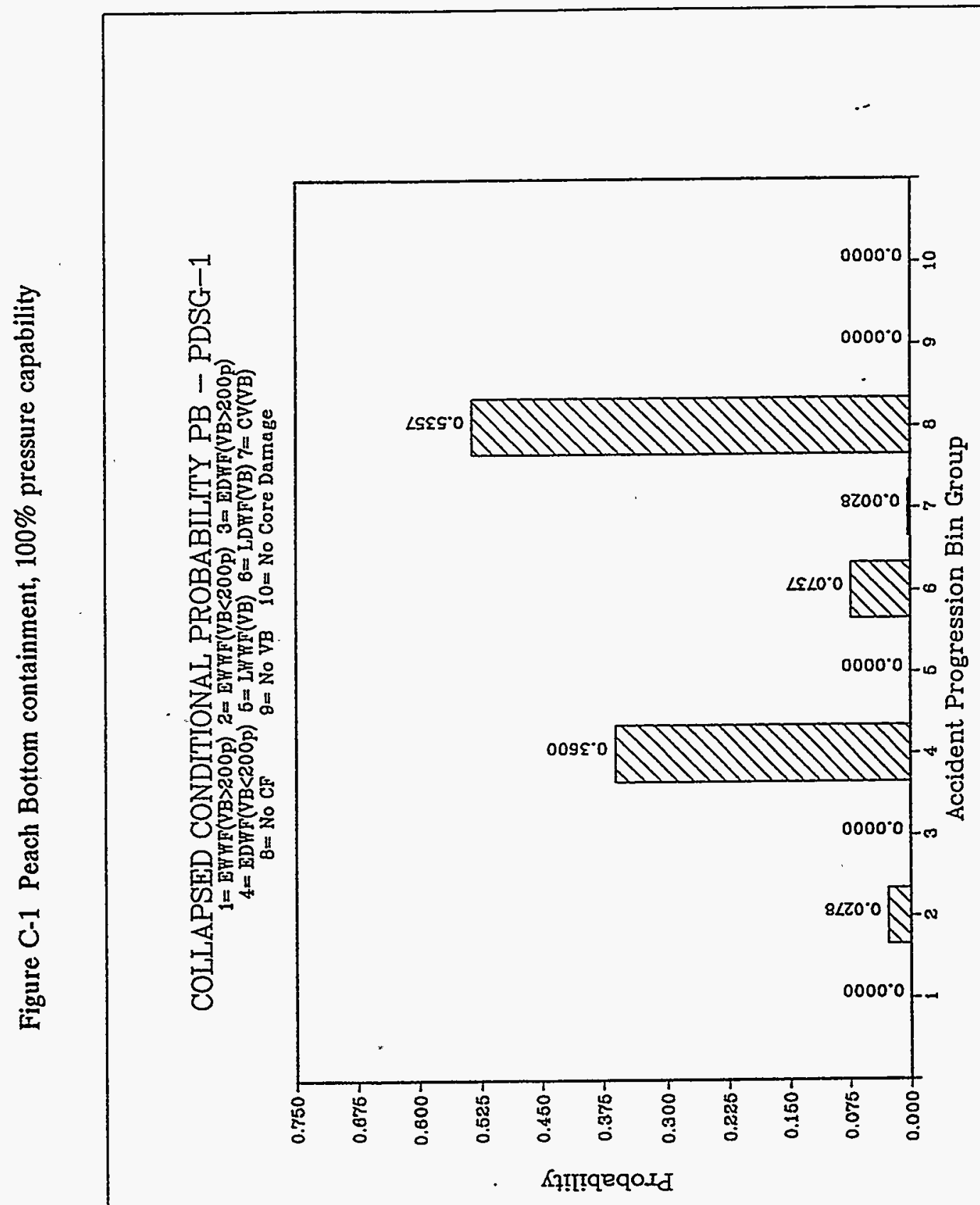

C-2 


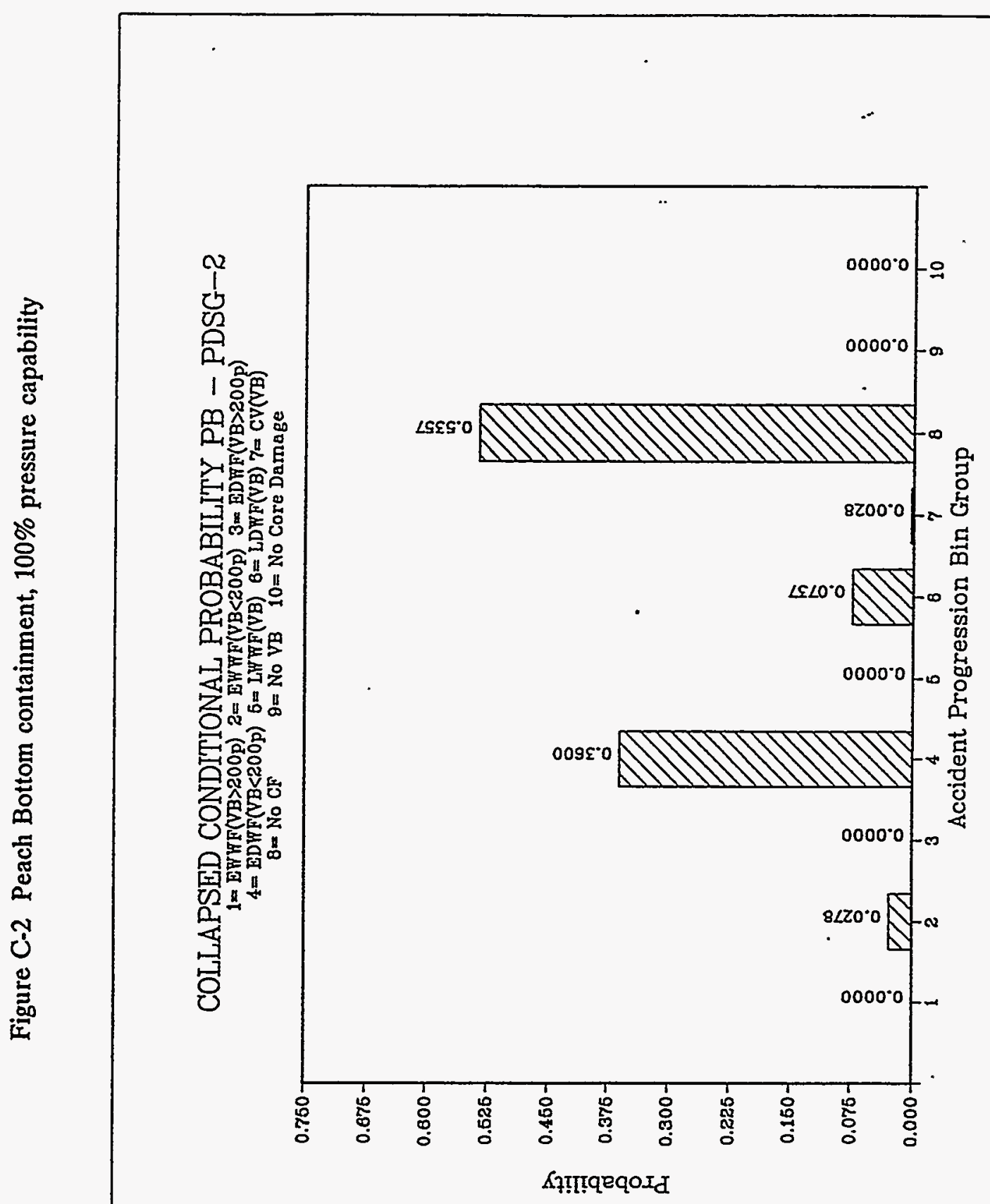

C-3 
Figure C-3 Peach Bottom containment, 100\% pressure capability

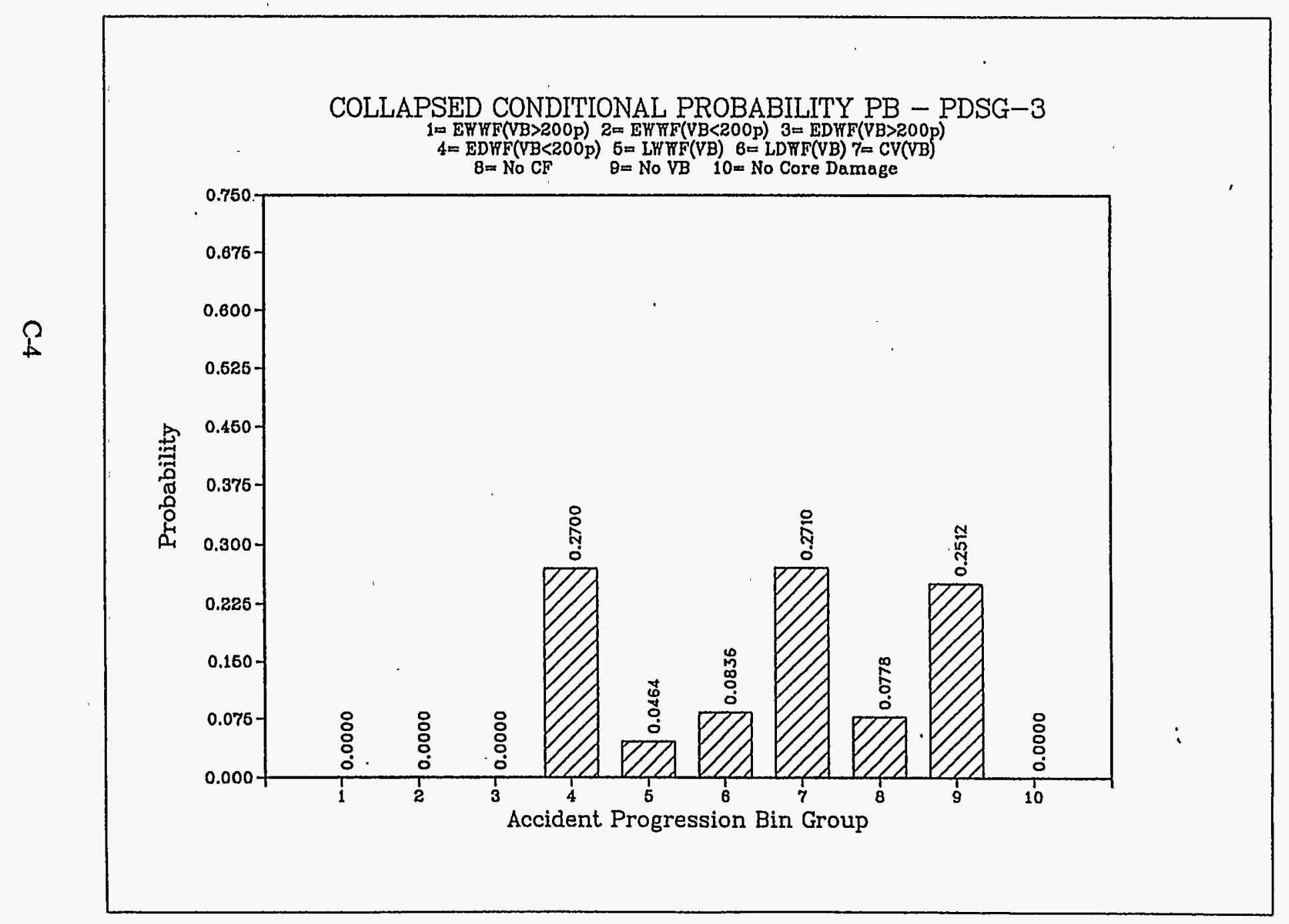




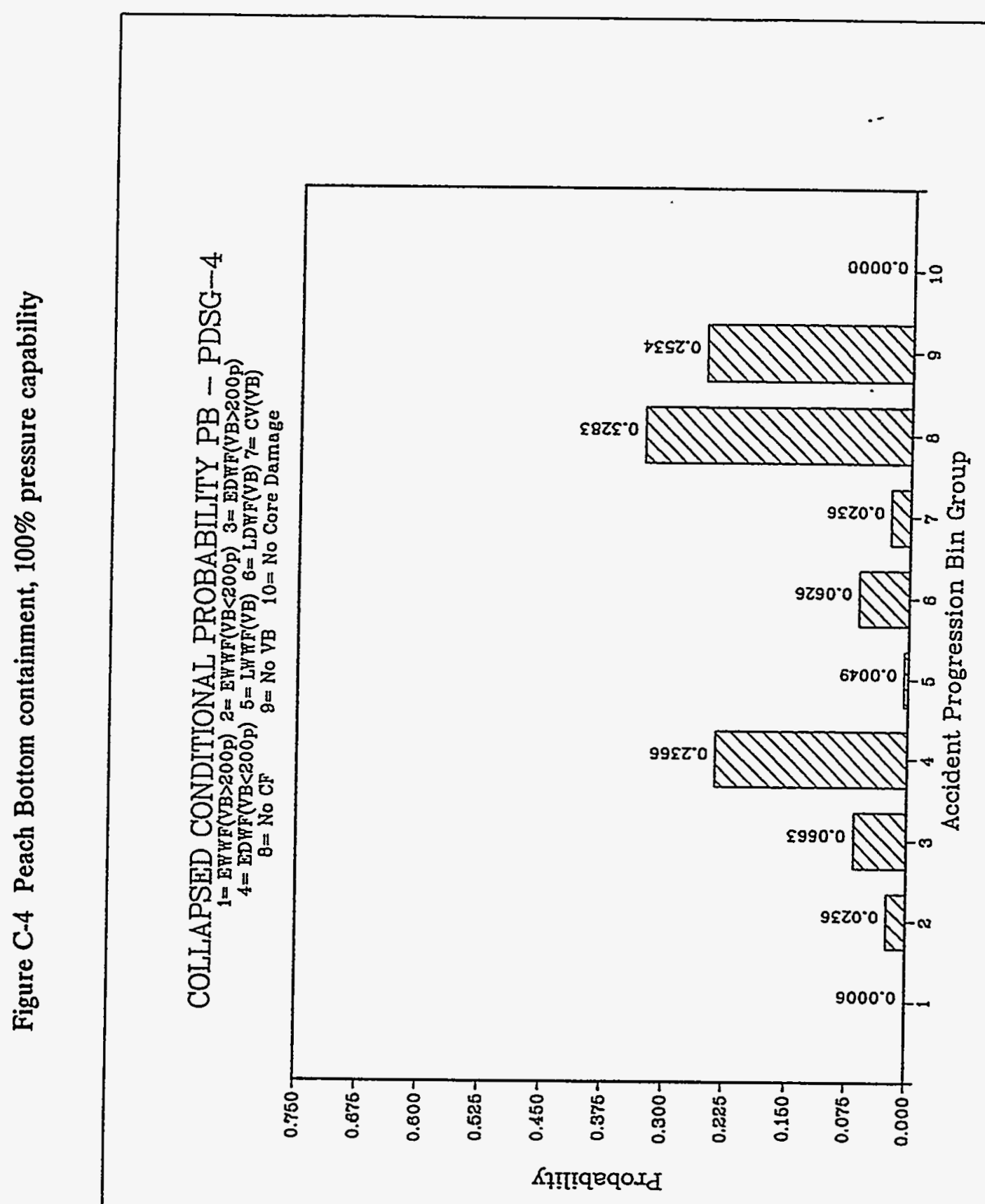

C-5 
Figure C-5 Peach Bottom containment, $100 \%$ pressure capability

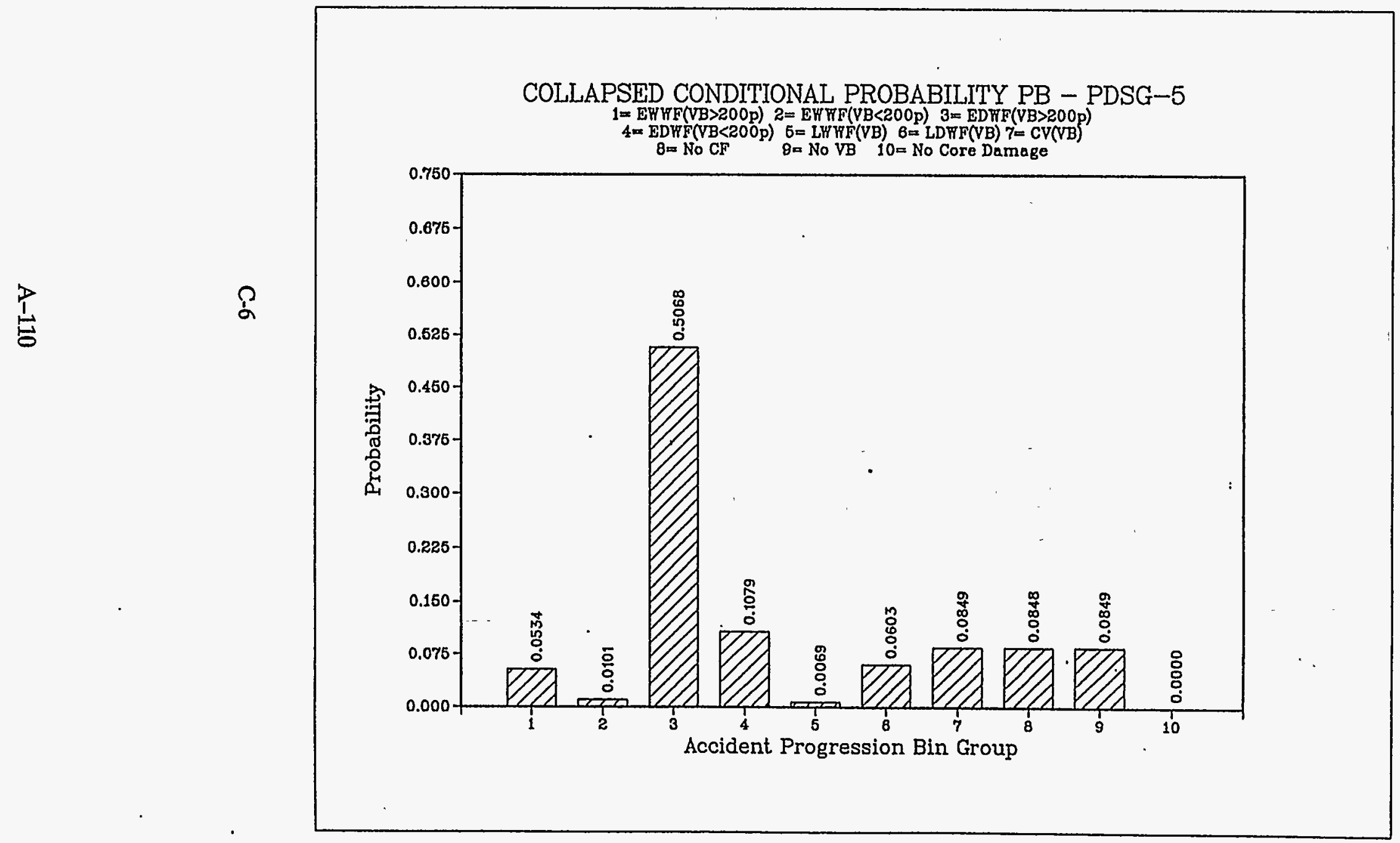




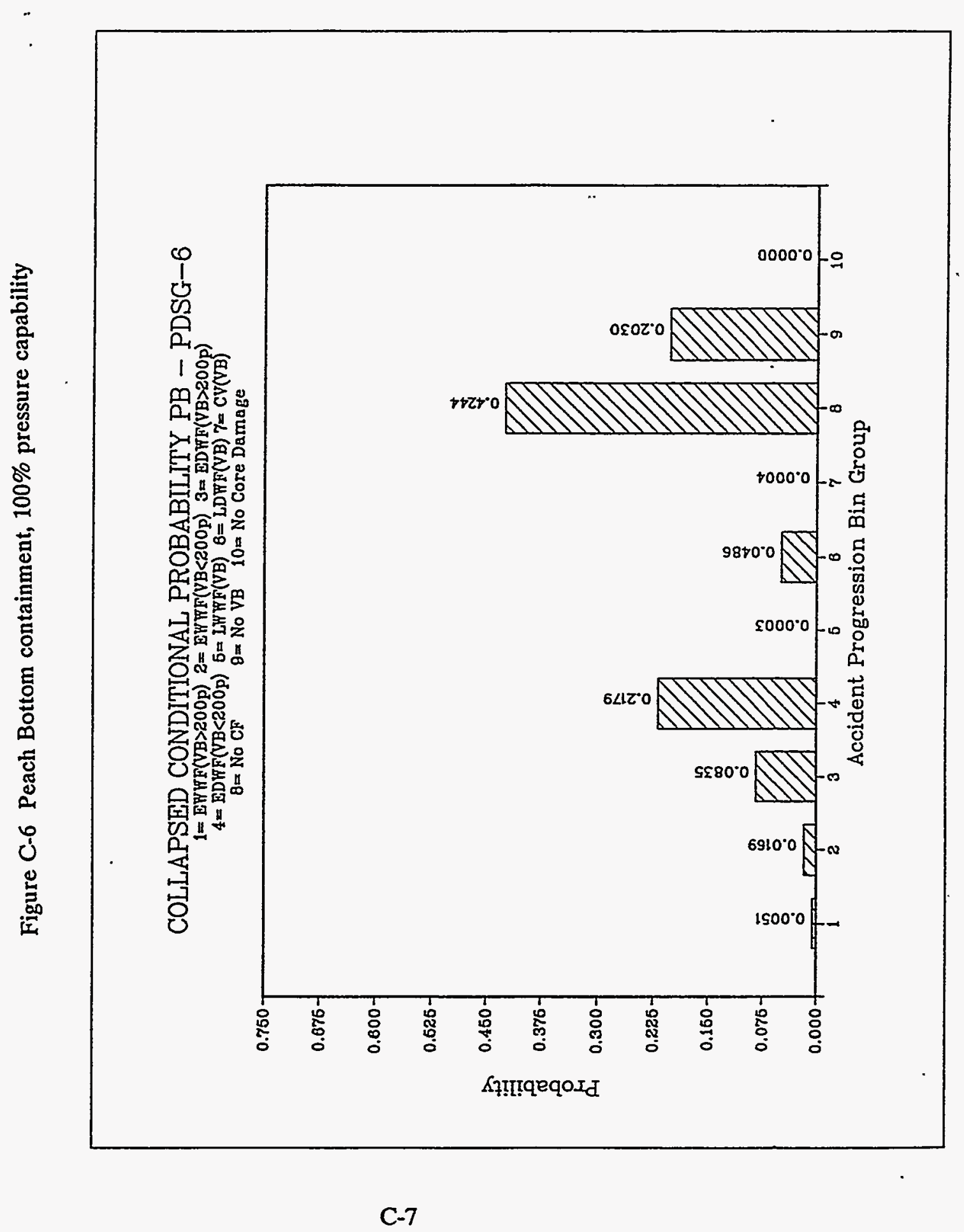




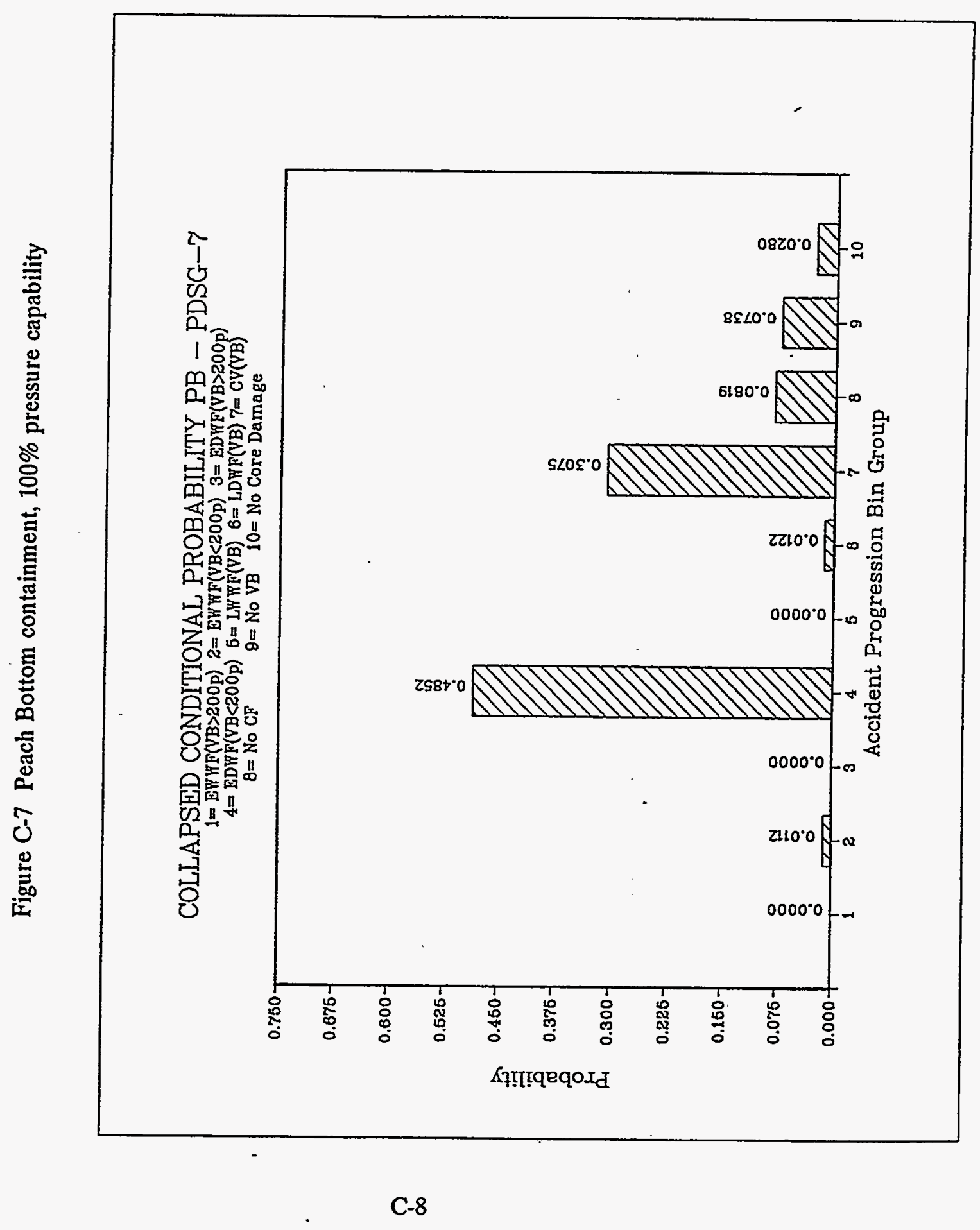


Figure C-8 Peach Bottom containment, $100 \%$ pressure capability

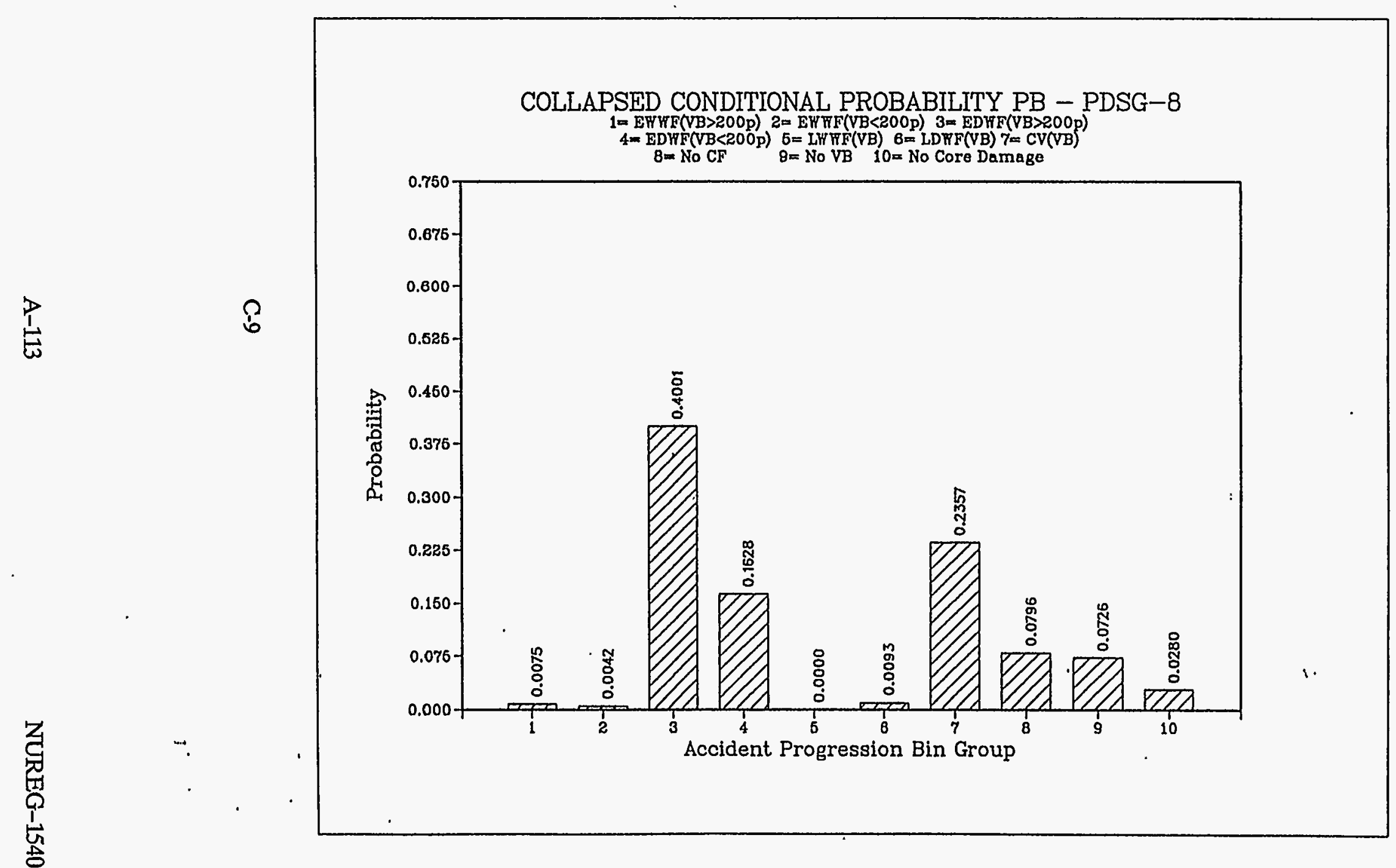




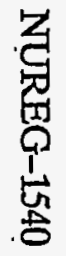

Figure C-9 Peach Bottom containment, 100\% pressure capability

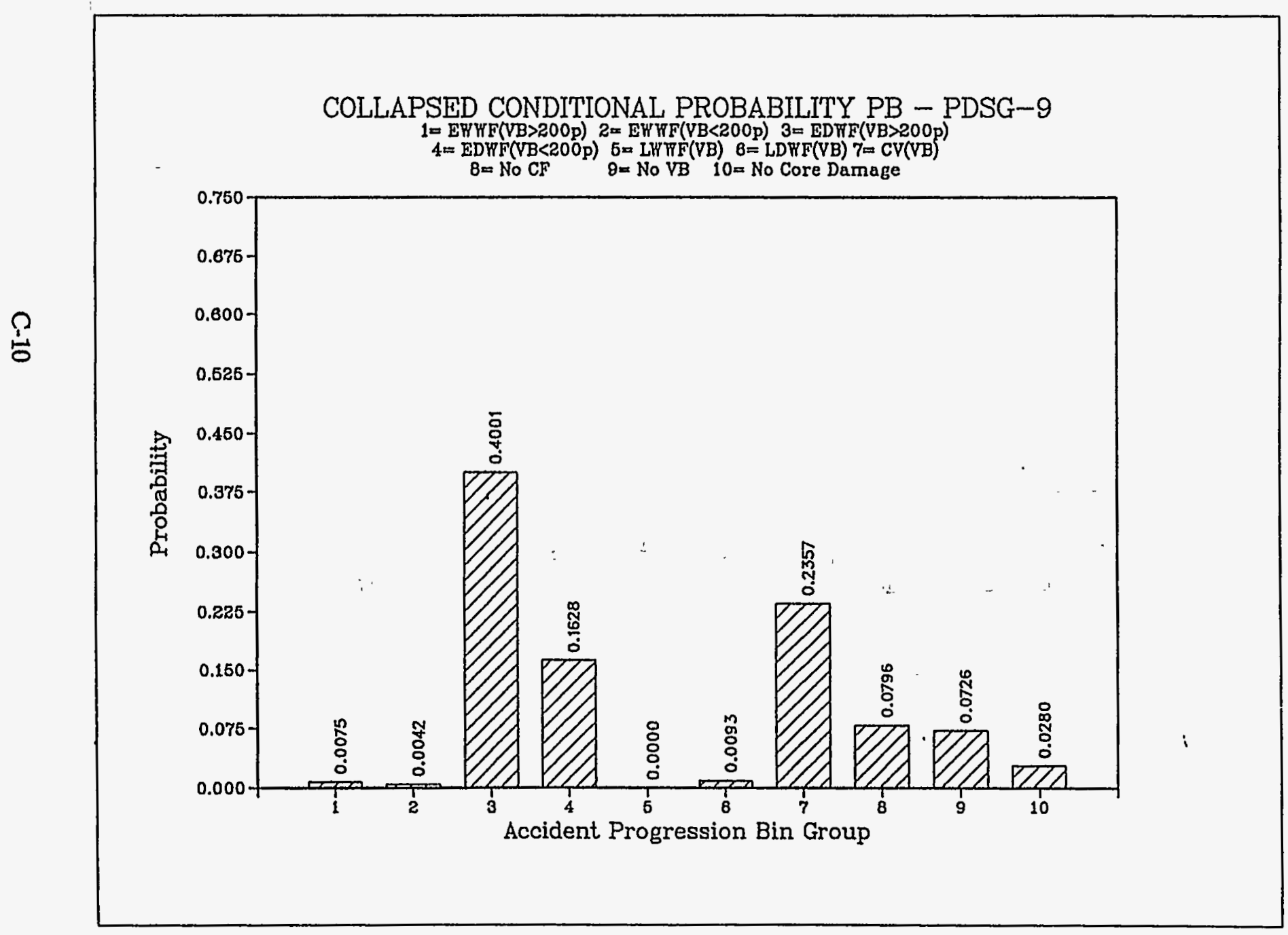




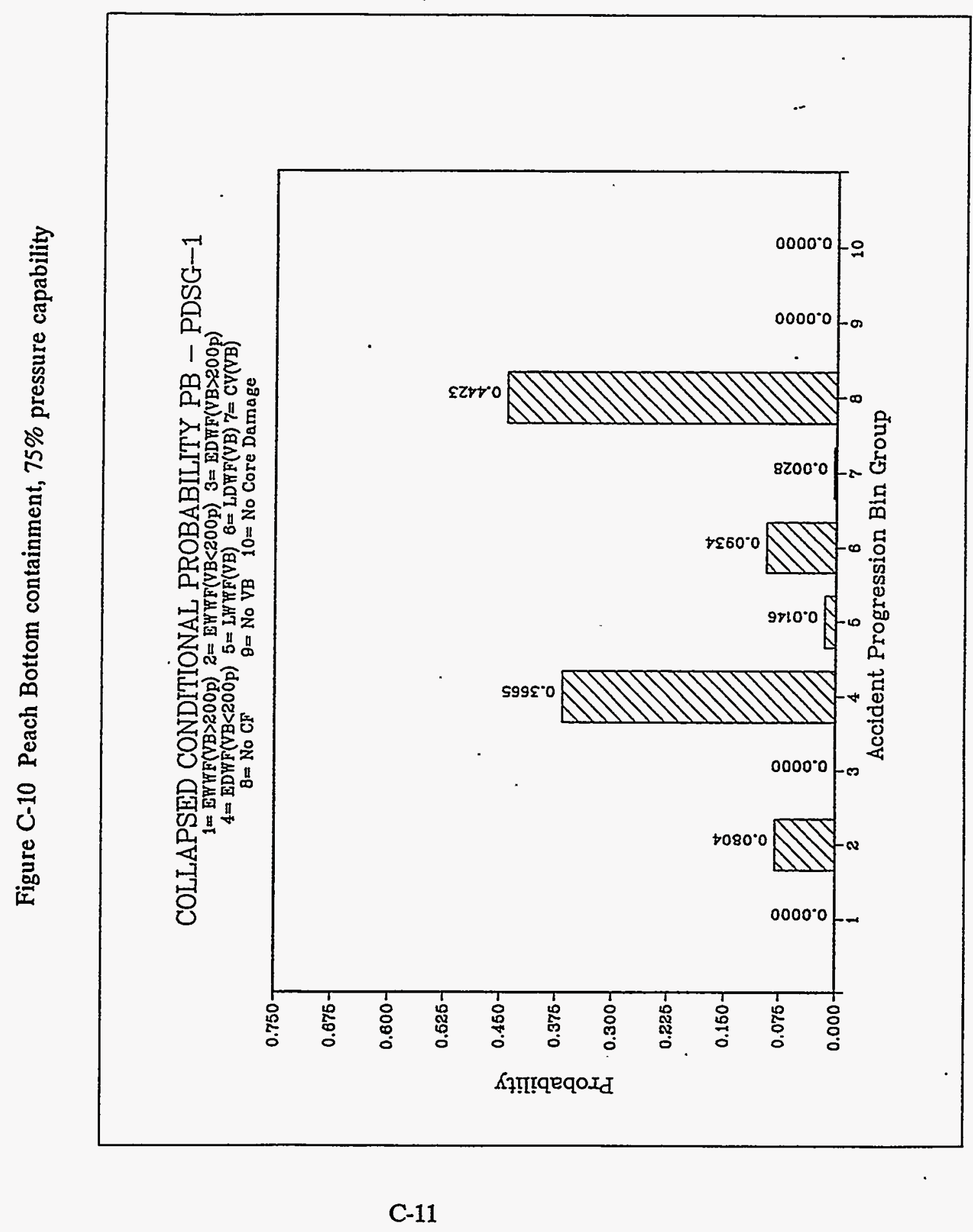


Figure C-11 Peach Bottom containment, $75 \%$ pressure capability

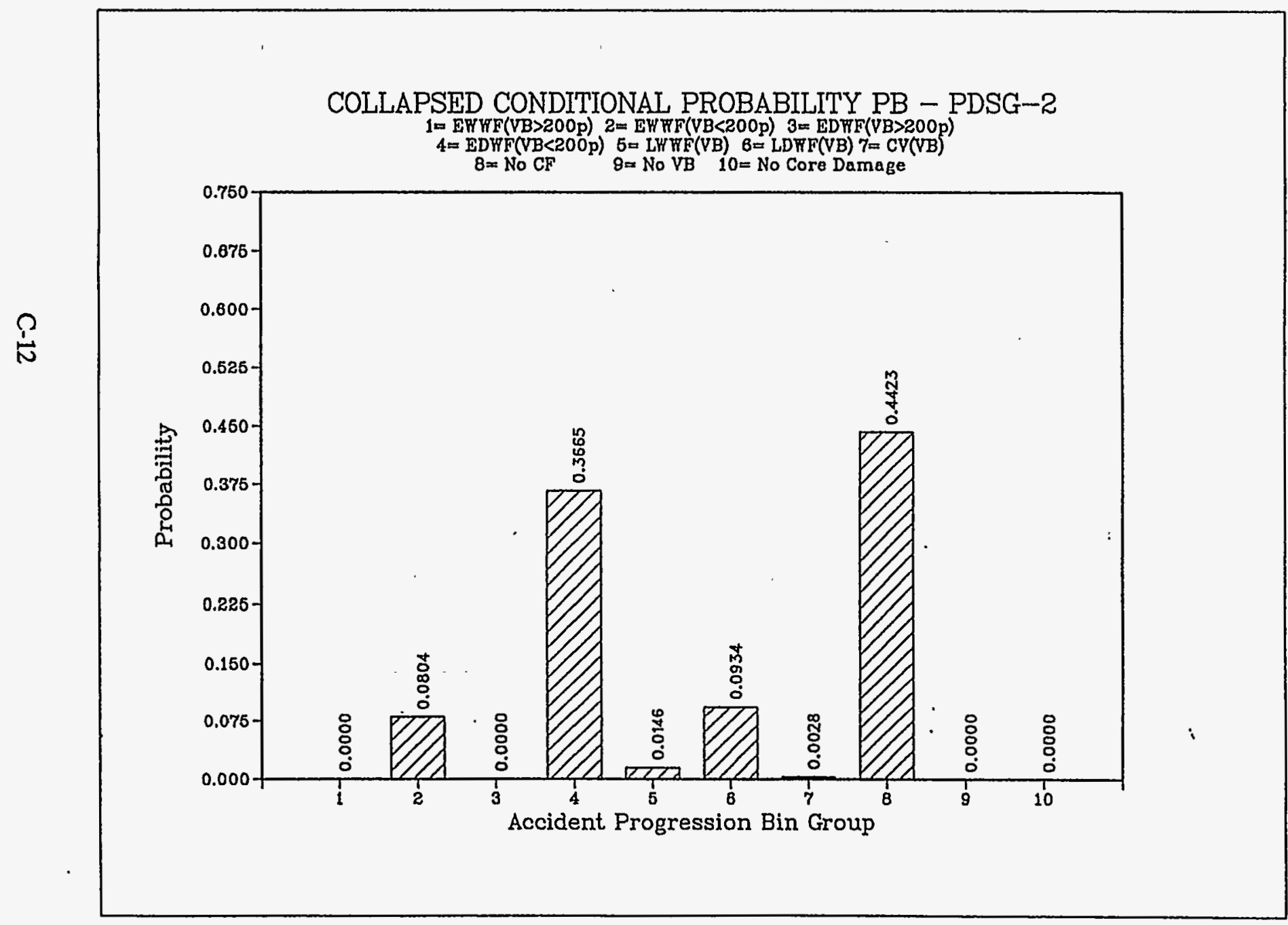


Figure C-12 Peach Bottom containment, $75 \%$ pressure capability

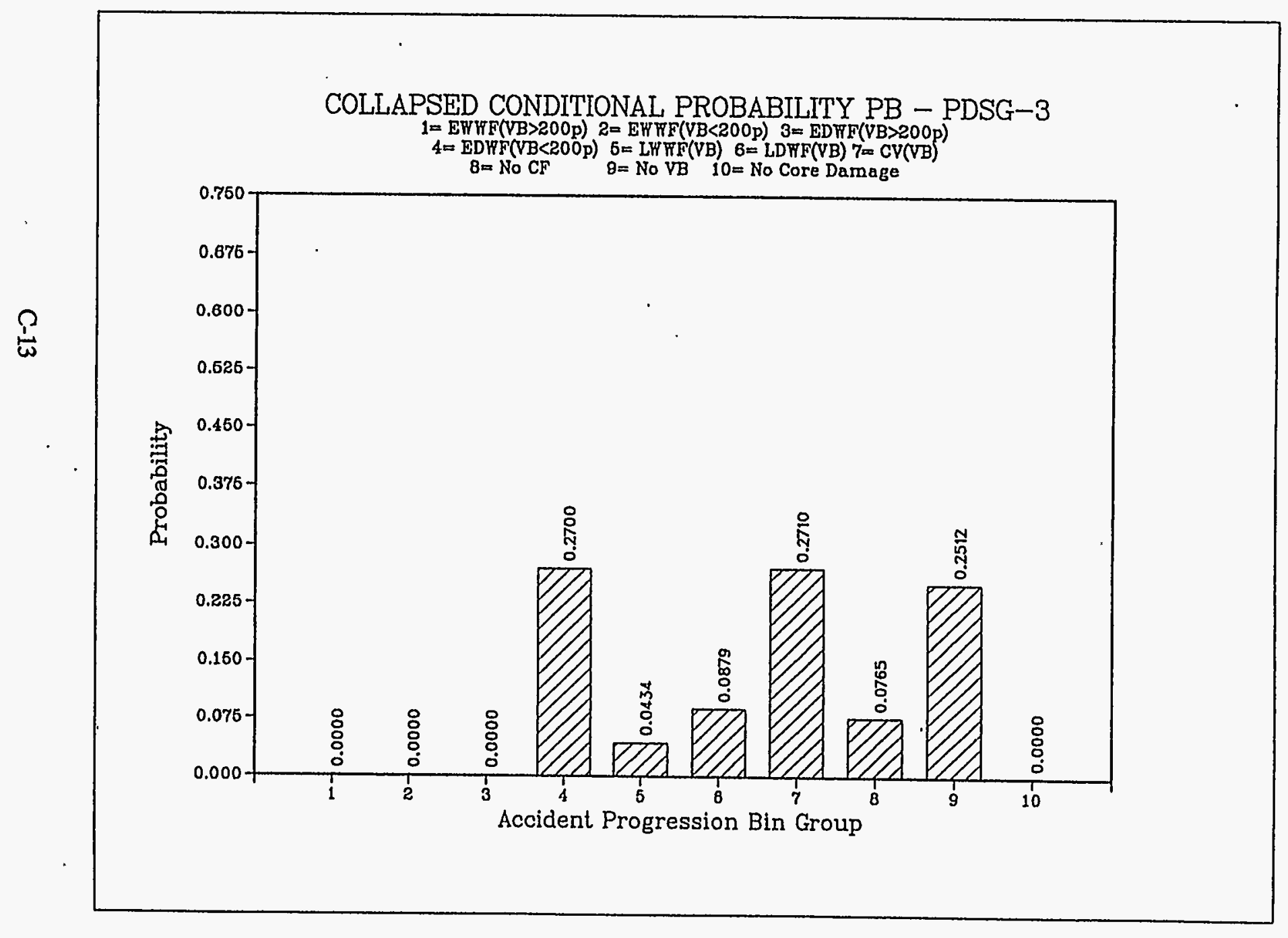


Figure C-13 Peach Bottom containment, $75 \%$ pressure capability

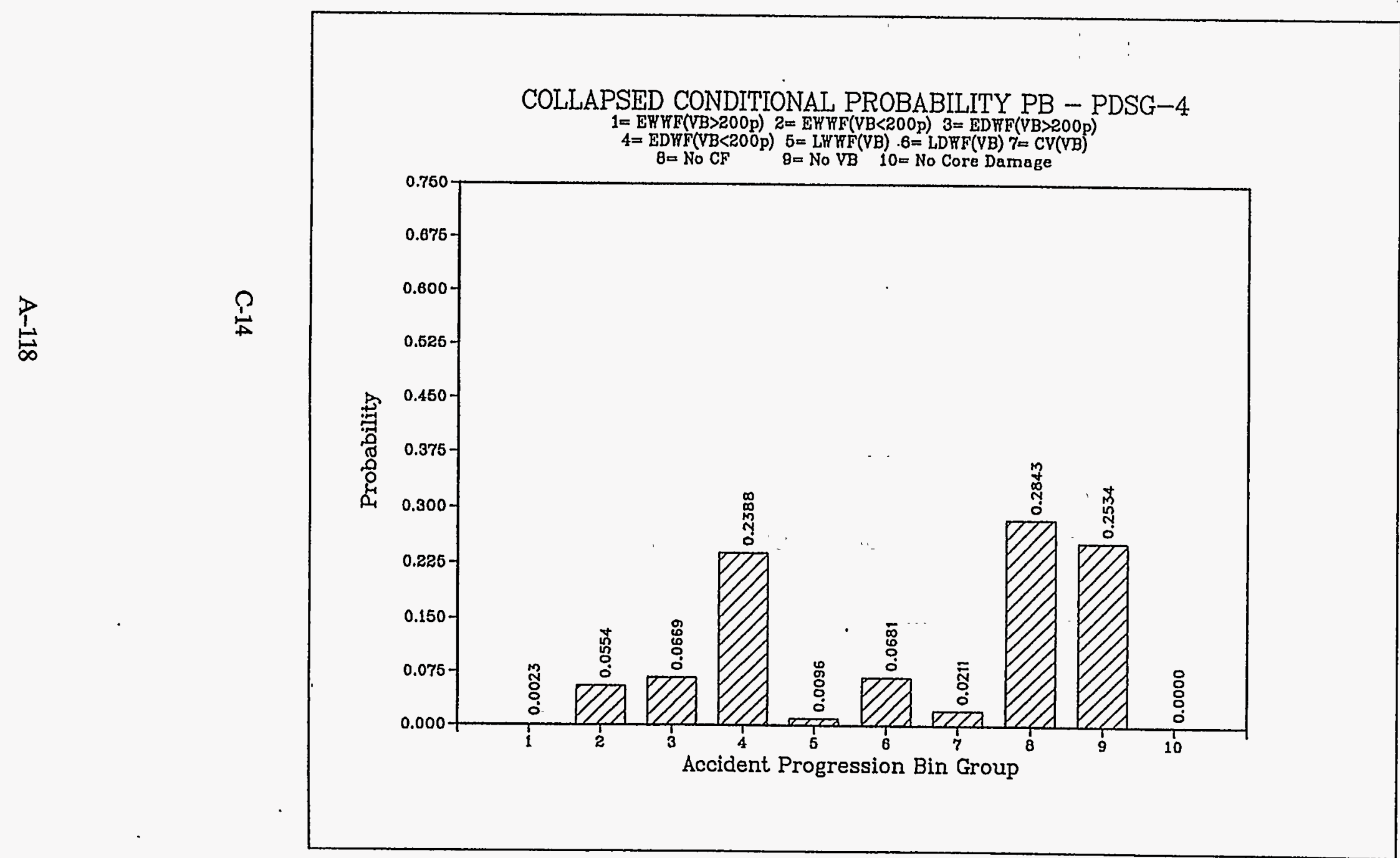




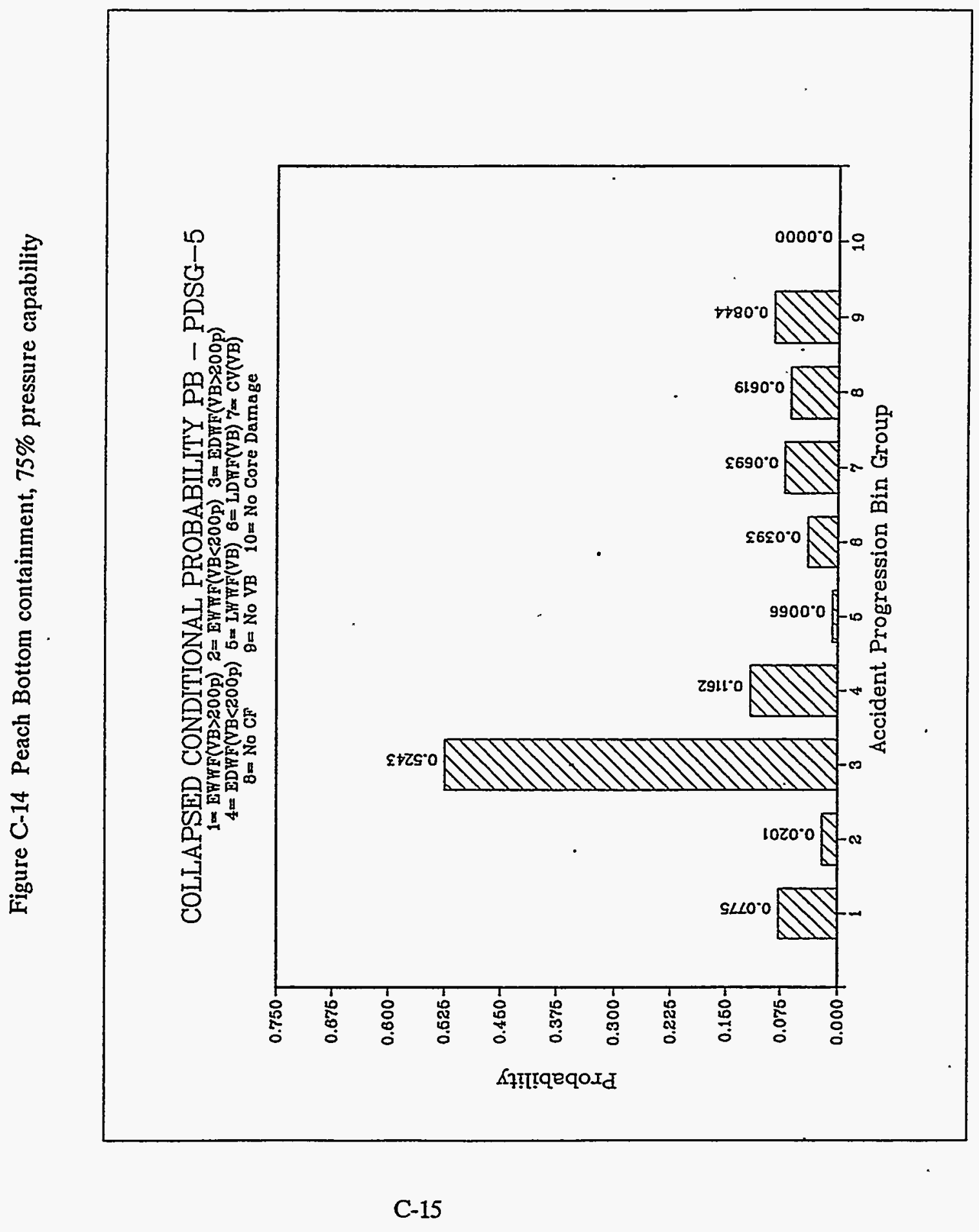


Figure C-15 Peach Bottom containment, 75\% pressure capability

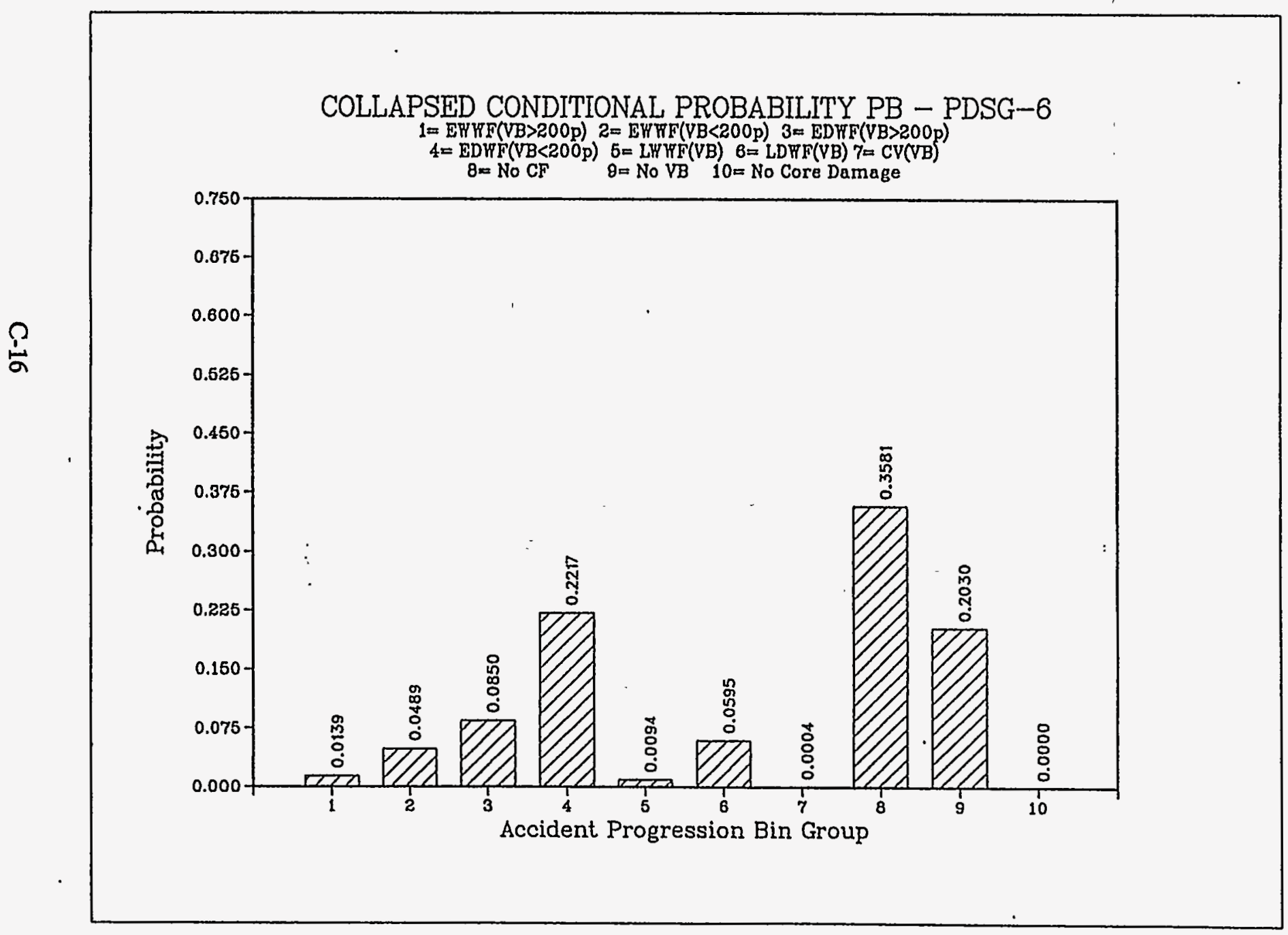




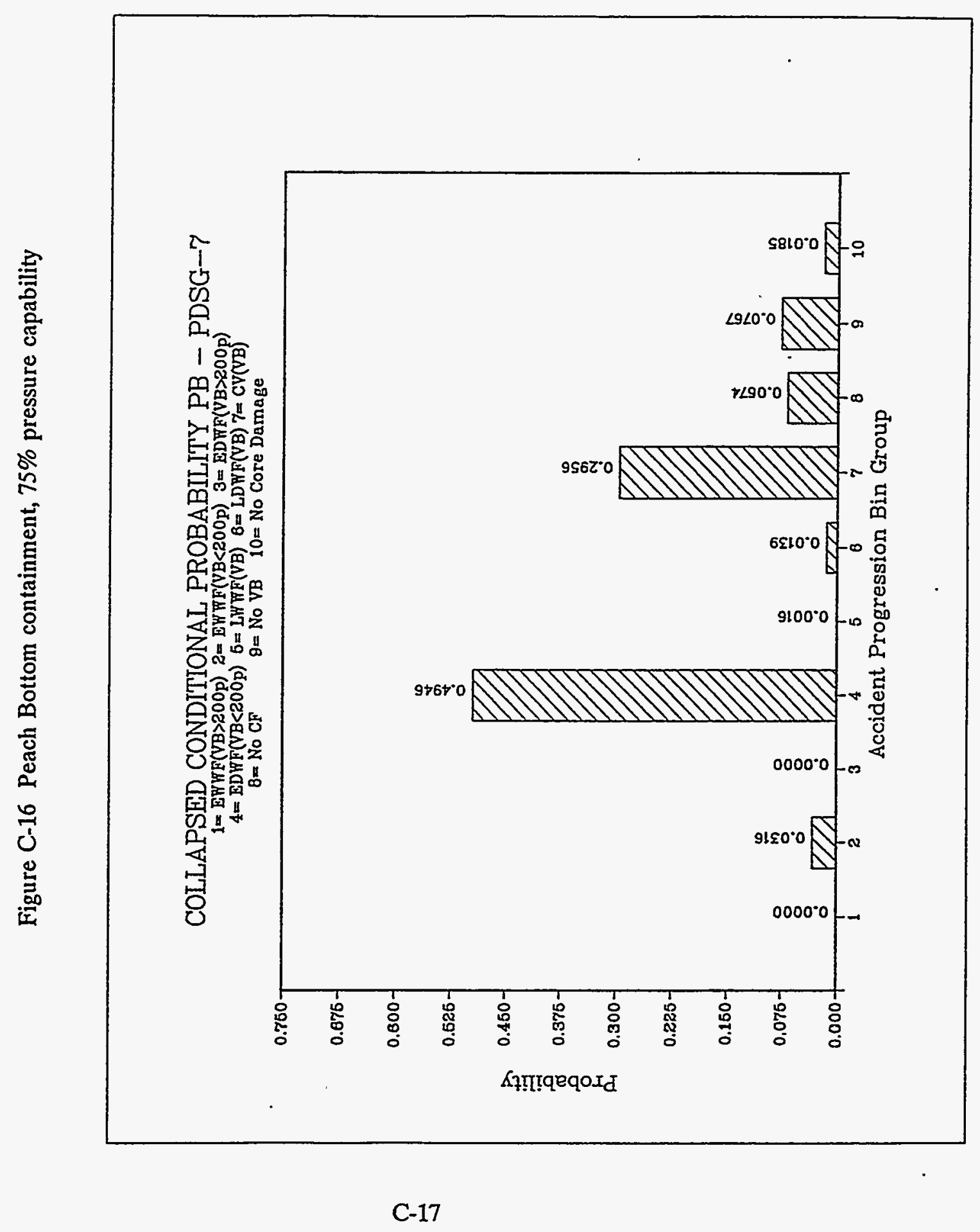


Figure C-17 Peach Bottom containment, $75 \%$ pressure capability

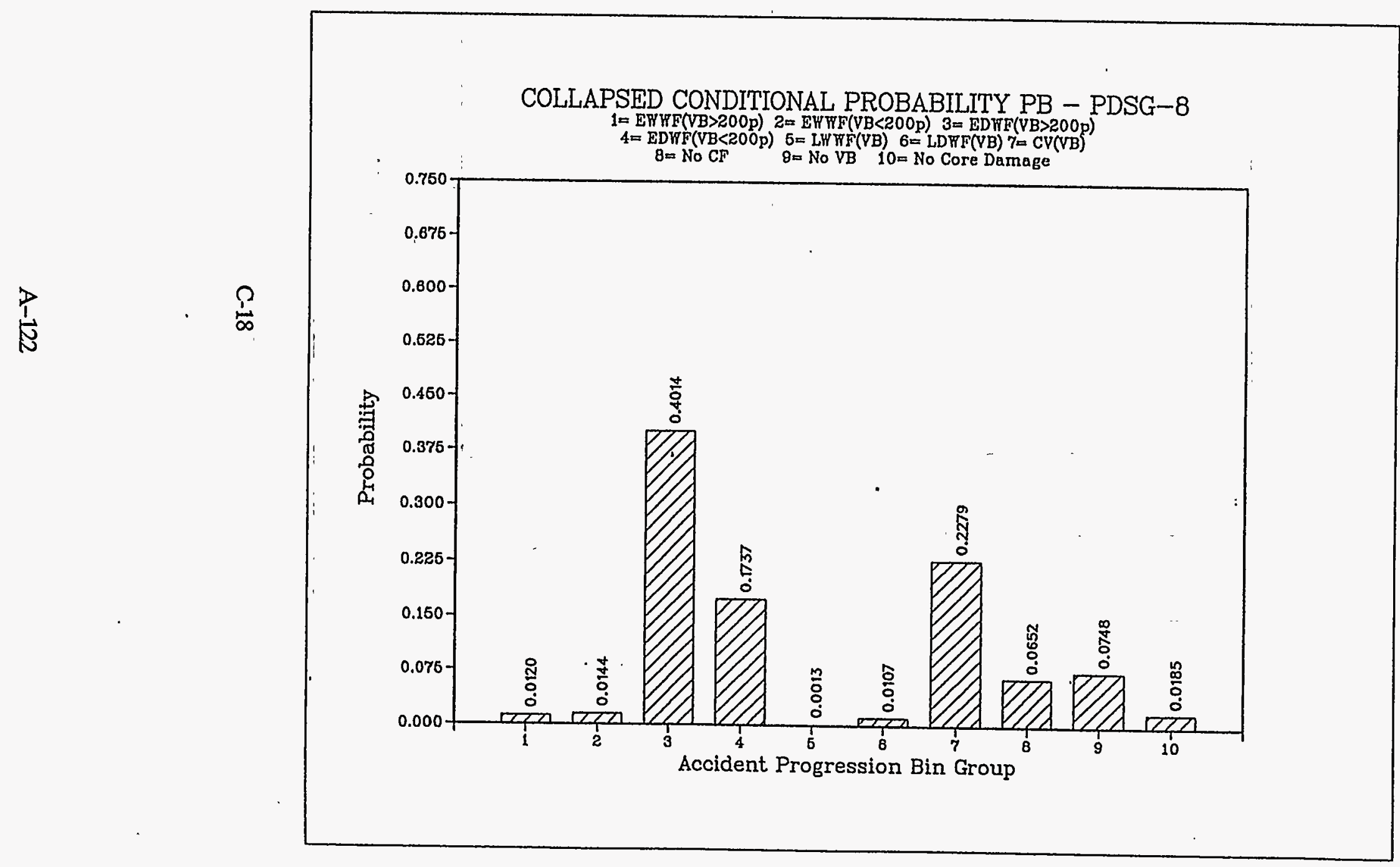




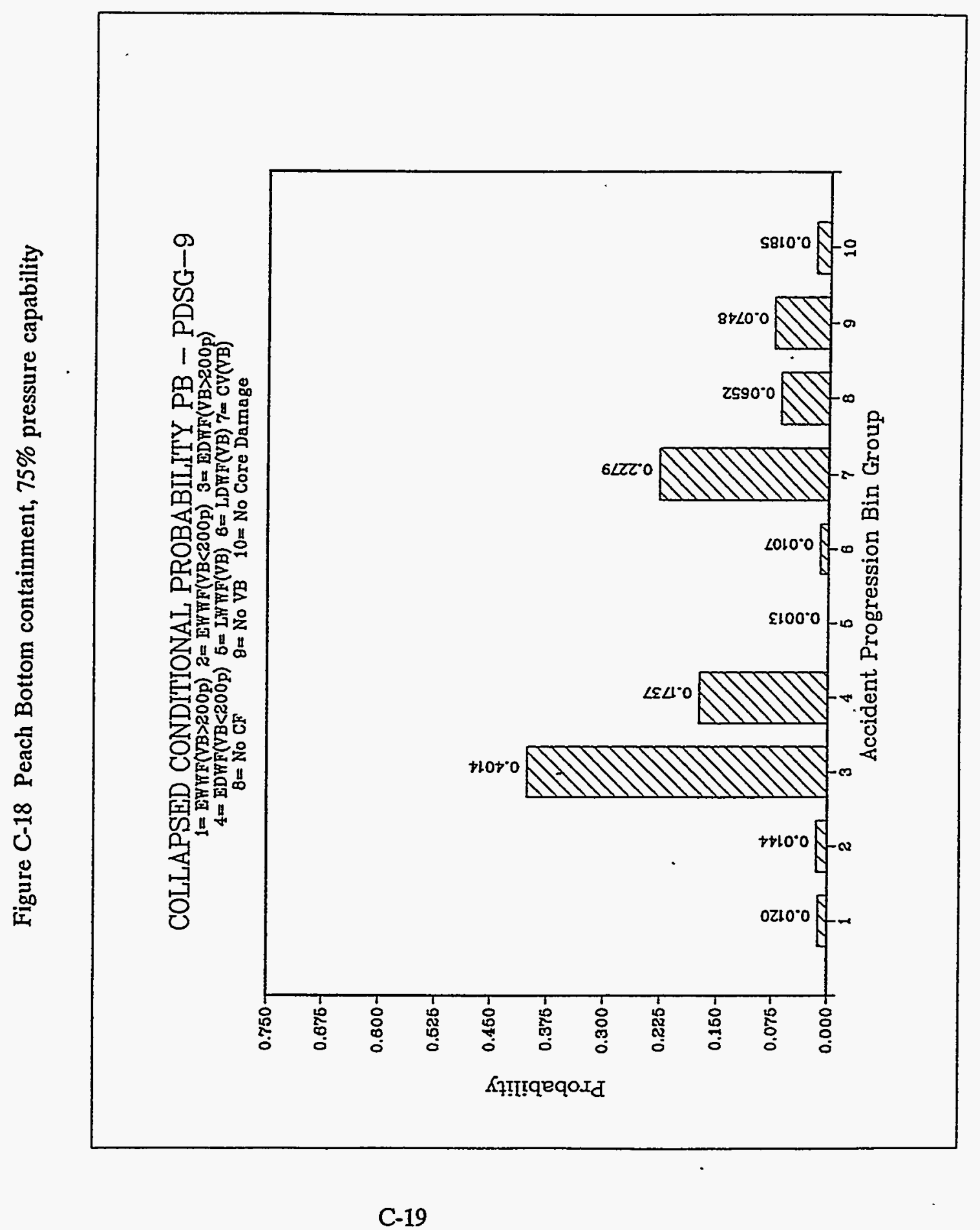


Figure C-19 NMP/OC containment, 100 psig vent pressure, design pressure capability

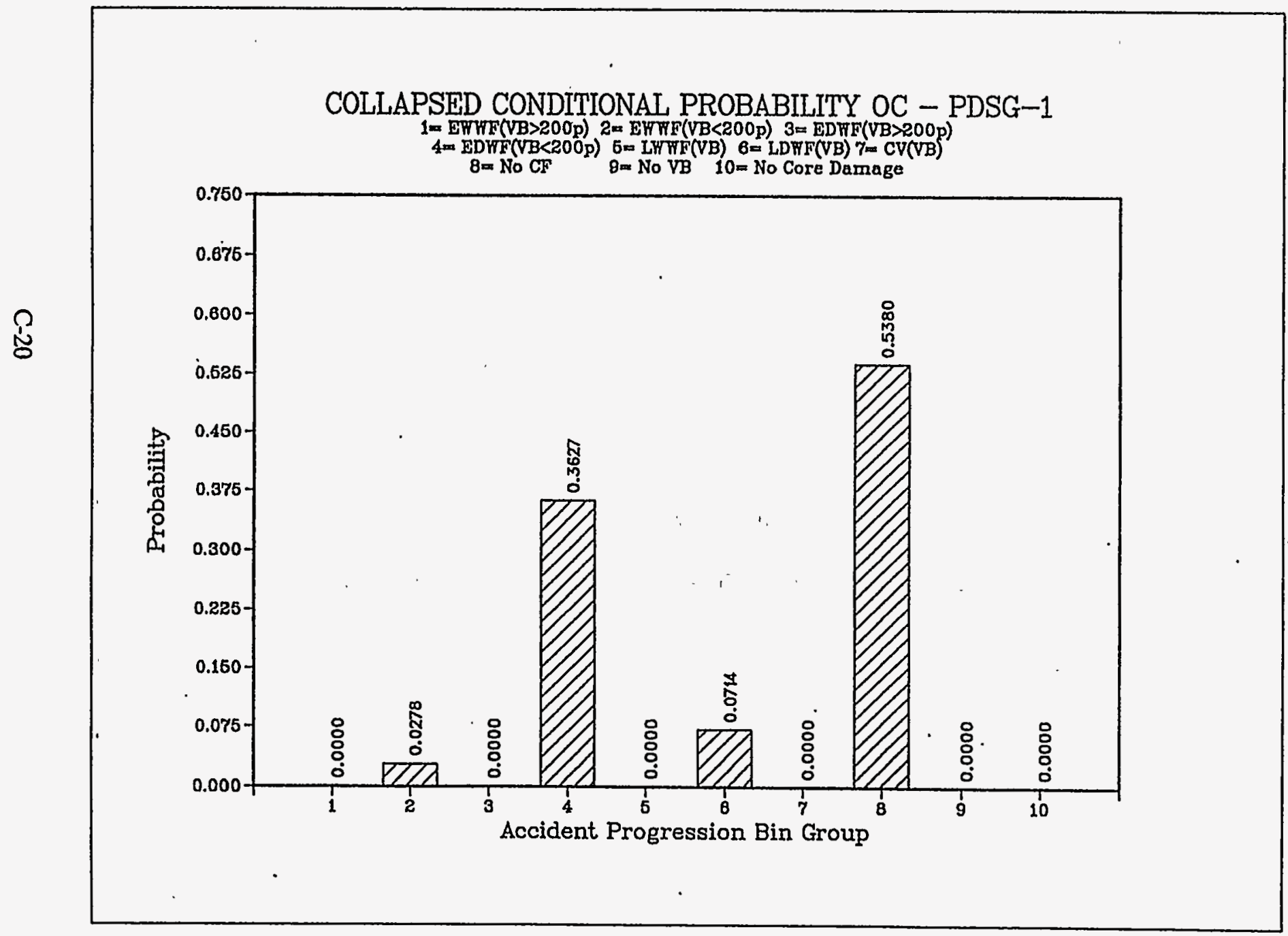


Figure C-20 NMP/OC containment, 100 psig vent pressure, design pressure capability

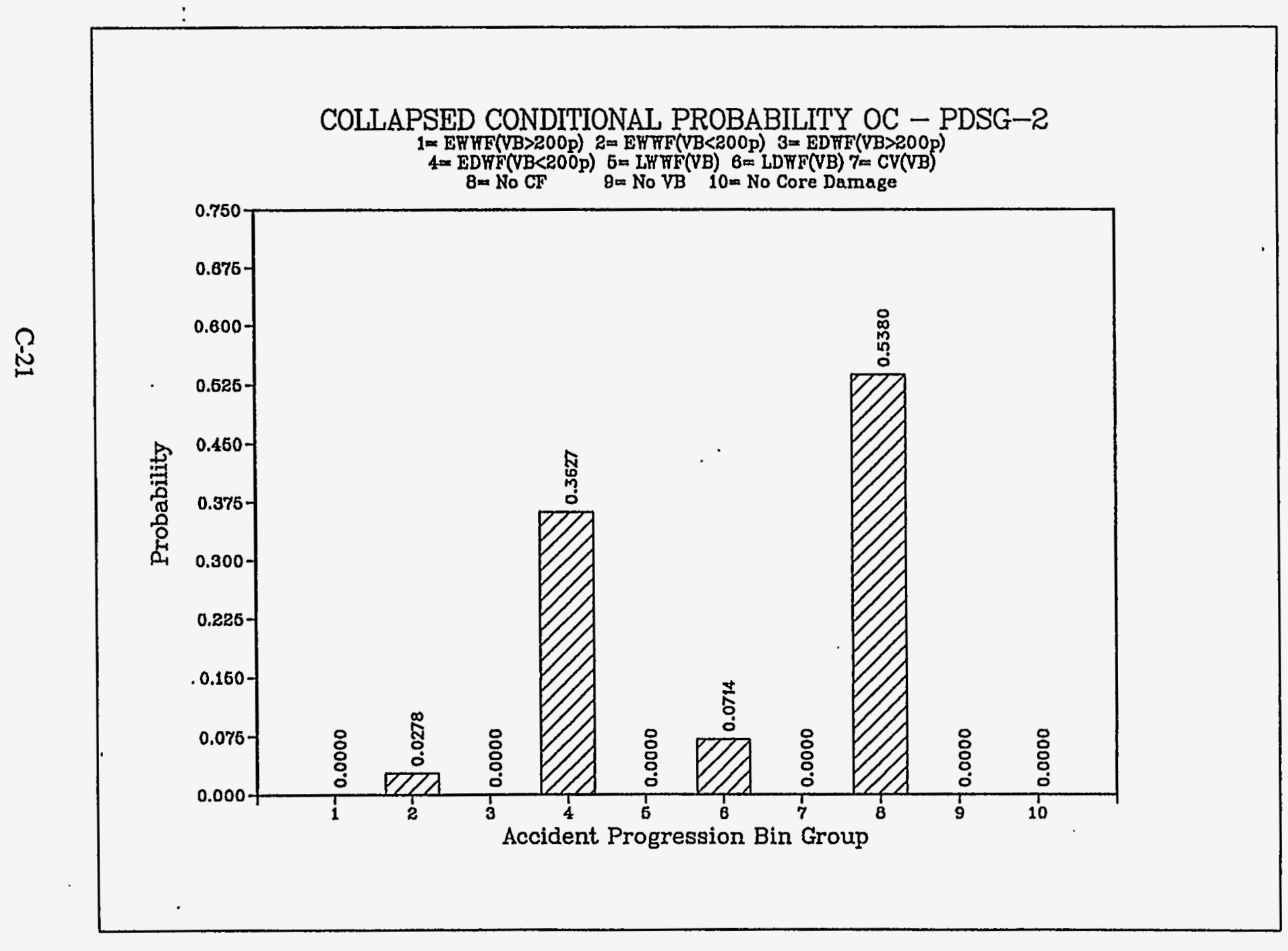


Figure C-21 NMP/OC containment, 100 psig vent pressure, design pressure capability

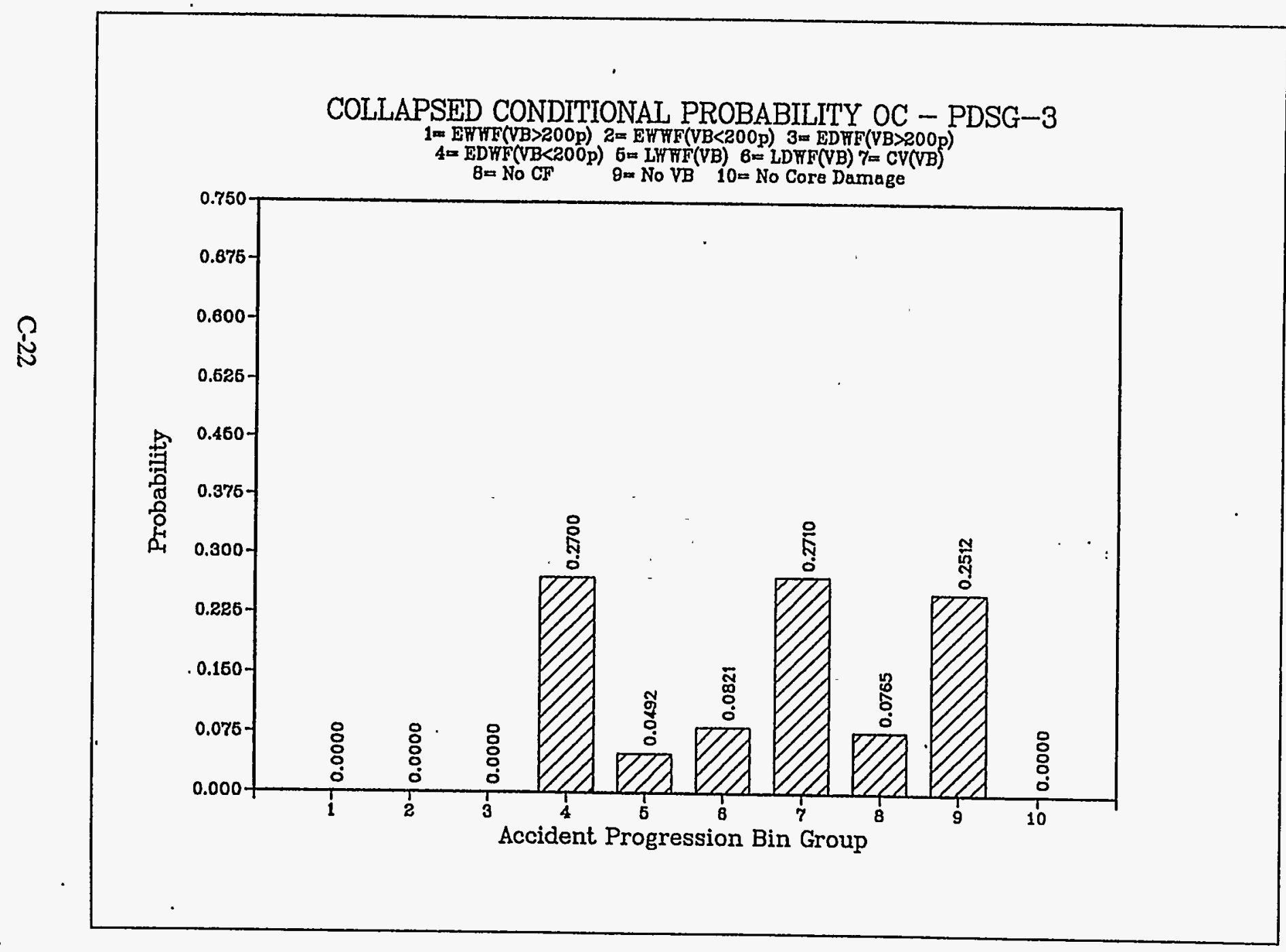




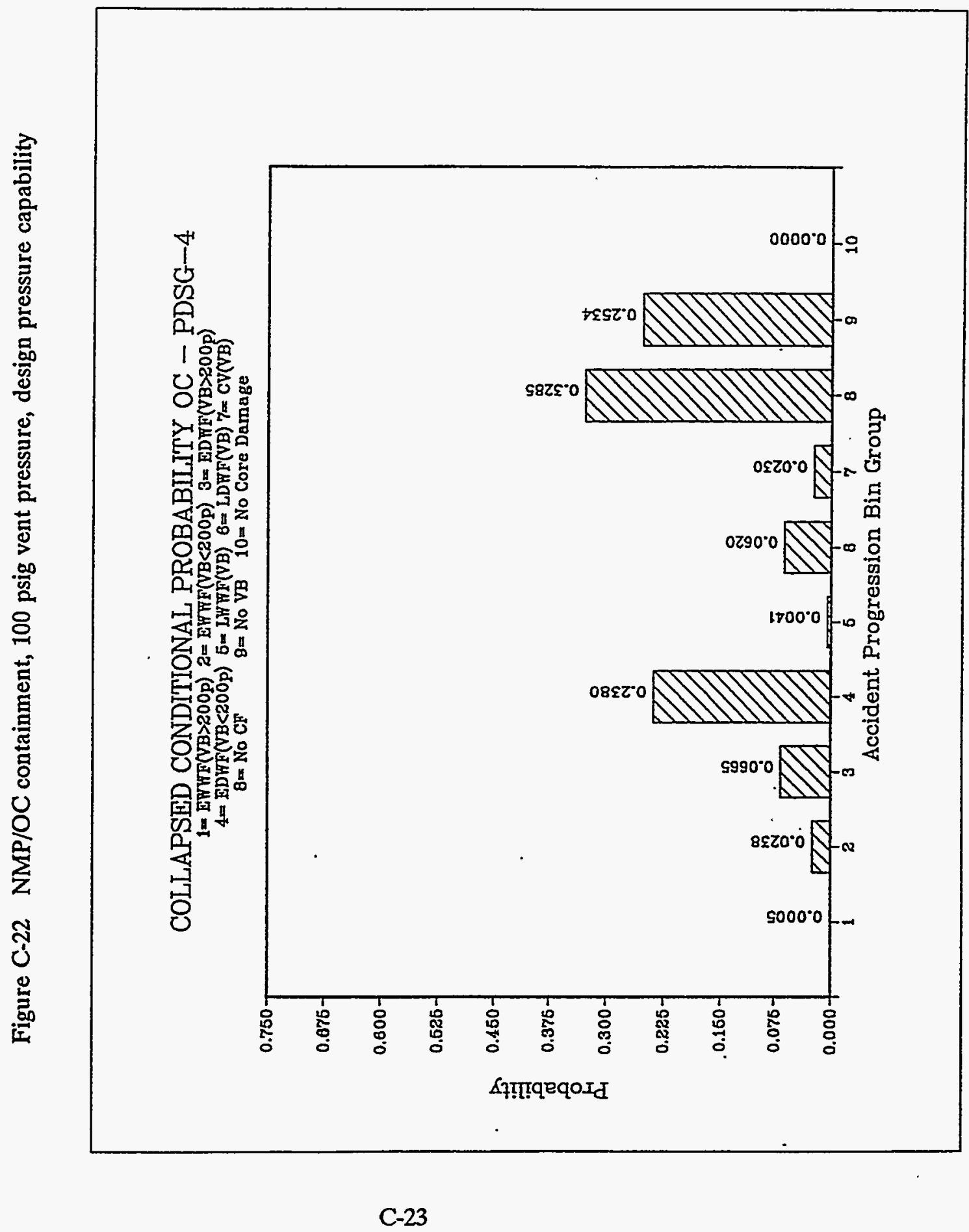


Figure C-23 NMP/OC containment, 100 psig vent pressure, design pressure capability

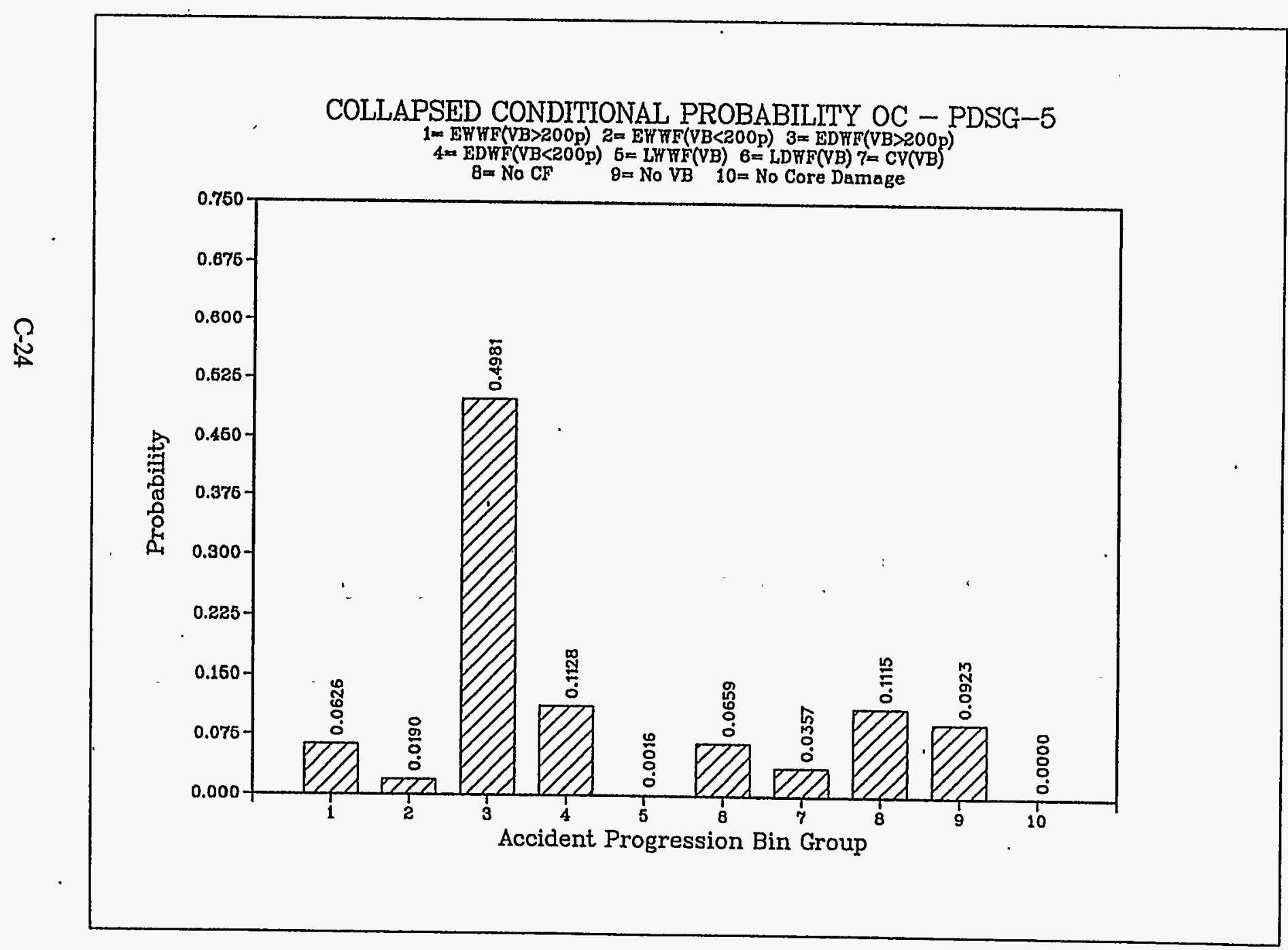




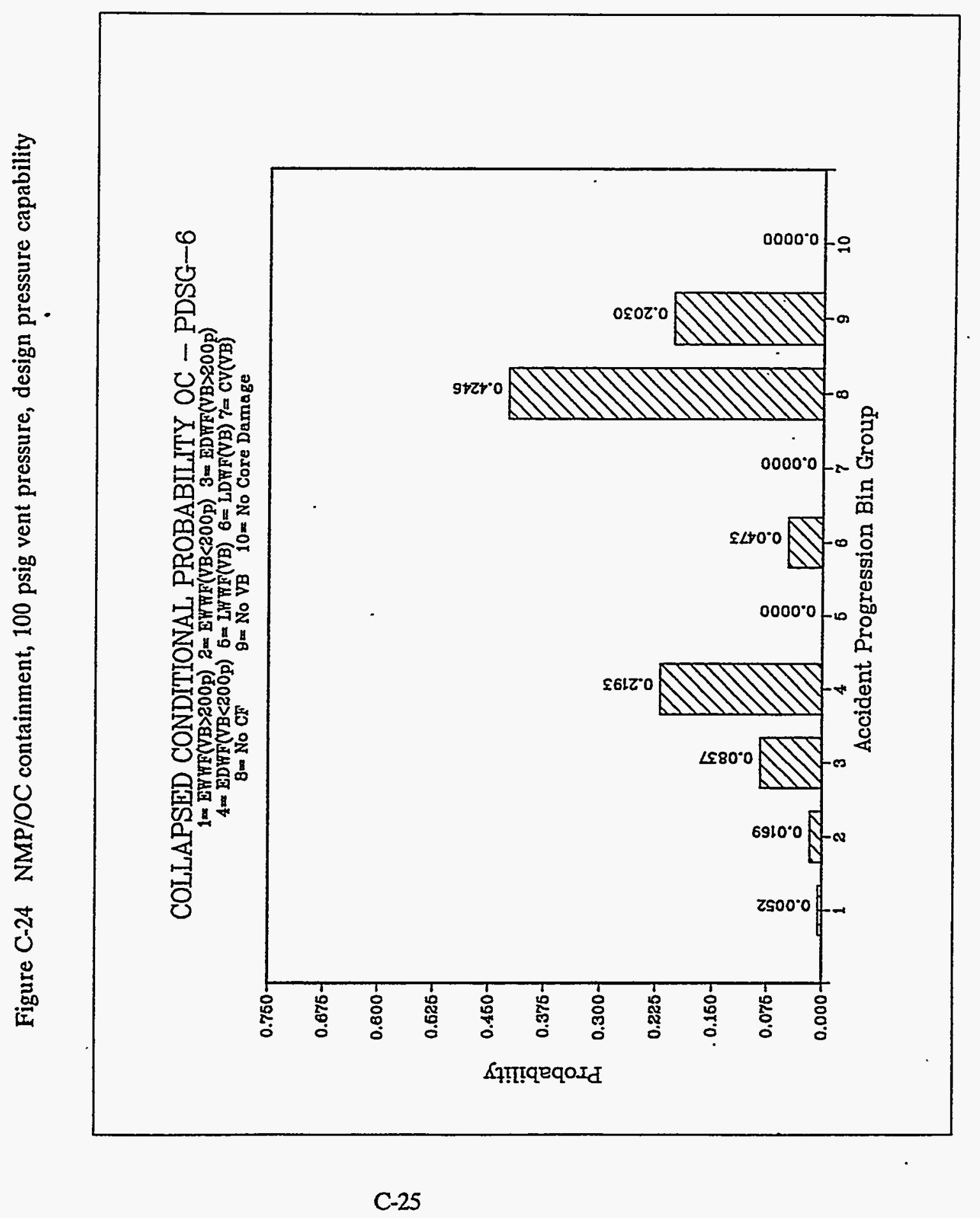




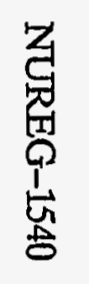

Figure C-25 NMP/OC containment, 100 sig vent pressure, design pressure capability

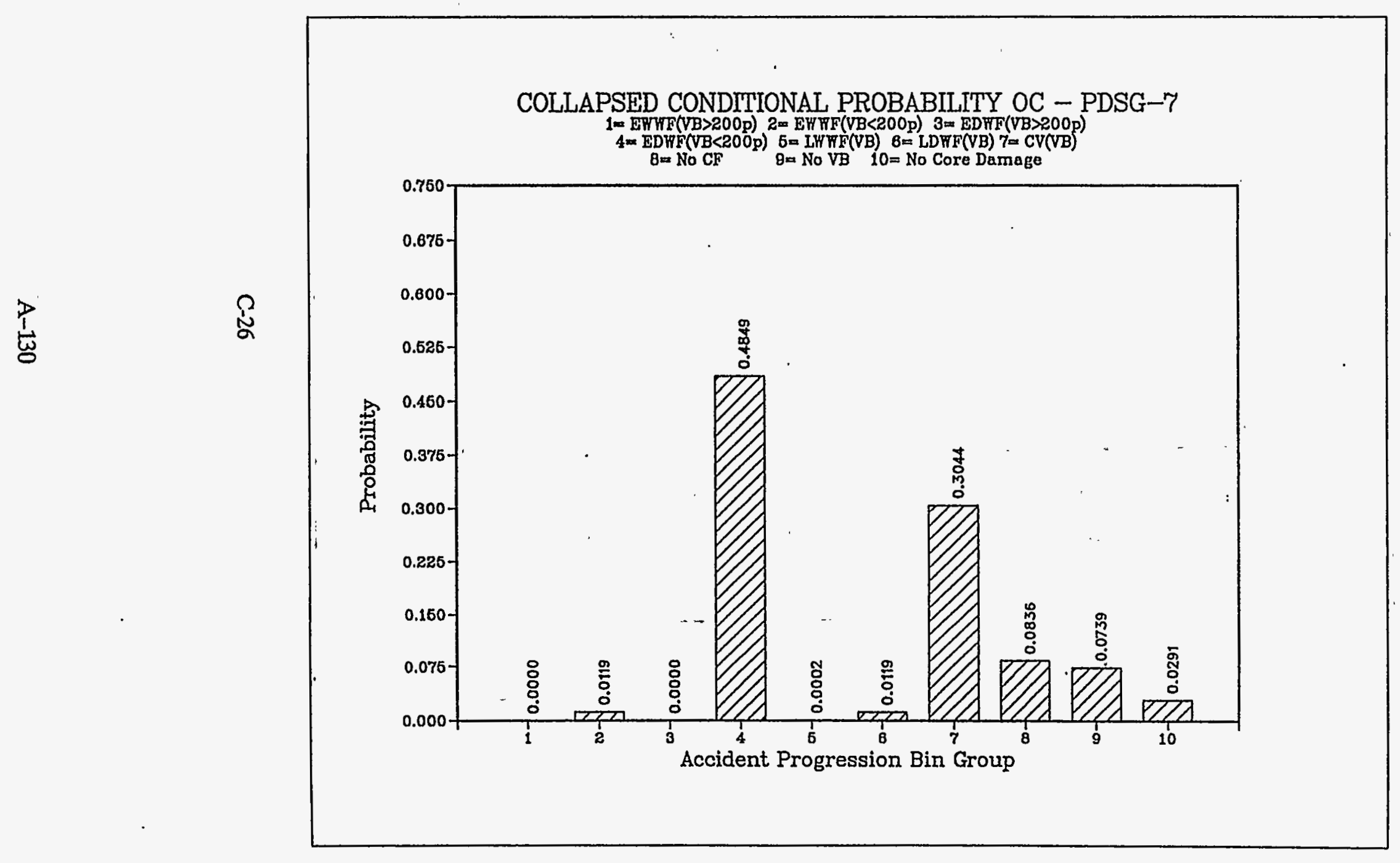




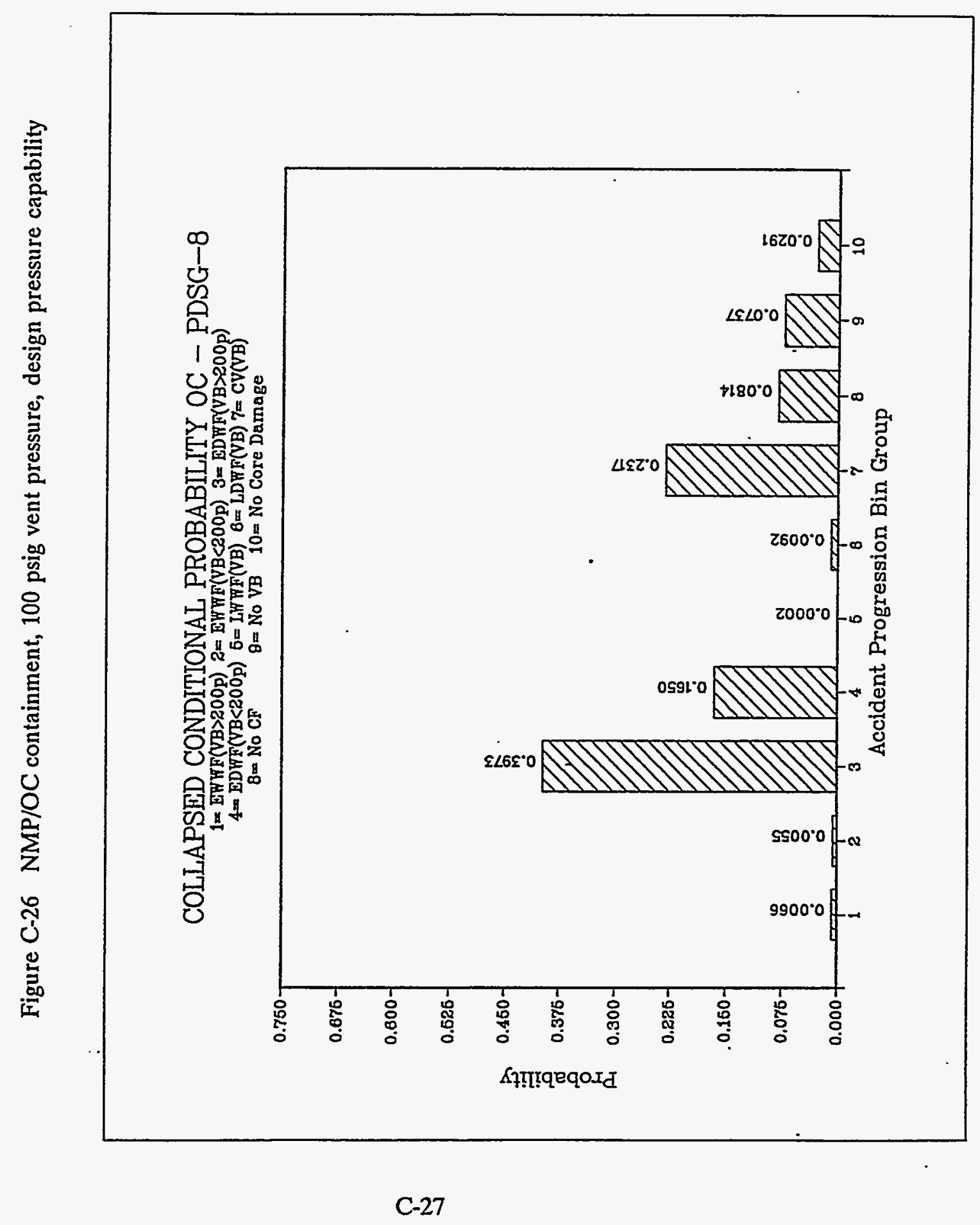


Figure C-27 NMP/OC containment, 100 psig vent pressure, design pressure capability

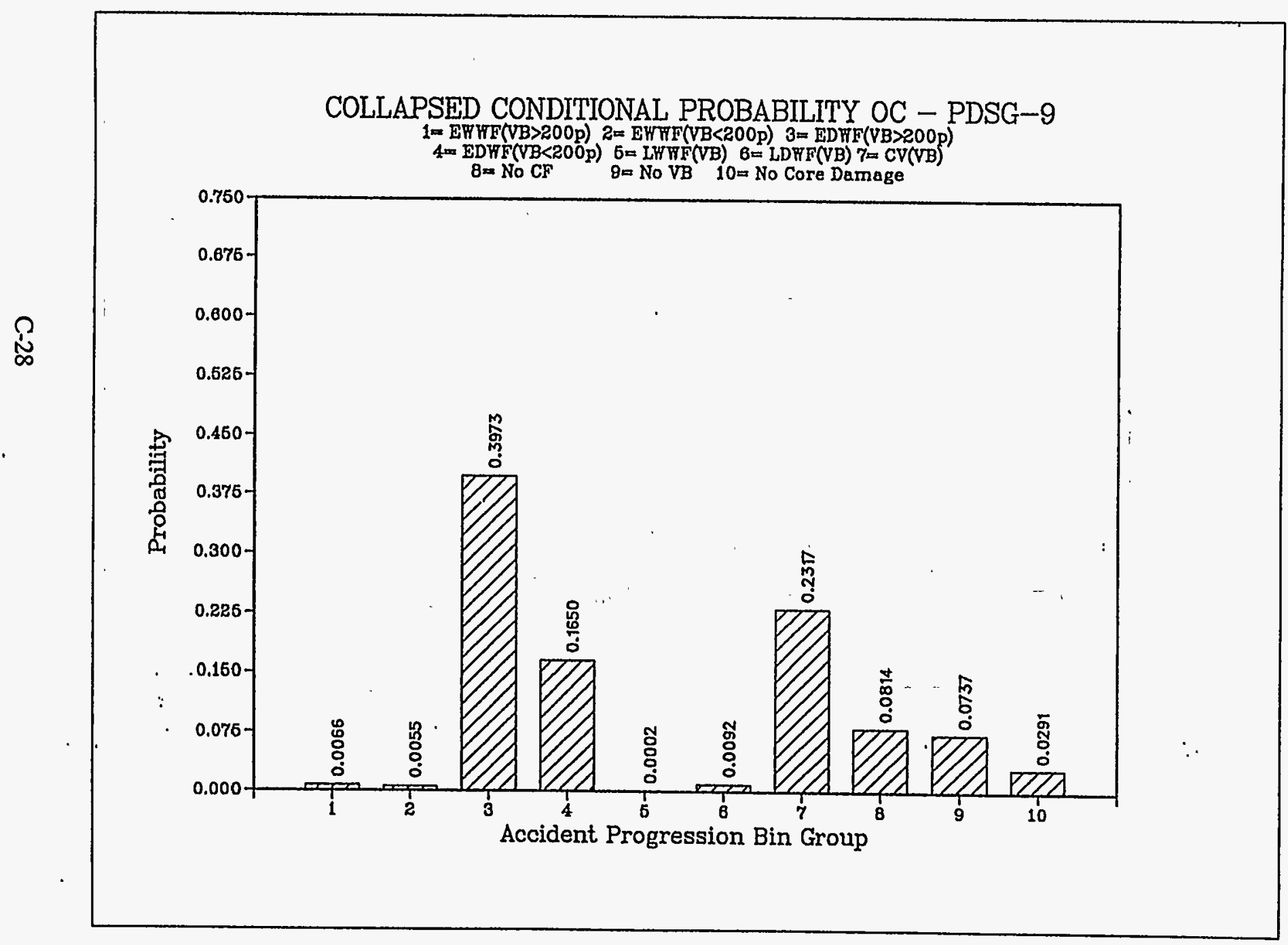




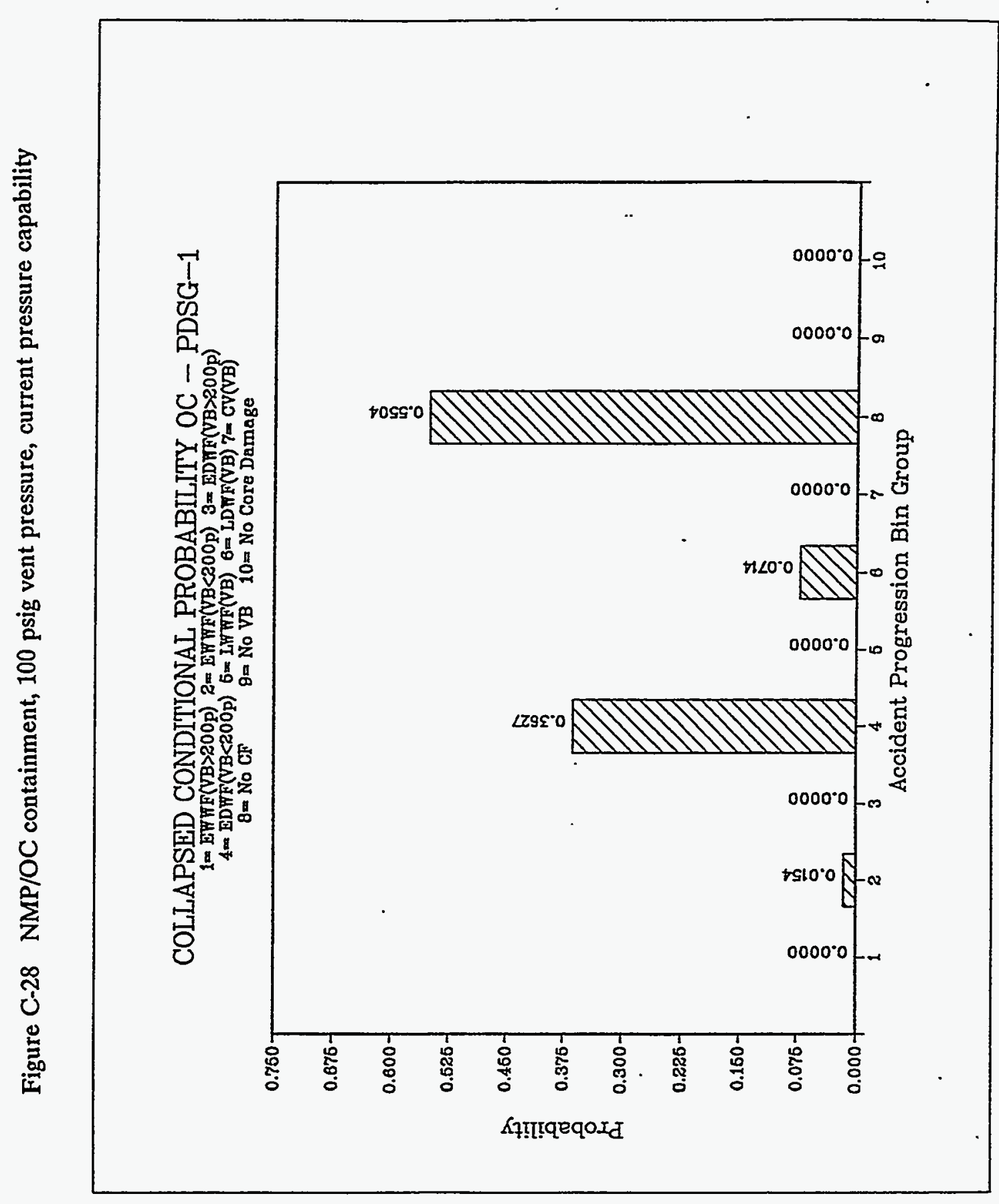

C-29 
Figure C-29 NMP/OC containment, 100 psig vent pressure, current pressure capability

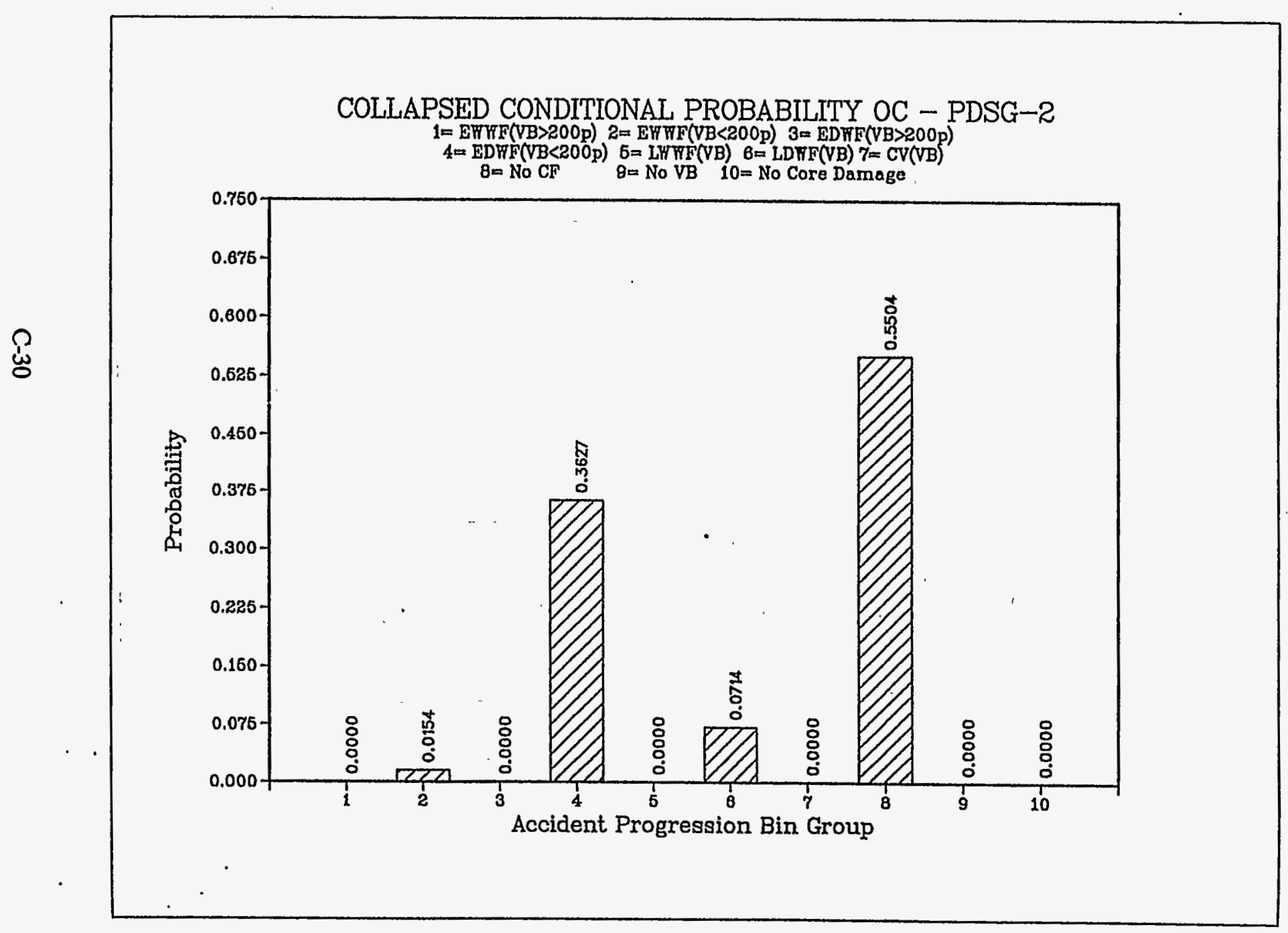


Figure C-30 NMP/OC contaiment, 100 psig vent pressure, current pressure capability

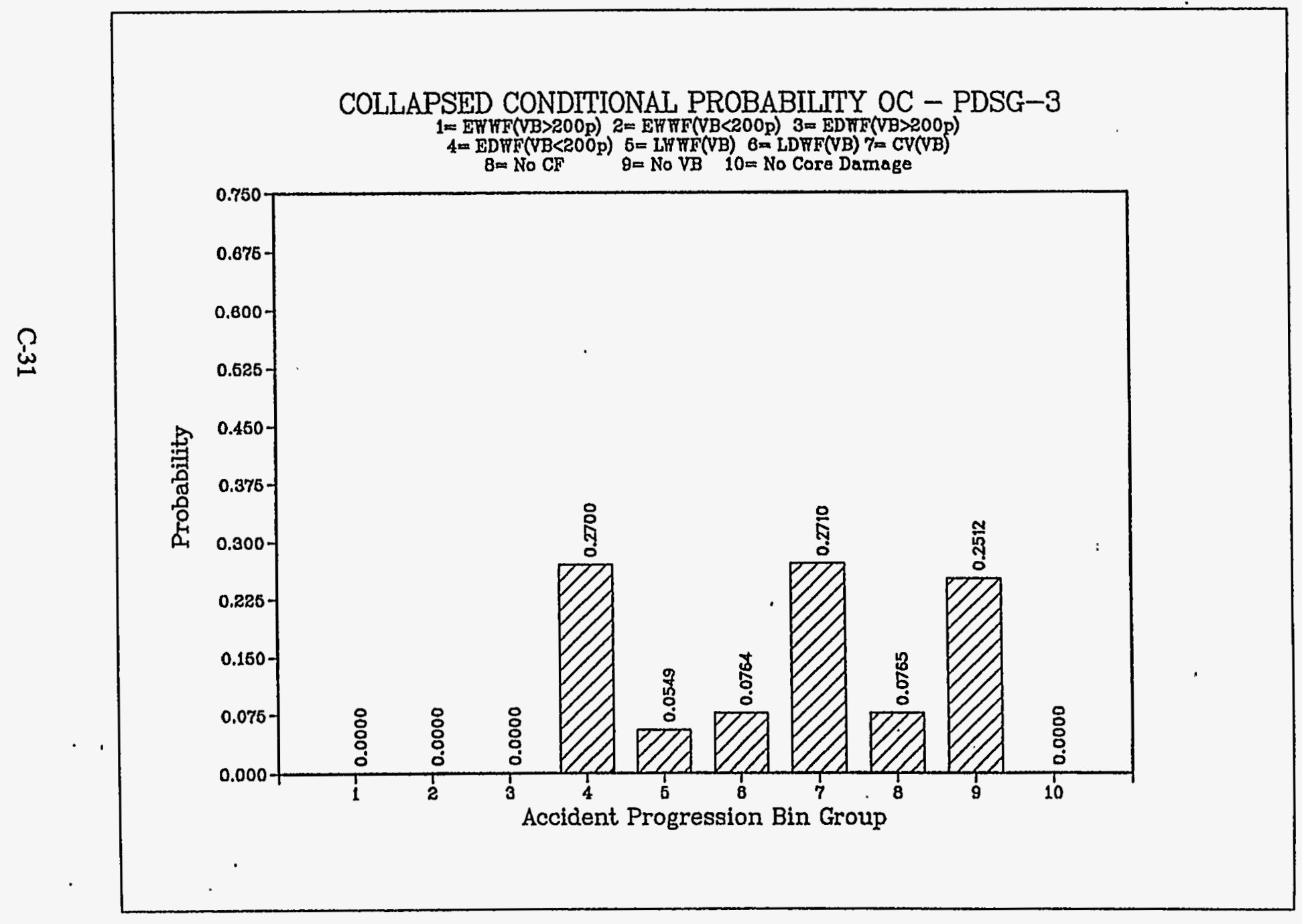

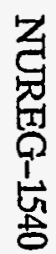


Figure C-31 NMP/OC containment, 100 psig vent pressure, current pressure capability

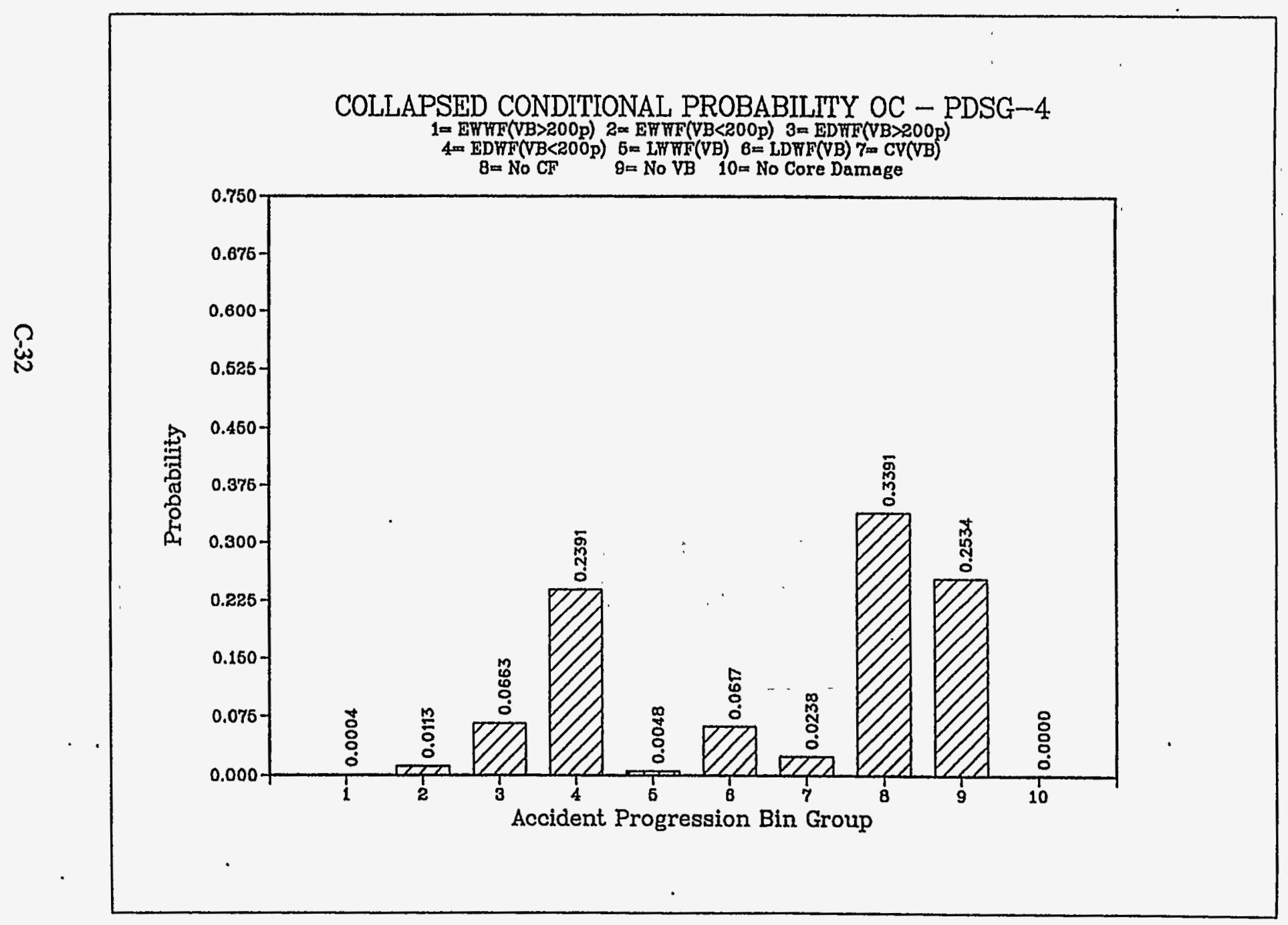




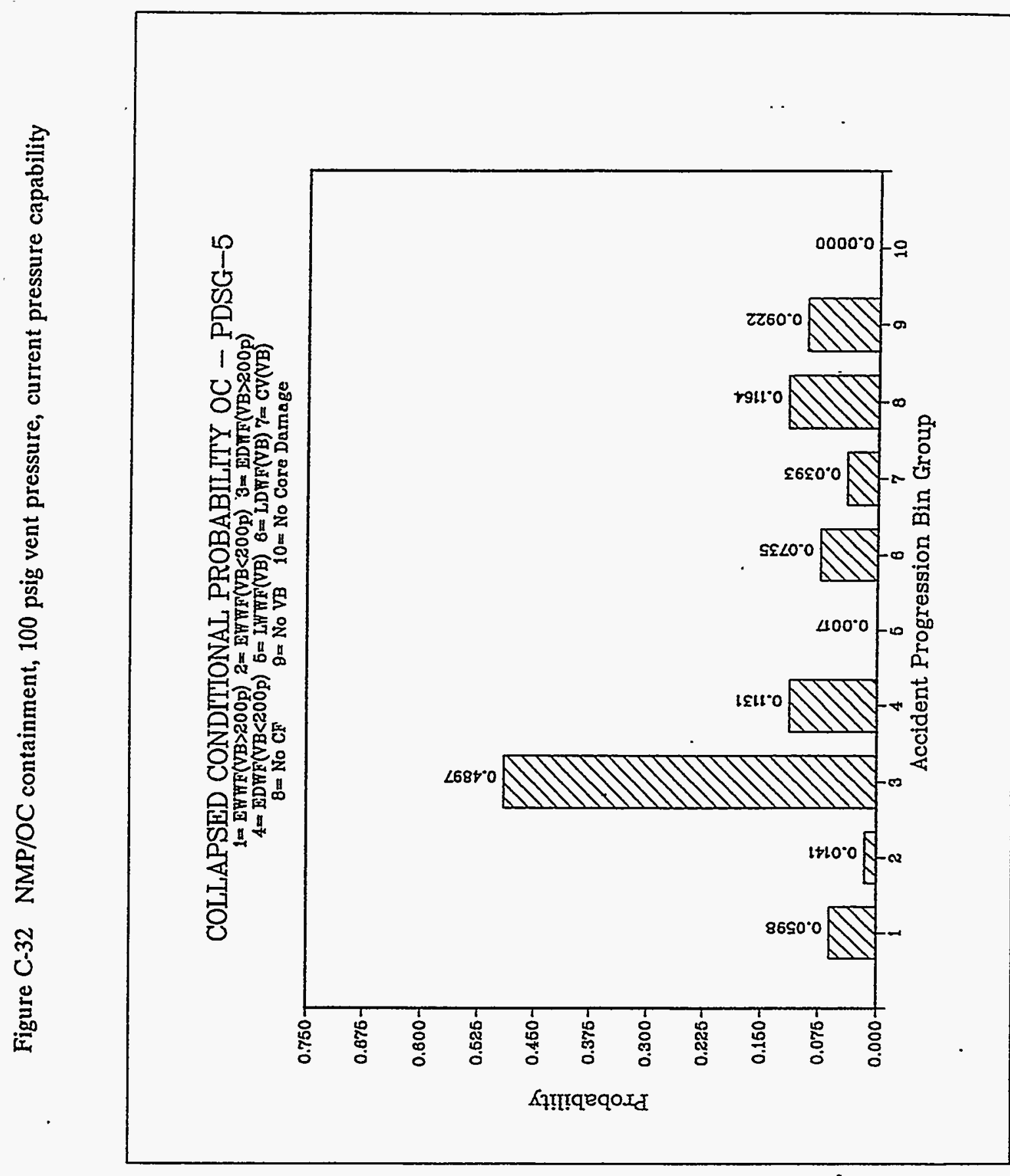

C-33 
Figure C-33 NMP/OC containment, 100 psig vent pressure, current pressure capability

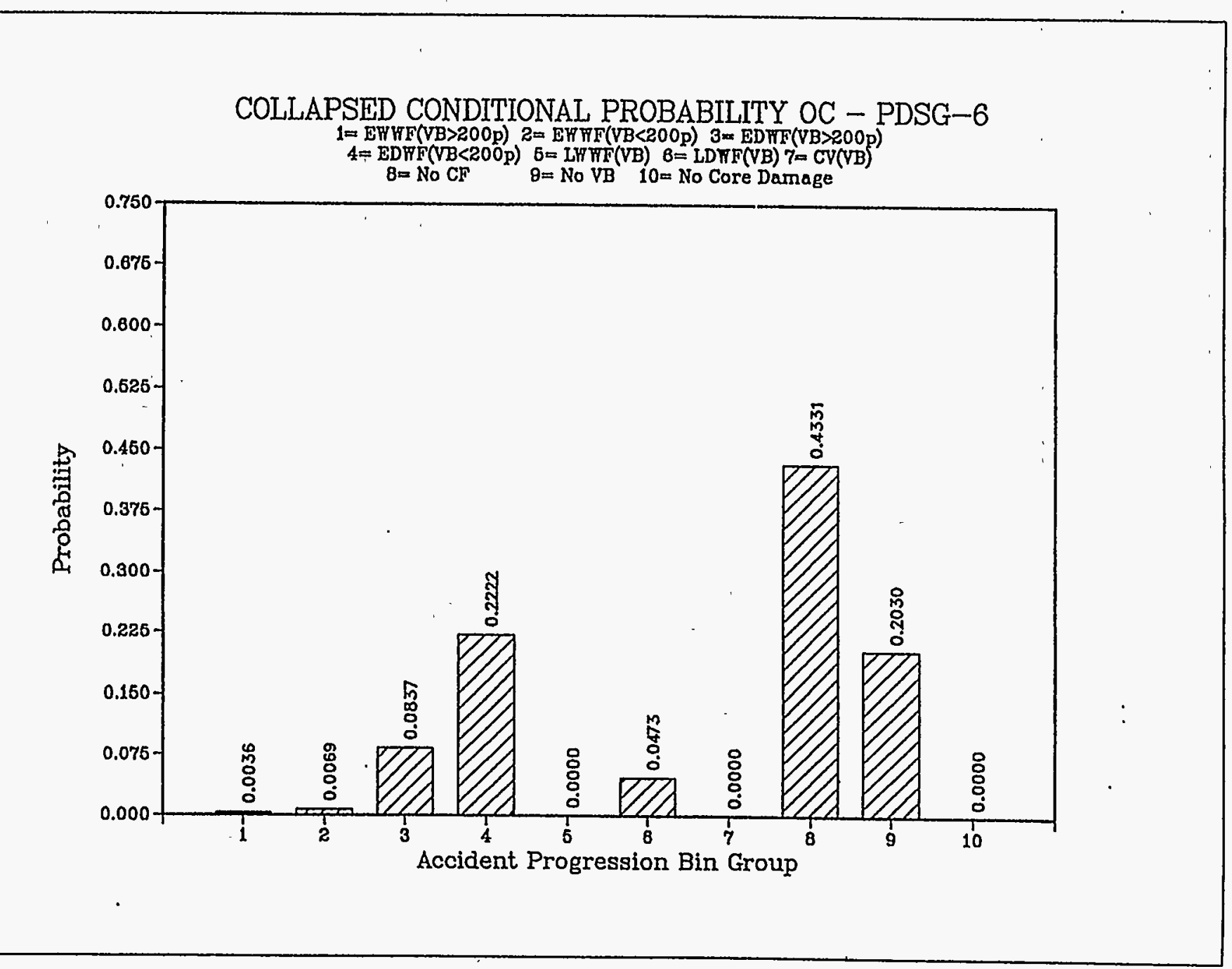




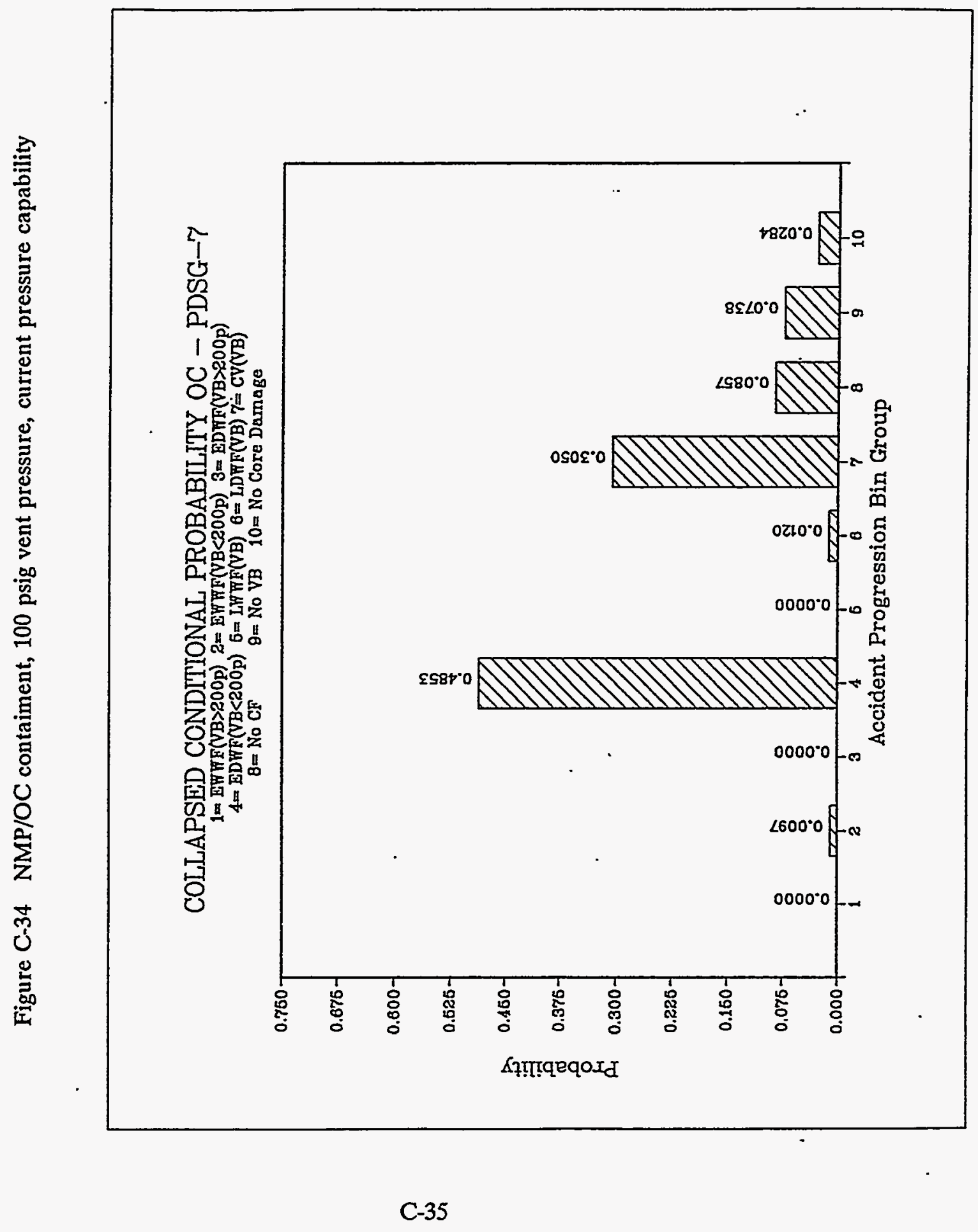




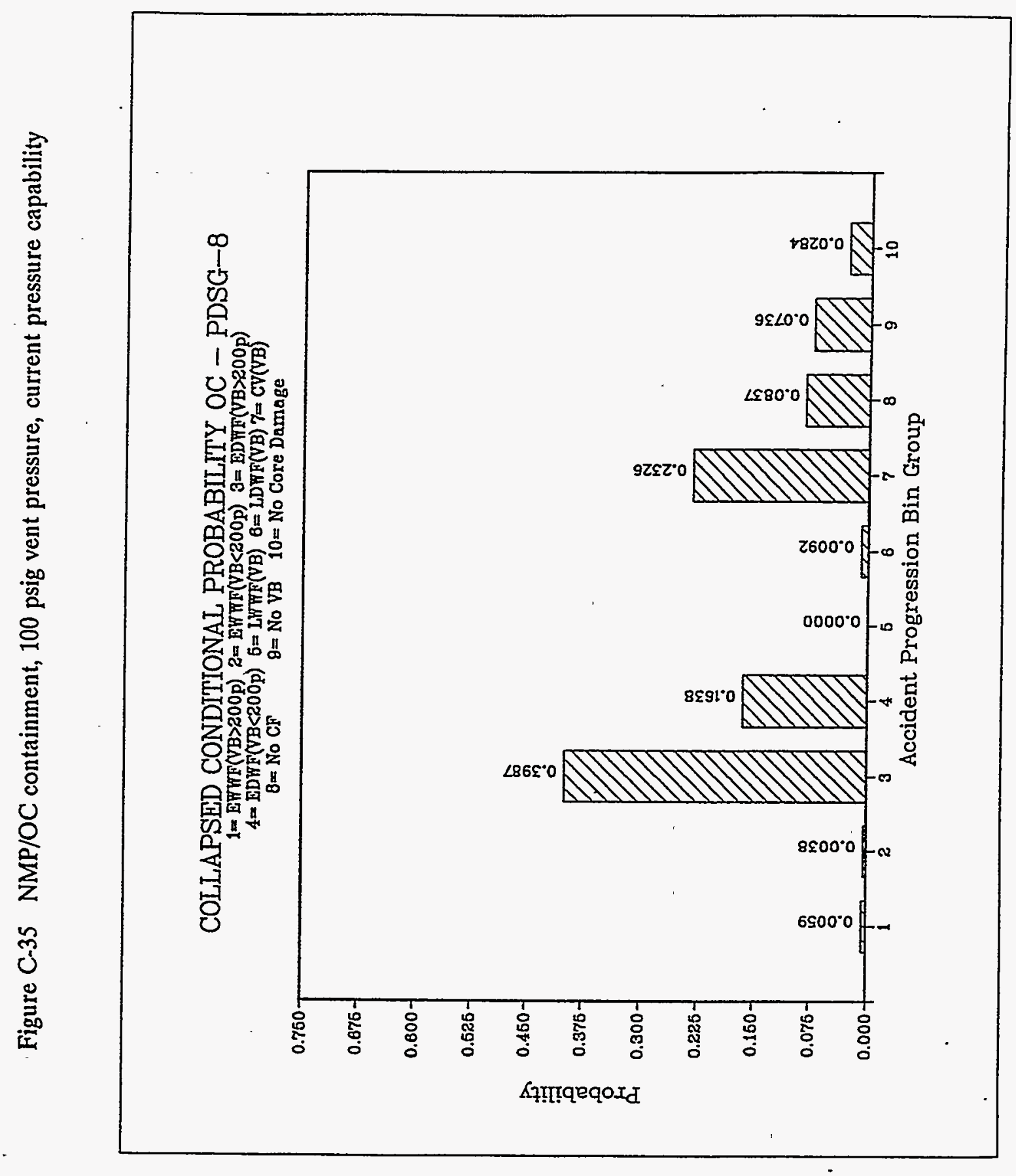

$C-36$ 
Figure C-36 NMP/OC containment, 100 psig vent pressure, current pressure capability

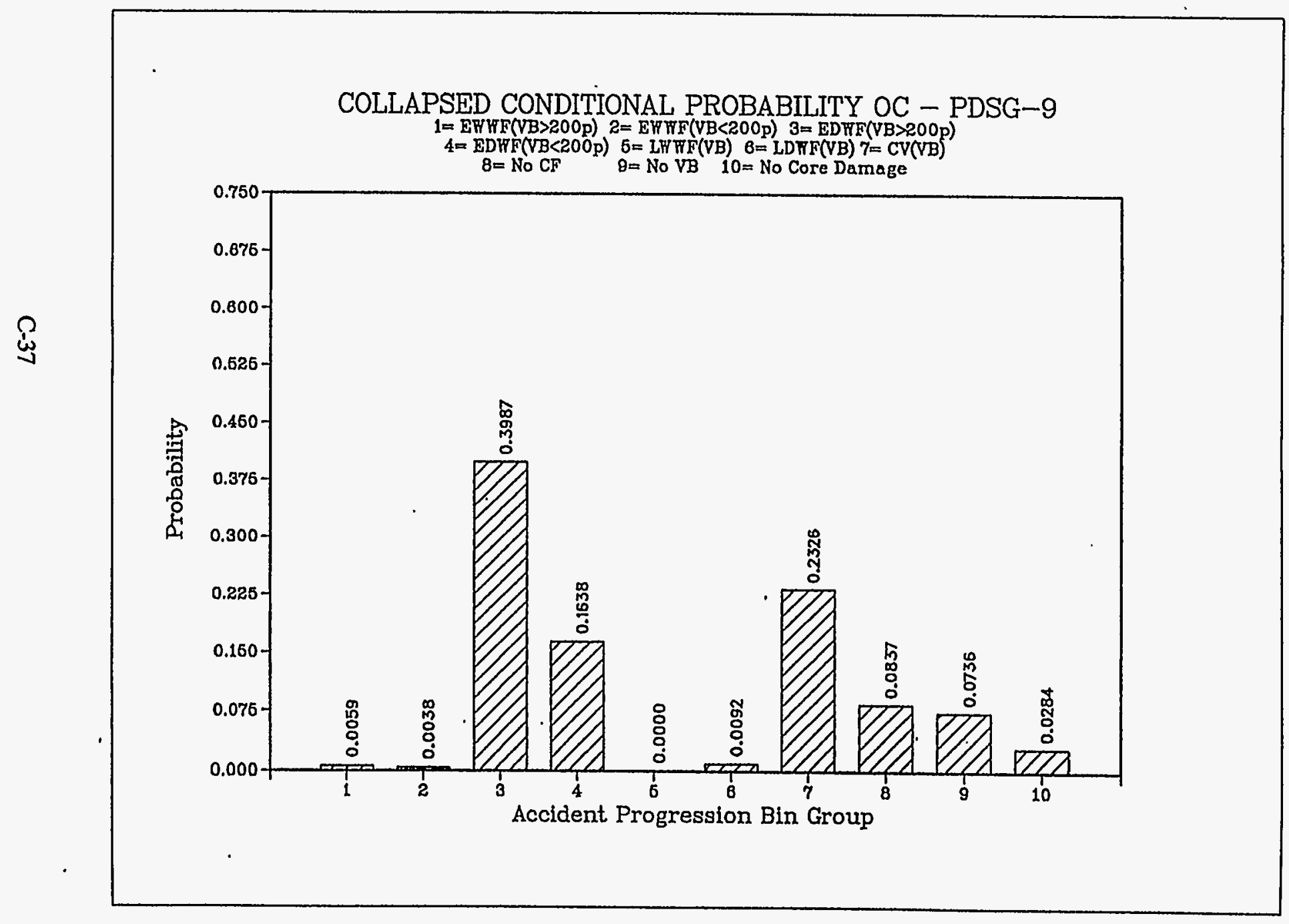


Figure C-37 NMP/OC containment, 100 psig vent pressure, corroded pressure capability

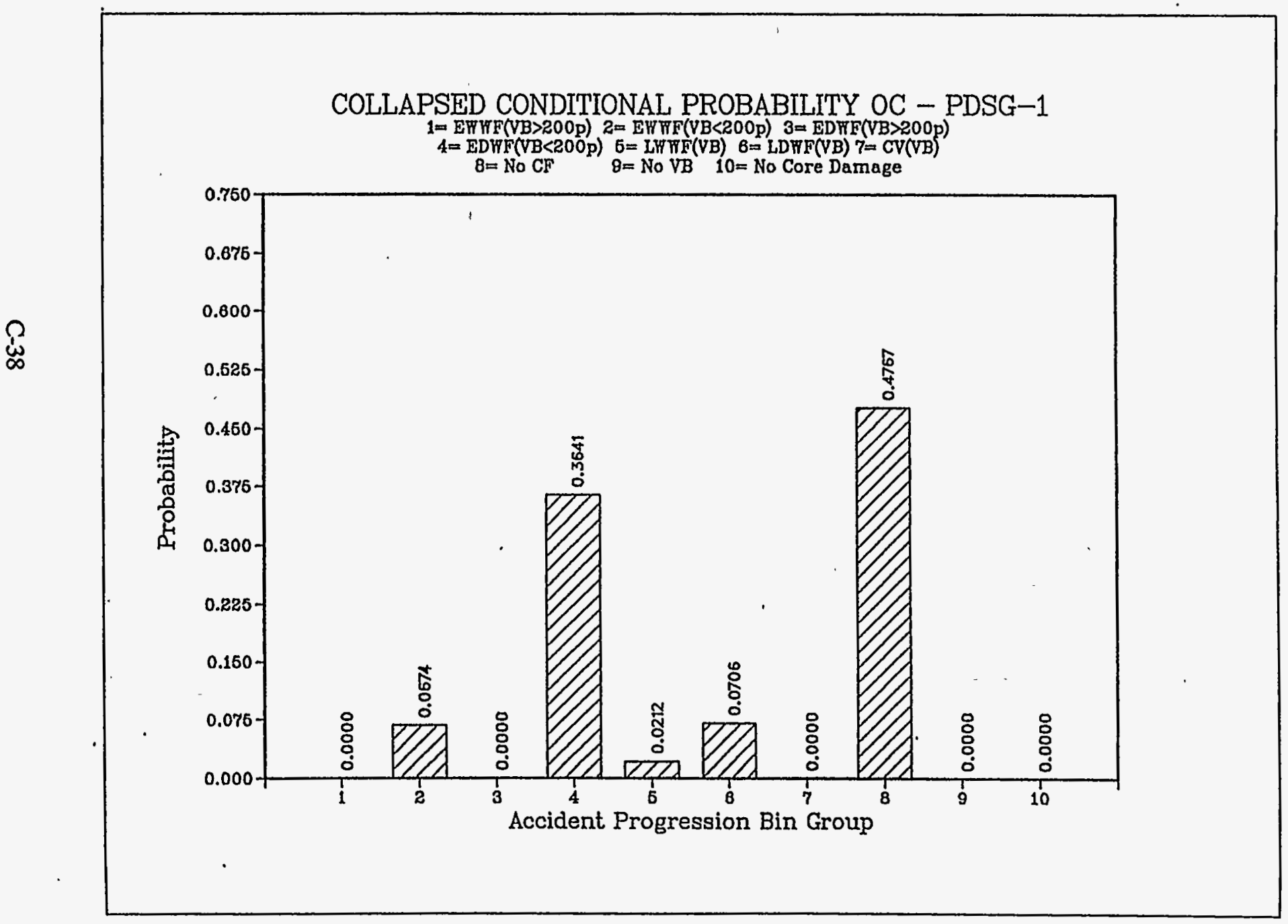


Figure C-38 NMP/OC containment, 100 psig vent pressure, corroded pressure capability

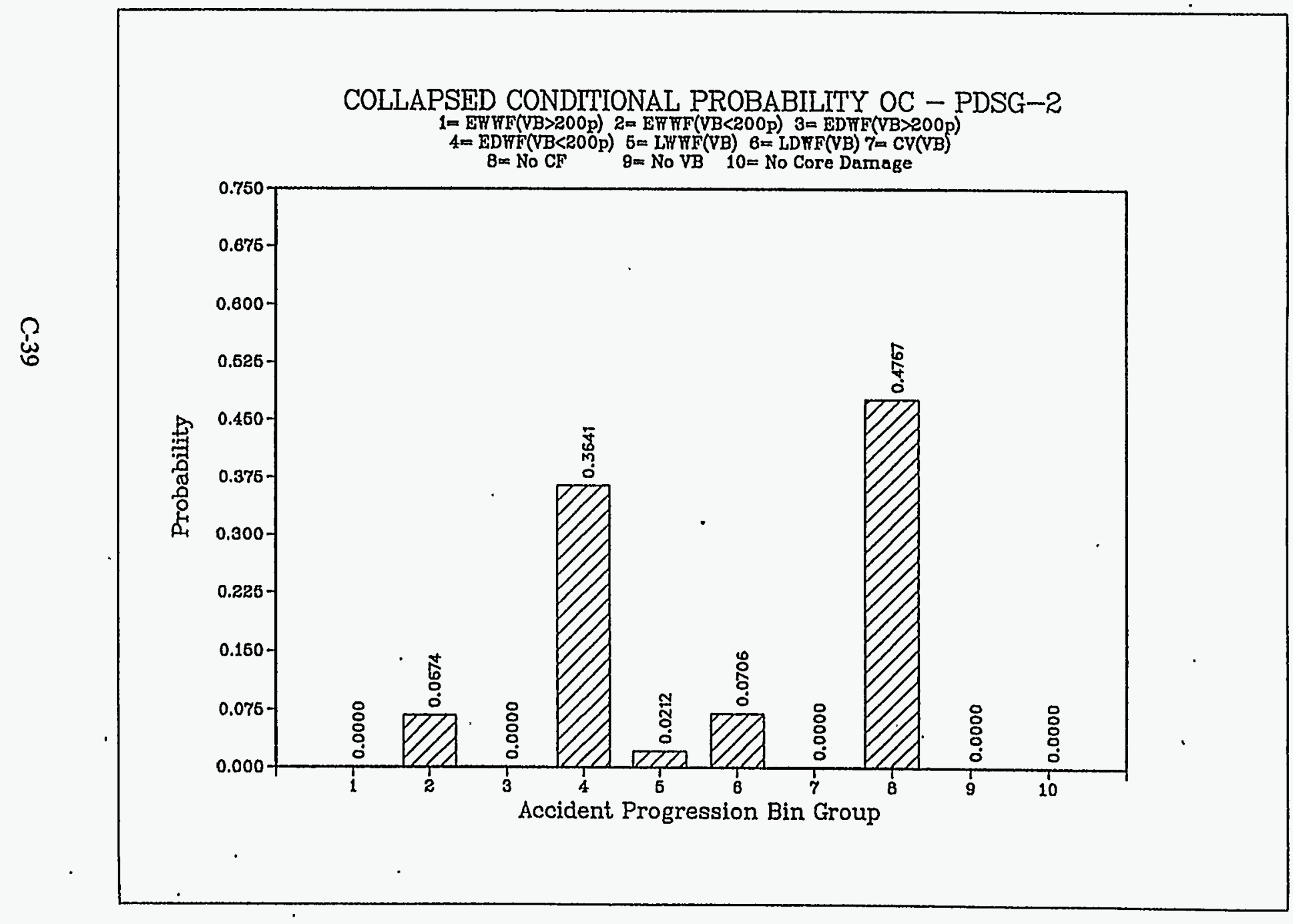




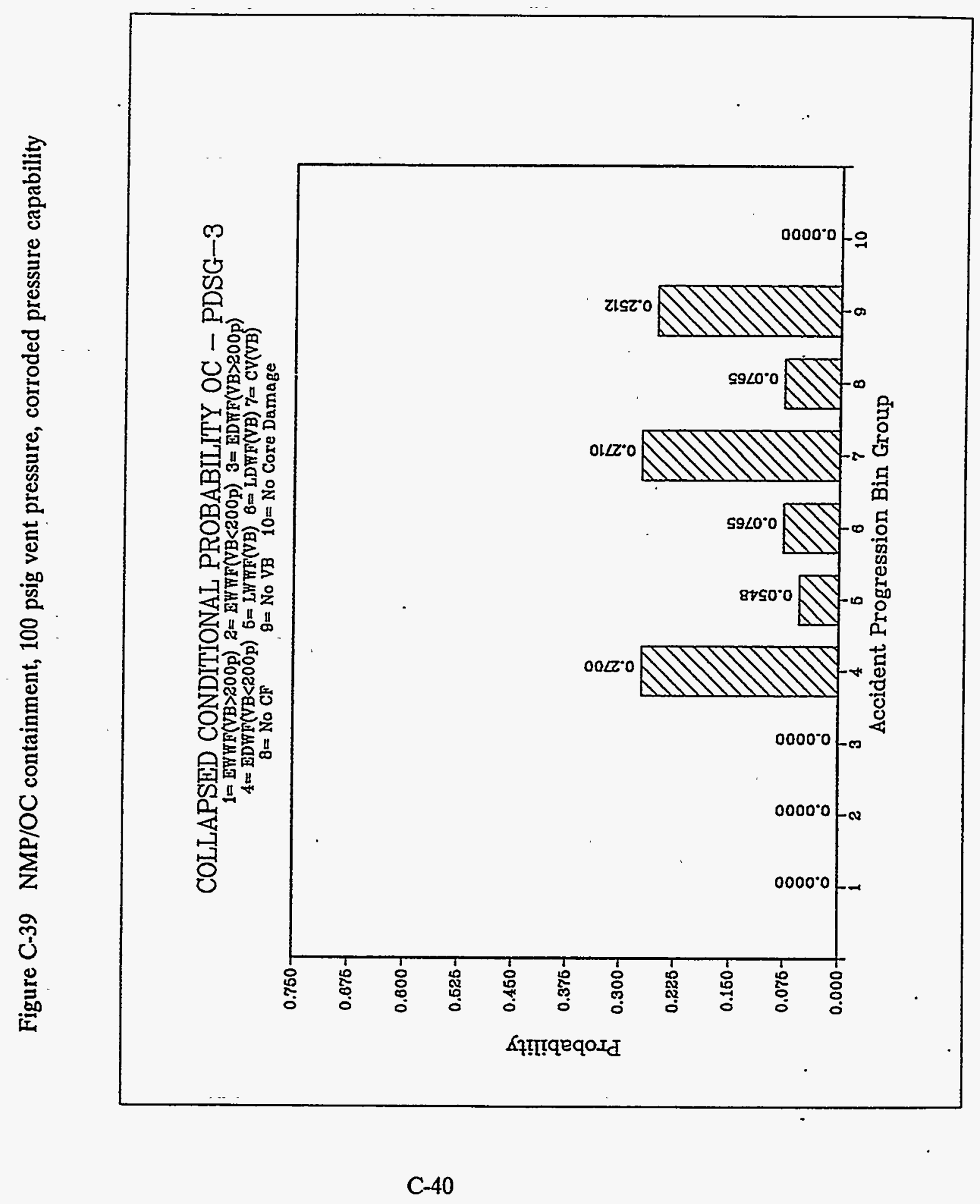




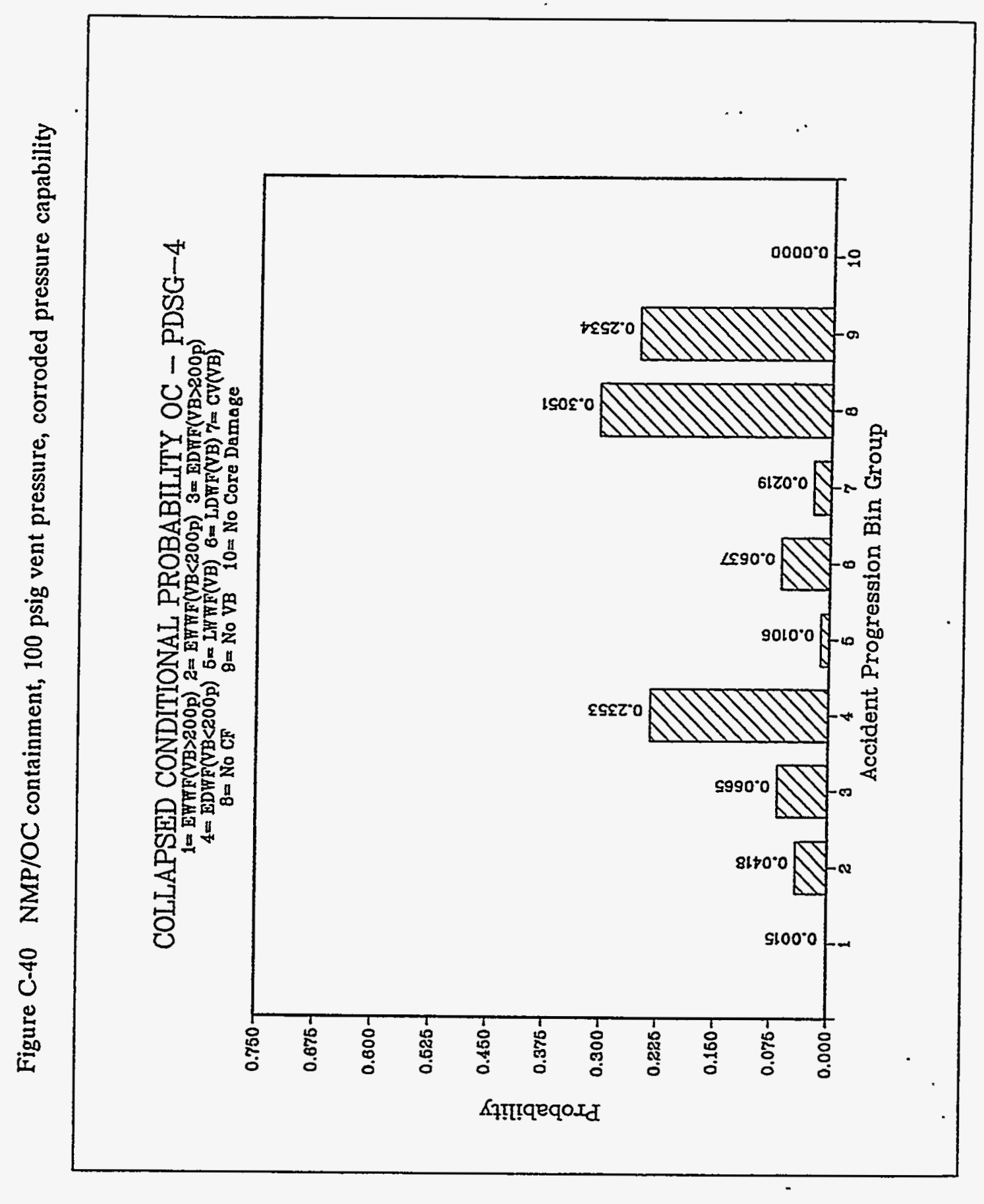

\section{C-41}


Figure C-41 NMP/OC containment, 100 psig vent pressure, corroded pressure capability

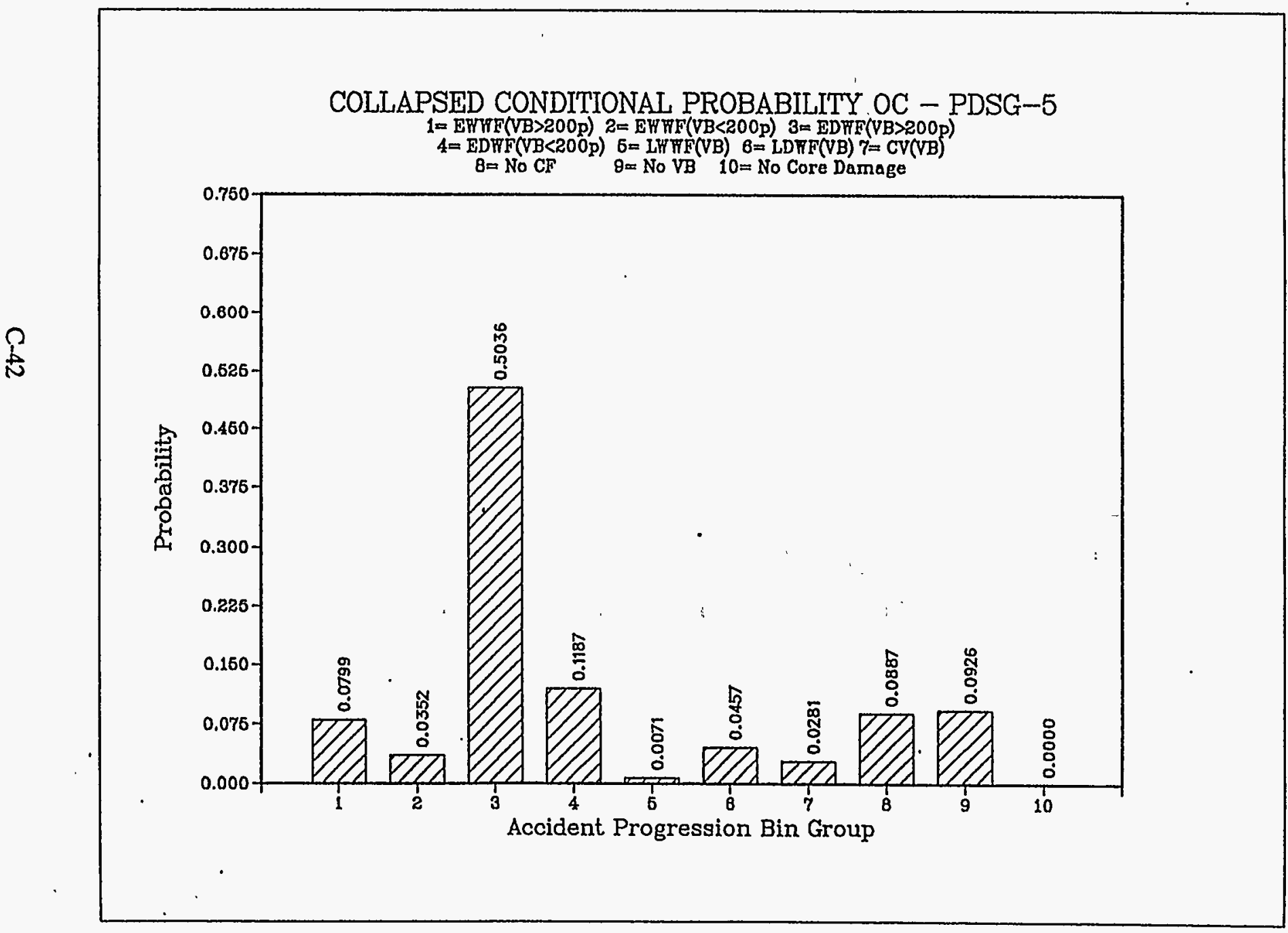




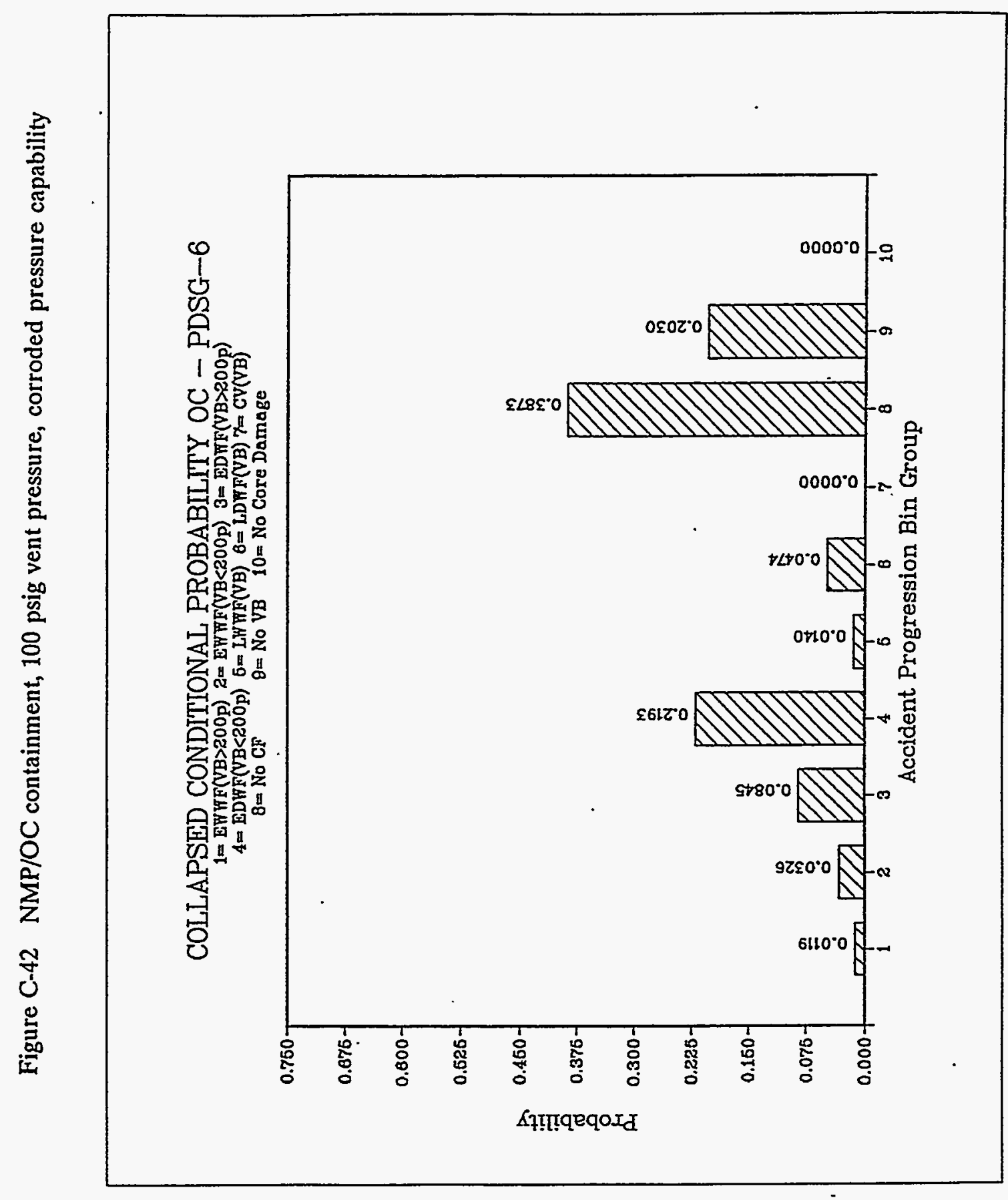

C-43 


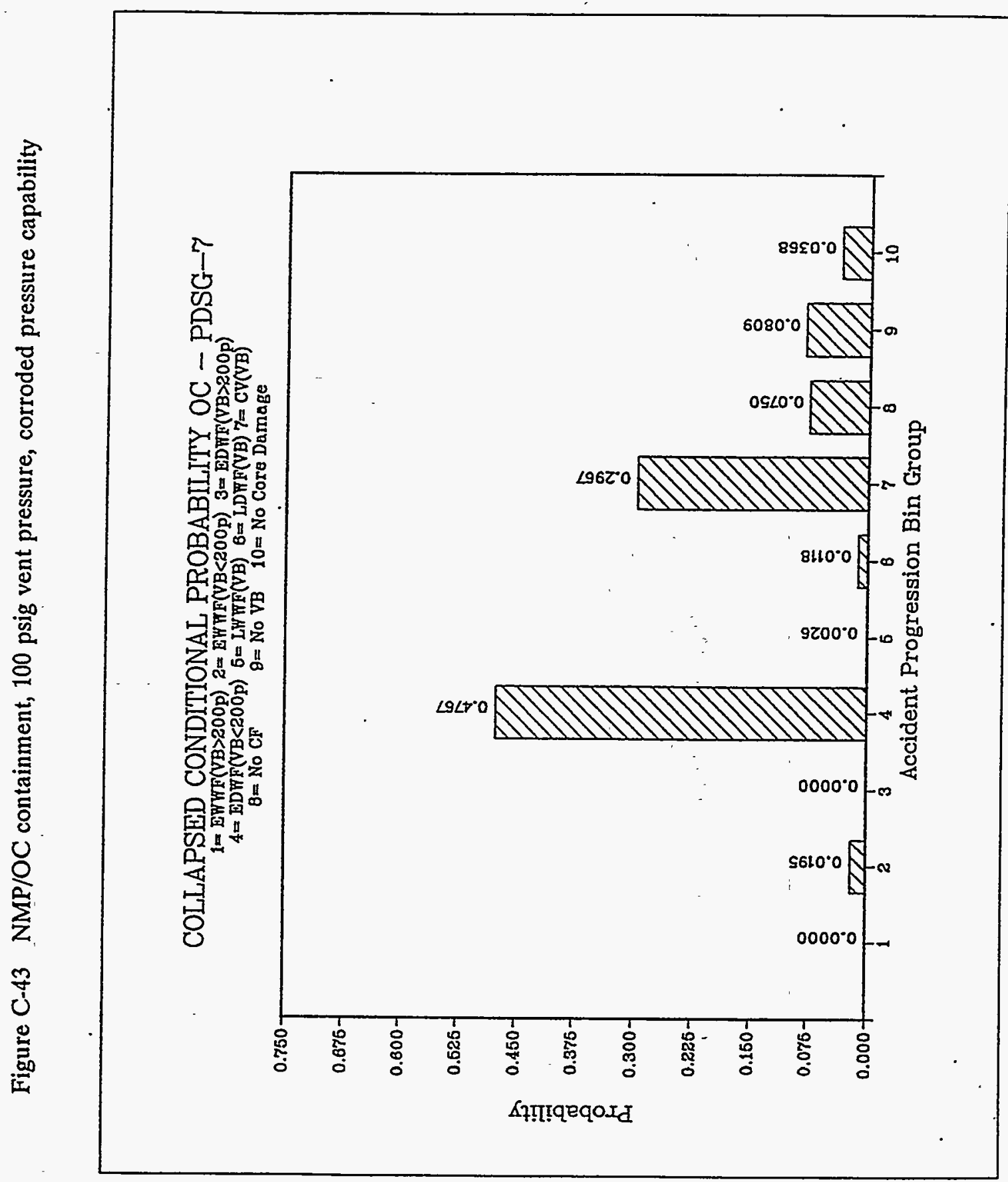

C- 44 


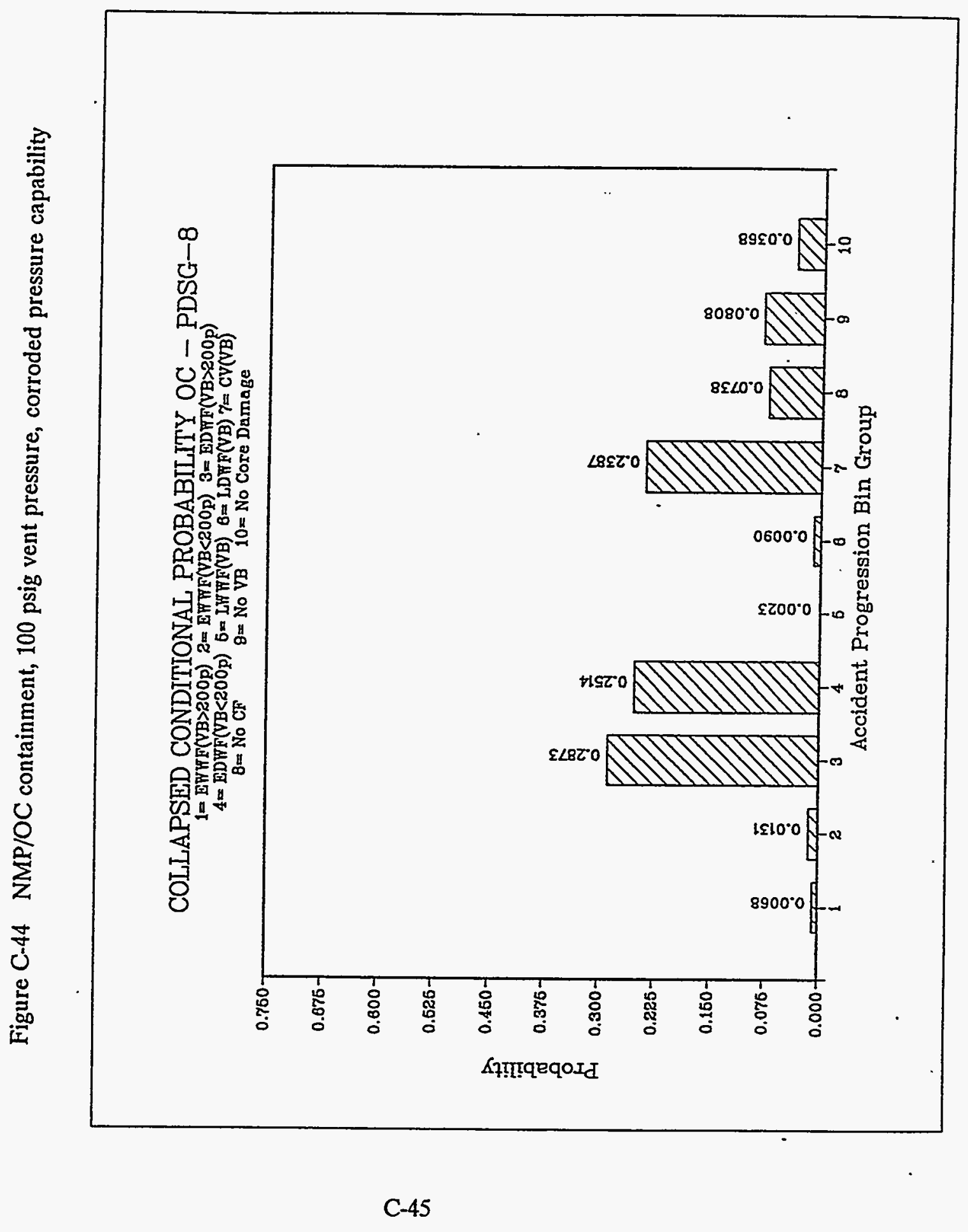


Figure C-45 NMP/OC containment, 100 psig vent pressure, corroded pressure capability

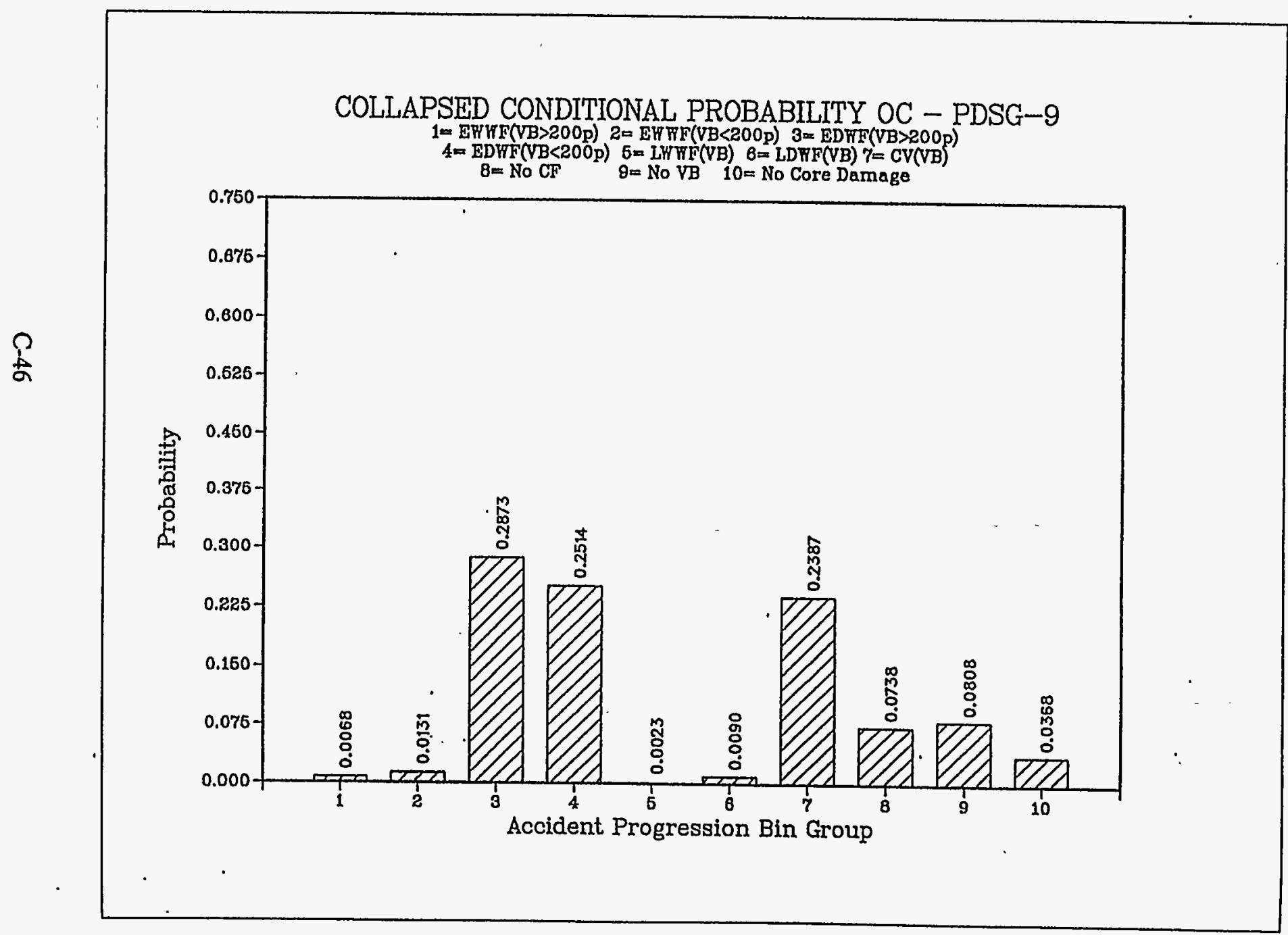


$\frac{-3}{2}$

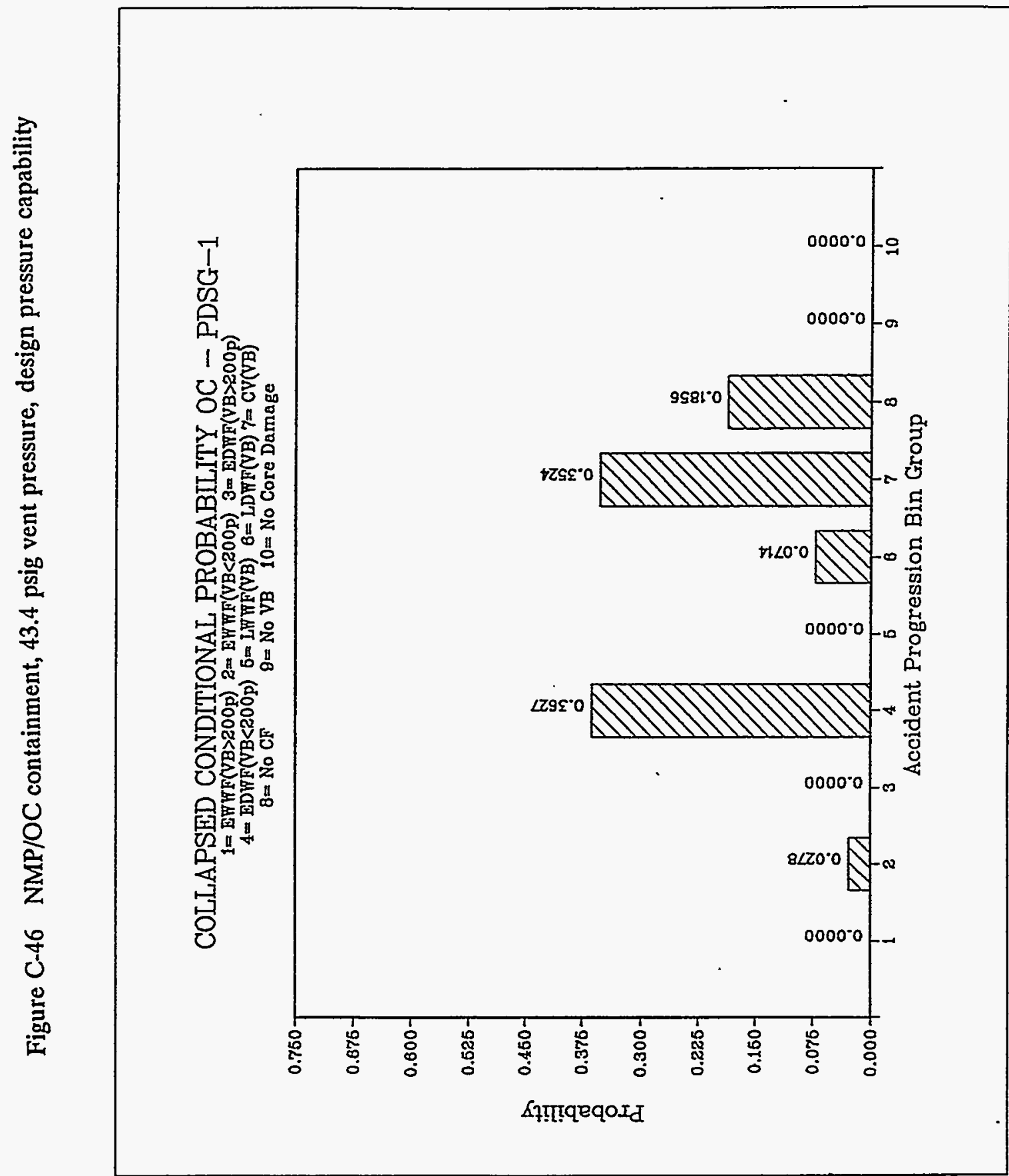

C- 47 


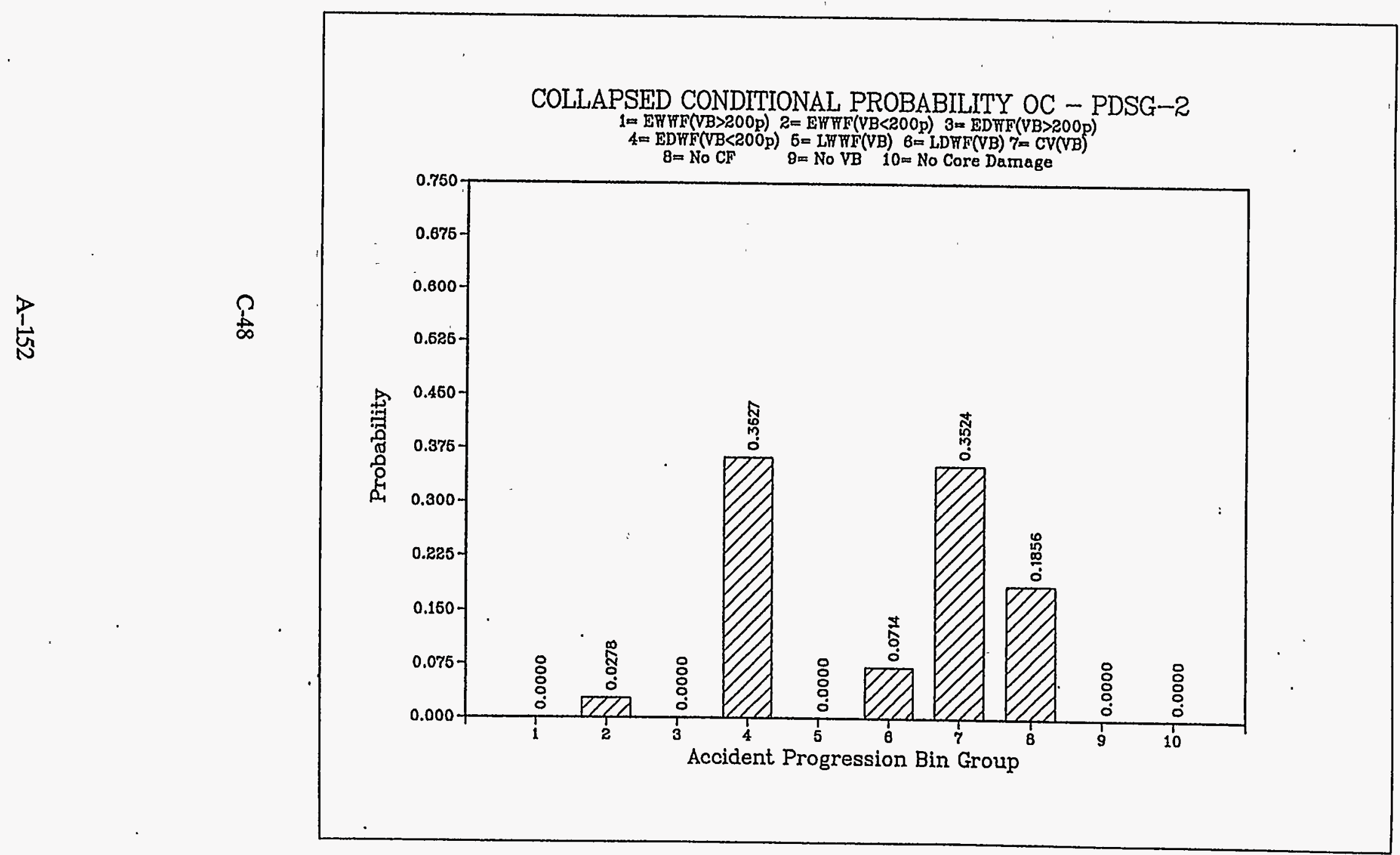


Figure C-48 NMP/OC containment, 43.4 psig vent pressure, design pressure capability

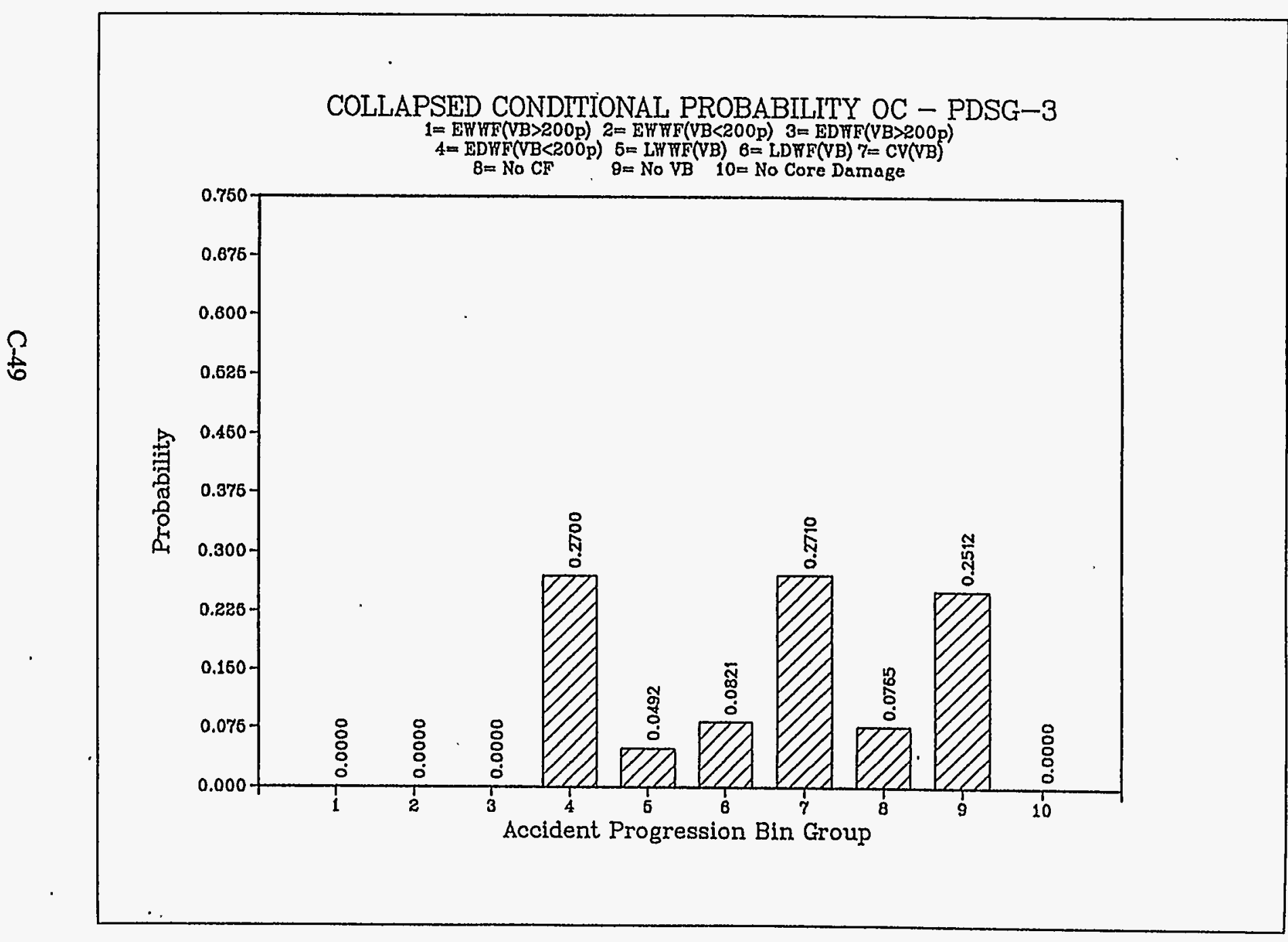


Figure C-49. NMP/OC containment, 43.4 psig vent pressure, design pressure capability

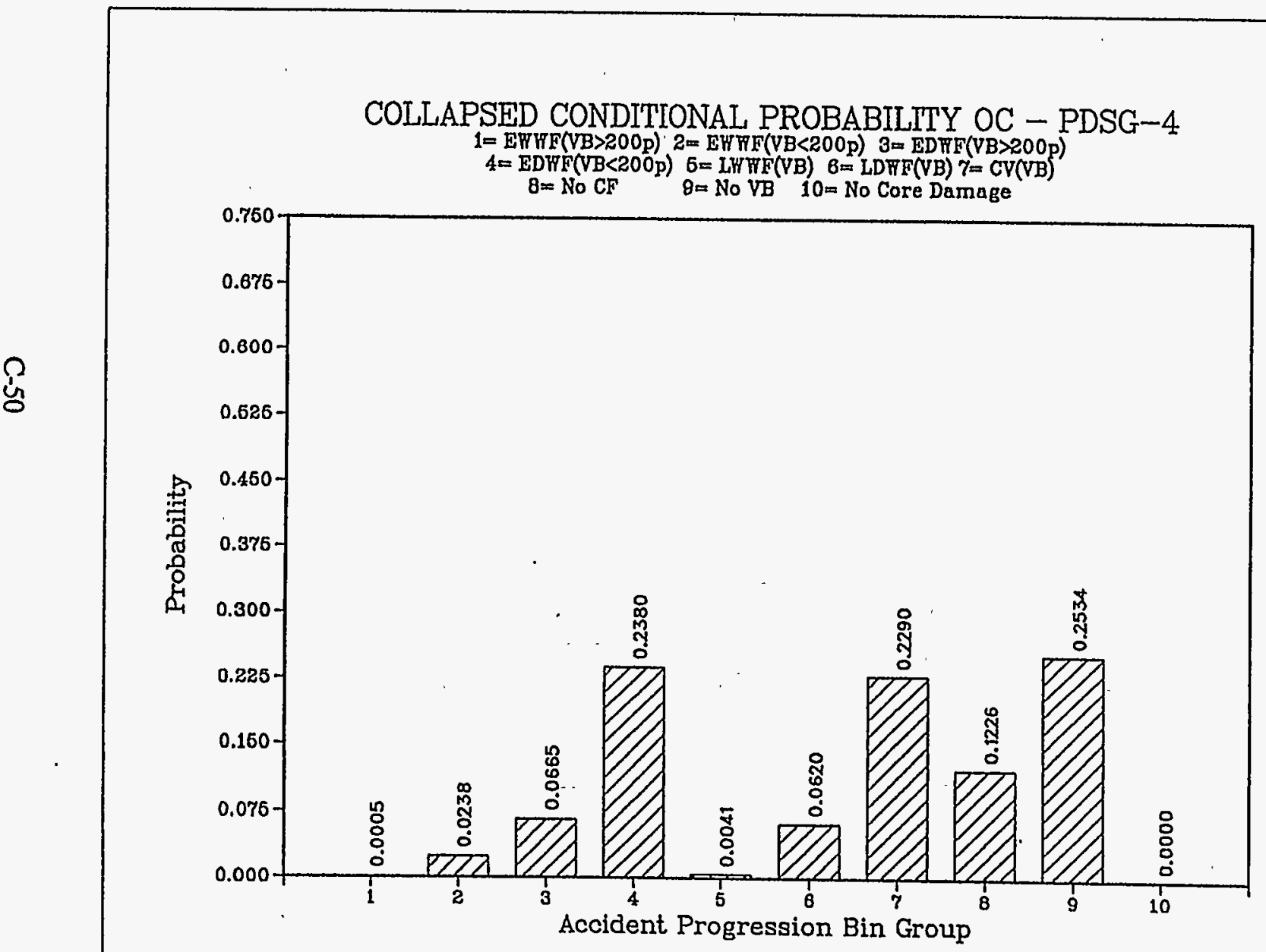




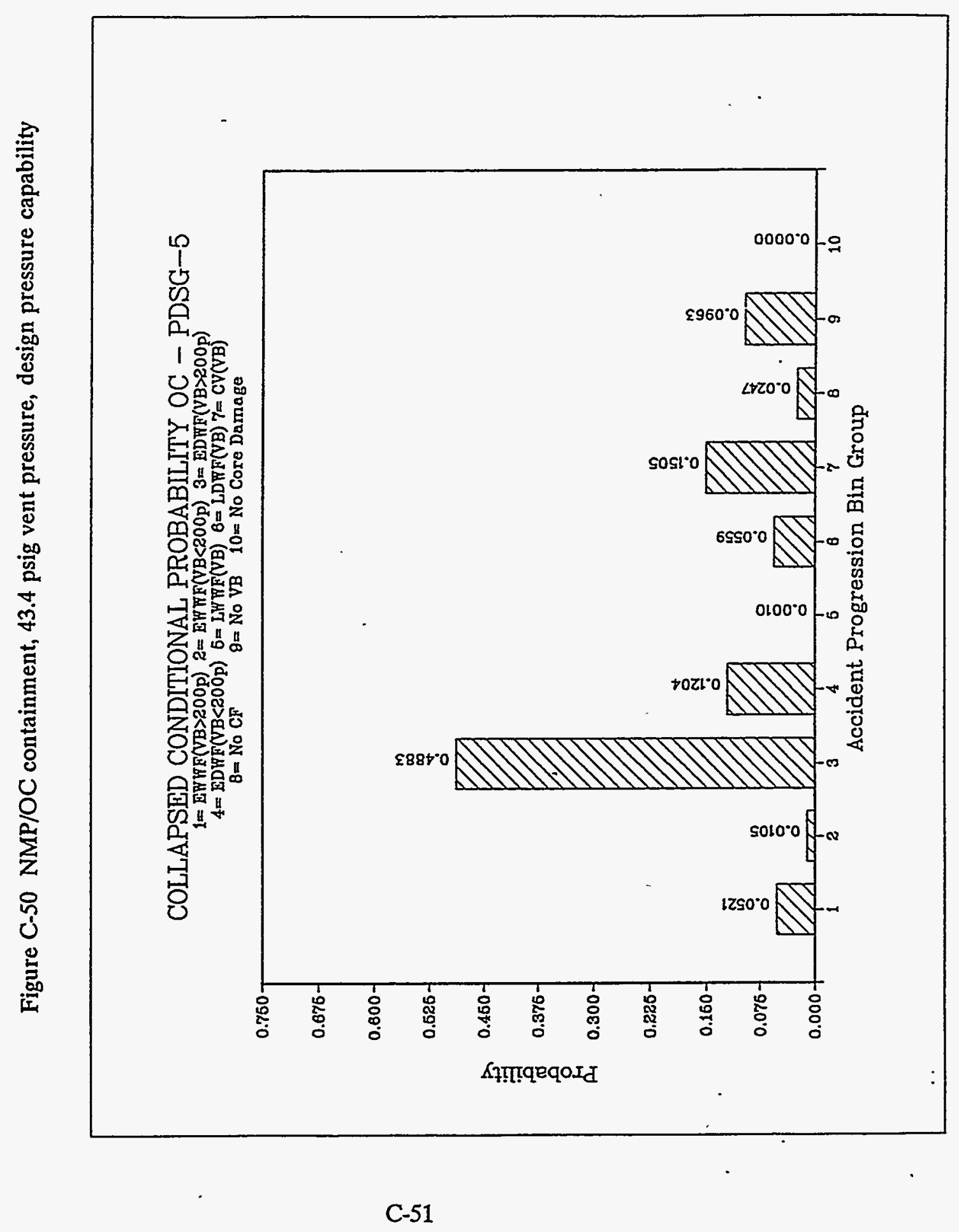




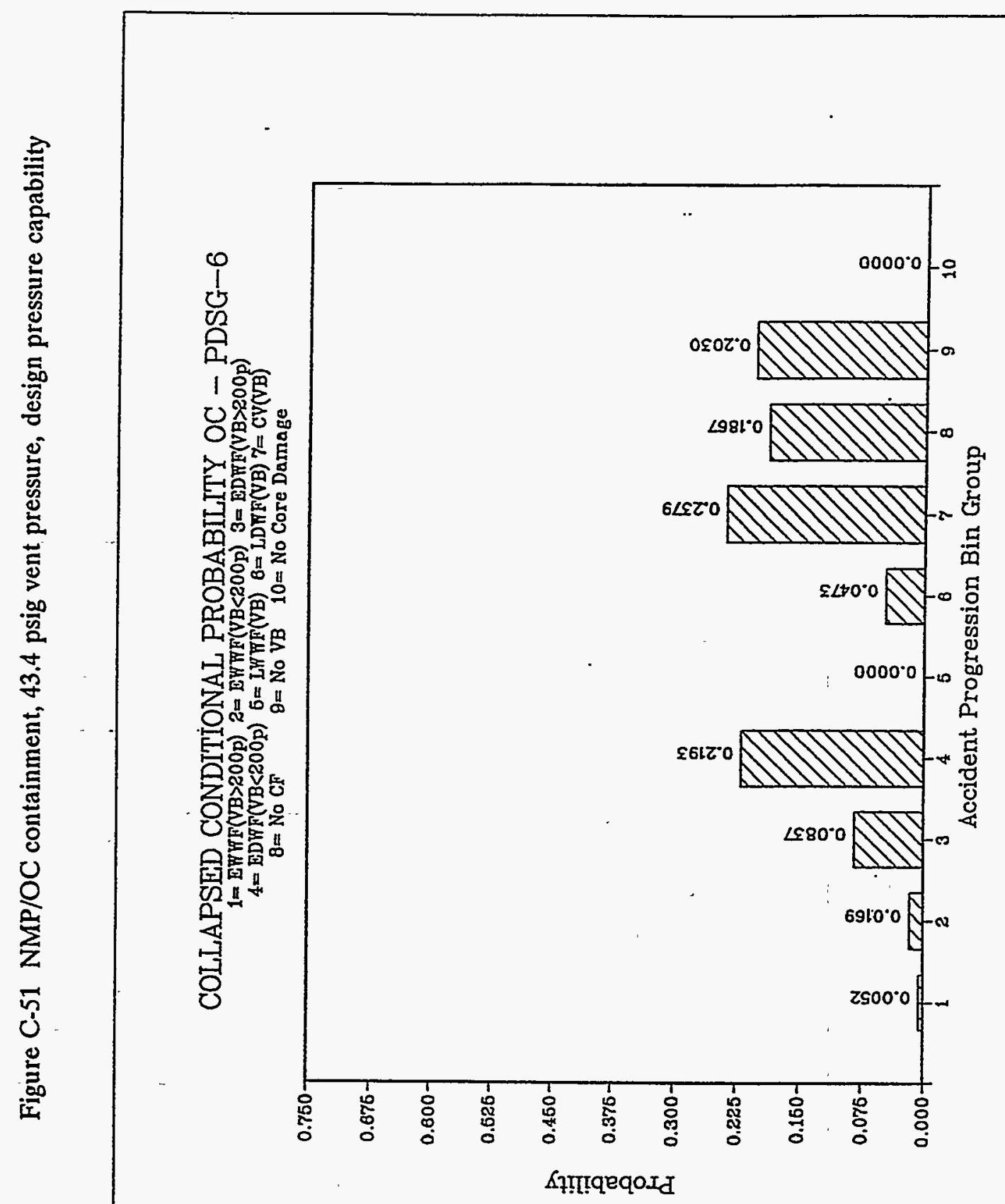

C-52 


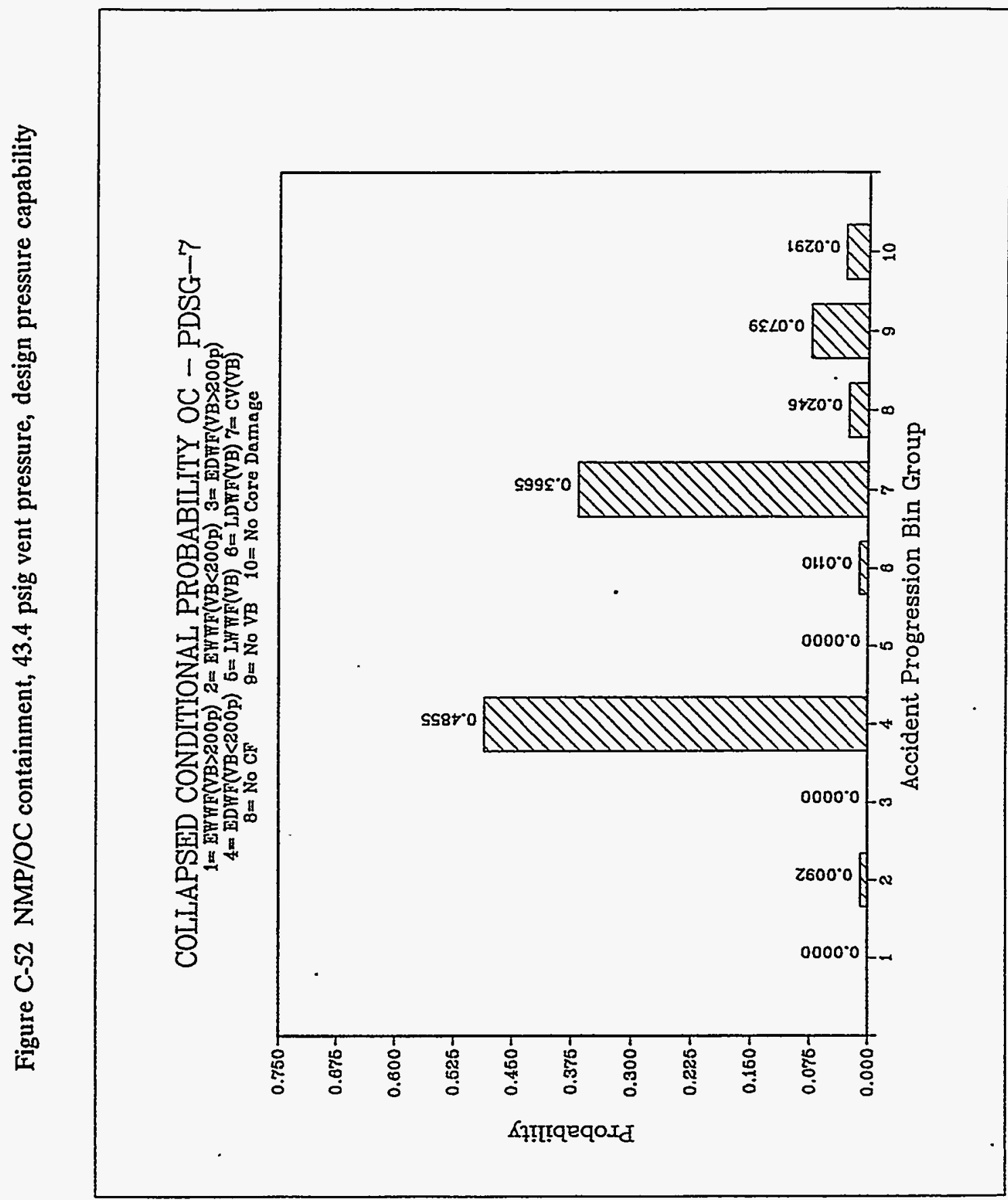

C-53 


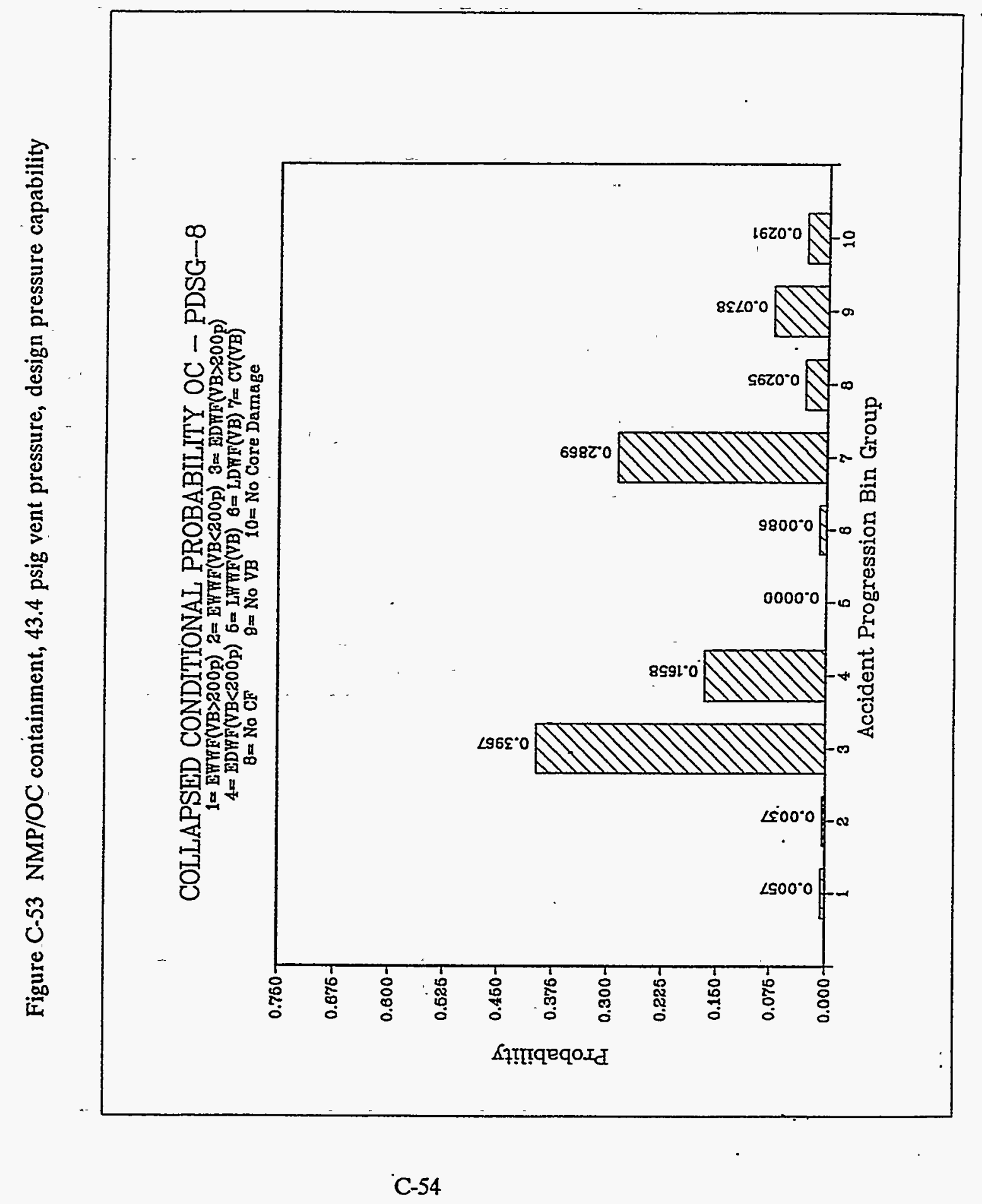


Figure C-54 NMP/OC containment, 43.4 psig vent pressure, design pressure capability

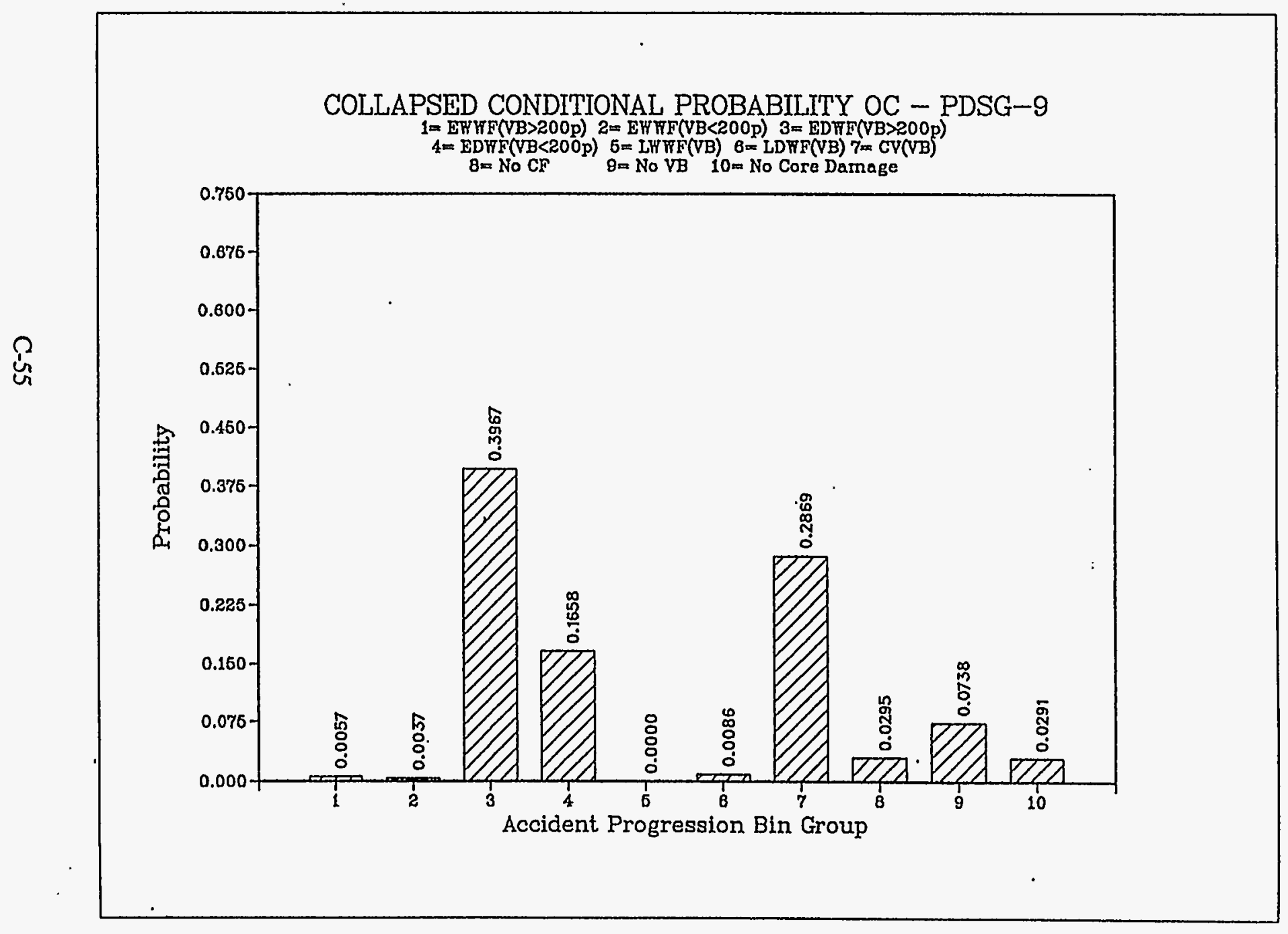

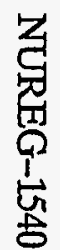


Figure C-55 NMP/OC containment, 43.4 psig vent pressure, current pressure capability

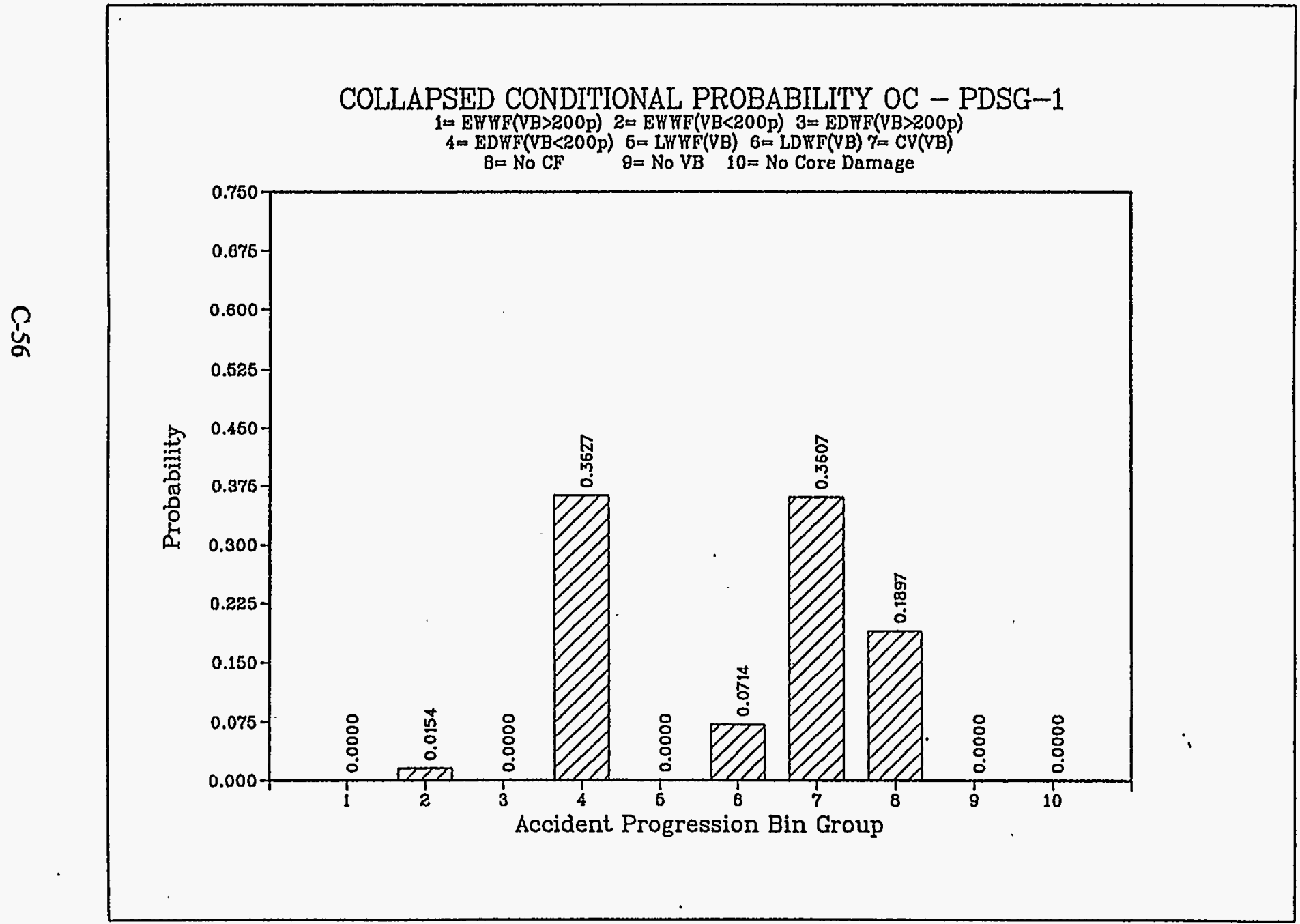




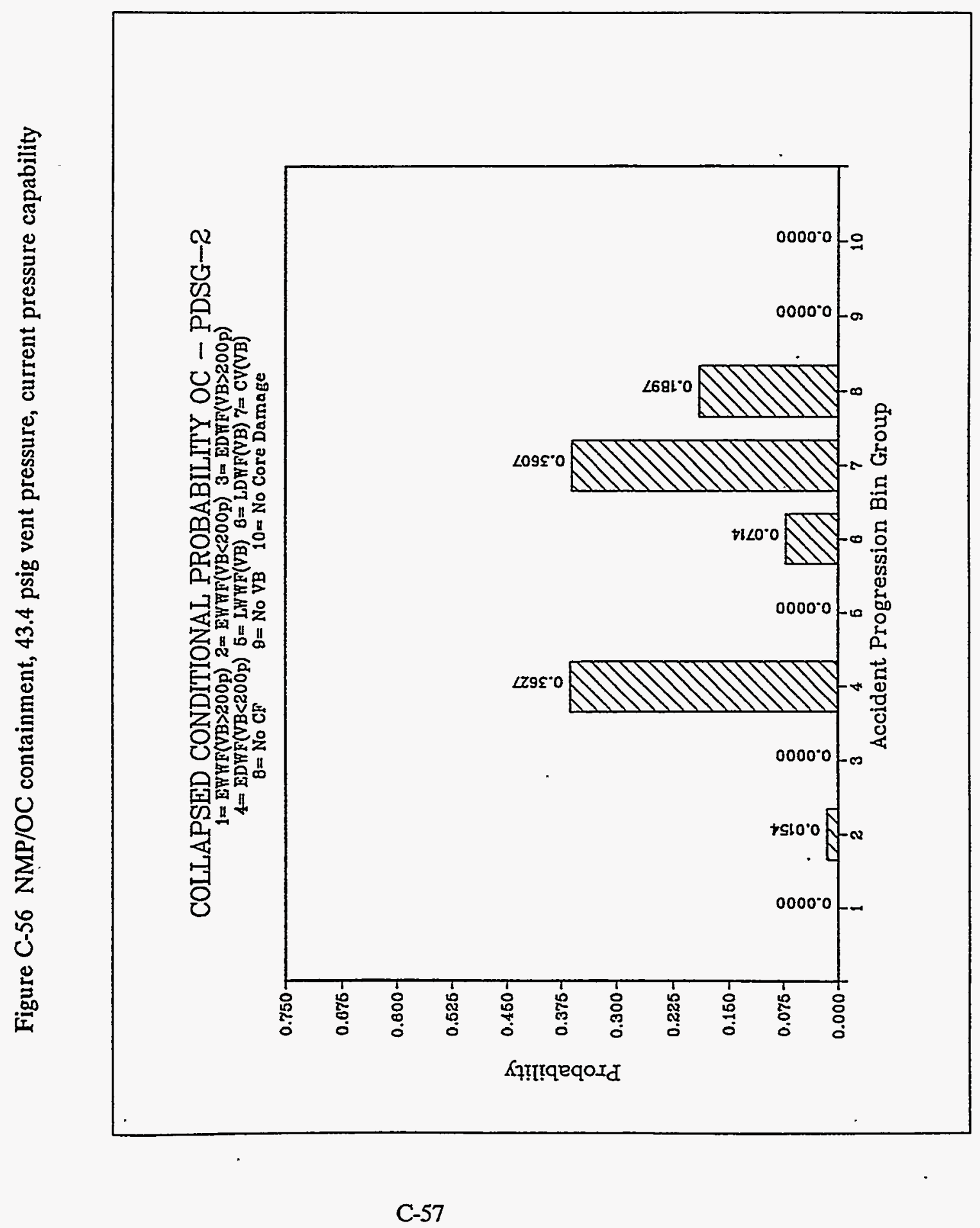


Figure C-57 NMP/OC containment, 43.4 psig vent pressure, current pressure capability

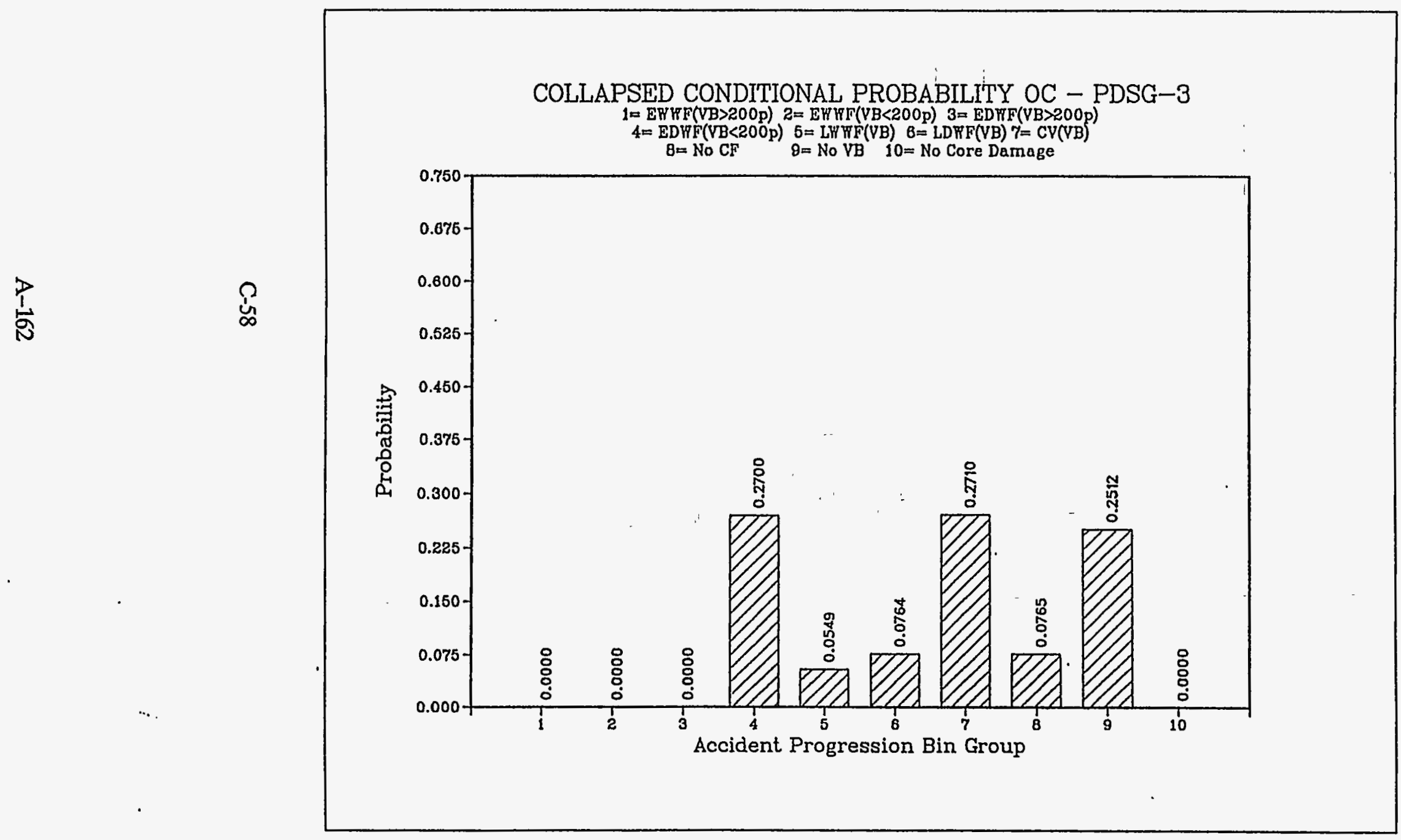




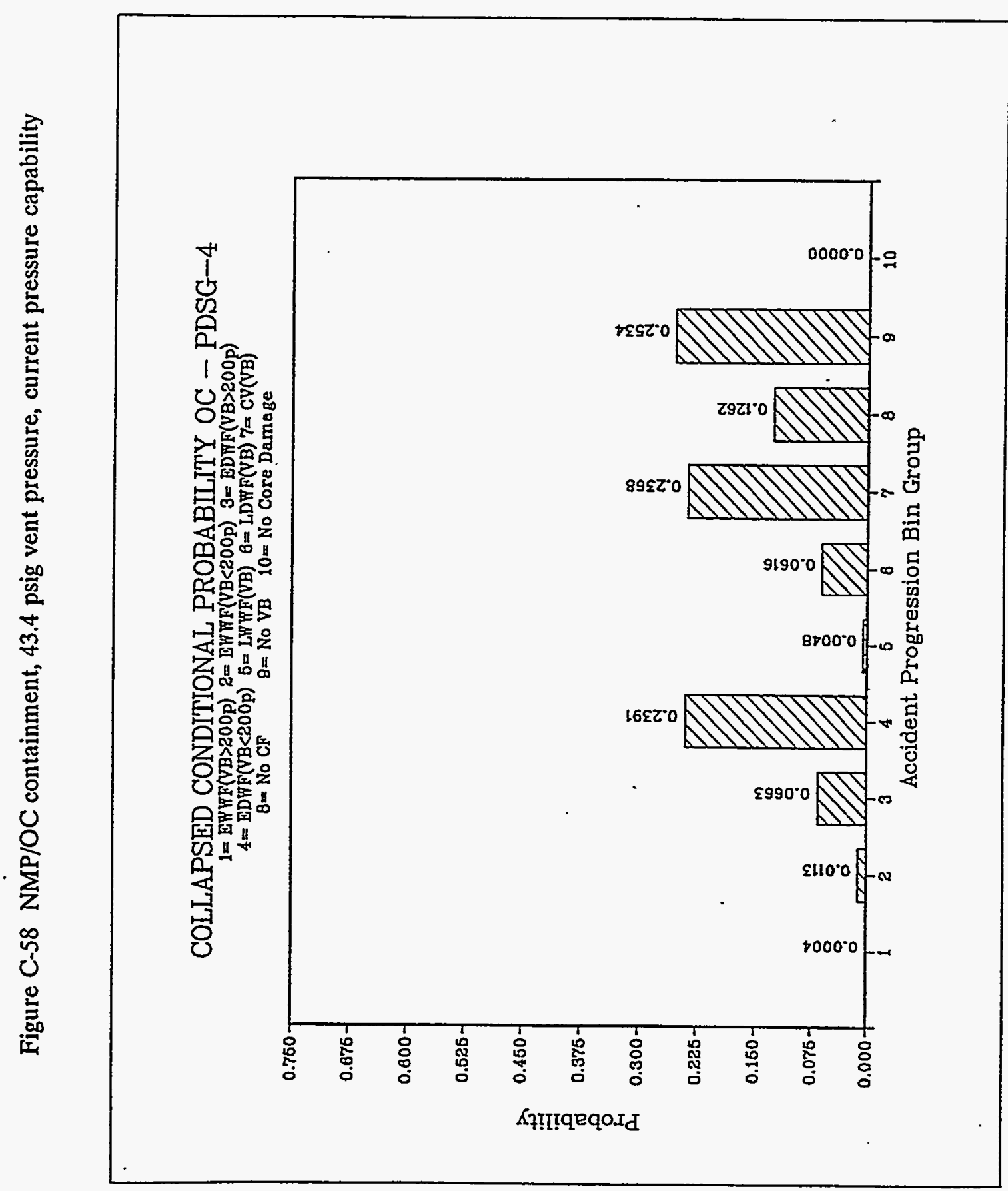

C-59 
Figure C-59 NMP/OC containment, 43.4 psig vent pressure, current pressure capability

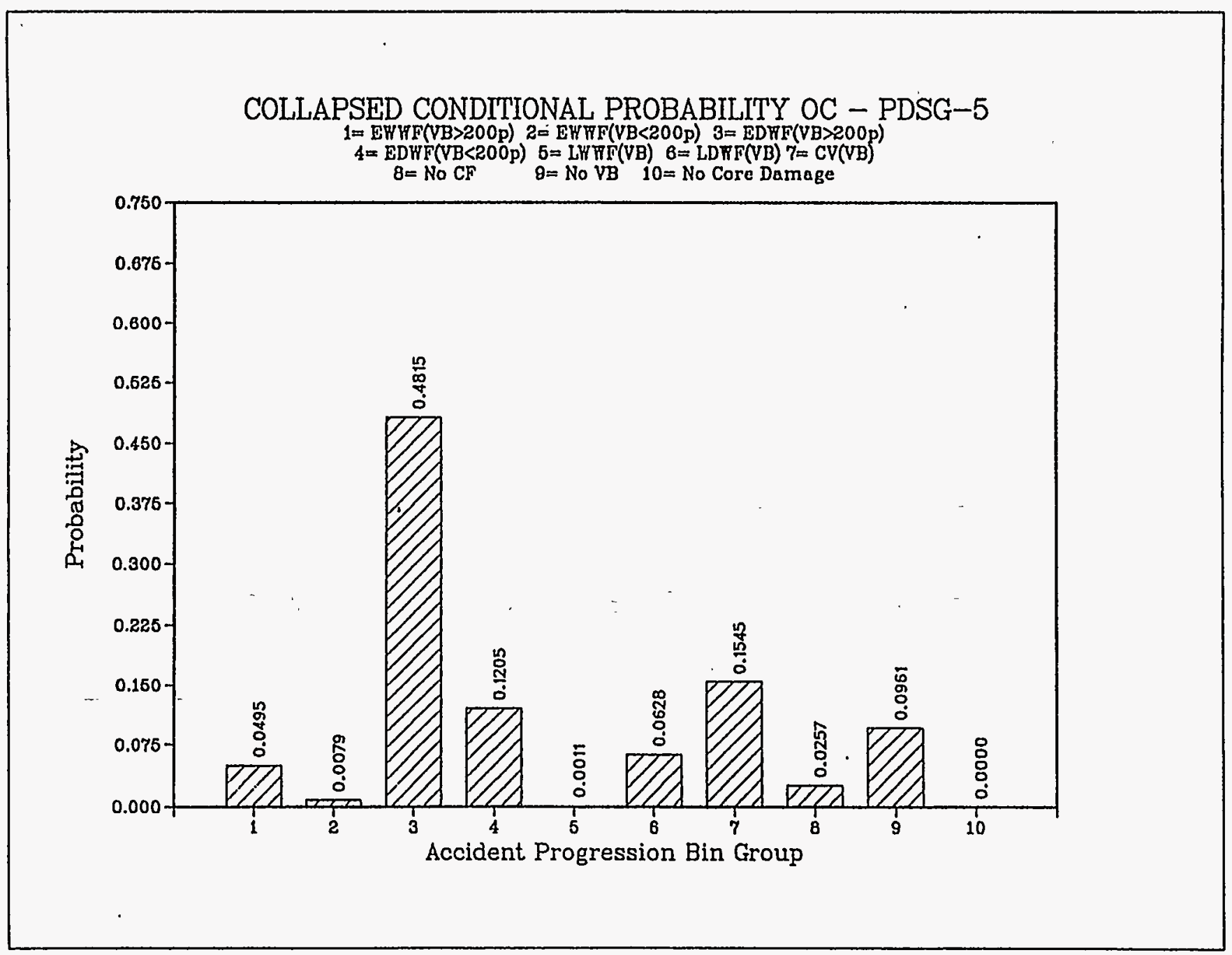


Figure C-60 NMP/OC containment, 43.4 psig vent pressure, current pressure capability

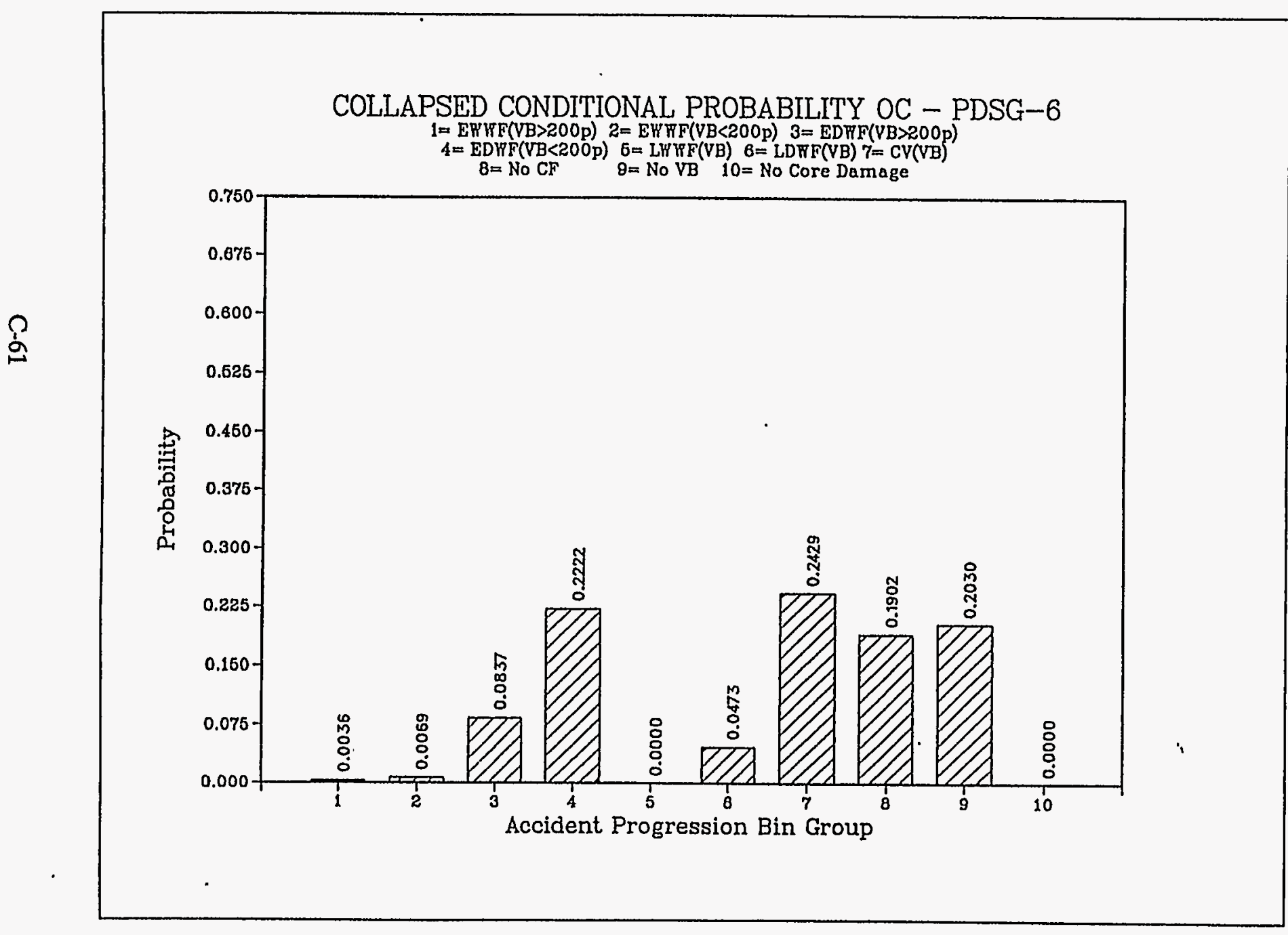


Figure C-61 NMP/OC containment, 43.4 psig vent pressure, current pressure capability

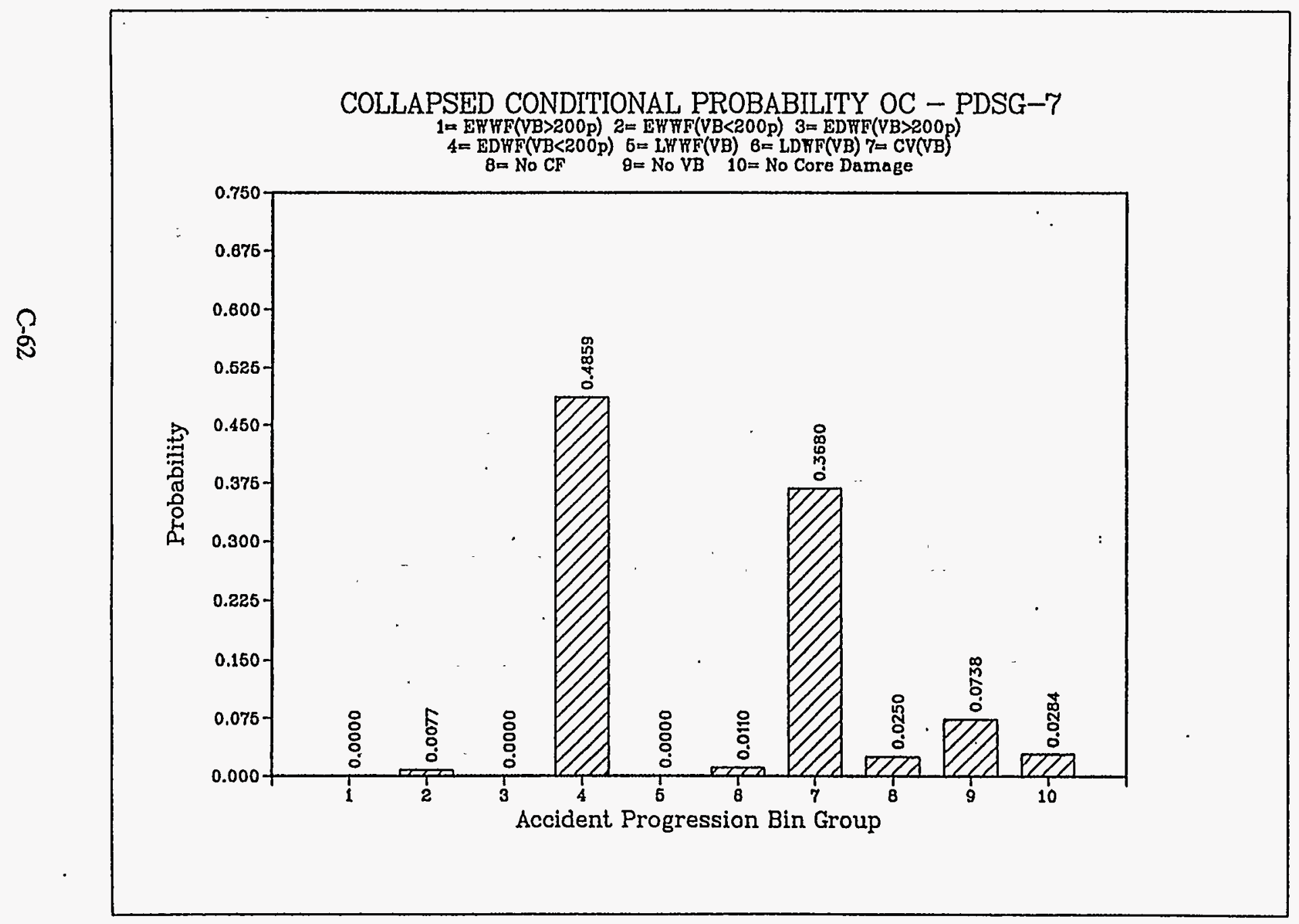




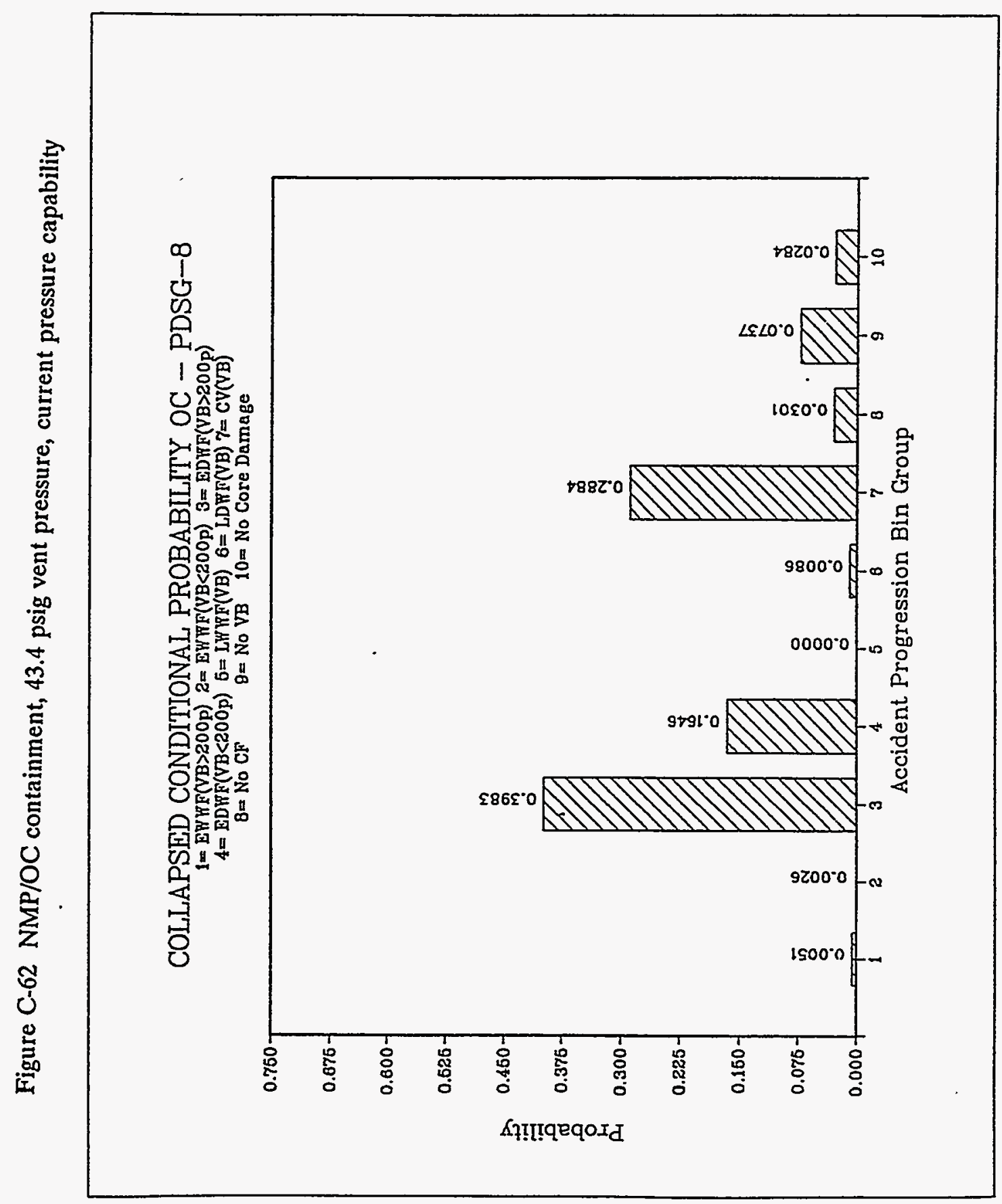

C-63 
Figure C-63 NMP/OC containment, 43.4 psig vent pressure, current pressure capability

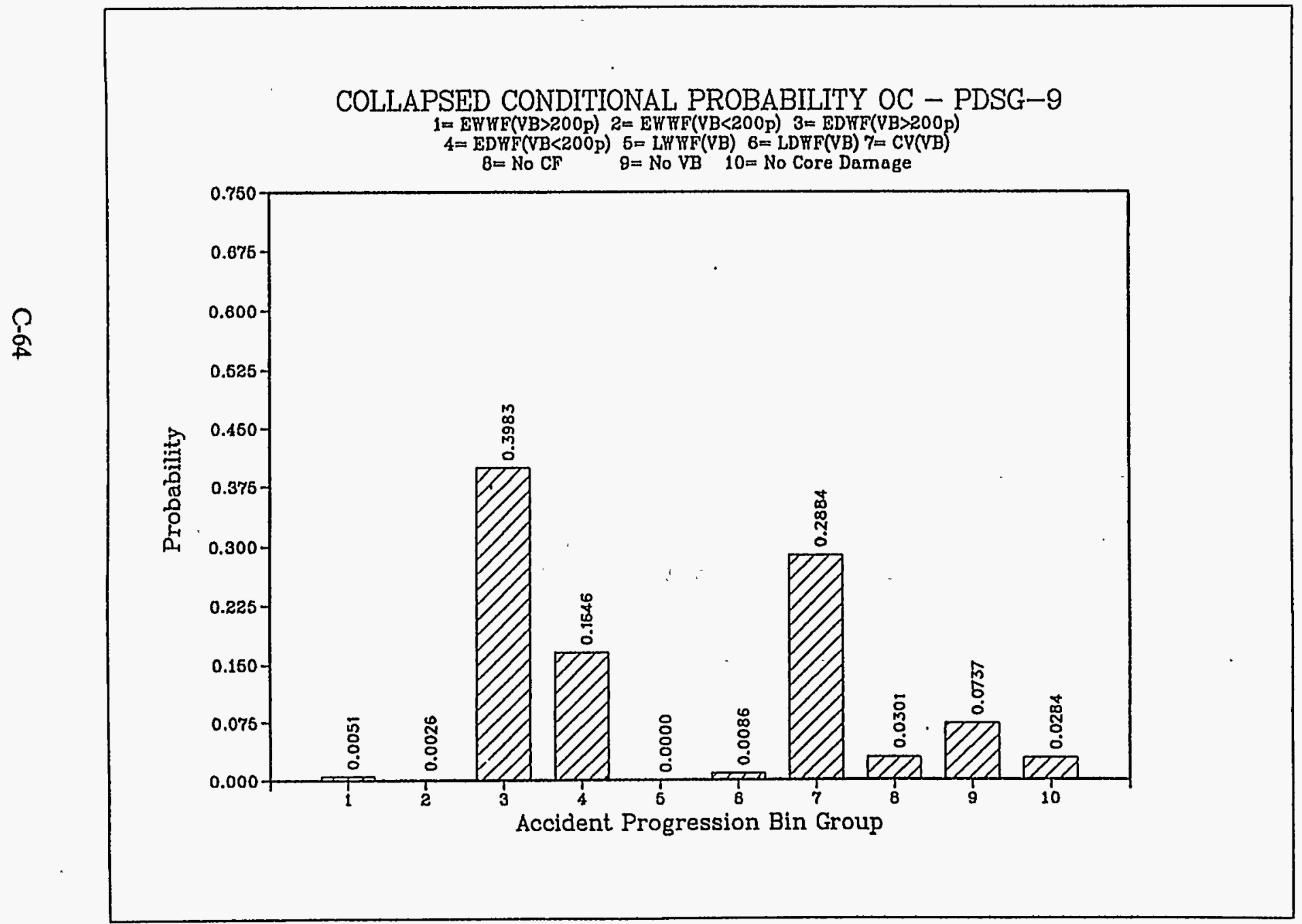




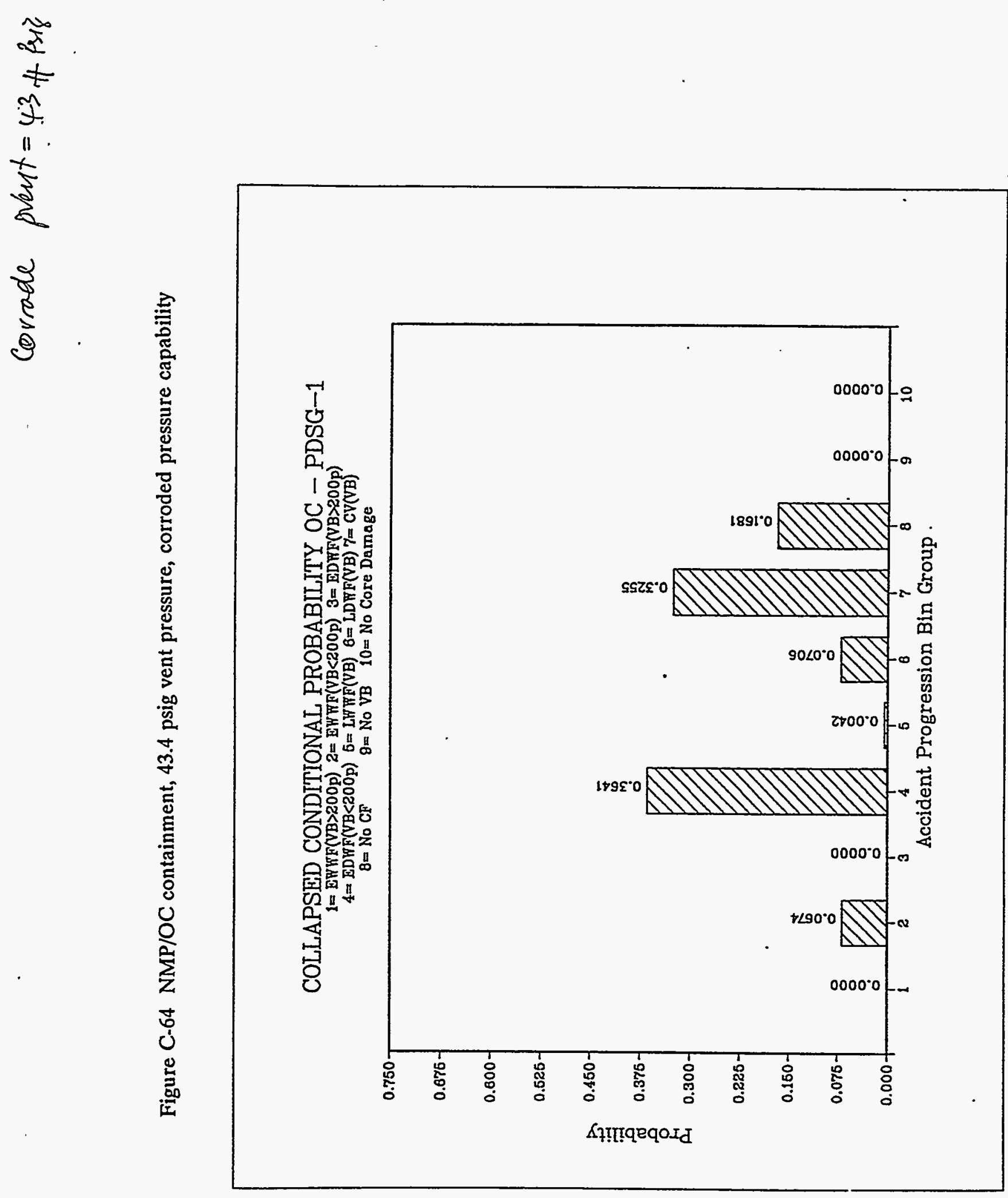

C-65 
Figure C-65 NMP/OC containment, 43.4 pig vent pressure, corroded pressure capability

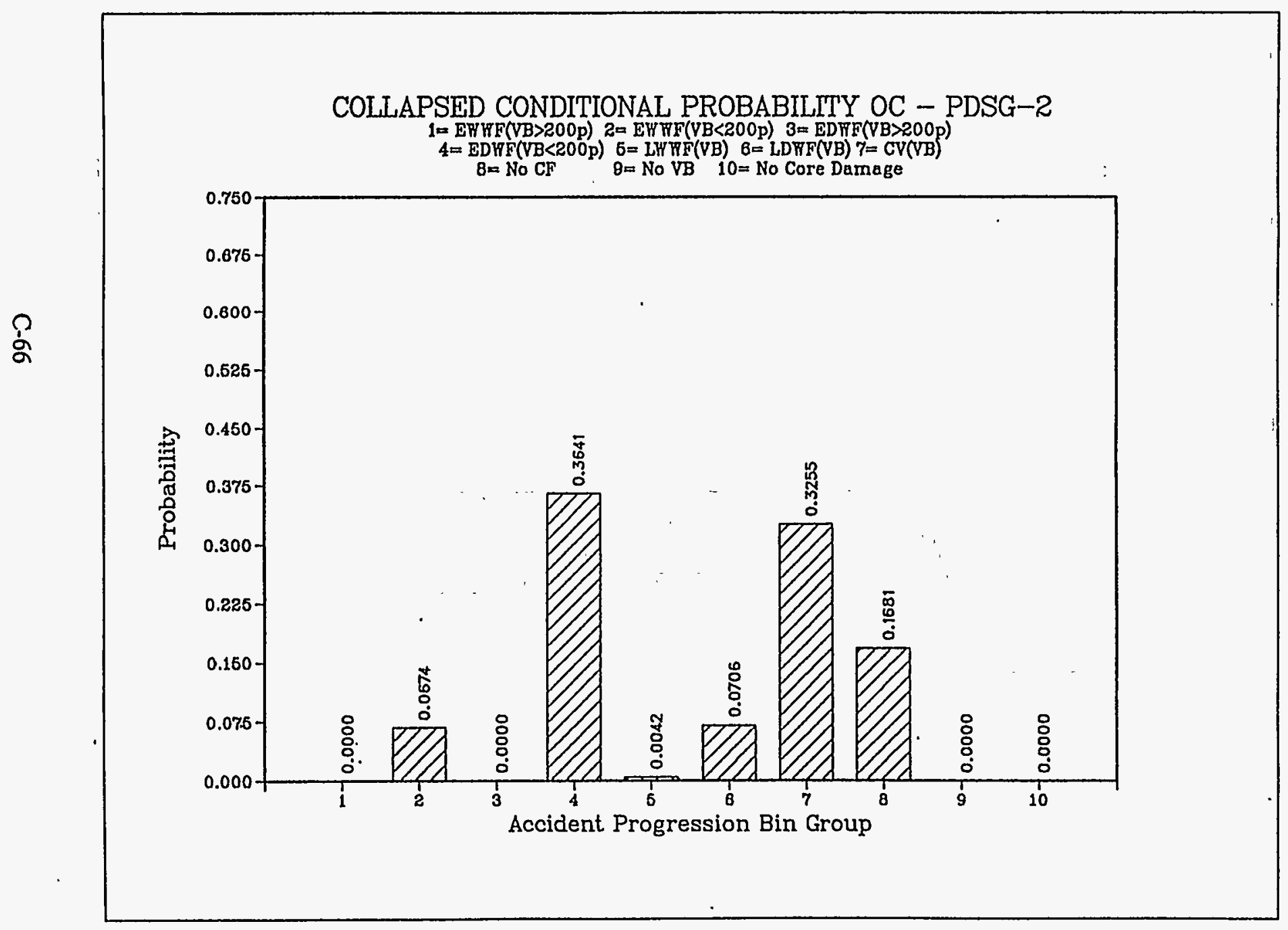




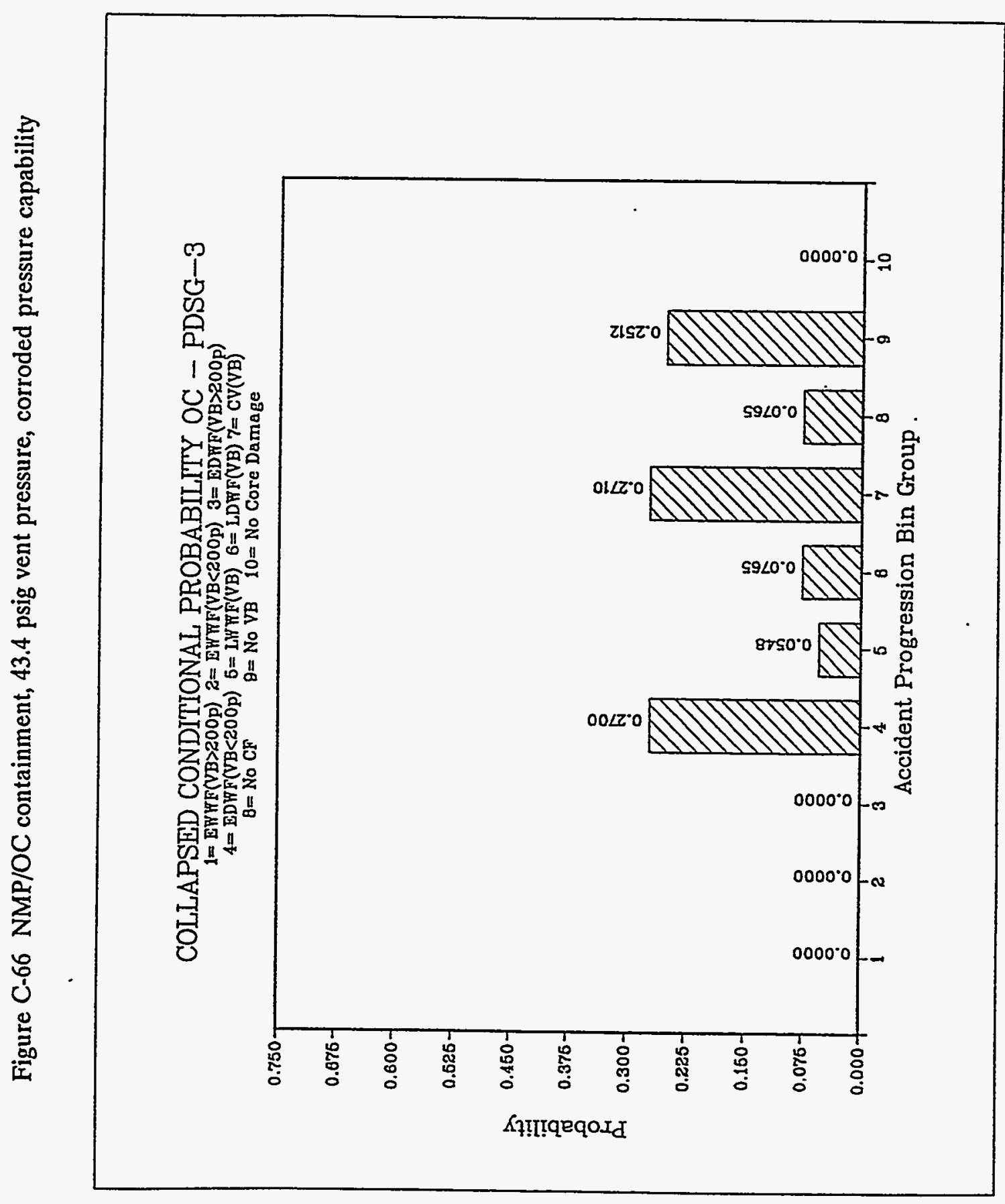

C-67 


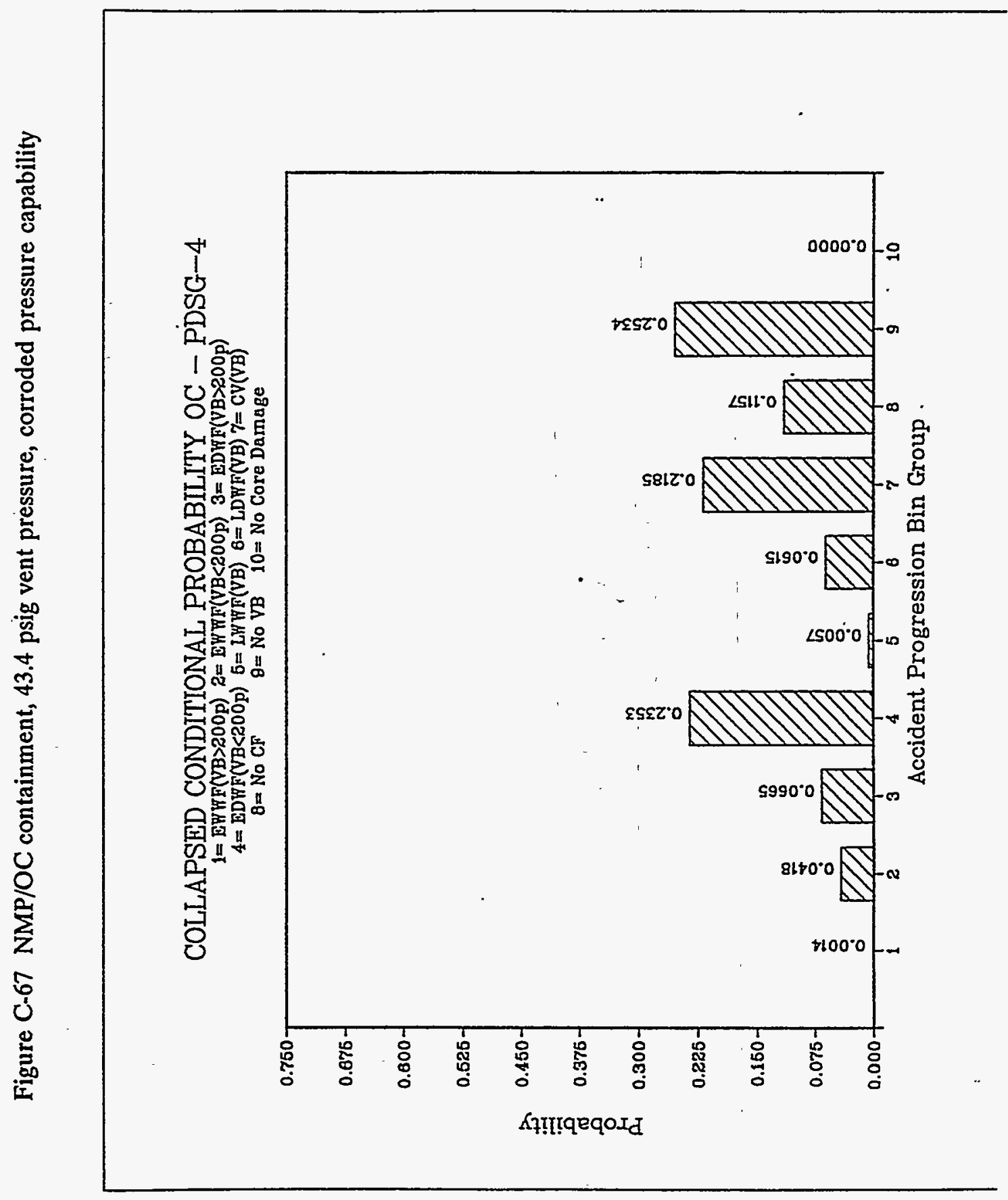

C-68 


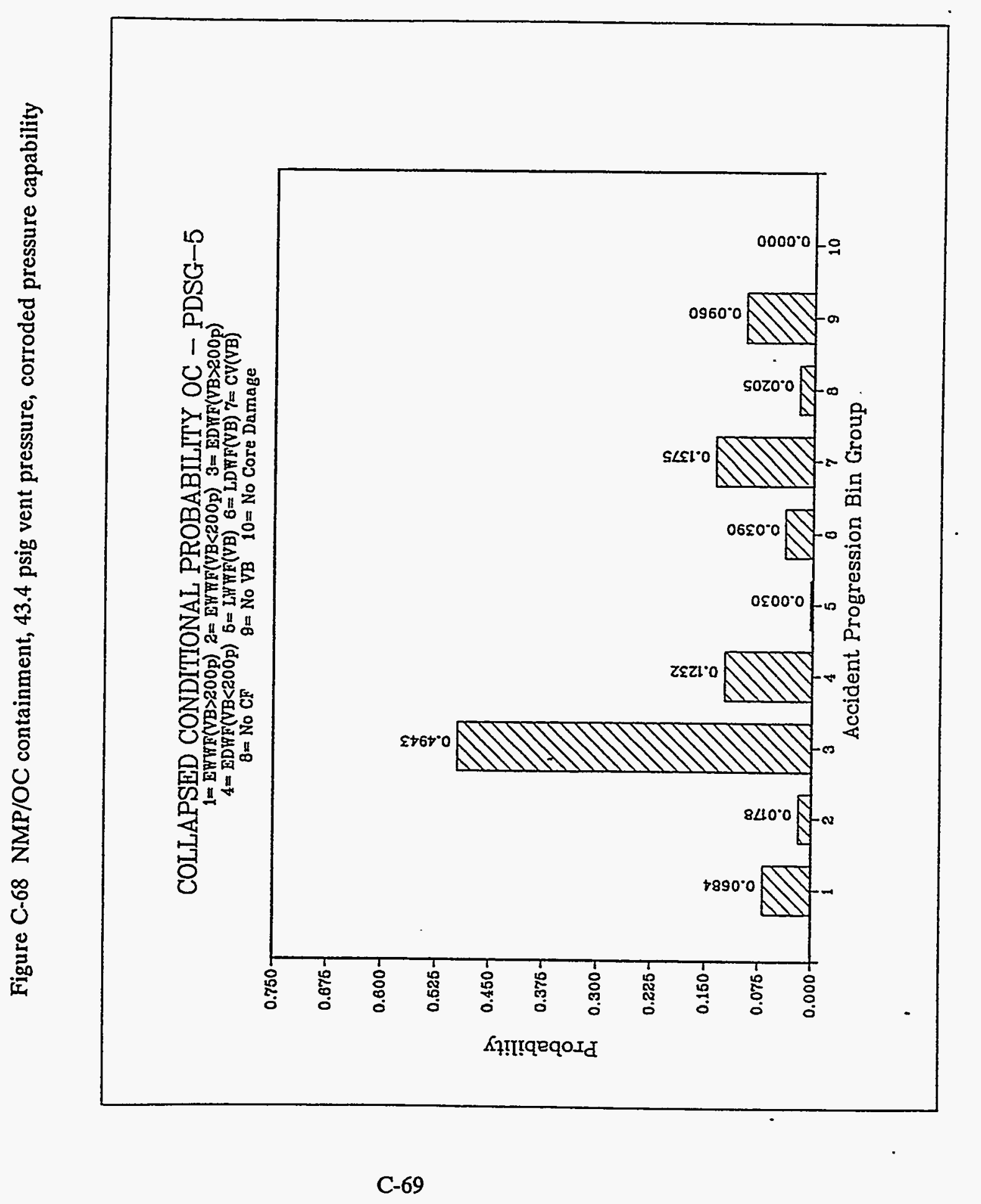


Figure C-69 NMP/OC containment, 43.4 psig vent pressure, corroded pressure capability

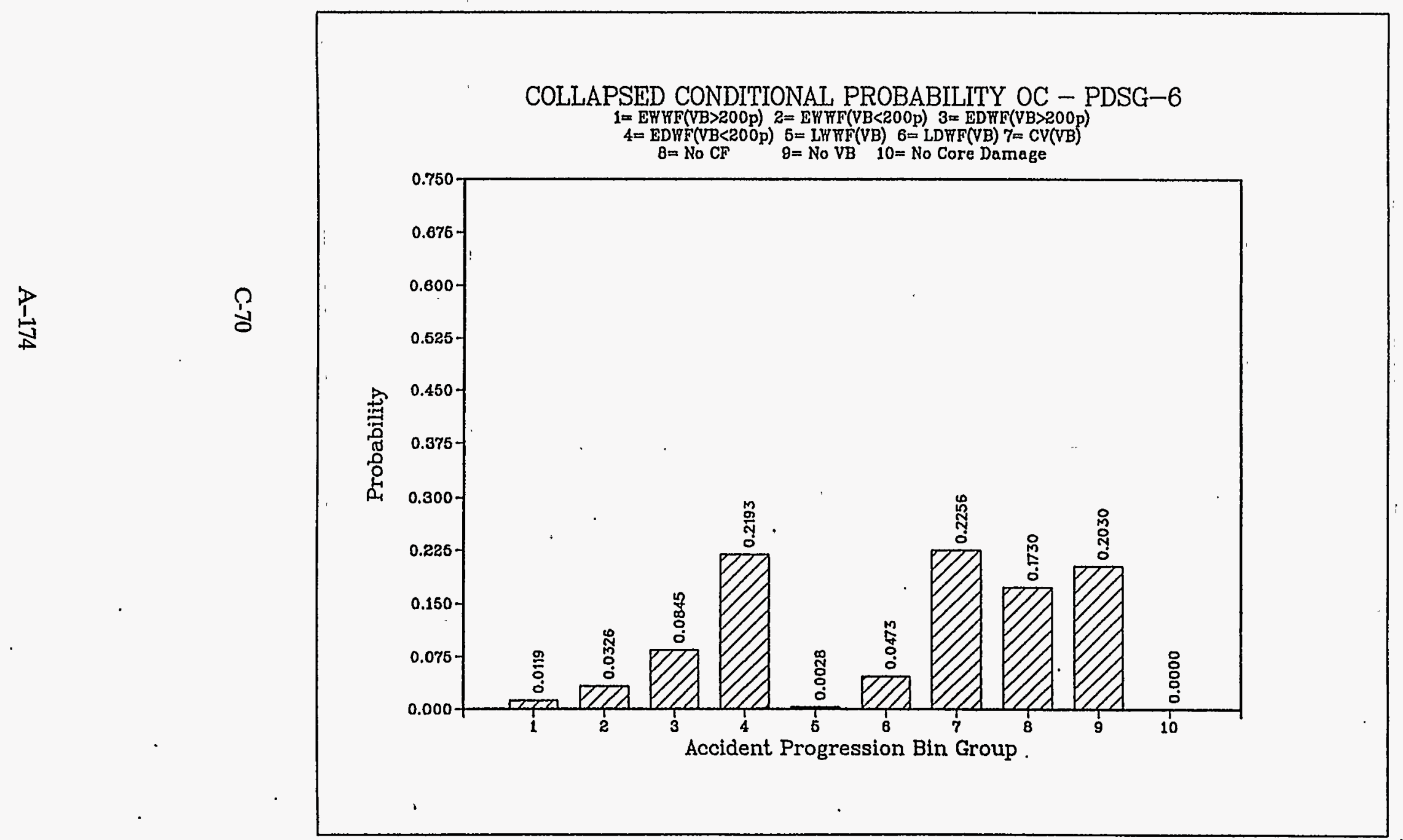




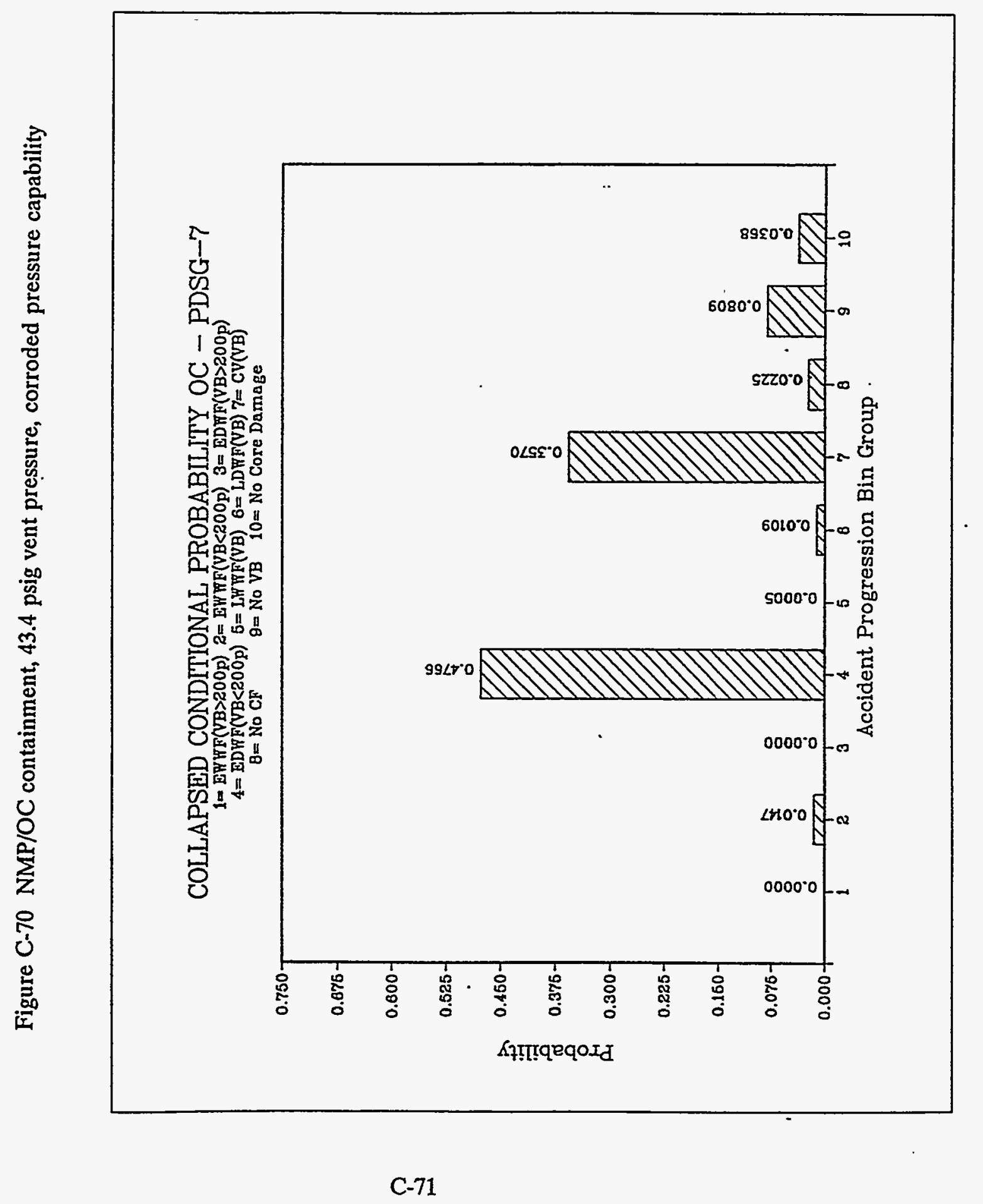


Figure C-71 NMP/OC containment, 43.4 psig vent pressure, corroded pressure capability

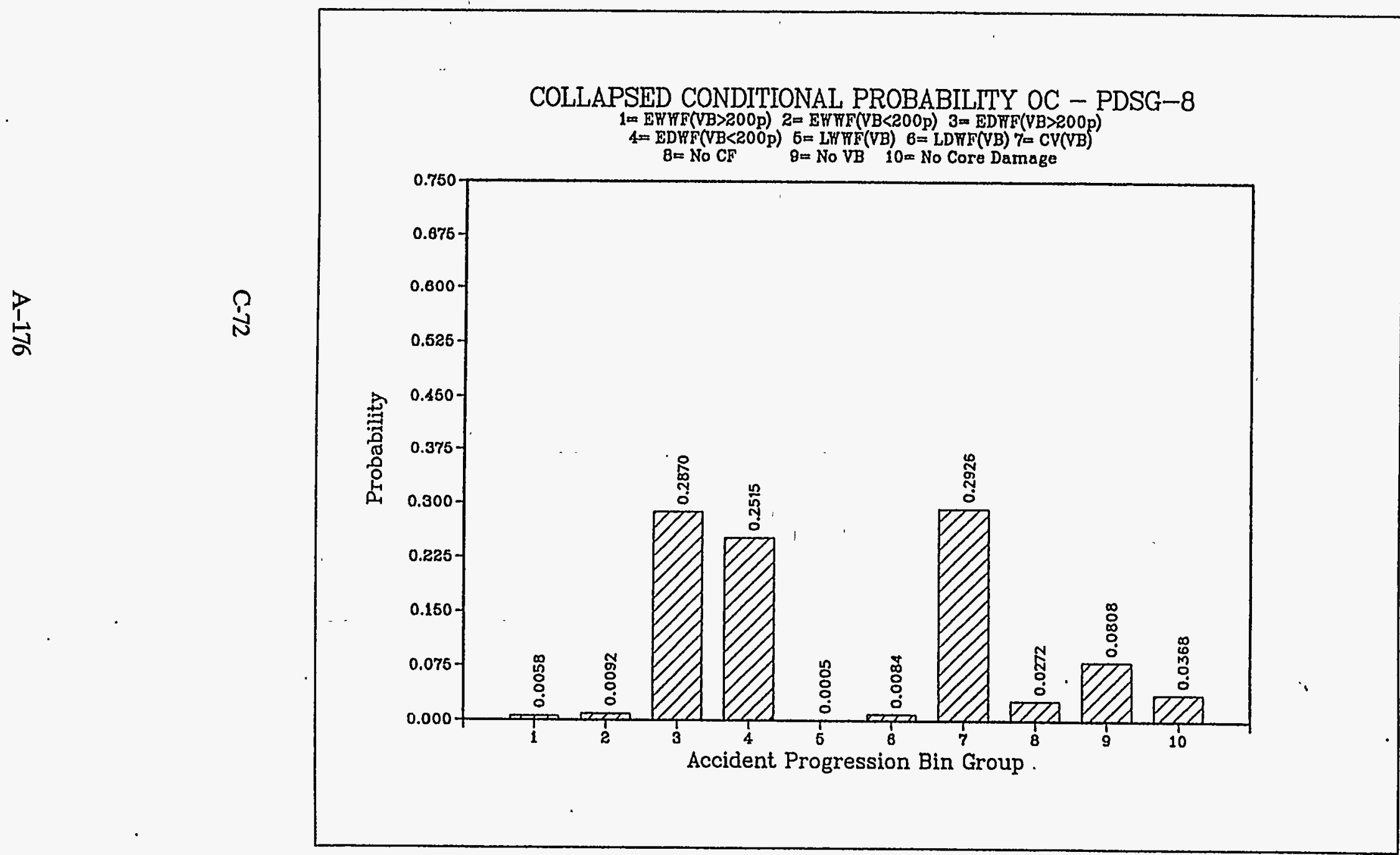


Figure C-72 NMP/OC containment, 43.4 psig vent pressure, corroded pressure capability

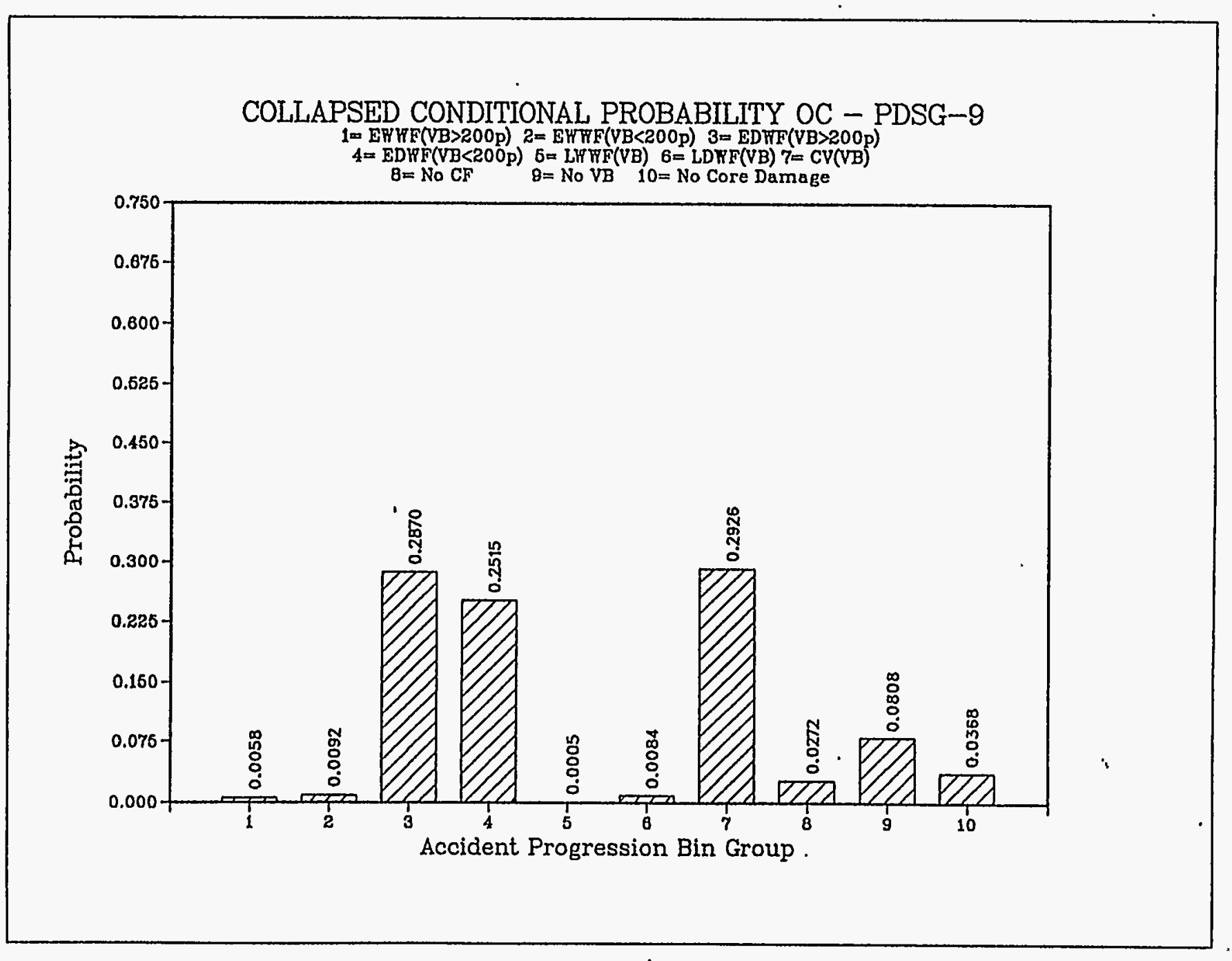


Figure C-73 NMP/OC containment, 35 psig vent pressure, design pressure capability

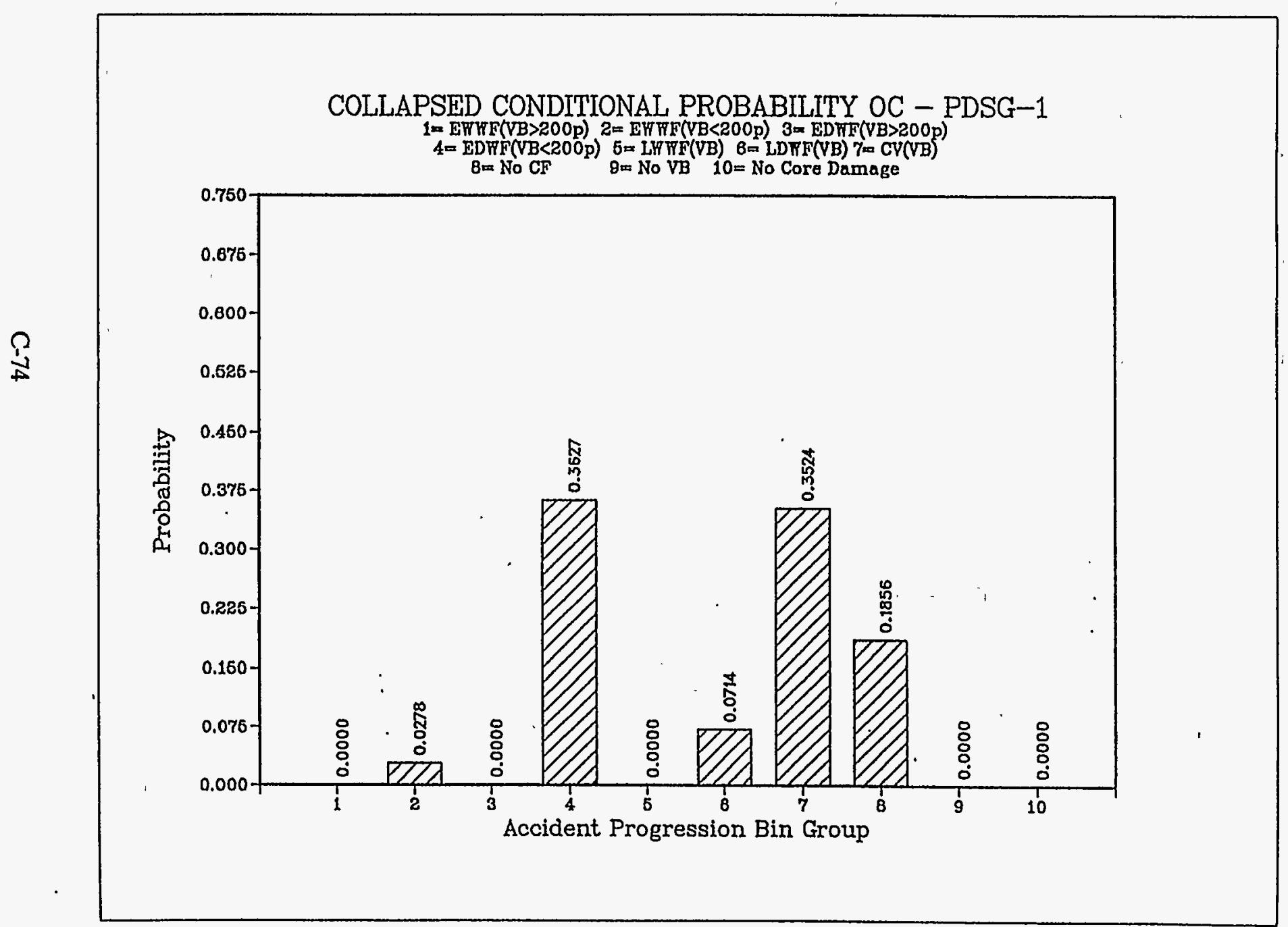




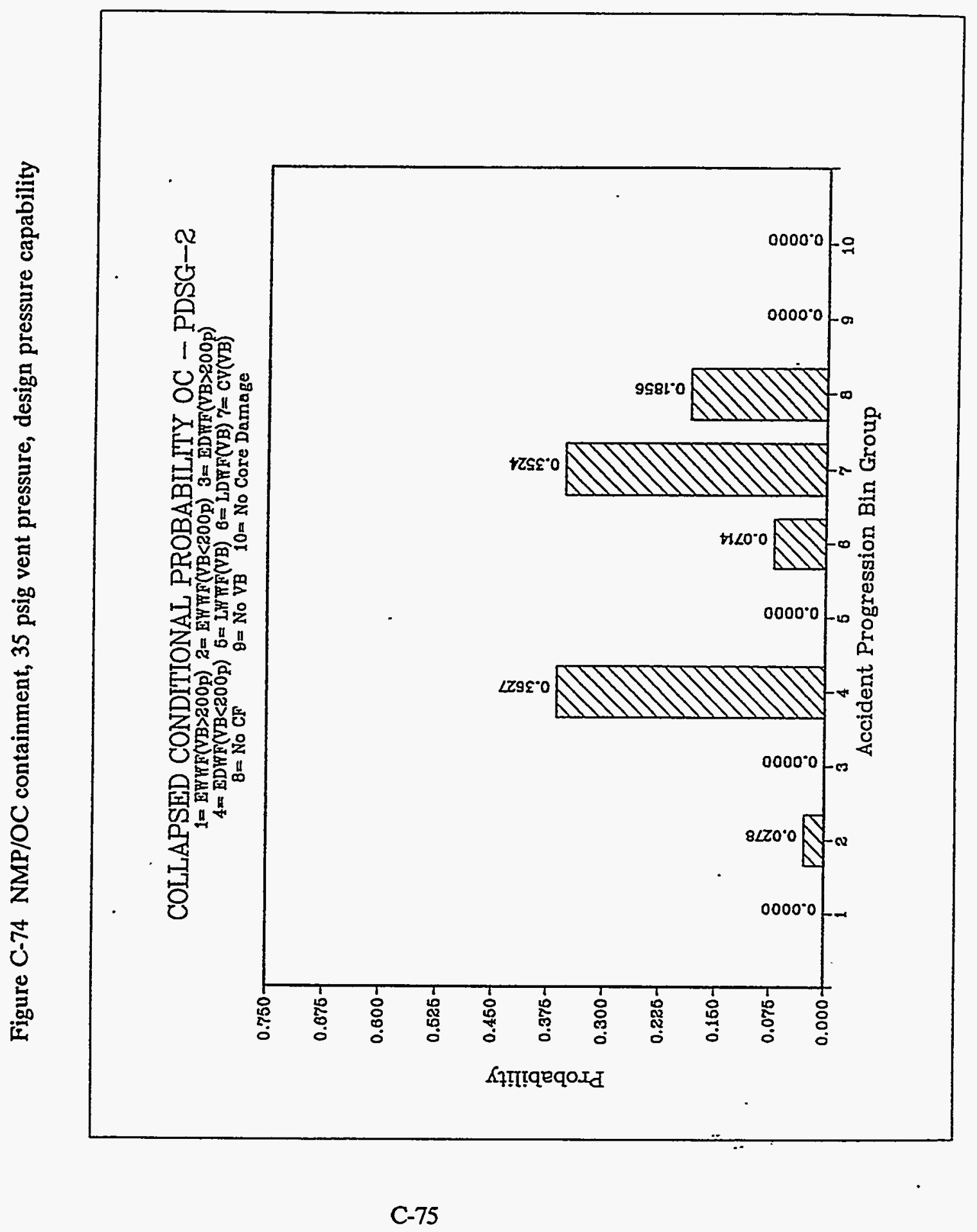




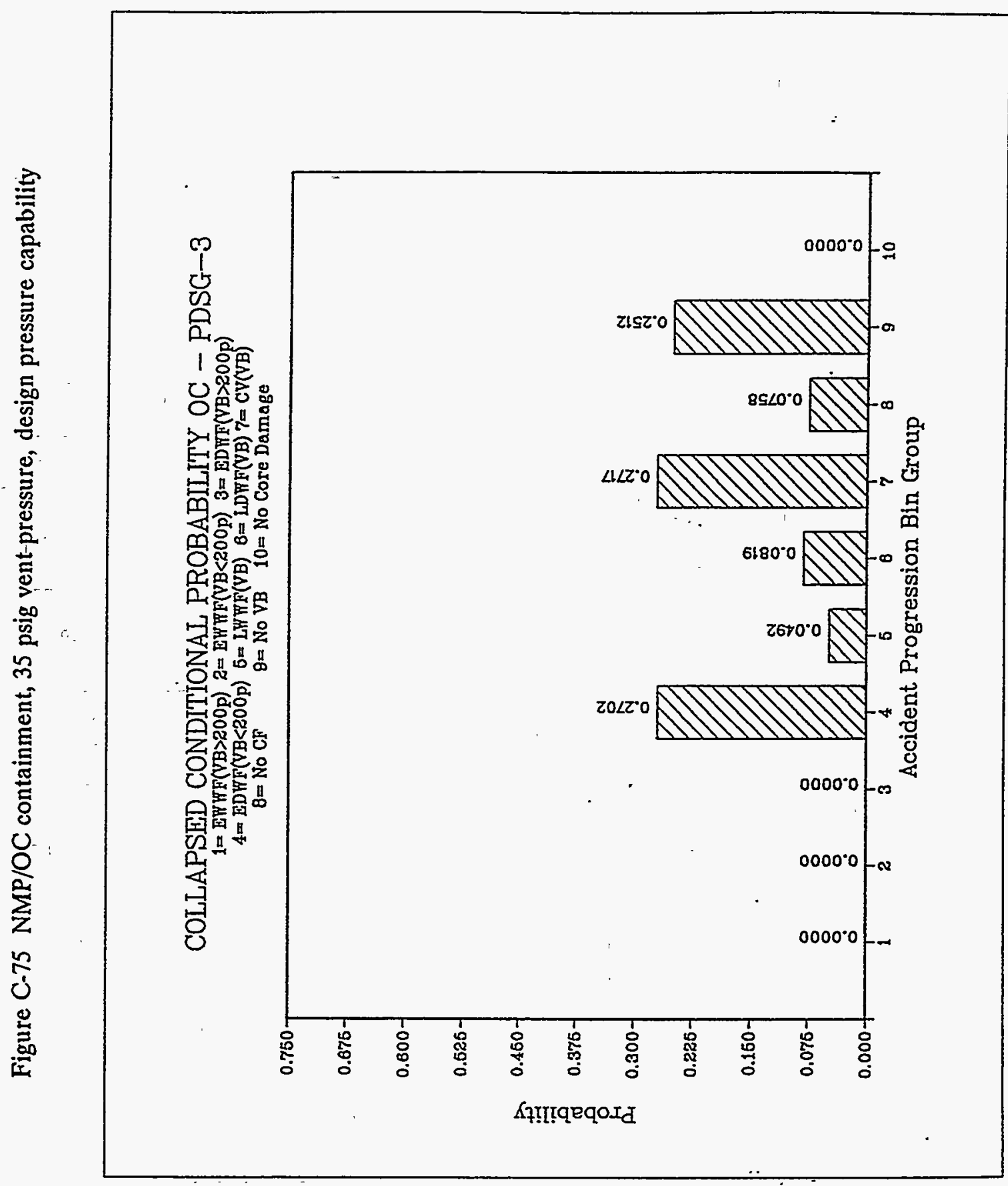

C-76 


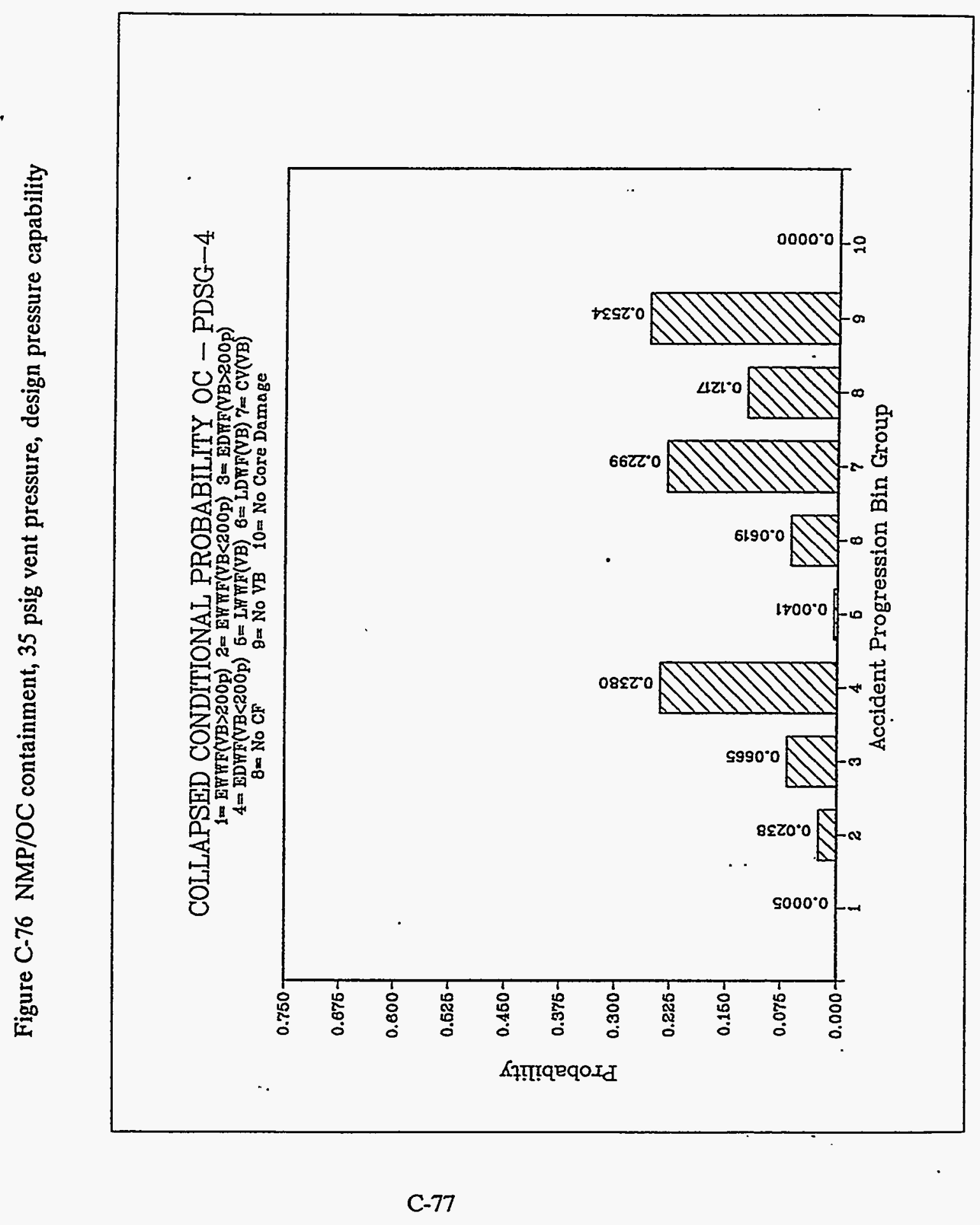


Figure C-77 NMP/OC containment, 35 psig vent pressure, design pressure capability

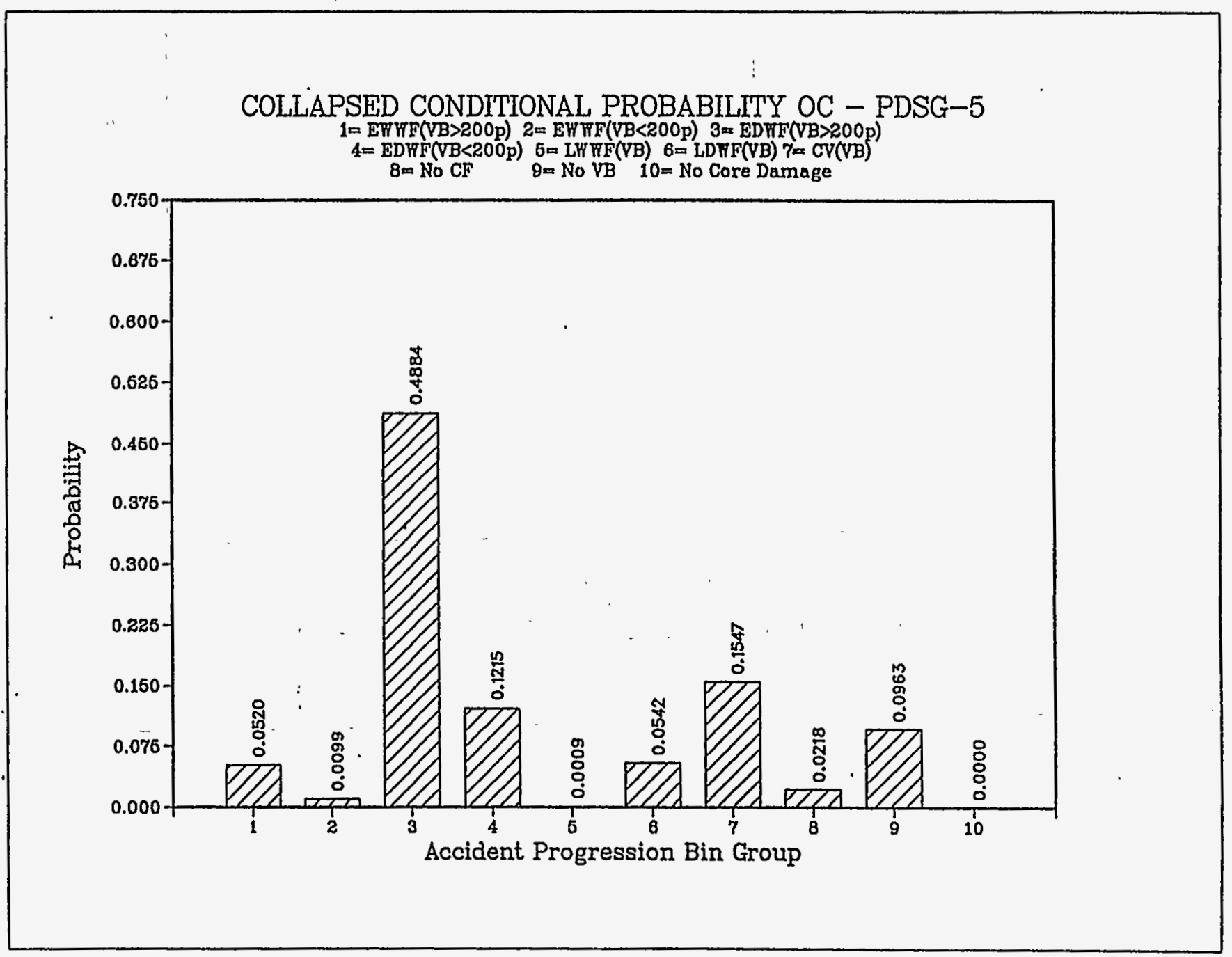




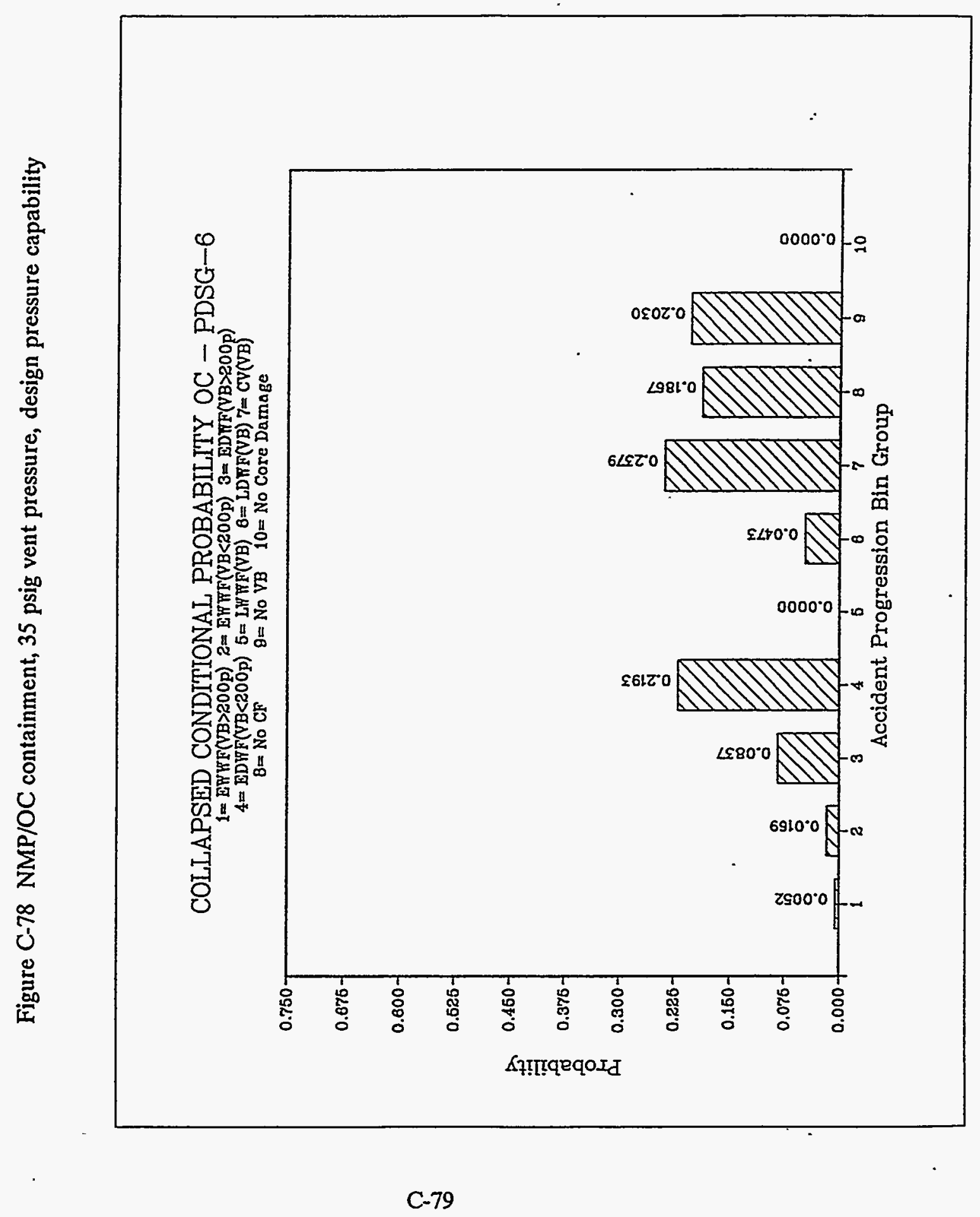


Figure C-79 NMP/OC containment, 35 psig vent pressure, design pressure capability

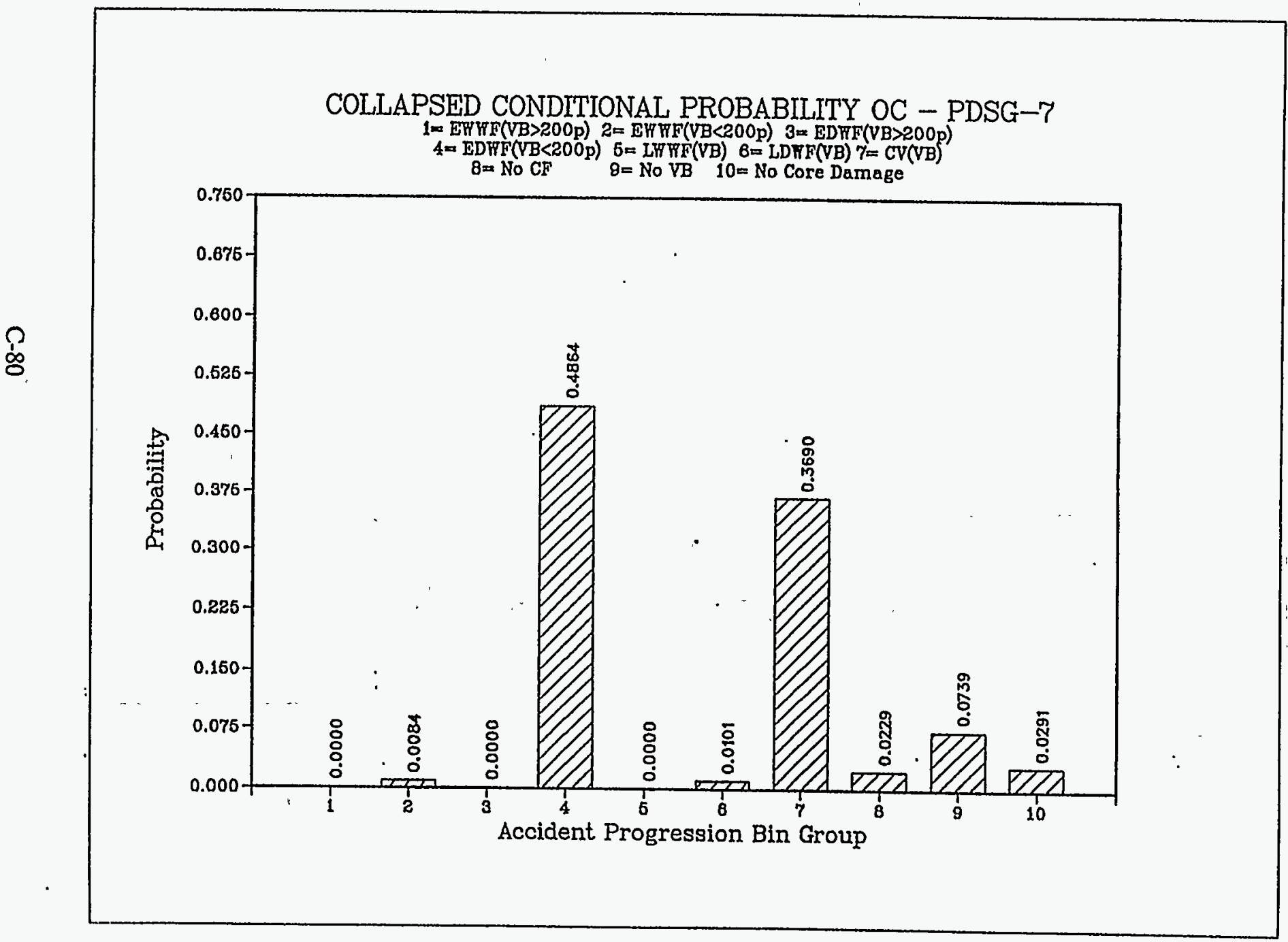




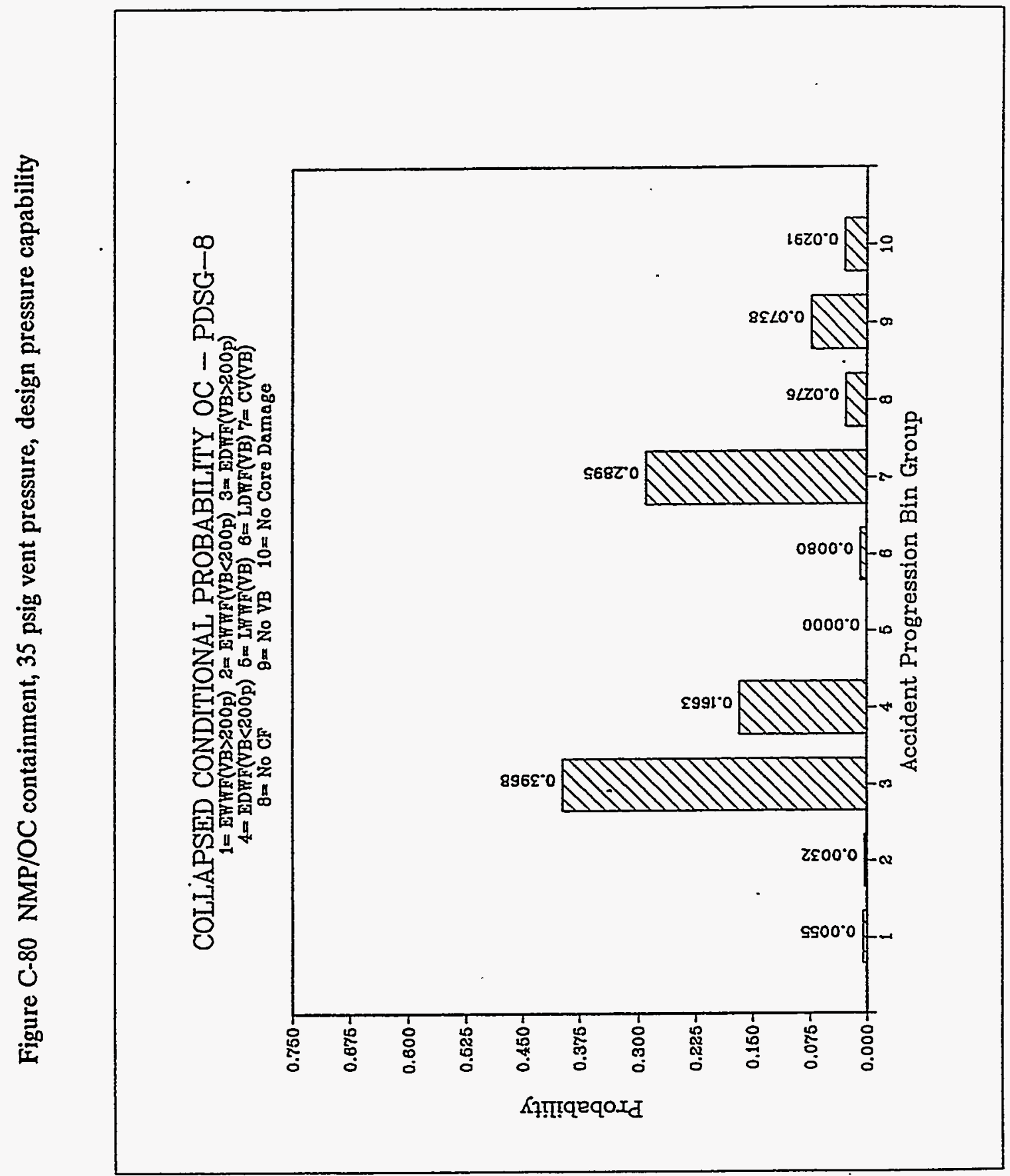

C-81 


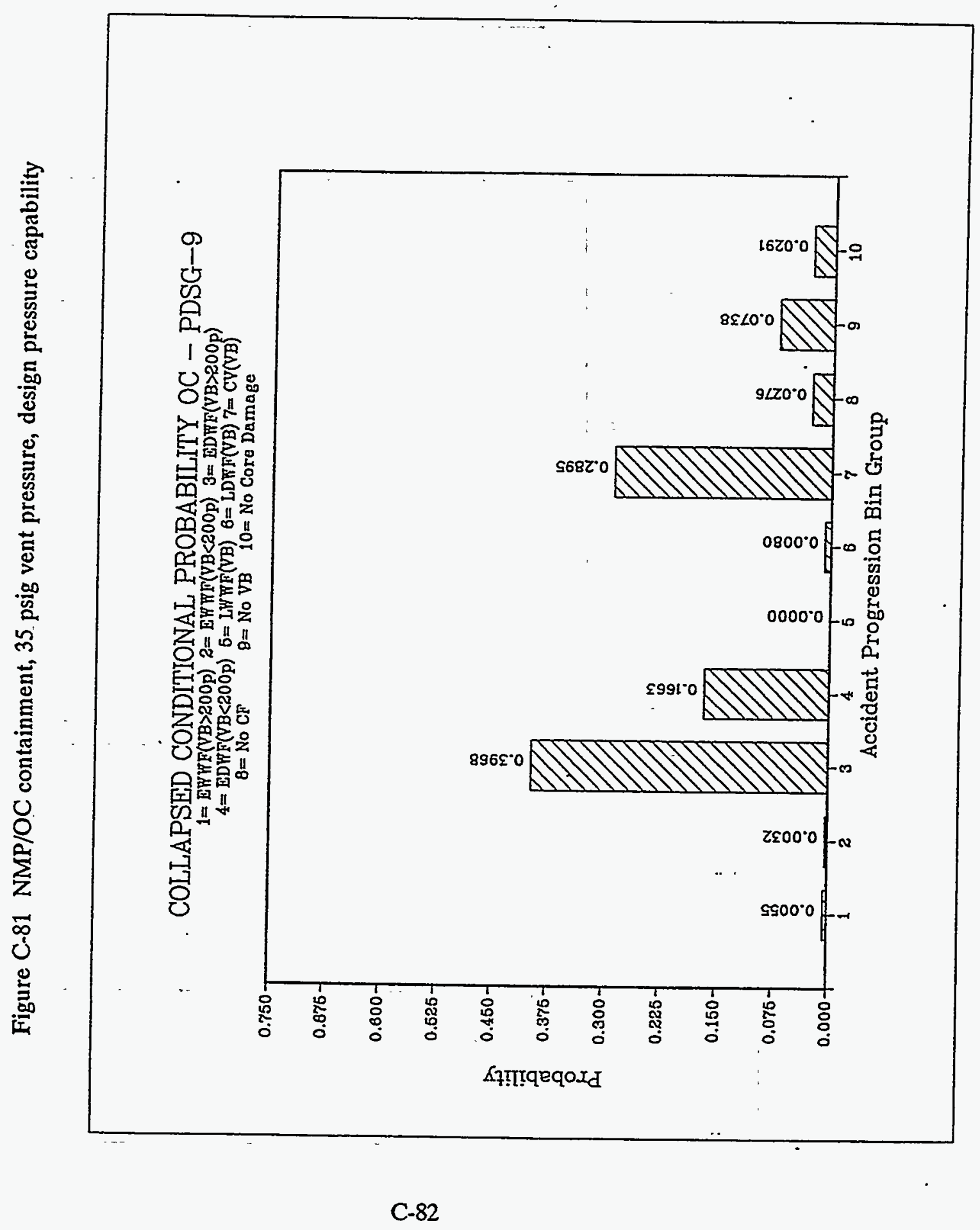


Figure C-82 NMP/OC containment, 35 psig vent pressure, current pressure capability

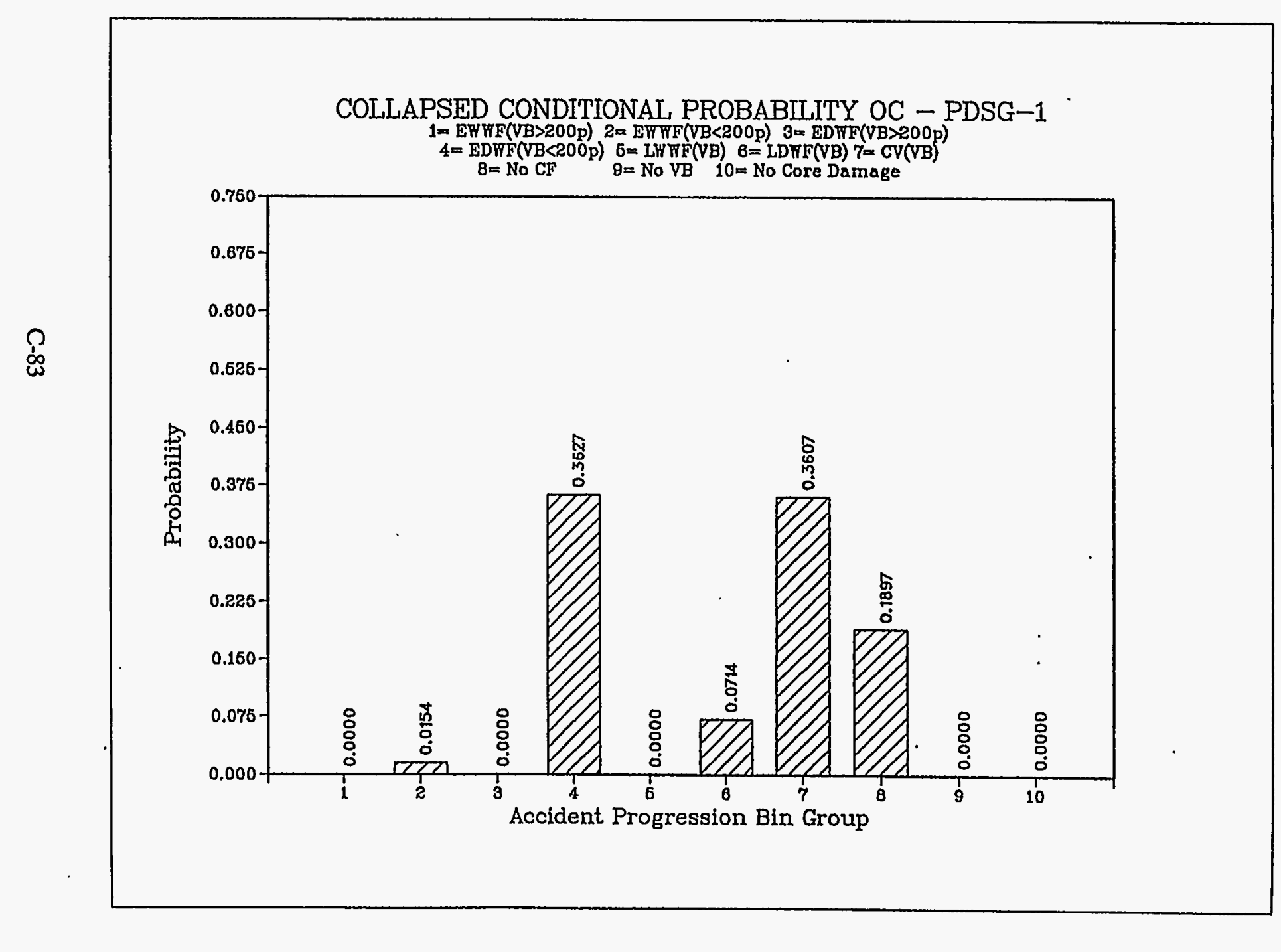

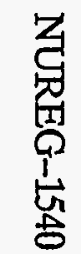




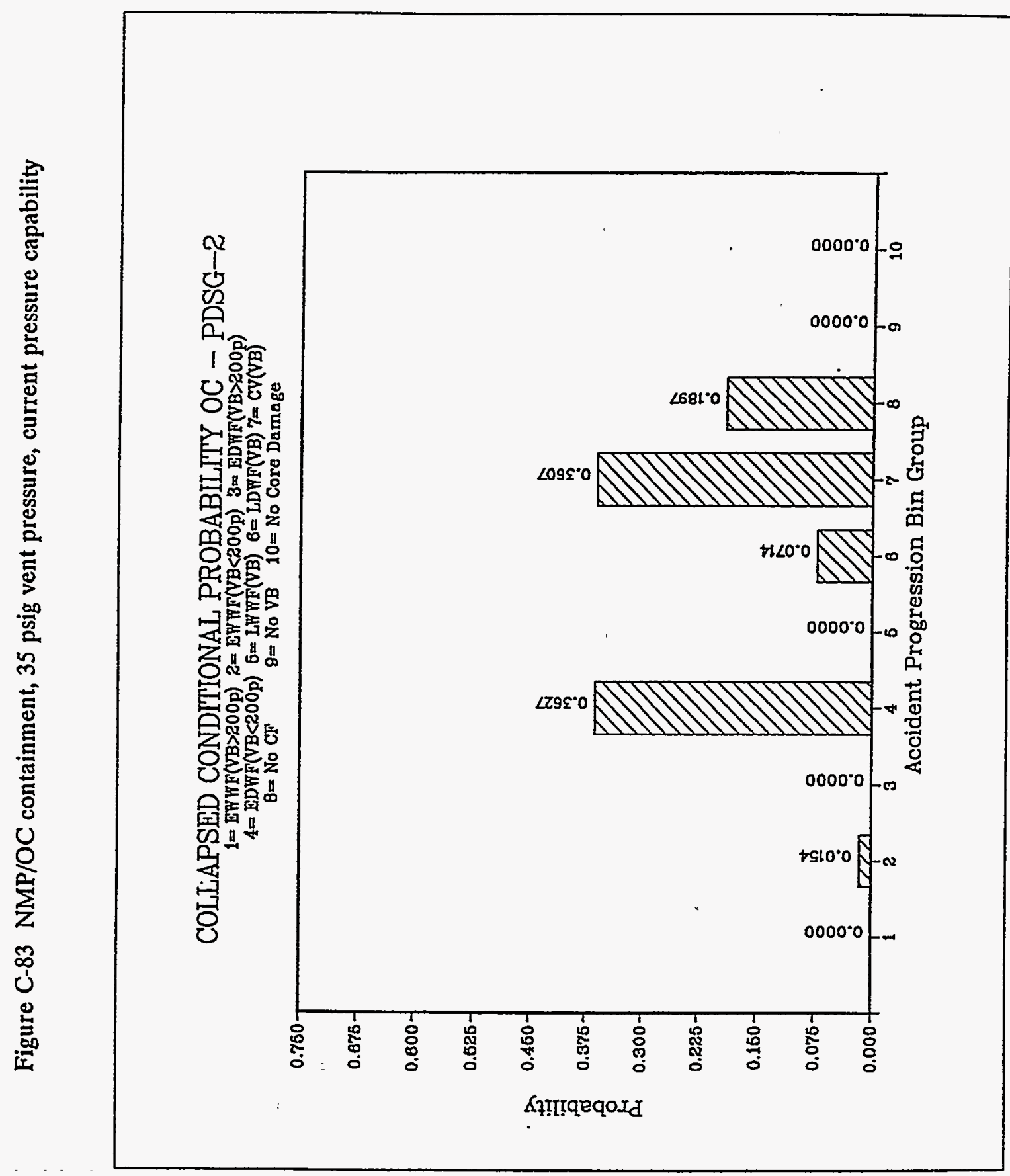

C-84 
Figure C-84 NMP/OC containment, 35 psig vent pressure, current pressure capability

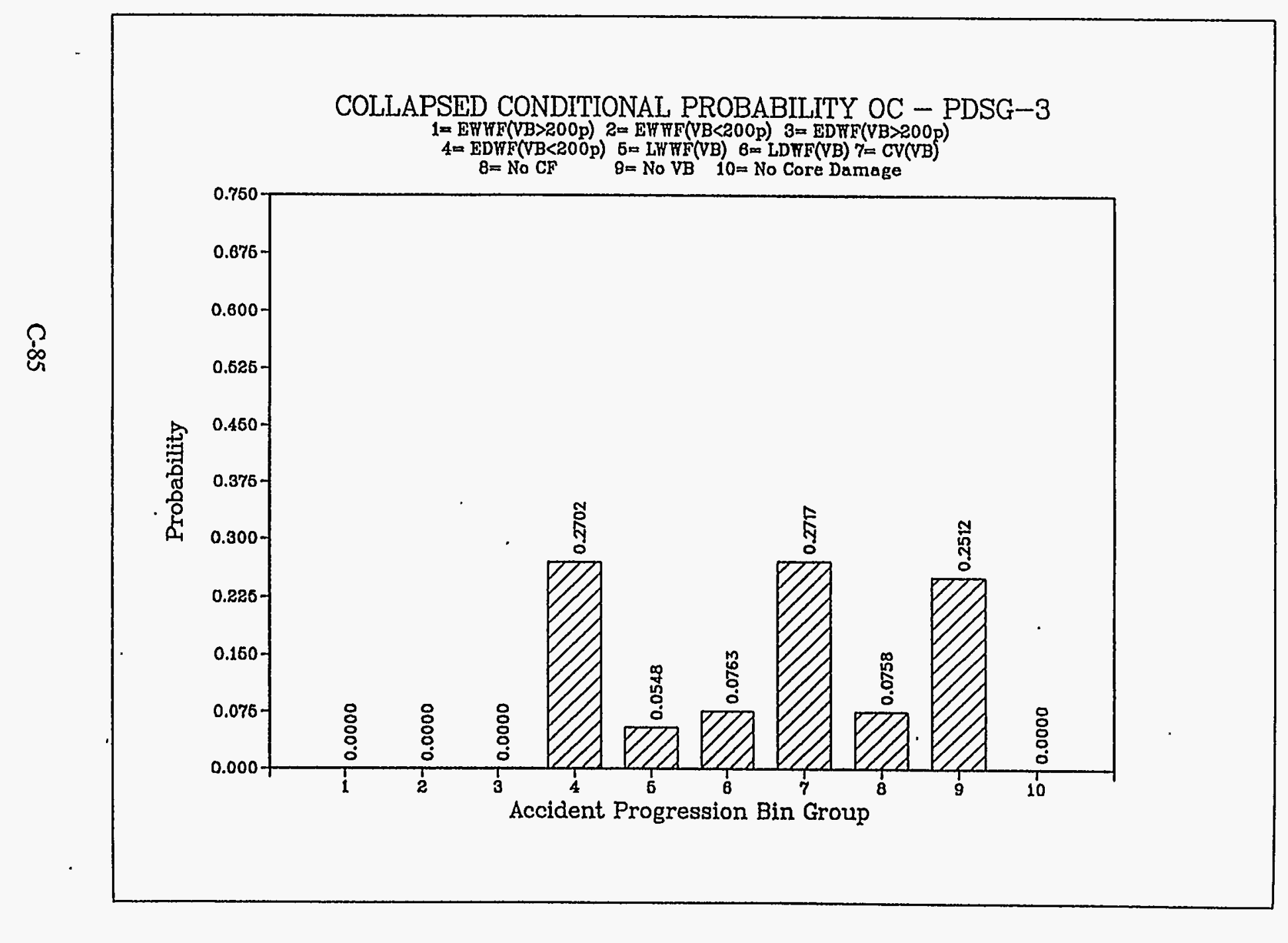

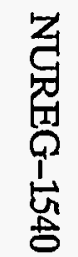




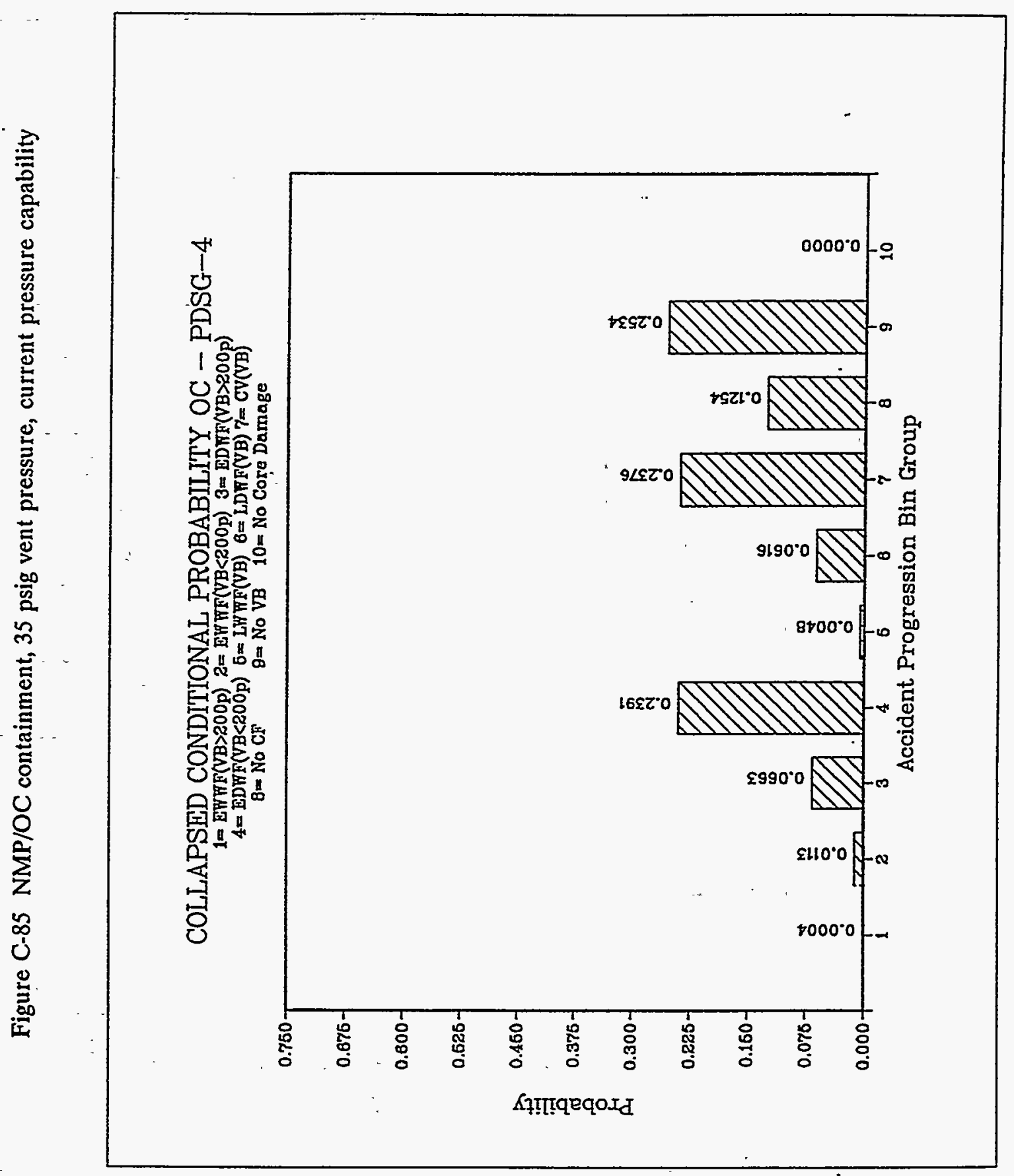

C-86 


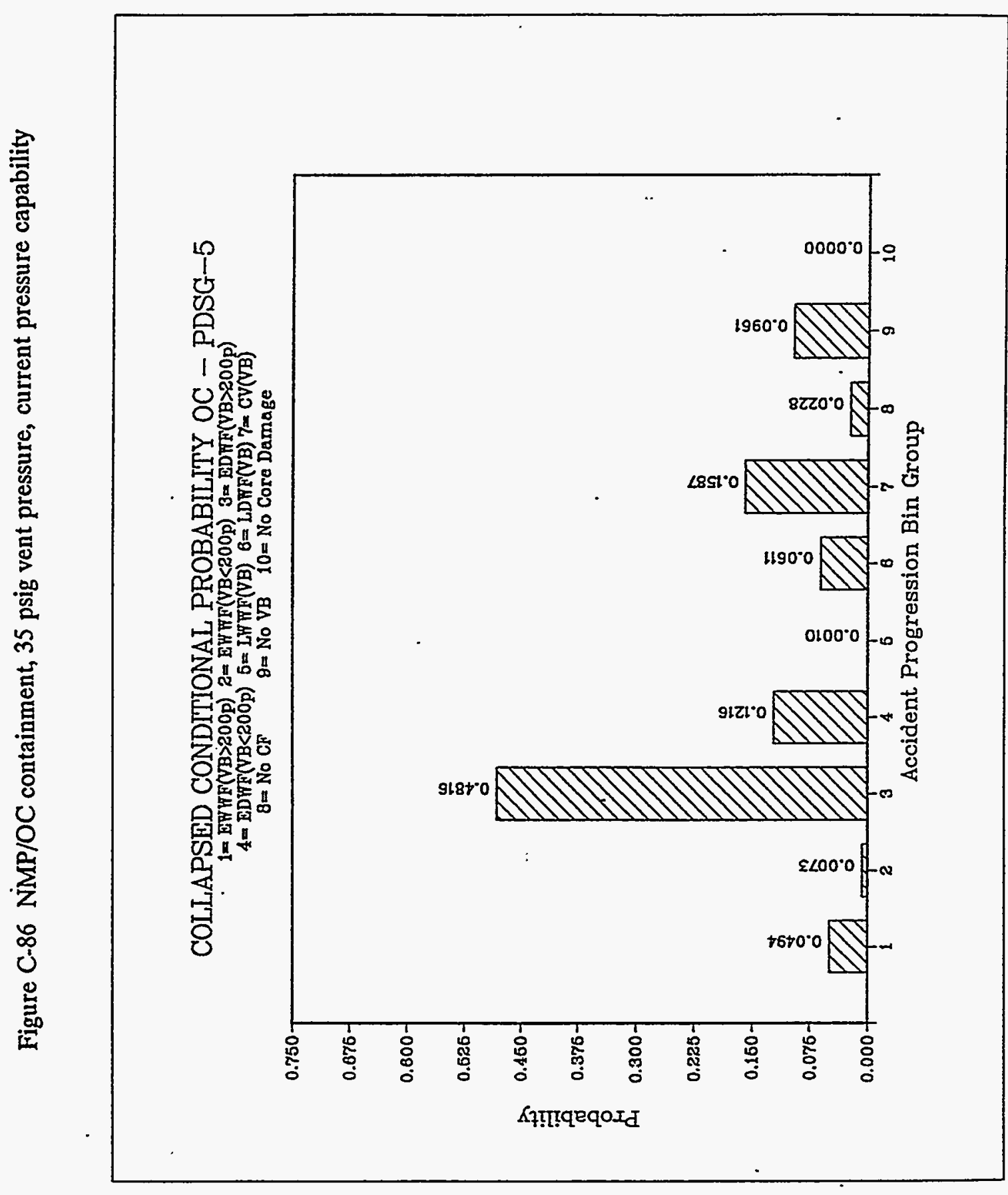

C-87 
Figure C-87 NMP/OC containment, 35 psig vent pressure, current pressure capability

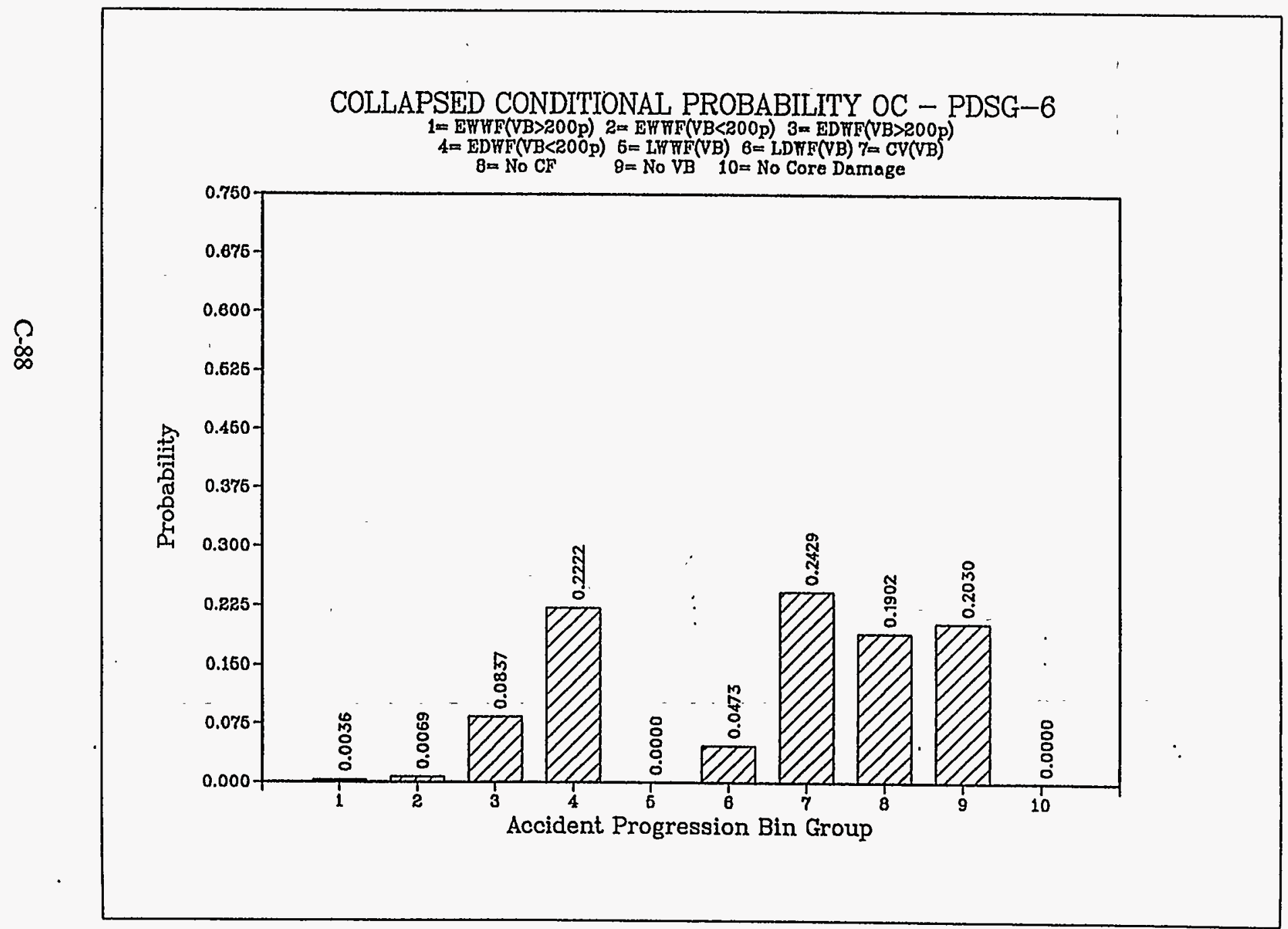




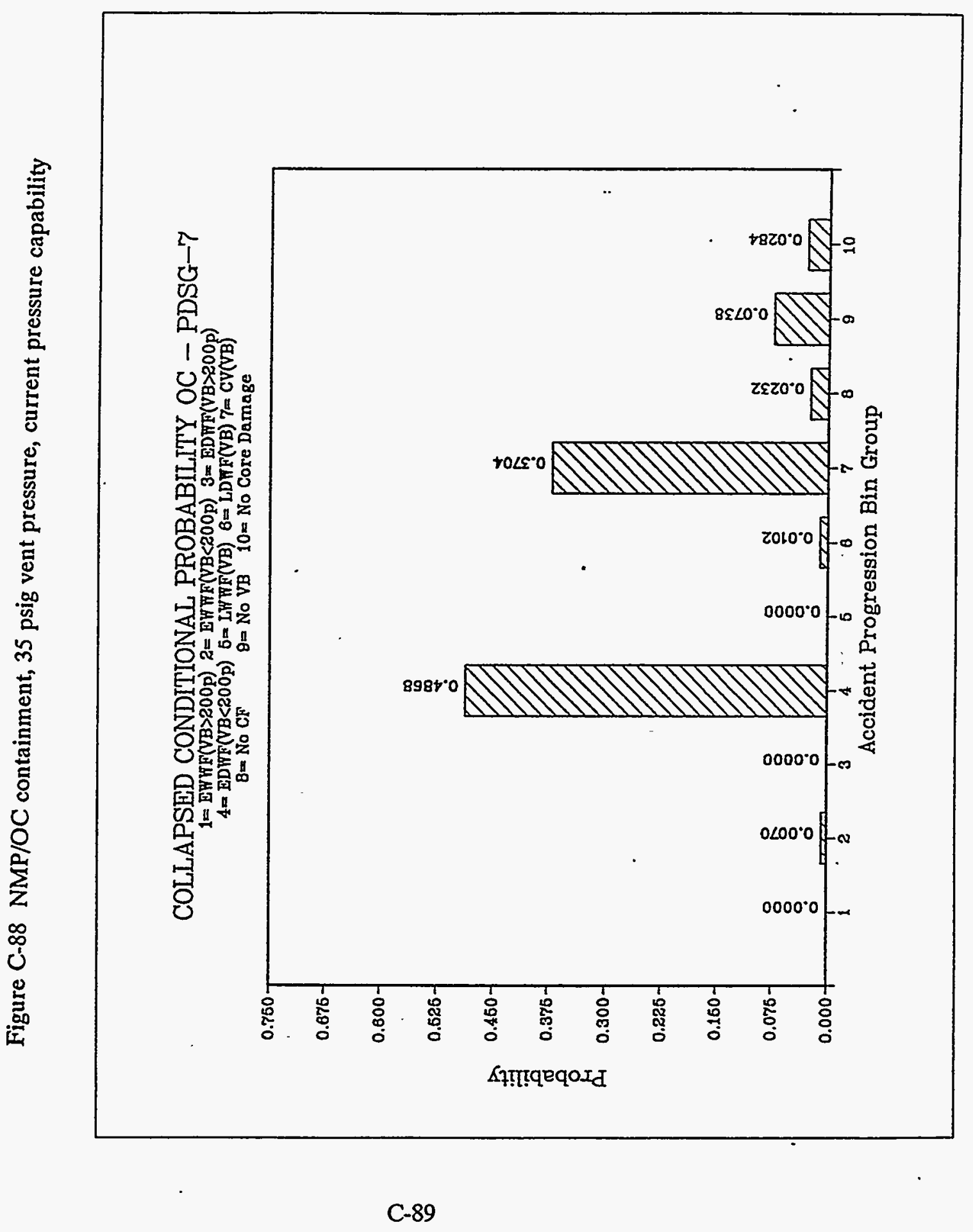


Figure C-89 NMP/OC containment, 35 psig vent pressure, current pressure capability

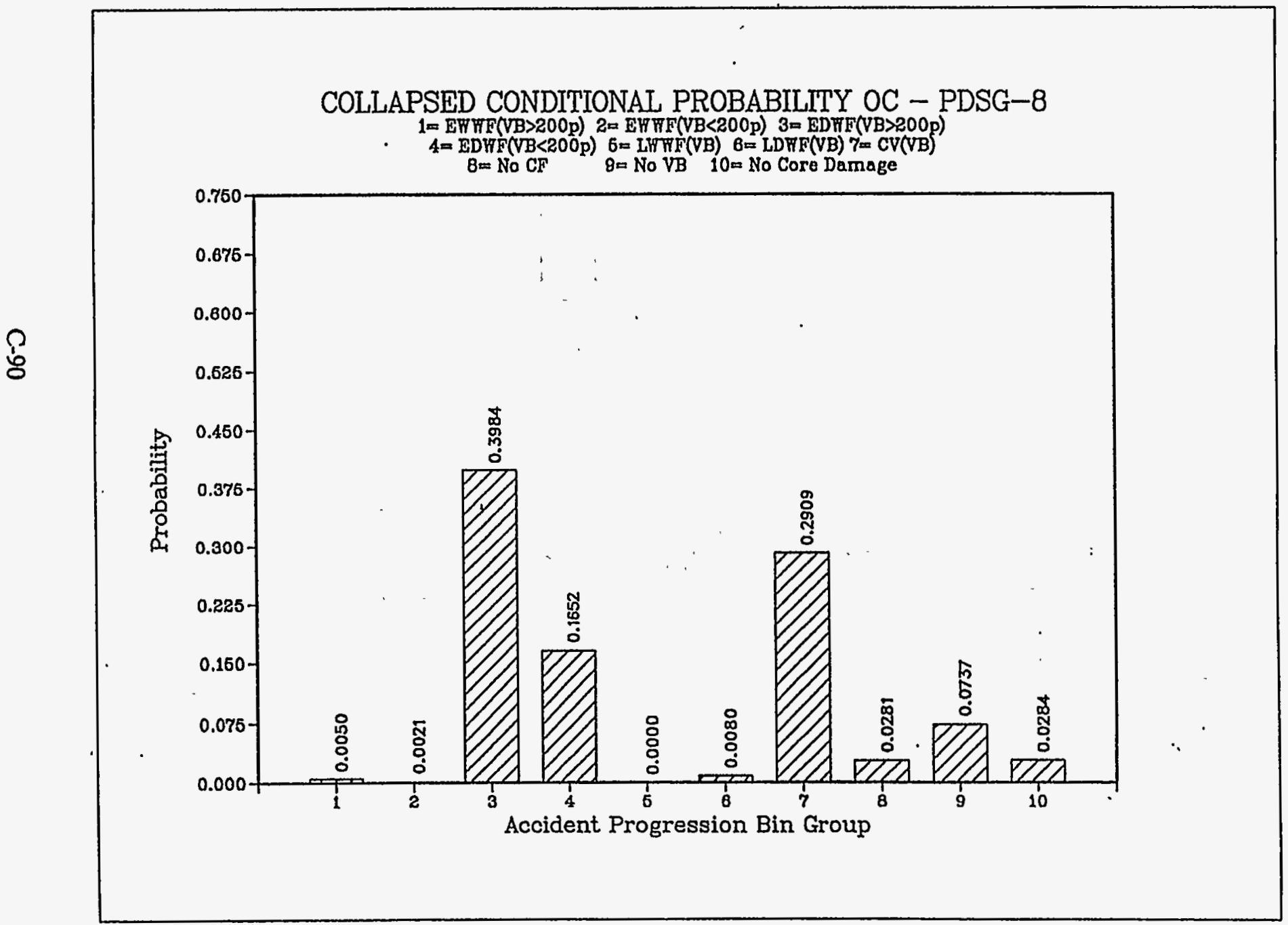


Figure C-90 NMP/OC containment, 35 psig vent pressure, current pressure capability

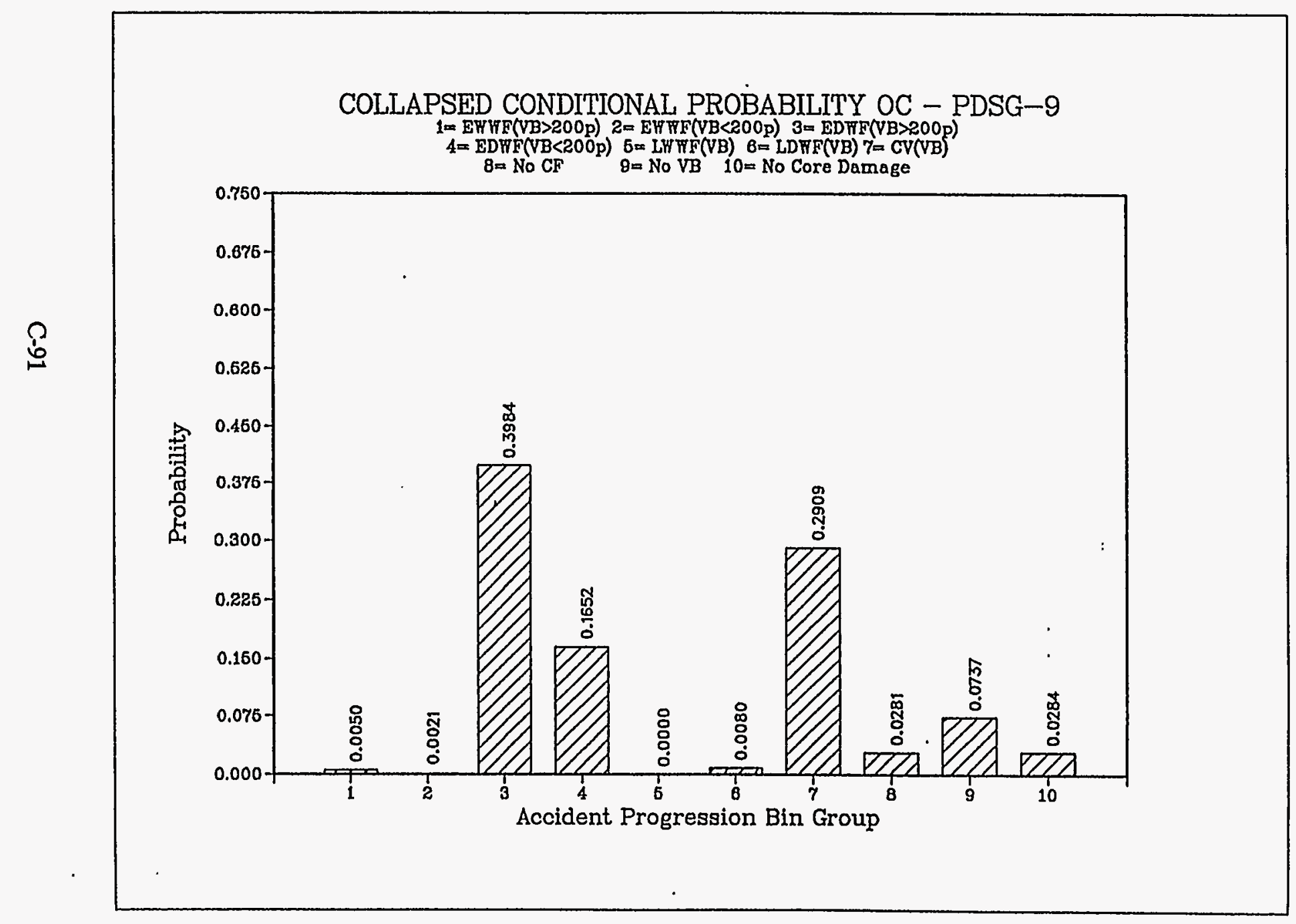

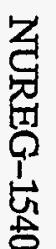




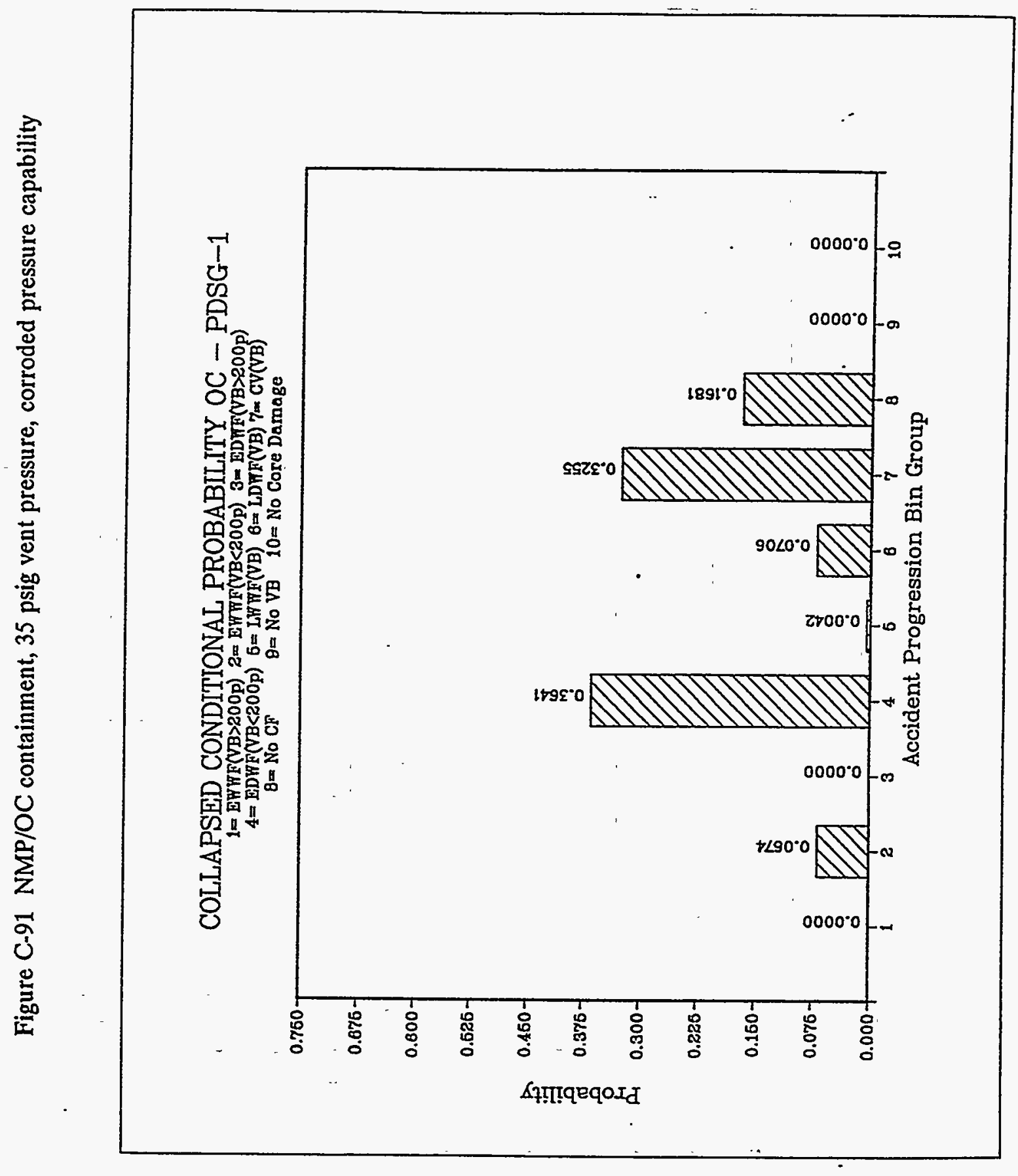

C-92 


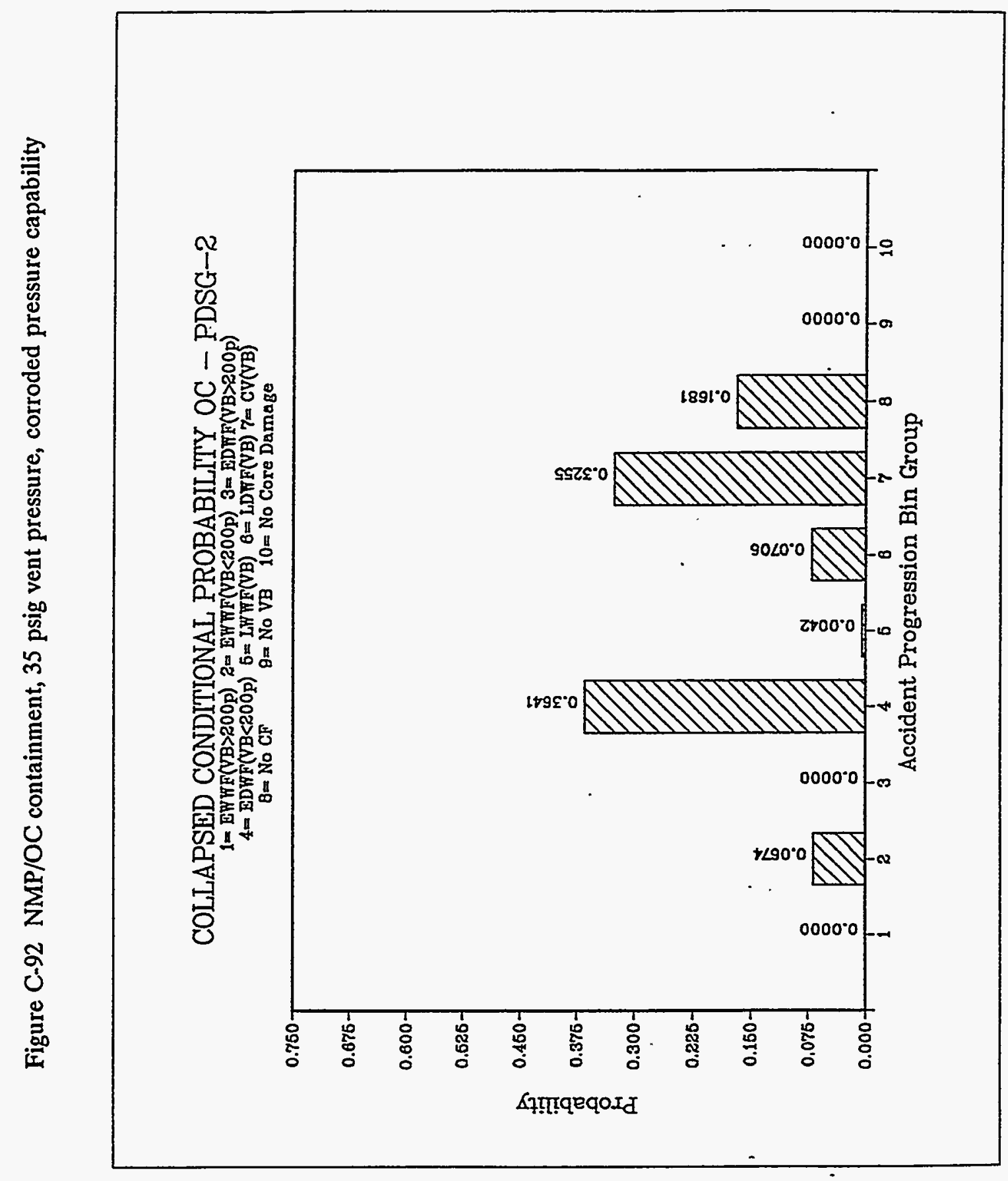

C-93 


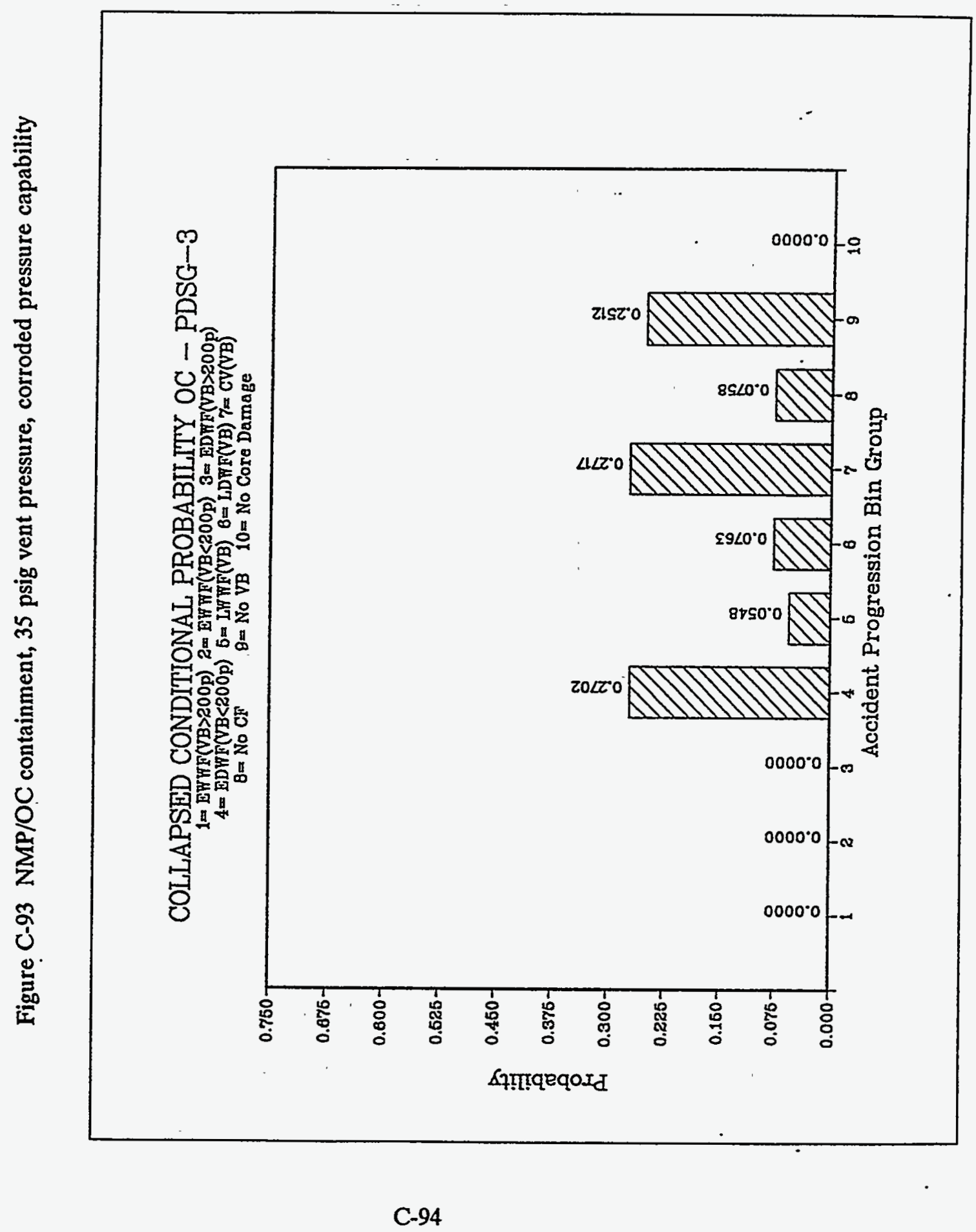


Figure C-94 NMP/OC containment, 35 psig vent pressure, corroded pressure capability

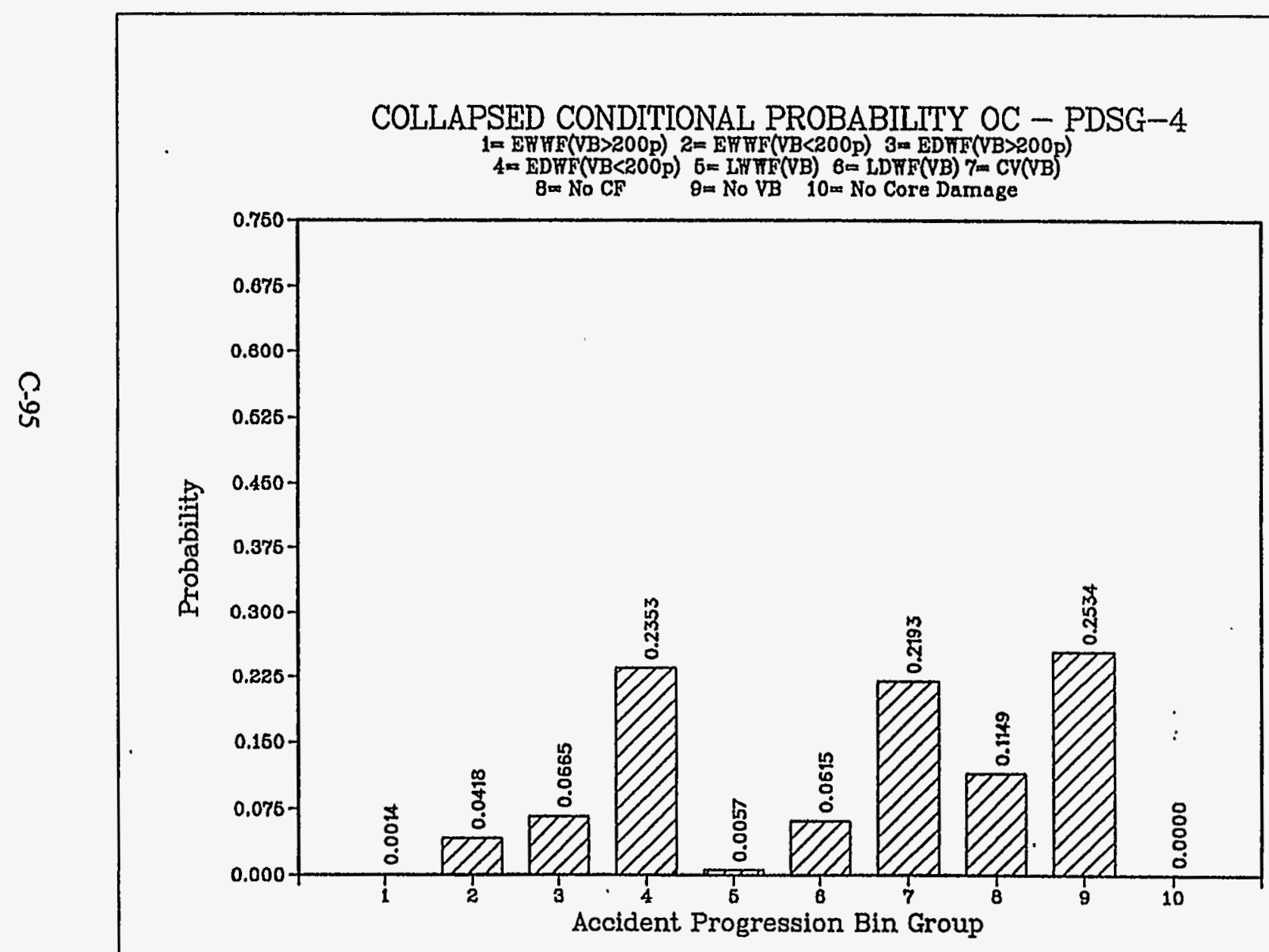

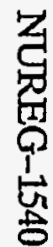




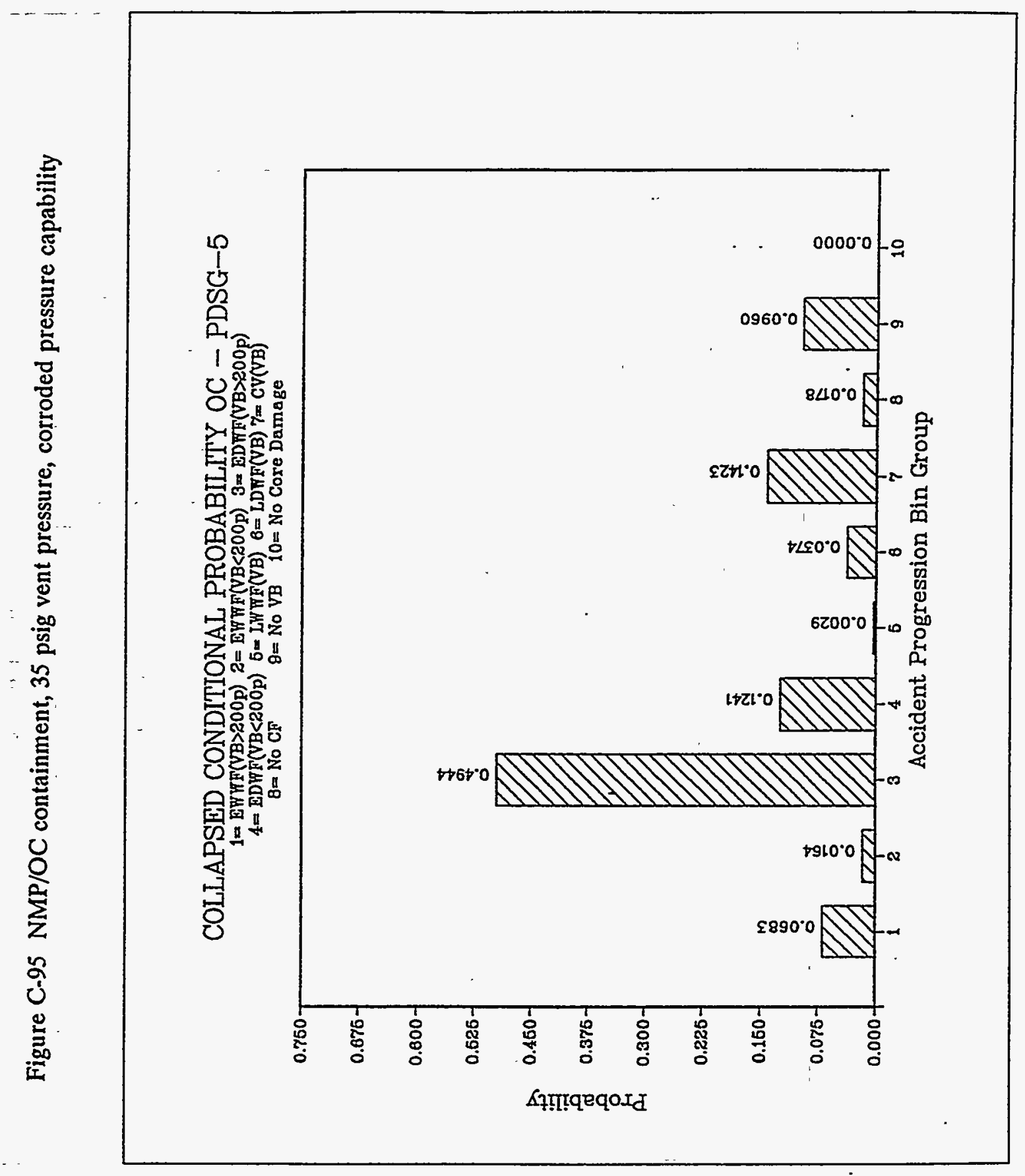

C-96 
Figure C-96 NMP/OC containment, 35 psig vent pressure, corroded pressure capability

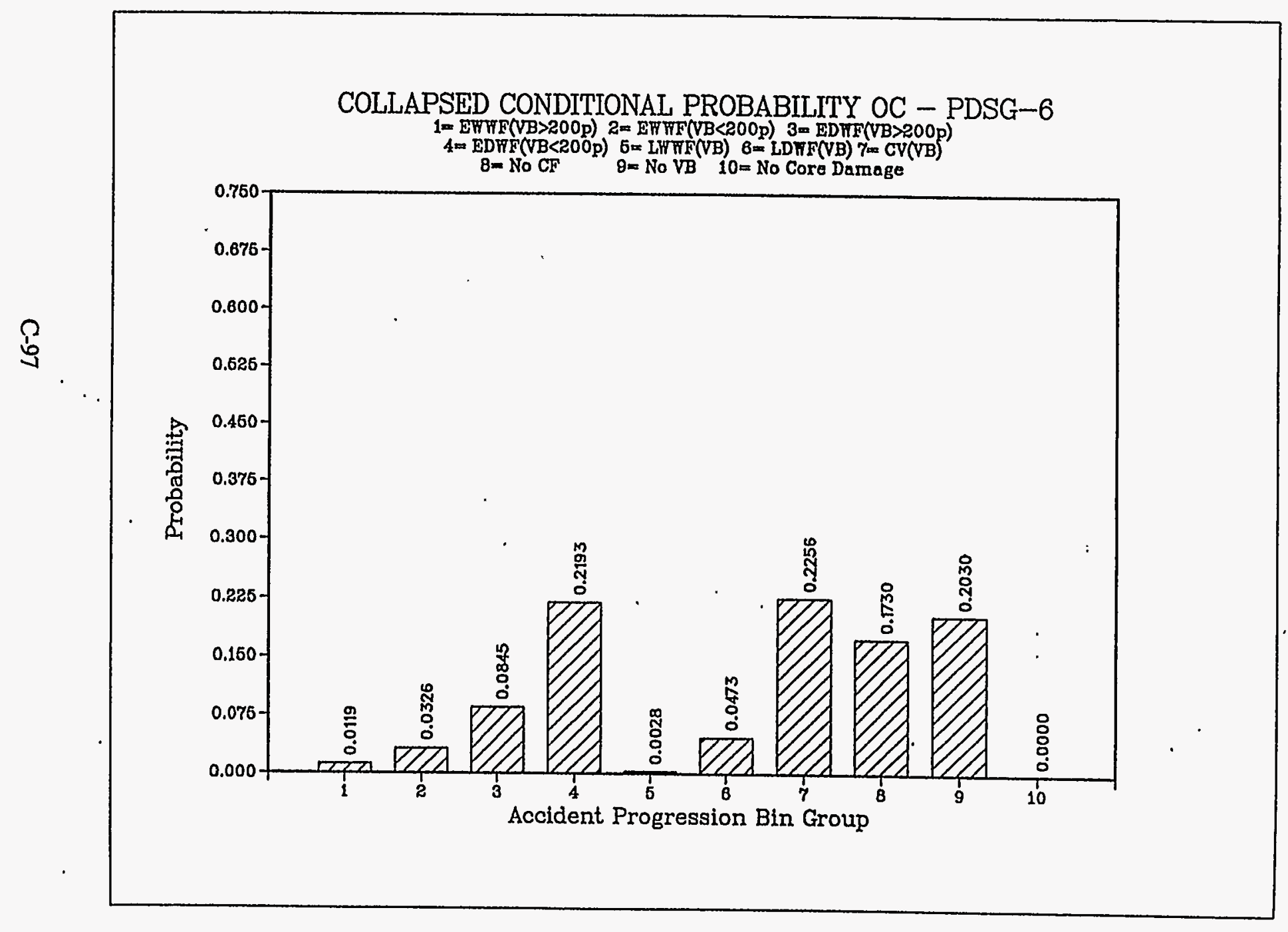

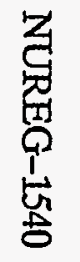


Figure C-97 NMP/OC containment, 35 psig vent pressure, corroded pressure capability

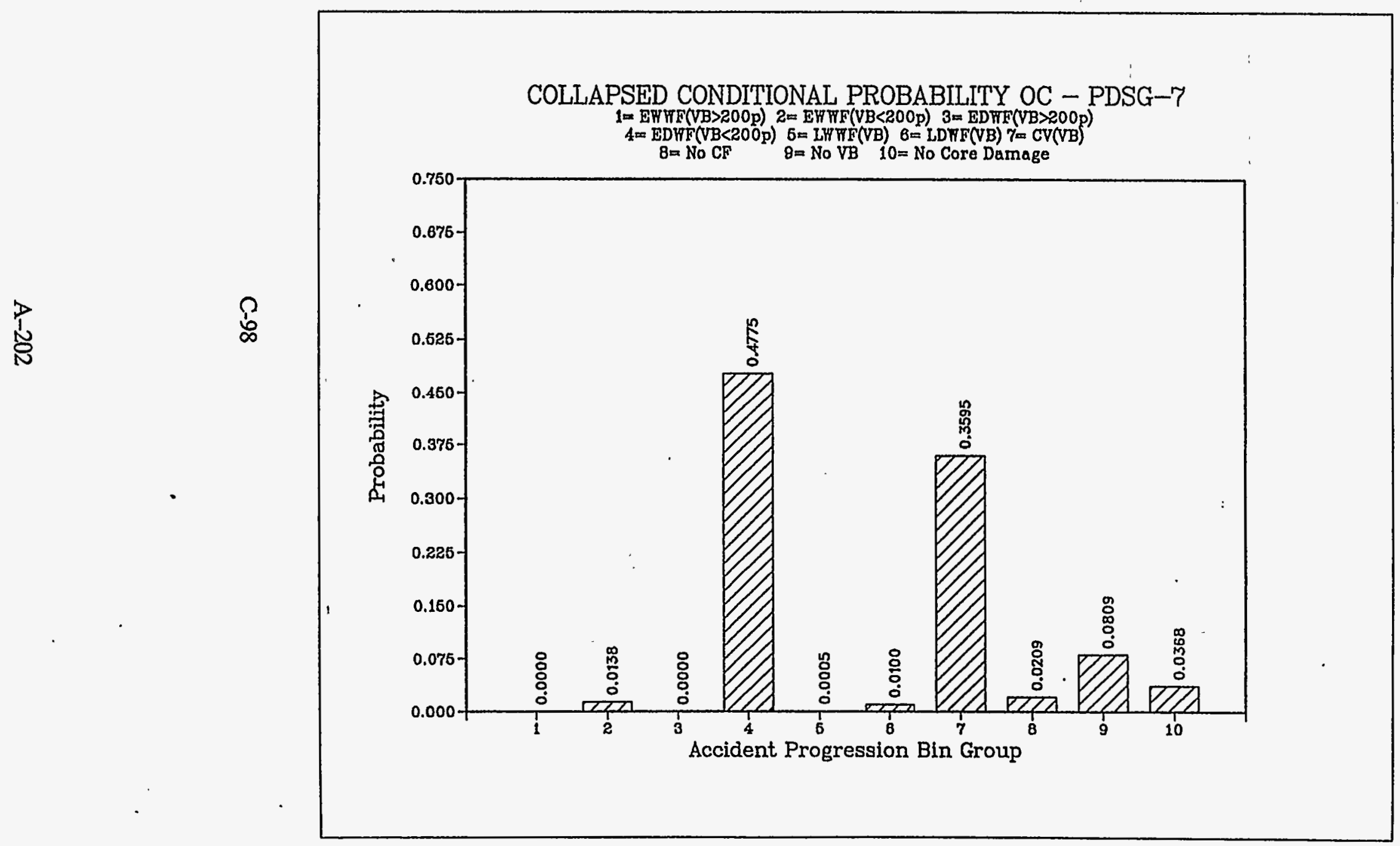




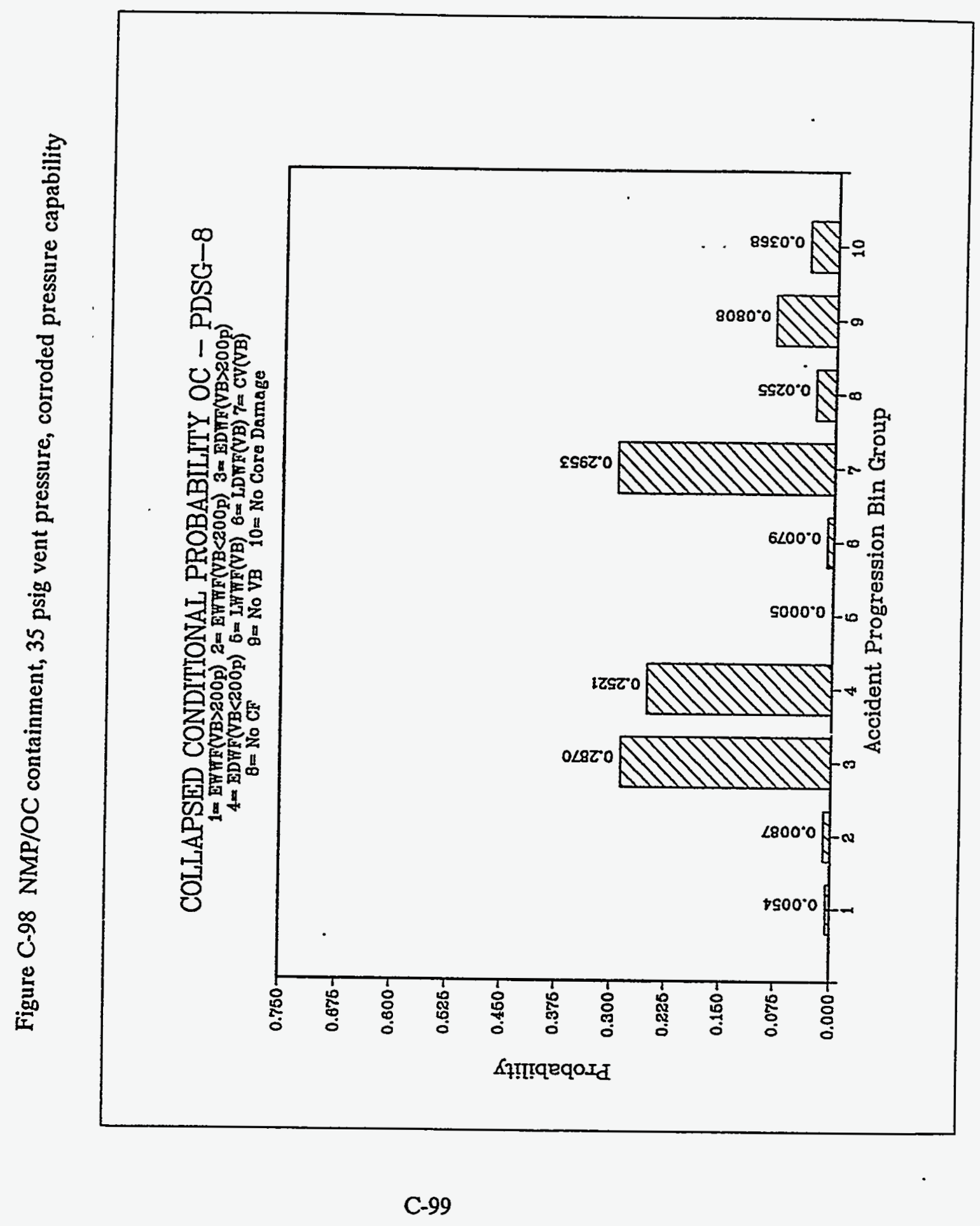


Figure C-99 NMP/OC containment, 35 psig vent pressure, corroded pressure capability

点

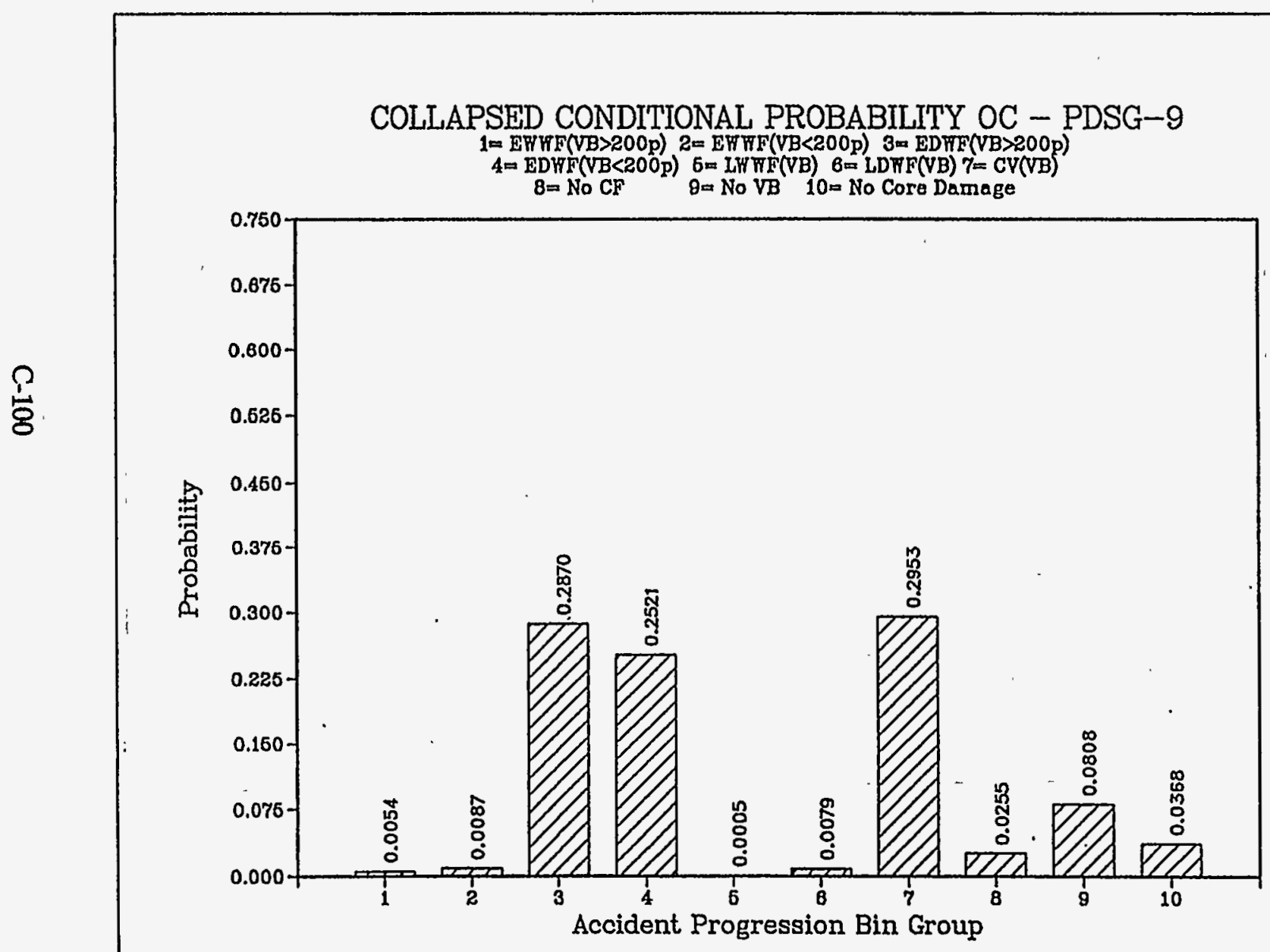


2. TITLE AND SUBTTTLE

BWR Steel Containment Corrosion

3. DATE REPORT PUBUSHED

\begin{tabular}{c|c} 
MONTH & $\begin{array}{c}\text { YEAR } \\
1996\end{array}$ \\
April & 199
\end{tabular}

4. FIN OR GRANT NUMBER

5. AUTHOR(S)

6. TYPE OF REPORT

C. P. Tan, G. Bagchi

Topical

7. PERIOD COVERED (Inclusive Dates)

N/A

8. PERFORMING ORGANIZATION - NAME AND ADDRESS (If NRC, provide Division, Office or Region, U.S. Nuclear Regulatory Commission, and malling address; if contractor, provide name and mailing address.)

Division of Engineering

Office of Nuclear Reactor Regulation

U.S. Nuclear Regulatory Commission

Washington, DC 20555-0001

9. SPONSORING ORGANIZATION - NAME AND ADDRESS (If NRC, type "Same as above"; if contractor, provide NRC Division, Office or Region, U.S. Nuclear Regulatory Commission, and mailing address.)

Same as above

10. SUPPLEMENTARY NOTES

11. ABSTRACT (200 words or less)

The report describes regulatory actions taken after corrosion was discovered in the drywell at the Oyster Creek Plant and in the torus at the Nine Mile Point 1 Plant. The report describes the causes of corrosion, requirements for monitoring corrosion, and measures to mitigate the corrosive environment for the two plants. The report describes the issuances of generic letters and information notices either to collect information to determine whether the problem is generic or to alert the licensees of similar plants about the existence of such a problem. Implementation of measures to enhance the containment performance under severe accident conditions is discussed. A study by Brookhaven National Laboratory (BNL) of the performance of a degraded containment under severe accident conditions is summarized. The details of the BNL study are in the appendix to the report.

containment inspection program containment performance

core debris

corrosion

design pressure

drywell inservice degradation integrity of containment margin of safety pressure capacity probability risk assessment release profile sand cushion

SCALINS factors severe accident condition steel containment torus (wet well) ultrasonic thickness (U'T) measurement VENTINS pressure
14. SECURITY CLASSIFICATION

(This Page)

Unclassified

(This Report)

Unclassified

15. NUMBER OF PAGES

16. PRICE 